\title{
PRESUPPOSITION
}

AND THE

\section{DEIIMITATION OF SEMANTICS}

Thesis Submitted For The Degree of

Doctor of Philosophy

BI

RUTH MARGARET KEMPSON

\section{School of Oriental and African Studies University of London}

1973

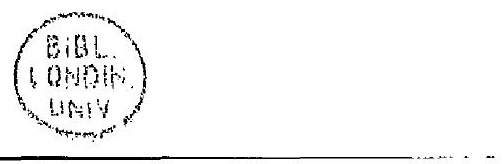


ProQuest Number: 10731263

All rights reserved

INFORMATION TO ALL USERS

The quality of this reproduction is dependent upon the quality of the copy submitted.

In the unlikely event that the author did not send a complete manuscript and there are missing pages, these will be noted. Also, if material had to be removed, a note will indicate the deletion.

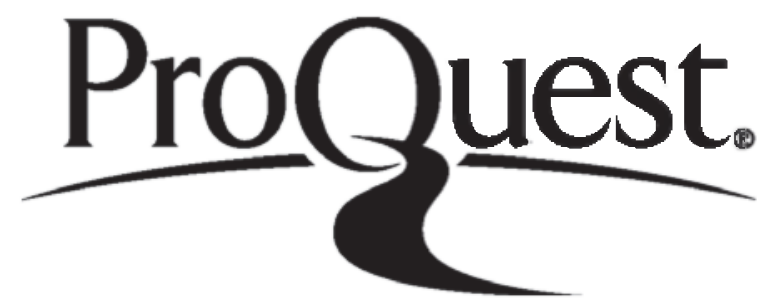

ProQuest 10731263

Published by ProQuest LLC (2017). Copyright of the Dissertation is held by the Author.

All rights reserved.

This work is protected against unauthorized copying under Title 17, United States Code Microform Edition (C) ProQuest LLC.

ProQuest LLC.

789 East Eisenhower Parkway

P.O. Box 1346

Ann Arbor, Ml $48106-1346$ 
ABSTRACT

The thesis is divided into three sections. In the first, I present the general theoretical framework within which the arguments of the thesis are considered. This framework contains an interpretive semantic component (in the sense of Katz 1966a, 1972, Bierwisch 1969, 1971) and the formalism assumed is that of Biexwisch. I argue however that this formalism in effect constitutes a statement of the necessary and sufficient truth conditions on the sentences of a language and that this is the correct basis for natural-language semantics.

This hypothesis appears to be threatened by the concept of presupposition. In the second section, I therefore discuss two separate concepts of presupposition and consider the issues both raise for naturallanguage semantics. In brief, I argue (chapter 4) that to incorporate a concept of presupposition defined in terms of speakers' belief has consequences which necessitate its exclusion by fiat from a formal linguistic theory. Furthermore I argue (chapters 4-5) that a logically defined concept of presupposition refers to an empty set of sentences, since every postulated presupposition is in fact an example of an entailment relation. So I conclude that neither definition of presupposition should be part of natural-language semantics. Accordingly the semantic framework set up in the first part remains at present unfalsified. However in addition to such a semantics, in the final section I set up a theory of pragmatics (along lines suggested by Grice; 1957, 1961, 1968, 1969) to explain those aspects of sentences which are not captured by a truth-conditional (but non-presuppositional) semantics. In over-all terins, my aim is two-fold: (i) to justify in some detail the formal properties of an interpretive semantic component (based on a non-presuppositional logic); and (ii) to suggest a tentative specification of a pragmatic theory as part of some more general theory of performance. 


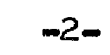

ACKNOWLEDGMENTS

I should like to record here the debt I owe to my various friends and colleagues. I have to thank Professor C.E. Bazell my supervisor, who with his incomparable wealth of experience has helped me in countless ways; Professor Randolph Quirls, to whom I shall always be in debt for my introduction to linguistics in the first place; and Dr. Anita Mittwoch, Dr. Neilson V. Smith, and Miss Deirdre Wilson, with whom I have had many stimulating discussions particularly in the early stages of the work for this thesis. Finally I must thank my husband for putting up with me so valiantly during the months in which this thesis has been completed. 
$\begin{array}{llllllllllll}\text { ABSTRACT } & \ldots & \ldots & \ldots & \ldots & \ldots & \cdots & \ldots & \ldots & \ldots & \ldots & 1 \\ \text { ACKNOWLLDGMENTS } & \ldots & \ldots & \ldots & \ldots & \ldots & \ldots & \ldots & \ldots & \ldots & 2 \\ \text { CONTENTS } & \ldots & \ldots & \ldots & \ldots & \ldots & \ldots & \ldots & \ldots & \ldots & \ldots & 3\end{array}$

CHAPTER I Preliminaries: The Linguistic Framework .. . 6

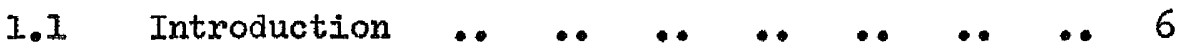

1.2 The Justification of Deep Structure and

The Relation of Syntax and Semantics .. .. 10

1.2.1 Criteria for Deep-Structure Analyses:

Selectional Restrictions (..

1.2.2 The Independence of Syntax and Semantics .. 17

1.3 On the Nature of Semantic Features and

The Semantic Component ..

1.3.1 On the Form of Semantic Features .. . . . 24

1.3.2 On the Nature of The 'Projection' Rules .. .. 30

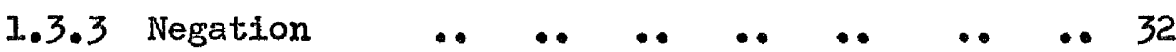

1.3.4 The scope of Negation $\quad \ldots \quad$. .

1.3.4. I Rules of Semantic Intexpretation Operating on

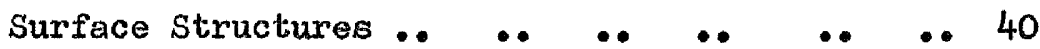

$\begin{array}{lllllllllll}1.4 & \text { Summary } & \ldots & \ldots & \ldots & \ldots & \ldots & \ldots & \ldots & 53\end{array}$

CHAPTER 2 The Basis of Semantics: A Definition of Meaning 56

2.1 On Katz' and Bierwisch's Definition of Semantic Marker . . . . . .

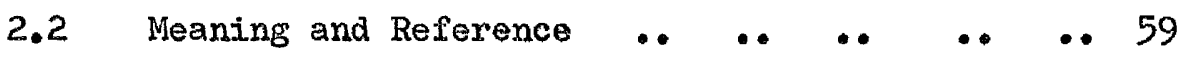

2.3 Sentence Meaning and Truth $\ldots$.. $\quad \ldots \quad \ldots 62$

2.4 The Limitations of a Truth-Based Theory of Semantics: A Criticism and A Defence .. .. 68

2.4.1 The Relation Between Sentence and Statement .. 68

2.4.2 Pexformative Verbs, Imperatives and Questions A Suggested Solution $\ldots$.. 
CHAPTER 3 Presupposition: Two Definitions .. $\quad . . \quad \ldots \quad 81$

3.1 Entailment v. Presupposition .. . . . . . 82

3.2 Speaker-Presuppositions: Presupposition

v. Assertion ..

3.3 Presuppositions of statements and sentences.. 87

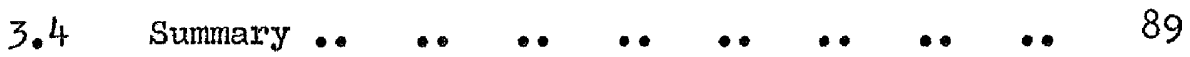

CHAPTER 4 Presupposition: Its Use by Linguists .. $\quad . .91$

4.1 The Introduction of Presupposition to

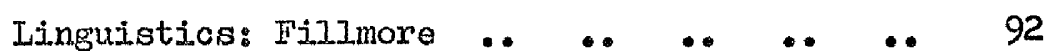

4.2 Factive Verbs: Kiparsky and Kiparsky .. .. 101

4.3 Some Remaining Examples of Logically

Defined Presupposition: Keenan .. . . . 109

4.4 A Pragmatic Concept of Presupposition:

Robin and George Lakoff.. . . . . . . 113

$\begin{array}{lllllllllllll}4.5 & \text { Summaxy } & \ldots & \ldots & \ldots & \ldots & \ldots & \ldots & \ldots & \ldots & & \ldots 25\end{array}$

CHAPTIR 5 The Problem of Reference and The Semantic

Interpretation of Noun Phrases .. .. .. 130

5.1 The Referring Properties of Definite Noun

Phrases: Entailment or Presupposition? .. 131

5.2 Presupposition and three-Valued Logic .. .. 139

5.3 Assertion: Strawson v. Russell .. . . . . 149

5.4 Anaphora: The Problem of Coreference .. .. 152

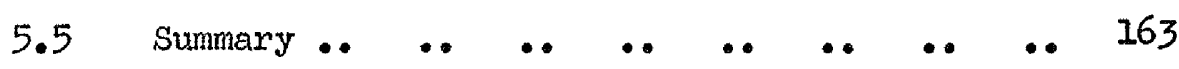

CHAPTER 6 The Formalisation of The Solution .. .. 166

6.1 The Syntactic Relation Between Definite and Indefinite Noun Phrases .. . . . . . 166

6.2 Definite and Indefinite Noun Phrases:

A Preliminary Formulation .. $\quad$. $\quad \ldots \quad$. . 173

6.3 Inter-Sentence Relations - Which Solution? .. 179

6.4 The Formulation of Factive Complements .. 183

6.5 Summaxy .. 


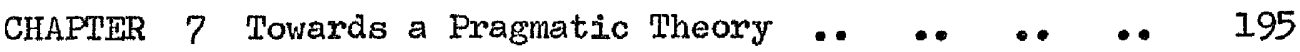

7.1 Grice's Theory of Meaning $\quad$. $\quad \ldots \quad \ldots \quad \ldots$

7.2 On Criticisms of Grice .. $\quad \ldots \quad \ldots \quad \ldots \quad \ldots \quad$. . 209

7.2.1 Speaker's Meaning and Non-Indicative

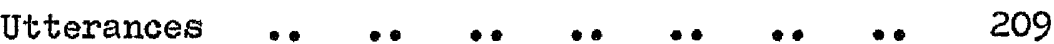

7.2.2 The Infinite Regress Problem . . . . . 216

7.2.3 The Vacuity of The Maxims . . . . . . . 219

CHAPTER 8 The Application of Grice's Theory $\quad$.. $\quad$.. 225

8.1 The Concept of Relevance $\quad \ldots \quad \ldots \quad \ldots \quad \ldots \quad 227$

8.2 The Maxim of Quantity: Some Preliminaries .. 231

8.3 The Maxim of Quantity and The Pragmatic

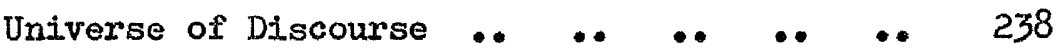

8.3.1 The Pragmatic Universe of Discourse:

A Definition ..

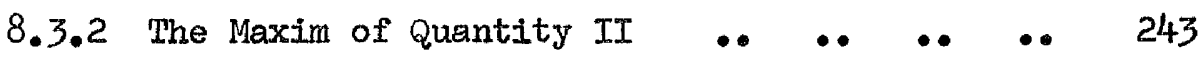

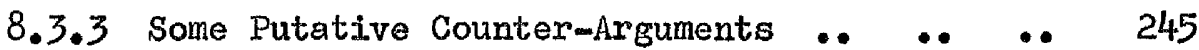

8.3.4 Exclamations and The Requirement of

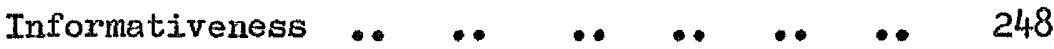

8.4 Definite Noun Phrases and The Pragmatic

Universe of Discourse $\quad \ldots \quad \ldots \quad \ldots \quad \ldots \quad 252$

8.5 The Pragmatic Interpretation of Factive

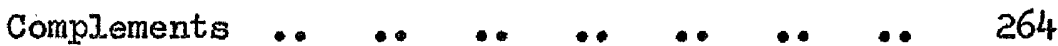

8.6 The Assertion-Presupposition Contrast .. .. 268

8.6.1 Speaker-Presupposition, Stress Assignment and The Maxim of Relation $\quad \ldots \quad \ldots \quad$.. $\quad$.. 272

$8.7 \quad$ And and The Maxim of Manner .. . . . . . 280

$8.8 \quad$ Even Remains .. $\quad \ldots \quad \ldots \quad \ldots \quad \ldots \quad \ldots \quad \ldots \quad \ldots 283$

8.9 Illocutionary Force: Its Status Within

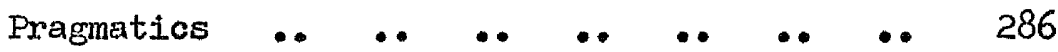

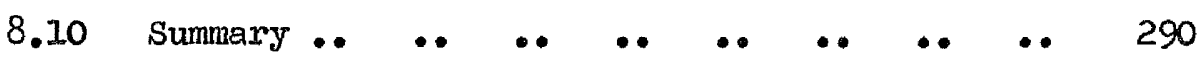

CHAPTER 9 Pragmatics and The Competence-Performance

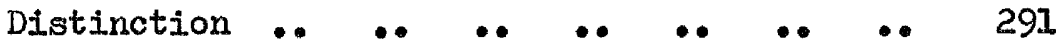

BIBLIOGRAPHY 
CHAPTER 1: Preliminaries: The Linguistic Frameworis

\subsection{Introduction}

Throughout this thesis I shall assume that there is one aim which undexpins all research within a theoretical linguistic framework - to explain the phenomenon of human language, to characterise how and why human language is distinct from other ordered hierarchical systems. Fuxthermore I take it for granted that this can in principle be achieved by the formulation of a theoretical framework which places constraints of a specific and clearly defined nature on the form a language might take, thus excluding all the forms it does not take. For example, one might claim that every language is a system expressing a relation between meaning and sound in the form of three levels, semantics, syntax, and phonology/phonetics, and that these are characterisable with particular types of rule-formulations. More specifically, within the framework of transformational grammax, one might claim (as I shall in fact be assuming) that every language can only be described with the appropriate generality if two separate levels of syntactic structure are set up - deep and surface structure; that the syntactic structure of a sentence in any language can invariably be characterised by a system of phrase structure rules which describe the hierarchical structure of the underlying level; that a system of ordered 'transformational' rules relate this level by a systematic series of phrase markers to the phrase marker which describes the superficial surface structure of the sentence; etc. etc. All statements of this kind constitute so-called formal. Iinguistic universals (cf. Chomsky 1965, p.28 f.), and by their very nature it follows that if any one such claim can be 
shown to be false for even a single language, this constitutes a falsification of the given framework as it stands. Thus even though only one language (say, English) may be under consideration, the transformational linguist is (or should be) concerned with the wider perspective of testing potential universal claims about language. I therefore offer no apology for using English as my sole source of data, despite the fact that my arguments concern the universal issue of the nature of meaning in natural language. Apart from widespread agreement on the aim of linguistic inquiry, there is disappointing.ly little which can be taken for granted. As Postal pessimistically described the situation in 1971, 'Serious grammatical investigation at the moment is rather like travelling in quicksand. There are no firm supports. Every step is uncertain. Every move is questionable.' This assessment of current research in syntax (Postal 1971 p.3), made fourteen years after the publication of Syntactic Structures (Chomsky 1957), is even more strikingly true of semantics, where there is no established theoretical framework, and even no agreement as to the premises on which to construct a framework. Nevertheless Ieech apparently felt justified in suggesting in 1969 with tentative optimism that linguists working in semantics were beginning to show agreement at least on the aims of a semantic theory (cf. Leech 1969 p.4).

To what extent was this optimism justified? The extent of the agreement can be quickly listed on one hand. There are four conditions which linguists working within the framework of a formal model of language would agree must be satisfied by a semantic theory (or 
semantic component of a general theory):

(1) It must be able to predict the meaning of any sentence, and it must do so on the basis of the meaning of the lexical items in that sentence and the syntactic relations between those items - i.e. the model must state a systematic relation between the meaning of lexical items and the syntactic structure of the sentence. Moreover, where a sentence has more than one interpretation, the model must predict the appropriate number of interpretations. (How these predictions are carried out will of course vary from theory to theory.) (2) Since the set of sentences for any language constitute an infinite set, the semantic model must be made up of a finite set of predictive rules like its syntactic counterpart: the model cannot merely analyse an arbitrarily selected finite subset of this infinite set. (3) The model must separate the infinite set of semantically nondeviant sentences from another infinite set - that made up of contradictory or anomalous sentences, such as examples (1)-(8): ${ }^{1}$

(1) John ran but he didn't move

(2) The man who was running was walking

(3) The girl is a boy

(4) Bachelors are married men

(5) Green ideas sleep furiously

(6) Ideas ran to catch the train ${ }^{2}$

(7) Safety likes to be treated gently

(8) The boulders got married

1. Whether or not the model should treat contradictory and anomalous sentences as ungrammatical (i.e. not well-formed) is not generally agreed upon. For conflicting views, cf. Katz 1972, Jackendoff 1972, McCawley 1971, Lakoff 1971b. For further discussion of contradictory and anomalous sentences in this thesis, cf. p.16 fn.11 ch.2 p.64f.

2. The existence of non-anomalous metaphorical interpretations for these sentences is not predicted, since in order to explain a metaphorical interpretation on a sentence, one needs to refer to its literal interpretation (cf. ch.7 p.205) The statement of the literal interpretations of sentences is therefore logically prior to the analysis of metaphor. 
(4) The model must be able to predict meaning relations between sentences, e.g. entailment (cf. ch.3 p. 82), contradiction and synonymy (cf. ch.2 p. 64), since these relations hold by virtue of the meanings of sentences. These four demands are agreed in principle by all linguists.

But there the agreement ends. The old problem of what constitutes the meaning of sentences raises its ugly head again. ${ }^{3}$ There seem to me to be two principal alternatives: either meaning can be defined in terms of conditions for the truth of sentences - i.e. be defined in terms of the relation between sentences (and lexical items) and the external world they describe; 4 or it can be defined in terms of conditions on the use of sentences in communication - i.e. be defined in terms of the relation of sentences to the speech act, the speaker of the sentence, etc. But it was on just this question of the delimitation of meaning that Leech suggested that there had been 'a movement towards agreement' $(p, 4)$. How is it that Ieech's optimistic view is not borne out? The difficulty arises when the notjon of presupposition is incorporated into linguistics; because presupposition, like meaning, can be defined in one of two ways - either as a relation between statements (parallel to entailment, synonymy etc), or as a property of the speaker's belief in uttering a sentence. And only one of these definitions is compatible with a definition of meaning in terms of truth conditions. Yet if the presuppositions of a sentence are part of its semantic interpretation then by definition they are part of its meaning. Thus if presuppositions

3. Cf. Ogden and Richards 1923 for the classic collection of definitions of meaning.

4. I shall argue in ch.2 that Katz' and Bierwisch's and Leech's positions are not genuine alternatives to this. 
in terms of speaker-belief are considered to be part of the semantic interpretation of sentences, then it seems that the meaning of sentences must be in terms of speaker-hearer relations and not, or not solely, in terms of the relation between a symbol and the state or object it describes. My main concern in this thesis will therefore be to determine the exact nature of presupposition and to consider its relevance to an analysis of natural language. The main arguments of this thesis are thus exclusively semantic.

However the basis outlines of a formal model of language are currently so confused and provoke so much disagreement, that before broaching the main thesis, I shall briefly justify certain hypotheses about the nature of syntax and semantics which I shall assume to be correct for the remainder of the thesis.

\subsection{The Justification of Deep Structure and The Relation of Syntax and Semantics}

One of the major problems of current work in both syntax and semantics is that there is no real agreement as to what constitutes evidence about syntactic structure. This is a potentially dangerous disagreement, since it is a fundamental issue for all arguments pertaining to syntax, and yet it is one which at least until recently many linguists have appeared to assume is not in question. 5 The position they adopt over the nature of syntax may thus be an unspecified premise for the argument and not part of the argument itself. Since the delimitation of syntax goes hand in hand with the delimitation of 
semantics, the answer to the question 'What constitutes syntax?' is of equal importance for those arguing about the formal nature of semantics as it is to those worrying about syntax. I shall therefore review briefly (section 2.2.1) the types of evidence which have been used to justify deep structure and I shall argue that the only arguments which are relevant to the determination of some such syntactically defined level are those which depend on evidence of formal distributions. On the basis of this, I shall then discuss (section 1.2.2) evidence which suggests that the constraints on syntactic structure are different in kind from those of semantics and that the widely held view that there is no distinction between syntax and semantics (cf. McCawley 1968, Postal 1970, Lakoff 1971a) is a mistaken one. Since these latter arguments in particular are not original, I shall present them with a minimum of detail. I refer the reader to the original for the discussion in full.

\subsection{Criteria for Deep-Structure Analyses: Selectional Restrictions} While the original claim of two syntactic levels - deep and surface structure - has remained inviolate since its formulation by Chomsky in 1957, the detailed justification for and definition of deep structure have altered in several important ways, and this has a direct bearing on the status of semantics in the grammar. There are three alternative sets of criteria for deep structure which have been considered. Pre-Aspects, the justification for underlying structure was of two main types, arguments depending on formal distribution of elements, and arguments depending on selectional restrictions between lexical items. Thus for example it is necessary to set up a more abstract level of syntax in which you is the subject of imperative 
sentences if one is to capture the obvious generalisation for tage question formation and reflexivisation that only you and yourself respectively can occur in imperatives containing tags or reflexive pronouns, and no other pronoun. I give this argument in brief as a demonstration of a 'formal' argument and I shall not give further details of this by now standard argument (cf. Postal 1964). Examples of arguments depending on comoccurrence constraints, the other main evidence for underlying structure, are legion.

The first unified specification of the form a linguistic theory should take and the relations between its components was in 1964-5 with Katz and Postal 1964 and Chomsky 1965, and it is the definition of deep structure given in the latter that has been the source of controversy since. In this second formulation, there were three types of argument justifying the level of deep structure: formal arguments, arguments involving selectional restrictions, and (secondarily) synonymy between sentences. ${ }^{6}$ Tach of these criteria reflect (directly or indirectly) a different defining condition on deep structure: that it is the level at which syntactic relations are stated explicitly, that it is the level at which lexical items are inserted and selectional constraints operate, and that it is the level which determines the semantic interpretation of a sentence. Furthermore it is the level immediately prior to any transformations. Notice that if synonymy is included as a justification for underlying structure then this justification is no longer solely syntactic - it is partly semantic.

6. In fact Katz and Postal were careful to mention this as a consequence of their definition and not a defining criterion. But it was widely accepted as a defining function of deep structure. 
The third method of defining and justifying deep structure is to allow one type of argument only - the formal arguments. This is the most rigidly syntactic of the three possibilities and it is this that I wish to put in a plea for. Neither synonymy nor selectional restrictions are allowed as evidence. Using synonymy as a criterion is to assume that a semantic generalisation should be expressed in terms of a syntactic generalisation. Such an assumption predetermines the nature of the relation between syntax and semantics and leads directly to a generative semantics position. But as any first-year logic student knows, the proof that ' $p$ ' from the premise that ' $p$ ' is trivial. I shall therefore not assume that synonymy has any necessary bearing on syntactic structure. However, this third formulation also excludes the use of evidence from selectional restrictions. Why is such evidence suspect?

In Aspects, selectional restrictions are defined as a syntactic blocking mechanism on the insertion of verbs into the output of the phrase-structure rules; and they are stated in terms of the lexical properties of the preceding and following nouns. But McCawley cogently argues (1968 and elsewhere) ${ }^{7}$ that selectional restrictions are not a syntactic constraint but a semantic one. ${ }^{8}$ This being so, they are not evidence for a syntactically defined deep structure. There are five pieces of evidence that a blocking mechanism of the kind outlined above cannot be correct:

1) Such a constraint must be stated in terms of the semantic properties of the entire noun phrase, and not in terms merely of the surrounding

7. In fact he takes a stronger position, but this is not relevant to the argument at this point. Cf. McCawley 1971.

8. For a good summary of the arguments agajnst considering selectional restrictions syntactic, cf. Jackendoff $1972 \mathrm{pp} .18 \mathrm{ff}$. 
nouns, because Our male cousin became pregnant is just as deviant as Our brother became pregnant, and for the same reasons (cf. McCawley 1968 p.133 f.).

2) In every case where a selectional restriction looks like involving a syntactic feature it is in fact semantic. Consider the contrast between singular and plural, and the necessary non-singular specification of the object noun phrase of the verb count (cf. ibid p.134. f.):

(9) *I counted John (10) I counted the boys

But I counted the crowd is also grammatical and this suggests that it is not the syntactic specification plural which is demanded but the semantic implication of plurality. Cf. also the distinction between who and which, generally thought to be syntactic and the following sentences, where the head noun preceding who and which is identical in each case:

(11) The one who is most interesting is John

(12) *The one which is most interesting is John

(13) *The one who is most interesting is Aspects

(14) The one which is most interesting is Aspects

3) When embedded as a complement to verbs such as say, selectional restrictions can be broken without deviance:

(15) John said that rocks get diabetes

(16) John claimed that men get pregnant

(17) Our five-year old son told Mary that stones have babies

4) In certain negative environments, selectional restrictions can also be broken without causing deviance:

(18) A rock doesn't get diabetes

(19) Worms don't worry about money

(20) Men don't get pregnant

(21) It's not true that a rock gets tired 
In both of these two last cases, a Chomskian blocking mechanism on lexical insertion has to be prevented from applying; because if it applies, the syntax will not generate for example rock as the subject of get diabetes at all irrespective of the larger syntactic environment. Any constraint which applies obligatorily except when it has an ad hoc caveat that it doesn't is suspicious.

5) Where a verb or adjective has a particular selectional restriction and the noun it modifies is unmarked for that specification, the resulting phrase is interpreted as having that specification as part of its meaning:

(22) John hit it

(23) That person is pregnant 9

(24) Those that get pregnant sometimes regret it

Thus the last example is interpreted as having a subject which is female, human and adult, and this interpretation is due to the selectional specification of pregnant that its subject be ferale and adult (but not necessarily human) and the selectional specification of regret that its subject be human. Chomsky's formulation of selectional restrictions offers no account of this last set since selectional constraints are syntactic and do not operate in the semantic interpretation of a sentence - they are mereIy a condition on lexical insertion. Katz's formulation of selectional restrictions as a constraint on the operation of the semantic interpretation rules (cf. Katz and Fodor 1963) meets similar problems. Ad-hoc caveats have to be added for these cases.

9. With pregnant we enter the problematic realm of what constitutes knowledge of the language (viz. the meaning of pregnant) and what merely knowledge of the world (viz. our knowledge of which sex gives birth to children). For present purposes however I am simply assuming that it is part of the lexical specification of pregnant that it apply to females. 
But if selectional specifications are analysed as a semantic property of the verb in question no different in kind from its inherent properties, then there is a natural solution to all the sentences given above. Our male cousin became pregnant will be ruled out as a contradiction by virtue of the joint specification of the subject as male and female (cf. p.26 for an explicit formulation of contextual specification in terms of semantic components): John said that rocks get diabetes will not be ruled as deviant by virtue of the semantic property of the verb say; Worms don't worry about money will not be ruled as deviant since the specification of 'human' on the subject of worry is interpreted as falling within the scope of negation (cf. John isn't a woman) (Cf. section 1.3 .3 for a discussion of negation); and the interpretation of sentences such as Those that get premant sometimes regret it follows as an automatic consequence since the specification of the subject as human, female, and adult, simply is part of the meaning of the lexical items and hence of the sentence itself. 11 Furthermore, this analysis of selectional specification of lexical items as a part of their meaning makes an important and correct prediction (a sixth piece of evidence that selectional restrictions are semantic in nature): all synonymous lexical items will have identical selectional restrictions (even when they are syntactically distinct - viz. singular versus plural), and hence all synonymous sentences will have the same commutation potential:

(25) John used a knife to cut the cake

(26) *John used milk to cut the cake

10. Verbs such as dream, believe, with the same property are discussed on pp. $104 \mathrm{ff}, 138 \mathrm{f}, 156 \mathrm{ff}$.

11. It follows from this that there is no longer any distinction in kind between anomaly and contradiction. Cf. Bierwisch 1969 fn.13 for a critical assessment of this distinction. 
(27) John cut the cake with a knife

(28) *John cut the cake with milk

(29) The mother of John .....

(30) *The mother of dust

(31) The woman who gave bith to John ....

(32) *The woman who gave birth to dust

(33) John killed Maxy

(34) *John killed milk

(35) John caused Mary to die

(36) *John caused millk to die

If this is argument is correct and selectional restrictions constitute part of the meaning of lexical items, then selectional restrictions are no more relevant to a justification of underlying structure than shared synonymy. If either is used as evidence of deep structure, then the relation between syntax and semantics can no longer be argued about: it has been assumed.

1.2.2 The Independence of Syntax and Semantics

Nothing I have said so far provides any evidence as to the nature of the relation between syntax and semantics: my argument has merely been that only formal distributional arguments are relevant in considering the problem. This conttraint excludes many arguments which have been put forward. The issue of the interdependence or otherwise of syntax and semantics thus rests on whether synonymous structures have the same syntactic potential. The evidence so far available suggests that they do not. Fodor (1969) points out that John killed Mary and John caused Mary to dije differ in their constraints on adverbial modification and on pronominalisation. 12 His evidence is of three kinds:

12. I am assuming here that kill and cause to die do not differ in meaning. This has been questioned. Cf. Jackendoff 1972, p.27f. 
(a) a two-vexbstructure can have an interpretation such that the two activities referred to occur at different times, a possibility which is not open to a simple clause structure: viz. (36) John caused Mary to die on Saturday by poisoning her on Friday (37) *John killed Mary on Saturday by poisoning her on Friday (b) a twowerb structure allows either verb phrase to be pronominalised by do so, where a one-verb structure allows only one possibility: (38) Eva caused James Bond to die and everybody was surprised that she did so

(39) Eva caused James Bond to die and everybody was surprised that he did so

(40) Trva killed James Bond and everybody was surprised that she did so (4.1) *Eva killed James Bond and everybody was surprised that he did so (c) there are instrumental adverbial constructions which modify only the underlying subject of a sentence (as in John got in touch with Mary by using the telephone, which cannot mean that Mary used the telephone), and these are a source of ambiguity in a cause to die construction but not in a sentence containing kill. Thus John caused Bill to die by swallowing his tongue is ambiguous; John killed Bill by swallowing his tongue is not. In order to explain the first constraint in a framework In which cause to die and kill have the same underlying structure, there has to be a special caveat on the transformational rule of lexical insertion that it only takes place if a modifying sentential adverbial does not contain contradictory time specification. To explain the distribution of do so, lexical insertion has to be before pronominalisation though there is conflicting evidence with melt that lexical insertion must be after pronominalisation; and to explain (c) one would have to give up the apparently well-attested generalisation that such instrumental 
adverbials are restricted to deep structure subject modification. However each of the paradigms is explained naturally if the underlying structure of kill is a simple $\left[{ }_{S}\right.$ NP $\left[_{P} V\right.$ NP $]$ structure: all. the constraints then follow as an automatic consequence a a simple sentence cannot take conflicting adverbials, do so is a verb phrase pro-form and there is no verb phrase corresponding to the do so in (41), John killed Bill by swallowing his tongue is unambiguous because there is only one subject in the sentence.

Furthermore, Chomsky (1969) has provided evidence that a syntactically defined concept of deep structure along the lines of Aspects (1965) provides a natural account of the distinction between derived nominals such as destruction, belief, death, etc., and the corresponding gerundive constructions. These two types of constructions have many of the properties that have commonly been said to indicate shared underlying structure - viz. selectional restrictions, identical subject-verb-object relations. However, as Chomsky points out, they do not have the same freedom of occurrence. Derived nominals only enter constructions which parallel deep structure configurations and not derived structure configurations. Thus we get

(42) John's proof of the theorem

(43) John's destruction of the enemy

(44) John's death

(45) John's desire to go

(46) *John's likelihood to go

(47) *John's appearance to be sick

(48) *John's easiness to ignore

(49) John's eagerness to be helpful

This paradigm is significantly different from gerundives, which are formed freely from both deep structures and derived structures: 
(50) John's proving the theorem

(51) John's destroying the enemy

(52) John's dying

(53) John's desiring to go

(54.) John's being likely to go

(55) John's appearing to be sick

(56) John's being easy to ignore

(57) John's being eager to be helpful.

Gerundives and nominals differ further in that the former are sentential in nature: they can contain aspect, the gerundive itself allows adverbial modification but not adjectival modification, and John in the above examples is not replaceable by determiners. Dexived nominals differ in each of these respects: John can be replaced by a wide range of determiners, the nominal can be modified by the full range of adjectives but not by adverbs, and no aspectual modification is possible. Thus we have the following sets of sentences:

(58) John's having deceived Mary upset Bob

(59) John's deliberately deceiving Mary upset Bob

(60) *John's deliberate deceiving Mary upset Bob

(61) *The deliberate deceiving Mary upset Bob

(62) *John's having deception of Mary upset Bob

(63) *John's deliberately deception of Mary upset Bob

(64) John's deliberate deception of Mary upset Bob

(65) The deliberate deception of Mary upset Bob

For some premodified nominals the derivation From an underlying verbal structure is even difficult to conceive e.B. John's three Iinguistics qualifications are rather inferior. Thus while gerundives have sentential properties derived nominals have the internal structure of noun phrases. In order to capture this distinction, and yet retain the generalisation that they contain identical subject-object relations, Chomsky suggested describing gerundives transformationally in the 
normal way, but describing derived nominals by extending the base to generate them directly. The following phrase-markers demonstrate the different underlying structures for John's destroying the enemy, John's destruction of the enemy and for the intransitive expressions John's dying, John's death: ${ }^{13}$
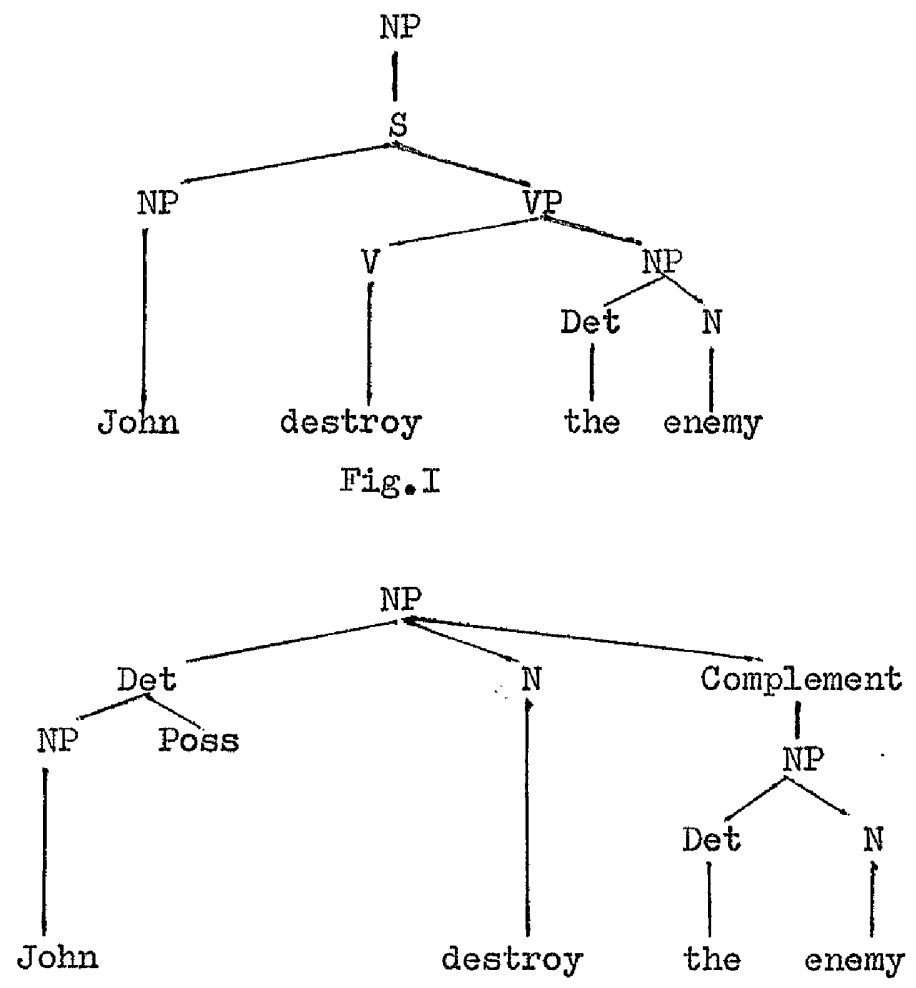

Fig. II

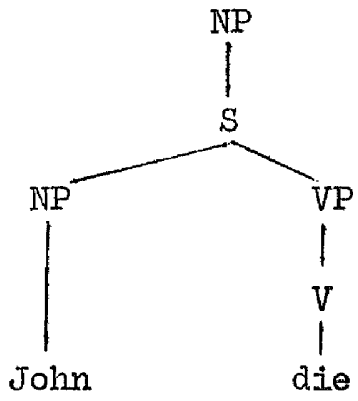

Fig.III

13. Cf. Ch. 6 for an argument in favour of a different deep structure to that given here for gerundives. The difference is not however relevant to Chomsky's argument and I am ignoring it here. 


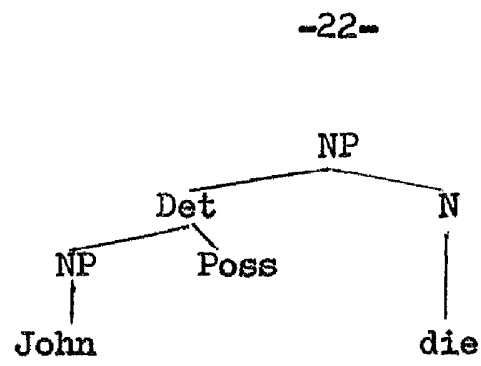

Fig.IV

The most striking difference is perhaps that die and destroy are entered directly under a noun node in Figures II and IV respectively. The details of this formulation are not important at this point. ${ }^{14}$ The interest 1ies in the consequent dictionary entries. All verbs which have derived nominals will have disjunct lexical entries along the lines of destroy and die: DESTROY $^{15}:+[\ldots$

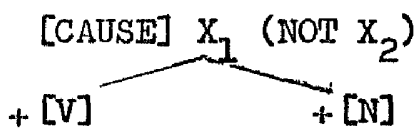

$\underline{D I E}$

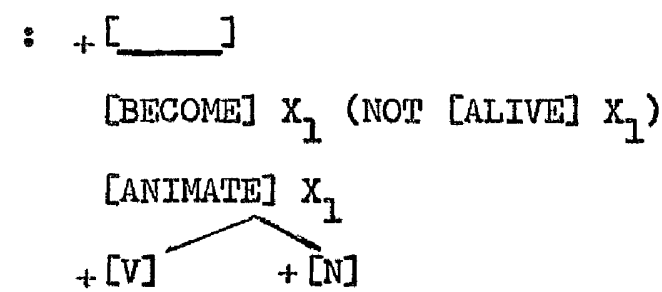

Both destroy and die are given lexical entries in which the semantic properties are neutral as to their syntactic function (noun or verb). This will be true for the great majority of verbs. Their lexical entries will contain a disjunction between noun and verb, together with a common core of properties which are common to these two syntactic realisations. But analysing lexical entries as having a common core of

14. For purposes of exegesis I shall retain the standard notation throughm out this thesis.

15. Binary features (preceded by ' + ' are syntactic features. Others are semantic. The specification of the semantic features is only approximate. For a detailod justification of the form of semantic features, cf. p.24 ff. I ignore the phonological specification. 
semantic properties with more than one syntactic realisation of this semantic core is equivalent to presenting the claim that syntax and semantics constitute two distinct levels of structure, since it allows identity on either level without this pre-determining identity at the other level, even within a single lexical item.

It is on the strength of evidence of the kind presented in this section that I assume that the constraints imposed by syntactic structure are not co-extensive with those of semantics. This stand leads to two consequent assumptions which provide the theoretical background to all the arguments in this thesis: (a) syntactic construsts ingeneral must be defined and justified without reference to semantics, (b) the semantic analysis of a sentence does not automatically lead to a reflex in the syntactic structure of that sentence.

\subsection{On The dvature of Semantic Features and The Semantic Component} While the nature of the rules of the semantic component remains quite unclear, this problem is not one with which I shall deal in any detail in this thesis. 16 I shall merely assume for the sake of exegesis that semantic specification operates largely along the lines suggested by Bierwisch (1969, 1971). In this formulation, the rules of the semantic component are interpretive in so far as they are dependent on a semantic specification of lexical items in the lexicon and the syntactic information provided by the underlying structure of a sentence (in this respect like Katz).

16. I shall therefore be largely ignoring the work done by logicians such Montague, Lewis etc whose semantics are interpretive in the stricter sense of defining a function which maps sentences into a model. Cf. Montague 1968, 1972, Lewis 1972. 
1.3.I On the Form of Semantic Features

One important respect in which Bierwisch differs from Chomsky (1965) and Katz (1964, 1966) is in the form of the minimal semantic unit. Bierwisch formulates semantic components along the lines defined by predicate calculus, and not in a different way as do Katz and Leech. One of the chief reasons for not using predicate calculus as the basis for description seems to have been the common assumption that the semantic properties of lexical items, like their phonological and syntactic properties, could be formulated in terms of binary features (whether implicitly, like Katz, or explicitly, like Leech). However it is apparent that binary features must be inadequate for analysing terms such as transitive verbs which express a relation between two objects, e.g. kill, chase, etc., since such features are equivalent to a one-place predicate and hence are not a suitable means of formalising two-place relations. Thus [MAIAT] $\mathrm{X}$, [HUMAN] $\mathrm{X}$, [ADULT] $\mathrm{X},{ }^{17}$ can be rewritten as the binary feature complex +MALE; +HUMAN; HDULP; but [CAUSE] $\mathrm{X}_{1}\left([D D D] \mathrm{X}_{2}\right)$ cannot be reformulated in binary features in any transparent way. The nearest equivalent is perhaps +CAUSATIVE, +RELATIONAJ, + DEATH, which is obviously unsatisfactory. Moreover both Katz' (cf. Katz 1966, 1967) and Leech's attempts to overcome this deficiency necessitate dubious additions to the semantic metalanguage, which to the extent that they are adequately justified are terminological. variants of predicate calculus formulations (cf. Bierwisch 1969

17. I adopt here the format of Bierwisch. A predicate is thus listed first in sequence, followed by its argument(s). Propositional arguments are enclosed in round brackets. 
for detailed criticisms of Katz' extended component system). 18

I shall therefore - like Bierwisch (cf. also Weinreich 1962, Bendix 1966) $\Rightarrow$ assume that semantic properties of lexical items can most appropriately be described by the formulae of predicate calculus, construing features as predicates with unbound variables indexed for subject and object (and indirect object in the case of three-place predicates such as give). There are however several respects in which the semantic apparatus differs from that of predicate calculus. One of these is the need to have propositions functioning as arguments. Thus for example the lexical entry for kill would be: KIII : $\quad+[$

[CAUST] $X_{\mathrm{NP}, \mathrm{S}}\left(\right.$ [BECOMP] $\left(\mathrm{NOT}\right.$ [ALIVE] $\left.\left.\mathrm{XNP}_{\mathrm{NPP}}\right)\right)$

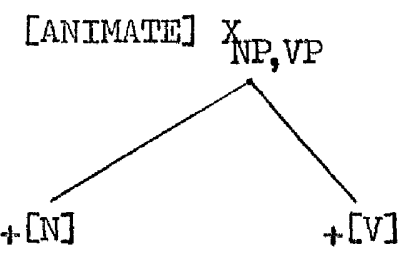

In each case the variable $X$ is given a syntactic index. In the first component above, $X$ and the poposition ( [BECONA] ( NOT [ALIVT] $X$ )) function as arguments of the predicate [CAUSE], the proposition (NOT [ALIVI] $\mathrm{X}$ ) is the argument of the one-place predicate [BECOME], and [ALIVE] has $X$ as argument. Implicit in this formulation is the assumption that the sementic properties of lexical items are expressed in terms of the contribution the items make to the meaning of a sentence. A further complication of predicate calculus is the need to have predicates as arguments for predicates. This is necessary in order to make explicit the meaning of for example run, as

18. The revision of Katz's system in Katz 1972 is not substantially different from earlier versions and is therefore open to the same criticisms. 
$\begin{aligned} \text { RUN : } & {[\text { [FAST }] \text { MOTION }] X_{\mathrm{NP}, \mathrm{S}} \cdot[\text { [EGS }] \mathrm{X}_{\mathrm{NP}, \mathrm{S}} } \\ & \cdot[\text { [PHYSICAL] ACTIVITX }] \mathrm{X}_{\mathrm{NP}, \mathrm{S}} \cdot[\text { [ANTMATE }] \mathrm{X}_{\mathrm{NP}, \mathrm{S}} 19\end{aligned}$

There is one principal difference between the formulation used here and that of Bierwisch. Unlike Bierwisch (1969), I recognise no difference in status between so-called selectional restrictions and inherent properties (cf 1.2.1). Kill thus contains as part of its meaning the specification that its object is animate. This specification is not a condition on the operation of projection rules in the manner of Katz and Bierwisch: it is no different in status from the specification of the action itself. This is essentially equivalent to the transfer-feature mechanism of Weinreich 1966 (cf. also Leech 1969). This latter is a means of allowing properties of the verb to be 'transferred' to neighbouring noun phrases, to account for the contextual specification of the kind demonstrated in Those that get pregnant sometimes regret it. The necessity for such a mechanism is however solely due to the lack of specification in binary features of what it is that the components describe. Since there is no explicit indication of what the components axe predicated of, there is no means of distinguishing cases where components are specifications of different arguments. Thus the complication involved by this process is a direct consequence of using a binary feature specification for semantic components. The problem simply does not arise in a lexical entry in which semantic components are construed as predicates with variables which indicate which noun phrase functions as its argument.

19. I am assuming the standard definition of '.' as and. 
Wach of the lexical entries given here depends on some form of redundancy rule completing the specification of its meaning. For example:

\section{[HUMAN] $\mathrm{X} \longrightarrow$ [ANTMANE] $\mathrm{X}$ \\ [ANIMATE] $\mathrm{x} \rightarrow$ [CONCREIP] $\mathrm{X}$}

In fact the lexical entry for run given abore could be simplified if the following redundancy rule was taken into account:

[ACTIVITY $:$ MOTION] $\mathrm{x} \longrightarrow$ [ [PHYSICAT] ACTIVITY $] \mathrm{x}^{20}$ The need for these rules is very generally recognised. However their complexity has been discussed in detail only by Bierwisch (1969), who points out that many redundancy rules must be of a form

\section{$[\mathrm{M}] \longrightarrow[\mathrm{M}] \mathrm{N}]$}

rather than a mere addition of features. Thus for example a full specification of woman would not be in the form:

[FimaleE] $\mathrm{X} \cdot$ [HUMAN] $\mathrm{X} \cdot$ [ANTMATE] $\mathrm{X} \cdot$ [CONCRETE] $\mathrm{X} \cdot$ [ADULT. $\mathrm{X}$ but rather in the more complex hierarchical form:

[ [ [FmMAIE - HUMAN - ADULT] ANIMATE ] CONCRETE ] X since the minimal entry [FGMALE] $X$. [HUMAN] $X$. [ADULT] $X$ would be subject to redundancy rules:

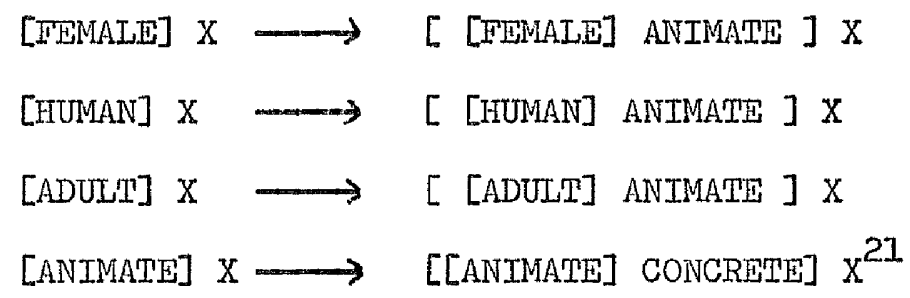

This hierarchy is not only needed to account for relations of inclusion between properties but also to account for the behaviour of semantic complexes under negation (cf. section 1.3.3).

20. Cf. Bierwisch ibid p.170 f.

21. Bierwisch's formulation is:

[[RED*] $v$ [[BLUE]*] $v$ [[GRTEN] $*] \vee \ldots \rightarrow$ [COLOR]

but the difference is not substantive ( $1 * 1$ is interpreted as a placeholder for the more inclusive term). I have preferred the simpler formulation for purposes of clarity. 
There is one further potential criticism here which must be rebutted. It might be argued that the semantic structure postulated for $\mathrm{kill}$ is terminologically equivalent to the following phrase-marker:

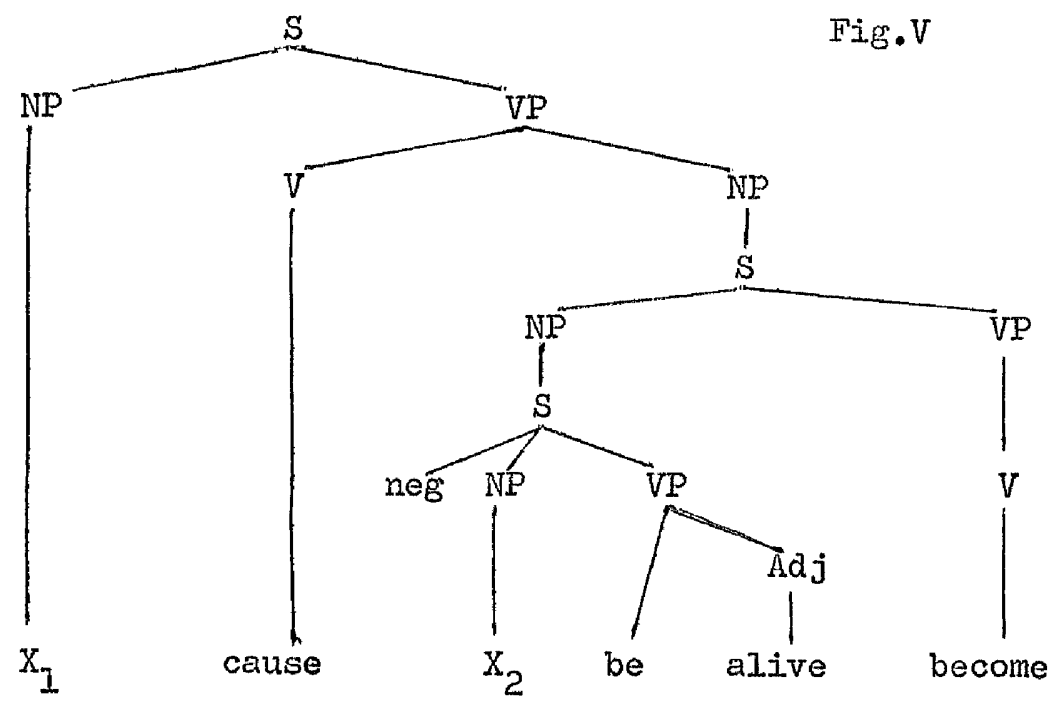

Anyone holding this position would presumably furthex argue that since all semantic representations can be represented in the form of a phrase. marker, the syntax-semantics dichotomy is untenable and is reduced to mere terminology. 22 It is indeed a consequence of my position that the semantic representation of the sentence John caused Mary to die is similar in many respects to its syntactic representation, and the semantic representation can be presented in a form which accentuates the similaxity:

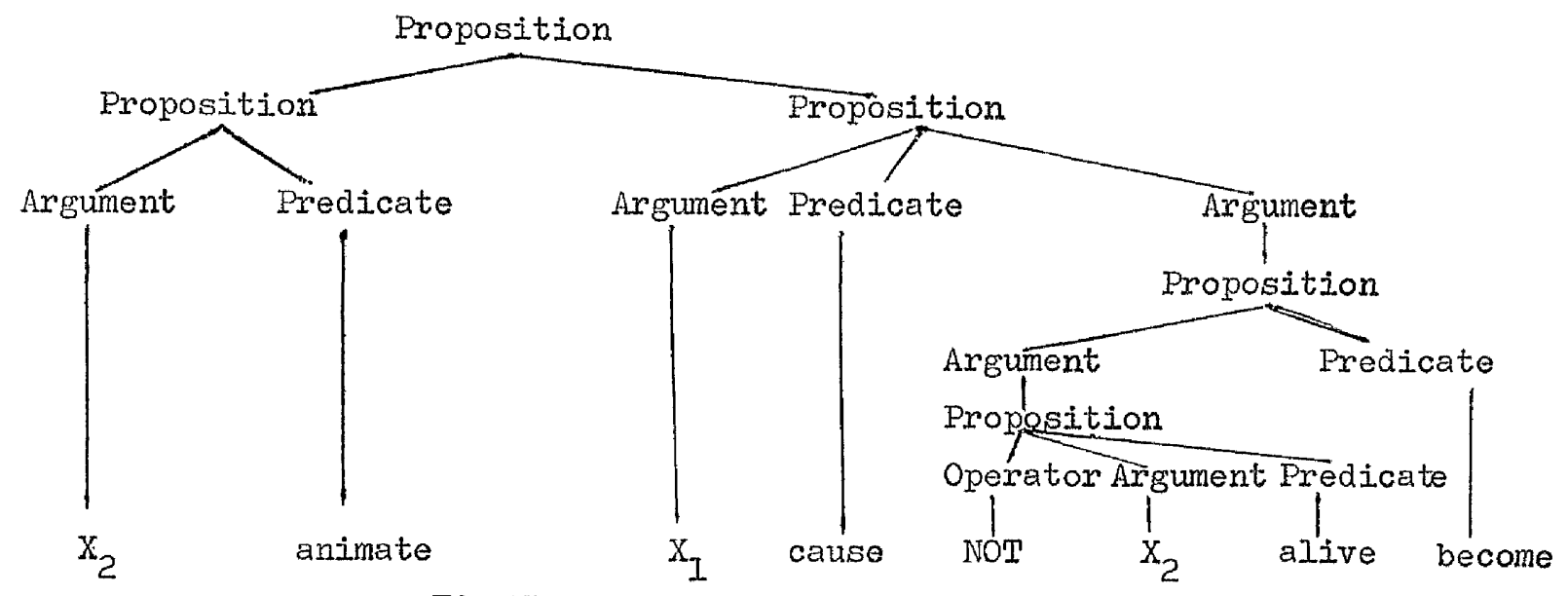

Fig.VI

22. This is implicit in some of the work by linguists such as McCawley, Postal, Lakoff etc. Cf. McCawley 1968; and Chomsky 1972 for an argument against any such assumption on the grounds of its vacuity. 


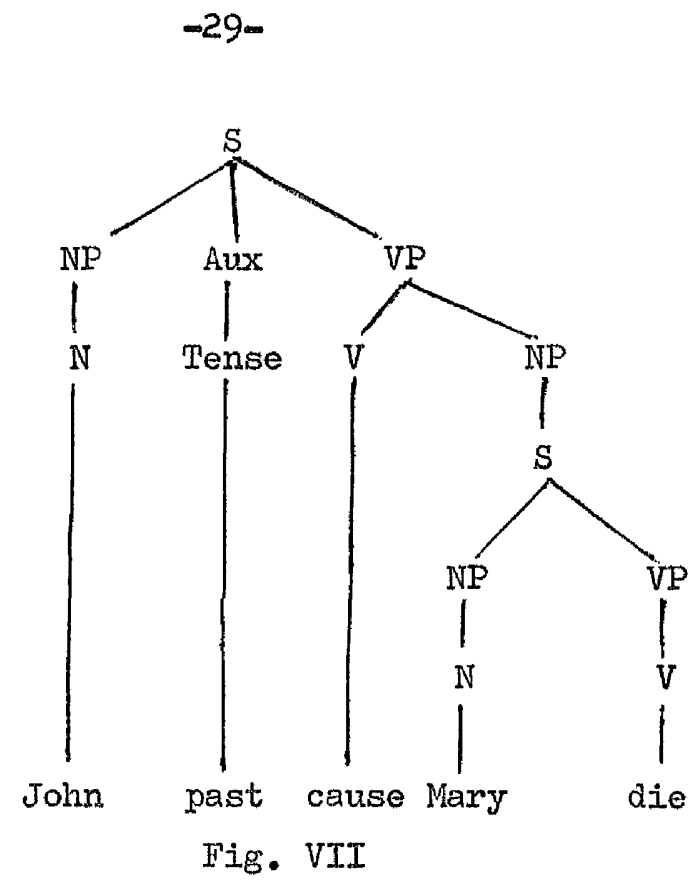

However, there is one crucial difference - the labelling of the relations. Figure VI uses the terms Proposition, Argument, Predicate and Operator, whereas Figure VII uses S, NP, Aux, Tense, VP, V, N. And this distinction is not merely terminological. All that is conveyed by the terms in Figure VI is:

Argument : nonrelational term

Predicate : relational term

Proposition: combination of argument and predicate

Operator : term which alters argument-predicate relation

There is no more specification of the properties and relations than this. And apart from the addition of quantifiers, this list constitutes the entire metavocabulary of semantics. Now while this js a form of syntax in so far as it relates items syntagmatically, it is not a syntax of any specific language. Moreover it is so general that it can describe any system of relations such as mathematics, biological systems, and systems such as those descrjbing growing cells. What is common between linguistic syntax and predicate calculus is that both use linking and hierarchical relations: there are concatenation relations between Argument-Predicate 
and between subject and verb, and there are hierarchical relations between propositions and also between sentences. The difference between them lies in the very much greater abstractness of the relations in the semantic structure and, conversely, in the specification of the relations in syntax - the labelling. Since the information given in the semantic structure is so general, the fact that it can be represented in the form of a phrase-marker merely states, trivially, that semantics, like syntax, involves hierarchical relations. Such a conclusion is hardly justifjcation for renouncing the distinction between syntax and semantics. Intopder to justify rejecting the distinction, one needs to argue that the labels NP, N, V, Aux etc are relevant to semantics, a claim that Chomsky's disjunct lexical entry specifications (cf. p. 22 ) implicitly deny.

\subsubsection{On the Nature of the 'Projection' Rules}

The rules providing the semantic interpretation of a sentence are dependent on the semantic specification of the lexical items as fully interpreted by the redundancy rules, and their syntactic relations as defined by the deep structure phrase-marker. In addition, Bierwisch's system of interpretive rules depends on all noun phrases having a reference index as part of their deep-structure specification. ${ }^{23}$ These reference indices are substituted for the grammatical index specified in the lexical entry and all the components are combined to form an unordered conjoint set (i.e. joined by '.1). These 'projection' rules are constrained by the syntactic indices on the lexical items. These must match the noun phrase whose referential index is to be

23. Cf. Ch.2 for an independent justification of this position. Exceptions to this general statement are considered in ch.5, p. I62f. 
substituted (in the case of a noun, the grammatical index must match the noun phrase immediately dominating it). Thus for example the phrase marker in Figure VIII,

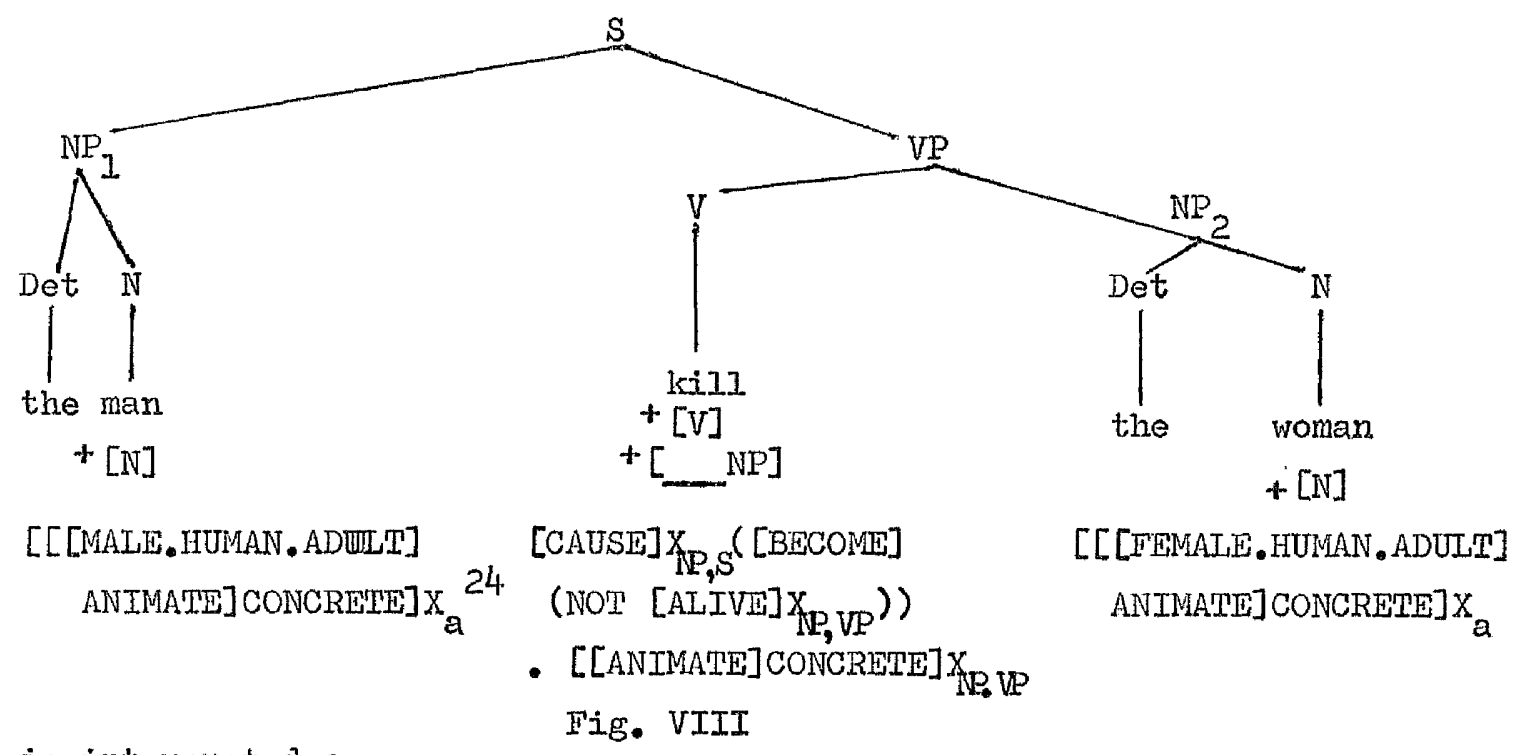

is interpreted as:

[C[MALE - HUMAN - ADULT] ANIMATES] CONCRETE] $\mathrm{X}_{1}$ •

[C[FEMALE - HUMAN - ADULT] ANIMATE] CONCRETET $\mathrm{X}_{2} \bullet$

[CAUSE] $\mathrm{X}_{1}\left(\right.$ [BECOME] (NOT [ALIVE] $\left.\left.\mathrm{x}_{2}\right)\right) \cdot$ [[ANTMANE] CONCRETE] $\mathrm{x}_{2}{ }^{25}$

Any specification which is given twice is then deleted, thus avoiding

redundancy (in this case [[ANIMATE] CONCRETE] $\left.\mathrm{x}_{2}\right)_{0}^{26}$

When all the semantic rules have taken place, there are well-

formedness conditions blocking any interpretation containing conflicting

components. Thus for example both The man is a woman and The man is

24. $a=[N P, S] \vee[N P, V P] \vee[N P, P P]$, where ' $v$ ' here and in all subsequent formulations corresponds to logically inclusive or.

25. I ignore here the problem of the definite article. For a more detailed analysis, ef. ch. 5-6.

26. For further details, cf. Bierwisch 1969. 
pregnant will be said not to be well-formed sentences of the language by virtue of their contradictory semantic components (cf. in il of this chapter on the putative distinction between anomaly and contradiction). 27 For detajis of this procedure cf. Katz 1964 p.526 f, Bierwisch 1969 p. 164.

\subsubsection{Negation}

The semantic rules of interpretation are not exhausted by the projection rules of substitution. Additional rules are needed to interpret negative sentences, and there are special problems over these which constitute the core of the disagreement over presupposition. The problems I shall consider later (cf. ch.4-6). Here I merely wish to set up a formal means of describing the interpretation of negative sentences. A detailed formulation was set up for negative sentences first by Katz (1964), and this was improved and genexalised by Bierwisch to cover all types of sentences and all types of semantic marker, simple and complex. I shall assume here that the latter is the more sophisticated and I shall not deal with Katz' (1964)

formulation (it has three caveats which both reduce its over-all generality and detract from its initial plausibility). In both Katz' and Bierwisch's formulation the rule is, in essence, a strict translation into componential terms of the logical equivalence defined by de Morgan (a borrowing which is not admitted by Katz though explicitly stated by Bierwisch). This states that for any conjoint set of items

27. I shall assume the correctness of this type of constraint merely for the sake of exegesis. A plausible alternative would be to demand that the semantics merely has to characterise them as a natural set, rather than exclude them as not well-formed. Evidence in support of this view is provided by the necessity of a pragmatic maxim (cf. ch.7) that speakers tell the truth. The deviance of contradictions is thus captured by rules of communication. The problem is on this view parallel to selfembedded constructions whose deviance is explained by some theory of memory rather than by the specifically linguistic competence model. 
(whether they be properties, objects or statenents), the negation of that conjoint set is equivalent to the disjunct set of the negation of each member of that set, viz:

$$
-(p \cdot q) \text { is }-p \vee-q
$$

Thus to take a simple example in componential terms, It was a pirl has the interpretation that the object described was female AND young AND human AND animate etc, but It wasn't a girl then has the interpretation that the object described was either not female OR not young $O R$ not human $O R$ not animate.

There are several complications to this statement. Both Katz and Bierwisch analyse negation in terms of an "antonymy operator". This is defined as follows:

For any antonymous set of components $M_{7} M_{2} \ldots M_{n}$ the antonymy operator $\left(A / M_{i}\right)$ of some arbitrary component $M_{i}$ is $\left(M_{1} \vee M_{2} \vee \ldots M_{i-1} \vee M_{i} I \ldots M_{n}\right)$.

For those cases such as [ANIMAIE] which are sole members of their set:

$$
A / M=-M
$$

It follows from these definitions that $A / A / M_{i}=M_{i}$ Bierwisch extends this to complex markers such that for any markers $M$ and $N$ (either simple or complex):

$$
\mathrm{A} /[\mathrm{M} \cdot \mathrm{N}]=[\mathrm{A} / \mathrm{M} \vee \mathrm{A} / \mathrm{N}]
$$

(equivalent exactly to de Morgan's law)

$$
\mathrm{A} /[\mathrm{M}] \mathrm{N}]=[[\mathrm{A} / \mathrm{M}] \mathrm{N} \vee \mathrm{A} / \mathrm{N}]
$$

(deducible from de Morgan's equivalences - cf. Bierwisch 1969 p. 173 ) The intexpretation of a negative sentence is then derived as follows (ignoring for the moment problems of scope): 
Given Neg $S$ where $S$ is interpreted as a conjoint set of semantic components $\left(p_{1} \cdot p_{2} \cdot p_{3} \ldots \ldots p_{n}\right)$ either simple or complex, Neg $S$ is replaced by $\mathrm{A} / \mathrm{S}$.

$$
A / S=A / p_{1} v A / p_{2} \vee A / p_{3} \vee \ldots \ldots v A / p_{n}
$$

By this rule the interpretation of It wasn't a woman is predictable in the following way. 28 The semantic specification of woman was given earlier as:

[C[FGMALE - HUMAN - ADULT] ANIMATE] CONCRETI $X$ Thus NEG [[[FEMALT - HUMAN - ADULT] ANIMATE] CONCRETE] $\mathrm{X}$ is replaced by A/ [ [TFMALE - HUMAN - ADULT] ANIMATE] CONCRETE] $X$ $\mathbf{z}_{\text {(by iii }}$ [A/[ERMALE - HUMAN - ADULT] ANIMATE] CONCRETE $v$ A/CONCRETE] $x^{29}$ $=(\text { by iii })^{[[A /[F E M A L P S} \cdot$ HUMAN . ADULT] ANIMATEL]CONCRETE $v$ [A/ANTMATE]CONCRETE v A/CONCRETE ] $\mathrm{x}^{30}$

$=($ by $i i)[[$ [A/FEMALE $\vee$ A/HUMAN $\vee$ A/ADULT $]$ ANIMATE $]$ CONCRETE $v$ [A/ANIMATE]CONCRETE $v$ A/CONCRETE ] $X$ $=($ by $i)$ [[ MALE $v$-HUMAN $v$-ADULT $]$ ANIMATE $]$ CONCRETE $] \mathrm{X}$

$$
\begin{aligned}
& \underline{a} \quad \underline{b} \quad \underline{c} \\
& v \text { [[-ANIMATE] CONCRETE] X v [-CONCRETT] X }
\end{aligned}
$$

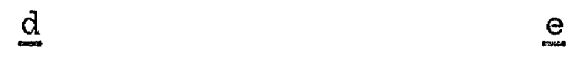

The or in each case is the logically inclusive or, with the additional constraint that readings containing contradictory components will be rejected as an impossible interpretation by the output condition mentioned earlier (p.31f). So if [ANIMATE] is negated, as in (d), it cannot be combined with a semantic complex containing [ANIMATE], as in (a), (b), or (c). Informally what the rule states in this example is

28. I here assume the incorrect simplification that negating a sentence is equivalent to negating its predicate. Cf. Ch. 5 for further instances which demonstrate this to be false.

29. In this application of (iii) $M=$ [[FBMALE . HUMAN . ADULT]ANIMATE] $N=[C O N C R T T E]$

30. In this application of (iii) $M=$ [FEMALE . HUMAN . ADULT] 
that the set of components specified by the statement It was a woman does not correspond to the state of affairs being described. 31

This failure of correspondence may have one of several causes: either the object described is not female (though human) as in (a), or it is not human (b), or it is not adult (c), or it is not animate at all (d), or it is not even a concrete object (e). Which of these is the cause of the lack of correspondence is not specified by the sentence, but is left vague. AlI the sentence states is that there is not a correspondence between the statement It was a woman and the situation in question. The context (Iinguistic or non-linguistic) may however clarify which of these four possible specifications is the basis of a speaker's asserting It wasn't a woman - viz:

(A) P "Was that a woman knooking on the door?"

Q "No. It wasn't a woman. (It was a man)."

(B) P "Was that a woman knocking on the door?"

Q "No. It wasn't a woman. (It was my dog.)"

(C) P "Was that a woman knocking on the door?"

Q "No. It wasn't a woman (It was my daughter.)"

(D) P "Was that a woman knocking on the door?"

Q "No. It wasn't a woman. (It was mot dustbin leaning up against it.)"

(E) P "Was it a woman that annoyed you?"

Q "No. It wasn't a woman. (It was my own incompetence.)"

In fact, as (A) demonstrates, the possibilities are yet more varied, as the complex (a) - (c) allows for any combination of [MALE] or [-MALE] with [HUMAN] or [-HUMAN] and with [ADULT] or [-ADULT] - except [-MALT . HUMAN . ADULT]. The sentence is in fact applied in (A) to

31. Cf. Ch.2 for a detailed discussion of the relation between semantic components and the non-Iinguistic entities they describe. 
describe a situation in which a combination of [MALE - HUMAN . ADULT] are involved. Notice that if the redundancy rules had been, as traditionally formulated:

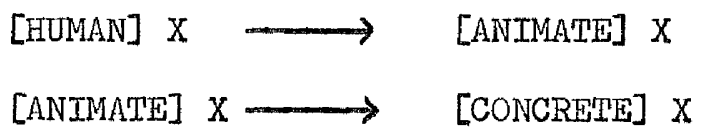

the wrong predictions would nave been made: the possible interpretations of It wasn't a woman would have been given as

$-($ [FGMALE]X . [HUMAN]X . [ADULT]X . [ANIMATE]X . [CONCRITE]X )

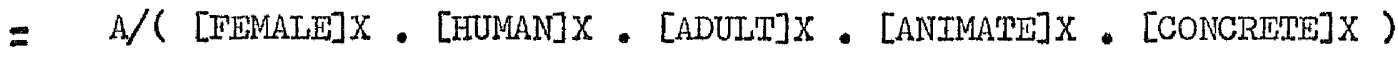

$=[A /$ FEMALE]X $\vee[A /$ HUMAN $] X \vee[A / A D U L T] X \vee[A / A N I M A T E] X \vee[A / C O N C R E T E] X$

$=[$ MALE] $X \vee[-H U M A N] X \vee[-A D U L T] X \vee[-A N I M A T E] X \vee[-C O N C R E T E] X$

Here the five contextualisations $(A)-(\mathbb{B})$ are predicted, but there is no means of blocking the combination of [-CONCRETE] and [MALE], [-ANIMATS] and [MAIT] etc: i.e. there is no way of capturing the intuition that if animacy or concreteness are negated, then wex human-ness or adult-ness must also be negated.

The fact that there are at least the five different contextualisations (A) -(E) of It wasn't a woman does not demonstrate that the sentence is five-ways ambiguous. What the disjunct reading states is that there is one interpretation of this sentence but that there are (at least) five ways of meeting the conditions set by this interpretation. This constitutes vagueness, not ambiguity. This can be shown by considering well-attested cases of vagueness. 32 There is but one interpretation of neighbour but more than one way of meeting this interpretation. It is met both by female humans and by male humans. If negative sentences were said to be ambiguous by virtue of their disjunct reading, then every example of vagueness could be shown to be ambiguous. Neighbour

32. I am using vagueness here and throughout as interchangeable with unspecified. It is arguable that there is a second kind of vagueness which is in principle unspecifiable. An example is You are the winner, which may be vague as to whether or not it is being used performatively. 
ior example would be shown (falsely) to be an ambiguous lexical item, since it can be used to describe quite different types of object, male humans and female humans. This is clearly incorrect. There is a syntactic test for distinguishing vagueness from ambiguity, which confirms this analysis of negation. 33 If a sentence is ambiguous, then in order for verb-phrase pronominalisation to take place in a conjoined structure containing that sentence, the two conjuncts must agree in their interpretation of the ambiguous sentence. Thus (66) is ambiguous two ways and not four:

(66) John likes visiting relatives and Harry does too.

This cannot be followed by the contextualisation John likes going to see relatives, and Harry for them to come and see him. If a sentence is vague in some part of its semantic interpretation, the interpretation of the pronominalised conjunct need not agree with the first conjunct: (67) John likes music and Harry does too: John likes pop and Harry classical.

(68) John paid a lot for his car, and Harry did too: John paid 3,000 pounds and Harry 6,000 pounds.

(69) John has one neighbour and Mary has one too: John's neighbour is a spinster, and Mary's is a widower.

In all these cases - unlike (66) - the further specification of the conjuncts can vary independently. Now just as the specification of sex in some contextualised use of neighbour can vary independently across a verb-phrase pronominalisation of this type, so can the interpretation of negative sentences: (70) John didn't run away and Harry didn't either: John walked slowly off and Harry stayed stock still.

33. Cf. Lakoff 1970d. 
(71) John doesn't seduce women and Harry doesn't either: John seduces young girls and Harry seduces boys.

(72) On the first day, it wasn't a woman and it wasn't on the second day either: first it was a man and then it was a young girl.

In each of these, the verb phrase of the second conjunct can be pronominalised (deleted in the case of the copula) by virtue of the two conjuncts sharing an identical negated verb phrase. This does not however constrain the specification of which conditions are interpreted as not being met, i.e. to what components of the sentence the negation applies. Thus the interpretation of the scope of the negation is vague, not ambiguous.

Furthermore, the two semantic concepts of vagueness and ambiguity are theoretically distinguished. An ambiguous sentence is formulated as having two quite separate structures, whereas a vague sentence is one which is characterised semantically by a disjunction. Thus neighbour will have a lexical entry which is unspecified for sex and which will therefore be specified redundantly as [MALE $v$ FEMALE]. Similarly a negative sentence has one underlying structure (given that it is not ambiguous for independent reasons) and is interpreted as vague in its interpretation by a semantic rule which predicts a disjunct set of possible reading's.

\subsubsection{The Scope of Negation}

So far I have referred only in passing to the so-called 'scope' of negation with an implicit assumption of its being understood. It must however be more rigorously defined. In the case of negation, the scope of negation constitutes those semantic components which are 
altered by the rule of negation. Thus for some conjoint set of semantic components $\left[e_{1} \cdot e_{2} \cdot e_{3}\right]$ the negation of that set is equivalent to:

$$
\left[\mathrm{A} / \mathrm{e}_{1} \vee \mathrm{A} / \mathrm{e}_{2}, \mathrm{v} / \mathrm{e}_{3}\right]
$$

and this formulation by definition allows any of the following combinations: 34

$$
\begin{aligned}
& {\left[A / e_{1} \cdot A / e_{2} \cdot A / e_{3}\right]} \\
& {\left[A / e_{1} \cdot A / e_{2} \cdot e_{3}\right]} \\
& {\left[A / e_{1} \cdot e_{2} \cdot A / e_{3}\right]} \\
& {\left[e_{1} \cdot A / e_{2} \cdot A / e_{3}\right]} \\
& {\left[A / e_{1} \cdot e_{2} \cdot e_{3}\right]} \\
& {\left[e_{1} \cdot e_{2} \cdot A / e_{3}\right]} \\
& {\left[e_{1} \cdot A / e_{2} \cdot e_{3}\right]}
\end{aligned}
$$

Now in each of these specified cases, the scope of negation differs: it includes all three components in (i), $e_{1}$ and $e_{2}$ in (ii), $e_{1}{ }^{a}$ and $e_{3}$ in (iii), $e_{2}$ and $e_{3}$ in (iv) etc. This may seem to stand in contradiction to my statement that the rule applied to a whole sentence reading, with the single disjunct output. But it is not. The specification of $\mathrm{Neg}\left(e_{1} \cdot e_{2} \cdot e_{3}\right)$ allows for each of these seven possibilities and the scope of negation is indeterminate. Thus It wasn't a woman in my example on $p .34 f$ does not specify that the object described was a boy, or that it was a girl, or even that it was the dustbin leaning against the door, etc, but merely states that the object described was not male, human and adult, a specification which

34. The only option excluded is $\left[e_{1} \cdot e_{2} \cdot e_{3}\right]$, since this would correspond to the assertion of such a statement, not its denial. 
covers and is neutral between each of these possibilities. So the scope of negation is indeterminate in this case.

Notice that this accords with our definition of the distinction between ambiguity and vagueness, since It wasn't a woman is given a single (disjunct) reading. If negative sentences were ambiguous according as their scope differed, then this sentence (and all other negative sentences) would be described as having the requisite number of different underlying structures with the scope stated specifically for each interpretation.

1.3.4.1 Rules of Semantic Interpretation Operating on Surface Structures The inherent vagueness of negative sentences has not been widely recognised among linguists. In fact attempts have been made to predict a fully specified scope of negation, and these attempts have led to a proposed revision of the standard (1965) theory's claim that the input to the semantic component is the set of deep-structure phrase markers. There are three chief protagonists in this issue - Lakoff (1970b), Jackendoff (1969), and Chomsky (1971), of whom two (Lakoff and Jackendoff) base theix arguments on the mistaken assumption that negative sentences are fully determinate in their meaning and scope-specification, and that they are therefore frequently ambiguous. 35 The point at issue is this: are deep-structure phrase markers a sufficient input for the

35. They are not alone in this mistake. In a comparable analysis of even, Fraser (1971) mistakenly assumes that sentences containing even are ambiguous as to itis: scope and on the basis of this, he claims to provide a deciding case for the deep-structure semantics $v$. surface-structure semantics issue. However each of his crucial examples "e.g. The statue was even photographed by the King, That man is even easy to please - which if they allow a VP-scope reading can only be naturally described in terms of derived constituent structure - are necessarily vague in scope. Thus any possibility for VP-scope interpretation is indistinguishable from and only one of a disjunct set of readings of a $S-s c o p e$ reading. The putative test cases thus fall to the ground, since a deepstructure specification of scope naturally predicts a $\mathrm{S}$-scope reading. 
semantic component to be able to predict the interpretations of sentences, or should this claim be dropped in favour of a weaker claim that information from both deep structure and surface structure is necessary in order to predict the meanings of sentences?

Lakoff argued that scope of negation could be predicted at underlying structure. His argument stemmed from the claim that John didn't hit Mary in the garden is synonymous to its cleft congener It is not in the garden that John hit Mary, and that a natural explanation of this would be provided if both were derived from the underlying structure corresponding to the cleft construction: Fig. IX

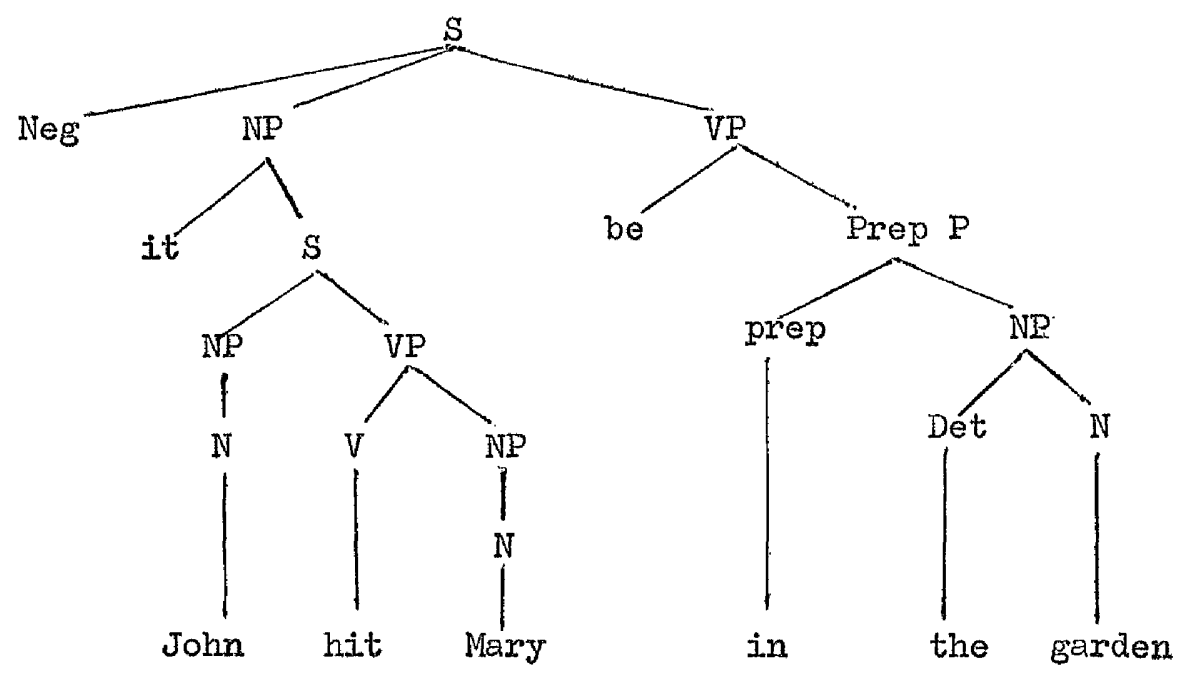

This was generalised to all adverbials so that for every case, the adverbial was analysed as the scope of negation; and the scope of negation was invariably expressed in terms of a cleft-type structure. That which was interpreted as falling within the scope of negation was analysed as the superordinate predicate and that which was not understood as negated was analysed as the subordinate. Even in its own terms this analysis can be shown to be insufficient for a general account of negation. First of all, as both Heidolph (1970) 
and Chomsky (1971) have pointed out, the scope of negation may be restricted to an item which is not a deep structure constituent, (73) John didn't run in front of the house, but behind it (74) John isn't easy to please or eager to please: he's just a fussy, idle old man

In (73), the focus of negation is not a constituent at all, and in (74), it is a dexived constituent but not a deep structure constituent. Secondly, an analysis which makes the focus of negation the superordinate term leads to a syntactic contradiction in examples such as: (75) John isn't a bright boy In (75), as the sole item in the scope of negation, bright should by definition be superordinate to boy, but its syntactic relation to boy demands that it be subordinate to boy. There is in any case no cleft for (75) to be parallel to. There is no Fit isn't bright that John is a boy. Moreover the argument stems from an incorrect analysis of John didn't hit Mary in the gaxden. It is not obvious that this sentence is synonymous with It is not in the gaxden that John hit Maxy, since it stands in a comparable relation to a whole set of cleft sentences: (76) It is not John that hit Mary in the gaxden (77) It is not Maxy that John hit in the garden (78) It is not in the garden that John hit Wary (79) What John did not do to Maxy was hit hex in the garden (80) What John did not do was hit Mary in the garden (81) What John did not do to Mary in the garden was hit her There is thus no reason to isolate any single cleft structure as the underlying structure for the corresponding simple negative.

A very similar mistake is made in Jackendoff's attempt to provide an altemative interpretive position. Jackendoff purports to show that 
some negative sentences are unambiguous as to scope and of these there is a set of sentences in which an active-passive pair are not synonymous since they differ in their scope specification. If the grammar is to maintain the active-passive relation and yet predict this difference, the rule determining scope specification must be carried out after the passive rule has taken place - i.e. at the surface structure. The following sets of data are central to his argument: (82)(i) It is not so that many of the arrows hit the target

(ii) Many of the arrows didn't hit the target

(iii) Not many of the arrows hit the target

(iv) The target wasn't hit by many of the arrows

(iia) Many of the arrows didn't hit the taxget, but many of them did hit it

(iiia)*Not many of the arrows hit the target, but many of them did hit it (iva)*The target wasn't hit by many of the arrows, but it was hit by many of them

(83)(i) It is not so that many of the demonstrators were arrested by the police

(ii) Many of the demonstrators weren't arrested by the police

(iii) Not many of the demonstrators were arrested by the police

(iv) The police didn't arrest many of the demonstrators

(iia) Many of the demonstrators weren't arrested by the police but many were

(iiia) *Not many of the demonstrators were arrested by the police but many were

(iva)*The police didn't arrest many of the demonstrators, but they did arrest many of them

The argument proceeds identically for both sets of data: 
(a) (i) is the characteristic paraphrase of sentence negation

(b) (i) is unambiguous and synonymous with (iii) but not with (ii). Therefore (ii) is not an example of sentence negation, but verb phrase negation

(c) (ii) can be denied without forming a contradiction, as in (iia), but (iil) cannot, giving confirmation that (ii) must be an instance of verb phrase negation, not sentence negation.

(d) (iv) is unambiguous and synonymous with (iii) and not with (ii) its syntactic congener. This is said to be demonstrated by the contradiction in (iiia) and (iva) which is not present in (iia).

(e) Therefore, since (iv) and (ii) are not synonymous, the passive transformation must take place before the specification of scope is predicted - i.e. at surface structure.

Steps (b), (c) and (d) are incorrect and unjustified. Moreover they lead to a contradiction. (b) is wrong in the same way that Lạkoff: was wrong. It is not so that many arrows hit the target covers both Many arrows didn't hit the target and Not many arrows hit the target since it is neutral as to scope specification. There is thus no evidence so far that either of these is not an instance of sentence negation. Step (c) is incorrect because (iia) is not an example of a negative sentence plus its positive counterpart, despite appearances . The fact which Jackendoff orerlooked is that (iia) is only noncontradictory if the many in the first conjunct is not coreferential with the many in the second conjunct. But on this reading the two conjuncts are thus not identical and do not provide evidence of the scope of negation in the first conjunct. It is this part of the analysis which leads directly to a contradiction. Sentence (iia) on the relevant reading is parallel to John didn't hit the target but John did. Therefore, if Jackendof's argument concerning (iia) is correct, 
it also follows that John didn't hit the target is an instance of verb phrase negation. But John didn't hit the target is

synonymous with It is not so that John hit the target. Therefore

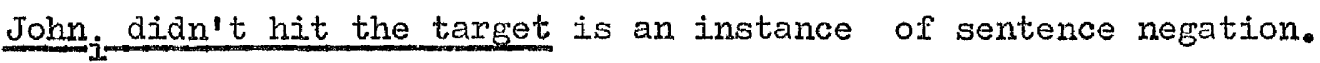
Thus John didn't hit the target is necessarily both an instance of sentence negation and not an instance of sentence negation. Furthermore step (d ) is wrong: (iv) is not synonymous with (iii) but is vague in its specification as between (ii) and (iii). This can be shown by contextualisations of sentences of type (iv):

(84) The doctors didn't treat many of the patients at a.1. They just sent them away with worthless prescriptions

(85) The police were persuaded not to arrest many of the demonstrators who then hung around being a nuisance

(86) John wasn't treated by many of the specialists, who just said he was imagining things.

In each of these cases many is interpreted as not falling within the scope of negation, and corresponds therefore to the natural interpretation of many when it is to the left of the negative particle - i.e. to sentence type (ii) in the paradigm. It thus follows that sentences of the type The target wasn't hit by many of the arrows must allow at least the two possible scope interpretations claimed of (ii) and (iii) in order to predict the interpretations as in (84)-(86) above. It is thus not obvious that the passive transformation does change meaning, and it does not follow that semantic rules must take surface structure into account. 36

36. What remains a puzzle for any analysis is the difference between (iiia) and (iva) on the one hand, and (iia). Though (iia) is the odd one out here, it constitutes less of a problem than (iiia) and (iva). It is predictable that two lexically identical sentences containing many should not be coreferential. This follows from the conditions for pronominalisation. Any NP which is lexically identical to an antecedent NP and which is not pronominalised is predictably interpreted as not coreferential with its antecedent. What is odd is that many in (iiia) and (iva) cannot be interpreted in this way. I have no explanation for this. 
Chomsky's argument for semantic rules at surface structure is the only argument of the three which predicts an indeterminacy in the interpretation of scope in negative sentences. His argument concerns the interdependence of stress assignment and the interpretation of the scope of negation (and question). It is very generally known that contrastive stress alters the interpretation of negative sentences, as in: (87a) JOHN didn't hit Mary in the garden 37

(87b) John didn't HIT Mary in the garden (87c) John didn't hit MARY in the garden (87d) John didn't hit Mary in the GARDEN

I shall return to this problem of the predictability of contrastive stress and the consequent interpretations in chapter 8. However Chomsky seeks to extend this interdependence of stress and scope specification to normal stress assignment and the scope of negation. He suggests that scope (focus in his terms) of negation can be determined as restricted to any phrase containing the intonation centre. Thus in John didn't give away a house in Barnes with normal final stress assignment, in Barnes, a house in Barnes, give away a house in Barnes, or the whole sentence can constitute the scope of negation, since each contains Barnes, the intonation centre. This definition of scope explicitly excludes the possibility of the scope being restricted to the rerb only, the subject only, or a house, since none of these constitutes a phrase containing the intonation centre. Furthermore it predicts that the smallest domain of scope is the lexical item. Both of these constraints are unjustified. Fach of the following is a possible scope of negation, given unmarked stress assignment: contrastive stiess. 
(88a) John didn't give away a house in Barnes - it was in Wimbledon (scope = adverbial noun phrase)

(88b) John didn't give away a house in Barnes - it was only a garage (scope $=$ object noun phrase)

(88c) John didn't give away a house in Barnes but he sold it at a fairly Low price (scope $=$ verb)

(88d) John didn't give away a house in Barnes - it was Bill who did (scope $=$ subject noun phrase)

(88e) John didn't give away a house in Barnes - he was arranging for an auction (scope $=$ verb phrase)

(88f) John didn't give away a house in Barnes - there hasn't been any property changing hands recently (scope = sentence)

(89a) John wasn't running - he was quite still

(89b) John wasn't running - he was walking

In (88), the scope can include only the verb, only the object noun phrase, and only the subject, as well as the possibilities predicted by Chomsky's formulation. In (89) the scope can not only include the lexical item run but it can be restricted to just one of its components, the specification of the type of motion - namely running. The component of motion is unaffected. So it appears that the scope of negation is not definable either in terms of syntactic units (lexical items) or in terms of syntactic constituents, or in terms of stress placement. Consideration of arguments such as these therefore suggest that scope of negation is not dependent on either syntax ox: phonology (with the exception of contrastive stress). There is thus so far no evidence of the necessity for rules of semantic interpretation operating on surface structures.

There is however one further argument concerning quantifier scope 
given by Barbara Hall-Partee (1970). 38 There is a transformation called conjunction reduction which relates

(90) Edward is touchy and Edward is difficult to please

(90b) Edward is touchy and difficult to please

(9Ia) Bill is popular and Bill is likely to succeed

(97b) Bill is populax and likely to succeed

As these pairs demonstrate, the rule is generally meaning-preserving.

However, it no longer preserves meaning when the subject ${ }^{39}$ includes

a quantifier such as numerals, many, some, few, or is modified by only.

Thus the following pairs are not synonymous:

(92a) Few rules are explicit and few rules are easy to read

(92b) Few rules are explicit and easy to read

(93a) Some women are married and some women are happy

(93b) Some women are married and happy

(94a) Three rules on this page are explicit and three rules on this page are easy to read

(94b) Three rules on this page are explicit and easy to read

(95a) Only the three rules on this page are explicit, and only the three rules on this page are easy to read

(95b) Only the three rules on this page are explicit and easy to read

Since the verb phrases may be derived constituents, as in all the examples except (93), the scope of the quantifier cannot be stated at the level of underlying structure, because the constituents involved are not necessarily constituents at that level. Thus Hall-Partee suggests the interpretation of scope must be stated at surface structure,

38. Some further arguments are provided by Hasegawa (1972) but I shal工 not take them into account here since Hasegawa's account, involving complements of think, cructally confuses ambiguity and vagueness. Cf. section 1.3.3. of this chapter.

39. The problem is more complicated than this but the additional complexity does not affect the argument. 
after the transformation has taken place. In luis reply (1970a), Lakoff suggested that this conclusion was not inevitable since there was a naturally stateable constraint preventing the derivation of the (b) sentence of each pair from its (a) counterpart, namely the constraint that conjunction reduction can only take place if the subject noun phrases are coreferential. Since the (a) members of each pair are understood to be non-coreferential, it would follow that the (b) member would never be derived from the structure underlying the (a) member. This explanation is not howevex adequate. Compare (94) with (96).

(96) Three rules on this page are explicit and they are easy to read By Lakoff's constraint, (96), which clearly involves coreferential subjects, should be synonymous with $(94 b)$, but it is not. Moreover, the noun phrases in (95a) are (pace Lakoff) also coreferential, and yet (95a) is not synonymous with (95b). His constraint on conjunction reduction does not therefore handle these cases, and a separate ad hoc condition would have to be added to exclude them. Moreover it provides no explanation at all as to why (96) and (94b) do not mean the same. If on the other hand we conclude with Hall-Partee that conjunction reduction applies blind with the interpretation of the conjoined verb phrase as falling within the scope of the subject quantifier being predicted from surtace structure, then these examples provide no problem. On this evidence it seems that the only natural solution is to allow rules of semantic interpretation operating on surface structures.

What is more relevant for our immediate concern is that the HaIIPartee argument appears at first glance to carry over directly to 
scope of negation: the pairs (97) and (98) are clearly not synonymous. (97a) John isn't ambitious and John isn't eager to become President (97b) John isn't ambitious and eager to become President (98a) John isn't ambitious or John isn't eager to become President (98b) John isn't ambitious or eager to become President (97a) denies both propositions, whereas (97b) denies only the combination of ambition and eagerness to become President: (98a) allows for one of the propositions to be true whereas (98b) denies both. (97a) is thus logically equivalent not to (97b) but to (98b), (97b) being equivalent to (98a). If the Hall-Partee argument concerning quantifiers is correct, it would seem natural to allow conjunction reduction also to apply blind in these cases, deriving the (b) sentence from its (a) counterpart with an interpretation of the sentence being read off from the surfacestructure configuration. In this case, the rule interpreting negative sentences would operate on the interpretation of surface struncture phrase markers.

Notice first of all, that whatever the input to the projection rules (i.e. the main core of the interpretation rules), the formulation of the rule of negation will not be affected. We have already seen how it operates when the input to the projection rules is the set of deep structure phrase markers. Suppose however the set of projection rules operated on surface structure phrase markers. In this case, as Lakoff has pointed out $\left(1970_{a}\right)$, there would have to be rules of interpretation creating structure as it were, interpreting for example gapped structures such as John tried to date many rich girls and Bill many poor girls in a way essentially corresponding to the reverse of gapping. Semantic

40. Called by Lakoff 'anti-gapping' I970a p.42I. 
rules of interpretation of this type would be required wherever the derived structure differs from the underlying structure (whether by virtue of deletion or permutation). 4.1 The rule of negation would only operate on the output of these structure-creating rules and it would thus not diffex in formulation from that given earlier (p.33f). Furthermore, it is not obvious that (97b) and (98b) should be derived from (97a) and (98a) respectively, despite their parallel to the quantifier examples. Iqually plausible deep structures would be the following:

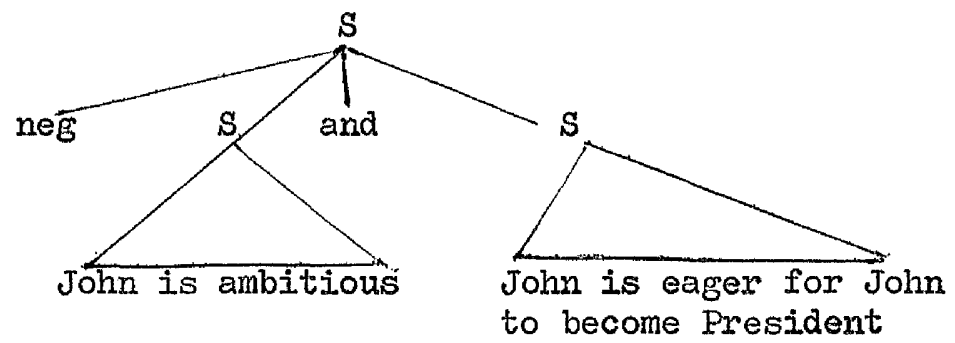

Fig. $\mathrm{X}$

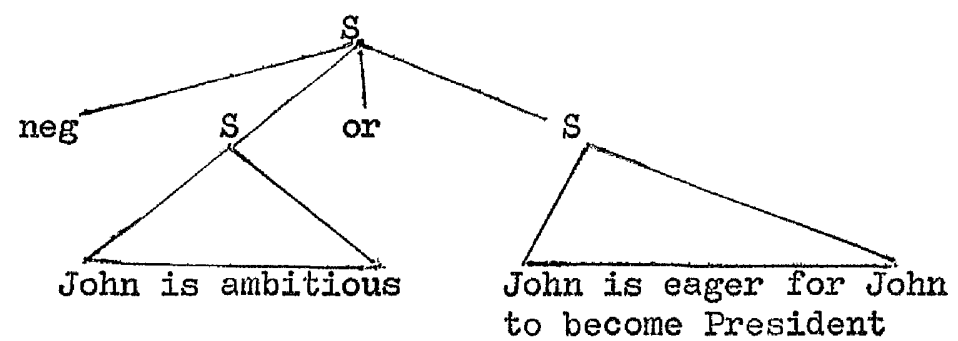

Fig. XI

and these phrase markers are reflexes of the semantic interpretation required for their respective surface sentences. If these phrase markers are syntactically justified, the rules of interpretation can operate on the (fully specified) deep structure phrase markers. Arguments for having the scope of negation be interpreted from surface structure configurations are thus logically independent of the Hall-Partee arguments concerning quantifiers.

41. Cf. Jackendoff's rule of negation which interprets the negative element generated in the auxiliary position as raised to the $S$ node, essentially the inverse of Neg-Placement (cf. Klima 1964). 
In any case, her argument is not as water-tight as the data she considered suggest. Both she and Lakoff assumed that when a quantifier was in surface subject position and modified by a co-ordinate verb phrase, it must be non-synonymous with its expanded counterpart. But this is not so. Consider (99) and (100).

(99) Many questions were answered by Richard and Allice (100) Five questions must be attempted by each candidate Under Hall-Partee's analysis (99), derived by conjunction reduction (and passive) from Richard answered many questions and Alice answered many questions, must imply that Richard and Alice answered the same questions. But this isn't so, just as in (100) the implication is clearly not that all candidates should attempt the same questions as each other. However under the interpretation that Richard and Alice did not necessarily answer the same questions, (99) is synonymous both with its active counterpart and with the sentence corresponding to its deep structure: there is thus no need to set up a rule of semantic interpretation from surface structure. This creates an anomaly. How can we allow sentences containing quantified subjects to change meaning over conjunction reduction only some of the time? Compare (99) with (101)。

(101) Many buildings are guarded by dogs and night watchmen There is nothing structurally to distinguish these two sentences, and yet only the latter is not synonymous with its expanded counterpart, Many buildings are guarded by dogs and many buildings are guarded by night watchmen. The only distinction seems to be the likelihood of a joint reading on the subject - more so in (101), less so in (99). This would imply that in both cases, both readings were possible, the 
prevalence of one ox the other being a non-linguistic matter. The question then arises as to whether this semantic vagueness, though pragmatically resolved, should be extended to the entire range of conjunction reduction examples. This being so, synonymy would be preserved between deep structure and surface structure. Decision on these questions would require another thesis, and for the moment I shall merely assume that the question of surface structure rules of semantjc interpretation remains an open one. ${ }^{42}$ In any case my main concern in chapters $4-6$ will be not with the general principle of surface structure rules of interpretation but with the specific problem of negation. And since the arguments concerning the prediction of negation scope from surface structure are on the one hand not strong and on the other hand do not affect the formulation I have adopted here, I shall assume that negative sentences are given a semantic interpretation from a fully specified deep structure phrase marker.

\subsection{Summary}

The linguistic framework which I shall be assuming in the central arguments of this thesis is now more or less complete. I have argued that syntax and semantics are two separate though related components, and that any constructs in either of these components must be justified solely in terms of that component. So arguments for deep structure must be based on syntactic evidence, and not semantic evidence. Conversely, arguments concerning the semantic structure of sentences

42. For similar reasons, I shall not take into account here the considerable body of arguments presented in Jackendoff 1972. 
- for example negative sentences - will not be taken as evidence for the deep structure of those sentences. In particular, I argued that so-called selectional restrictions are not in fact a constraint mechanism but rather part of the meaning of lexical items, no different in kind from the inherent meaning of lexical items. They thus play no part in demonstrating the necessity of a syntactically-defined level of deep structure.

With respect to semantic structure, I argued that a.l. components of meaning forming the meaning of lexical items should be expressed in terms of a predicate and its arguments, closely analogous to the formulation of predicate calculus. Furthermore the rules of the semantic component constitute (i) a set of interpretive projection rules which operate on a deep structure input and which replace the syntactic indices of the lexical items by referring indices on the noun phrases to give a sentence reading; and (ii) rules such as that for negation which operate on the output of the projection rules. I considered the possible necessity of surface structure input to the semantic component, but on the evidence presently available, this weakening of the constraint on the semantic component seems unjustified.

With respect to negation itself, I argued that in general negative sentences are not ambiguous as to scope, but rather vague (or unspecified), and hence they allow a range of possible interpretations. This range appears to be constrained by the semantic components of the sentence in question and is not stateable in terms of syntactic or phonological constraints. Further evidence of the independent 
non-syntactic nature of the negation rule is provided by examples such as the following:

(102) The prisoner had not escaped from Dartmoor and Brixton - he had only escaped from Brixton

Here the domain of the scope allows for a specification in which one part of a conjoint noun phrase, Dartmoor, is isolated as the scope of negation. This isolation of one noun phrase from a conjoint noun phrase structure constitutes a flouting of the Co-ordinate Structure Constraint which operates as a general constraint on syntactic processes preventing processes applying to :one part of a conjoint noun phrase (cf. Ross 1967). If the domain of the scope of negation is to be explained in syntactic terms, the example above must be stated as an exception to this widely attested constraint. If however the delimitation of scope is explained in terms independent of syntax, then the anomaly disappears. The rule of negation thus provides a further piece of evidence that constraints on semantic structure are different in kind from those of syntax, 43 a difference which can only be naturally captured in a framework containing two separate components of syntax and semantics.

43. The evidence is not in fact entirely clear-cut: there is opposing evidence (cf. Lasnik 1972) that the rule of negation shares at least some constraints with syntactic processes. 
CHAPTER 2 : The Basis of Semantics: A Definition of Meaning

2.1 On Katz and Bierwisch's Definition of Semantic Marker

In chapter 1, I put forward a linguistic framework which

purported to provide an explanatory and predictive account of all the well-formed sentences of any given language together with their semantic (and phonological) interpretation. As a seriously intended hypothesis about the structure of language, this framework should make a number of testable predictions. Some of these predictions (e.g. the relation between syntax and semantics) I have already discussed. But the status of the semantic constructs remains largely untested. In general, the semantic component ${ }^{1}$ can be said to make at least the following predictions:

(1) The semantic structure of sentences in any one language can be described in terms of the semantic structure of the lexical items of that language if its syntactic structure is taken into account in a systematic way.

(2) The semantic structure of a lexical item can be explained in terms of components of meaning, where these components predict the contribution that that lexical item makes to the meanings of sentences in which it occurs (cf. p. $30 f$ ).

(3) There are two infinite sets of sentences, one constituting wellformed sentences, another non-well-formed sentences, where 'non-well-m formedness' is characterised by the presence of contradictory semantic components.

(4) Semantic relations such as entailment, ambiguity, synonymy and

1. I am using the term semantic component with systematic ambiguity to refer to a component or section of the grammar on the one hand, and to the minimal semantic construct (semantic feature) on the other. Which interpretation is intended will always be clear from the context. 
contradiction can be defined in terms of semantic features. For example, entailment is definable as the relation between two sentences $S_{1}$ and $S_{2}$ which holds if $S_{1}$ contains as a subset those features which constitute the semantic representation of $s_{2}$ (e.8. A boy ran across the road entails A child ran across the road).

As an empirical claim about the semantic structure of language, this set of predictions is little more than vacuous. It is not entirely so, in that it fulfils the conditions I put forward initially (p. 8f ) as being demanded of any semantic theory - viz. the ability to relate lexical and sentence meaning, the ability to separate two infinite sets of sentences, and the ability to predict relations of entailment etc. But the circularity involved removes any inherent interest the claims might have. The circularity is transparent in (1) and (2) and only one step less so in the predictions (3) and (4). For example, all the definition of entailment claims - even assuming it to be correct ${ }^{2}$ - is that the meaning of one sentence is part of the meaning of another sentence. It does not give any explanatory account of this relationship. In particulax, this definition is not obviously relatable to the logical definition of entailment. And the circularity in the prediction of entailment from sentence meaning is made plain if we recall that sentence meaning is explained in terms of word meaning and word meaning is established on the basis of entailment relations. Such a definition scarcely offers an explanatory account of entailment itself.

The charge of circularity is not new (cf. Vermazen 1966). However, one might say in rejoinder, that the charge is mistaken - it conflates the discovery procedure of semantics with the theoretical statement.

2. It is not. It predicts that A1l boys like sweets entails $A 11$ children like sweets. Cf. Leech $1969 \mathrm{pp} .35 \mathrm{ff}$ for a more detailed account in terms of semantic features. Cf. also chapters 3-5 of this thesis for further discussion of entailment. 
It may be part of the discovery procedure of semantics to establish lexical meaning on the basis of semantic properties of sentences and semantic relations between sentences, but it is not part of the theoretical statement. Moreover, this procedure is standard in linguistic analysis. If this charge were justified for semantics, both syntax and phonology would also be condemned as vacuous, since for example the label. NP and its rewwite rule

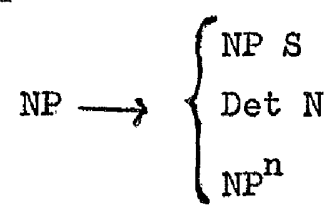

are set up on the basis of a set of distributional facts and the grammar then predicts these facts by virtue of this rule. For semantics, the way out of the circle is to define the term semantic component not as I suggest in my prediction (2) (p.56) but by some other way. But this way - the option taken and defended by Katz and Bierwisch - also leads to vacuity. The definition given by Bierwisch is that semantic components are 'not symbols for physical properties and relations outside the human organism, but rather for the internal mechanisms by means of which such phenomena are perceived and conceptualised' (1970 p.181). As an attempt to consider the consequences of universal linguistic constructs for psychology, this statement is irreproachable, but as a theoretical definition it is untenable. It has the immediate consequence that the status of any semantic component(s) is in principle untestable since there is no means of testing a so-called perceptual construct. By general principles of the philosophy of science, any such definition is vacuous. 


\subsection{Meaning and Reference}

The core of the problem is the definition of meaning. In the framework given above, the semantic components are mere artefacts which churn out appropriate artefacts as meanings of sentences. There is no direct attempt to explain the relation between the abstract symbols of language and the external world those symbols describe. Yet this is surely the goal of semantic theory, and any semantic mechanism which does not attempt to explain this relation is merely playing academic parlour games.

The standard defence of this separation in linguistics of the semantics of a language and the world the language describes is given by Lyons (1968). He assumes there (p.424pl) the correctness of Frege's sense-reference distinction, points out that words like unicorn have meaning no different in kind from horse despite their lack of referent, suggests that there are many words which do not refer to anything outside the language (such as intelligence, goodness), and concludes that the explanation of problems of reference need not therefore be a job for linguists. Though the book in question is introductory, the argument is a widespread one. Almost without exception, 3 linguistic descriptions assume that semantics involves only intra-theoretical statements and therefore does not include any predictions about the relation between words and their referents.

3. For arguments making this assumption, either implicitly or explicitly, cf. Postal 1971b, Bierwisch 1969, Katz 1966b, 1972. 
The assumption behind this argument is that reference is a relation which holds between a symbol of the language and the objects of the world as we know it. Now clearly what the language describes (given that the language - and hence the meaning of the words - is constant) is not merely this "real" world, but also 2,000 BC, 2,000 $A D$, the world of one's expectations, the world of one's dreams etc. It is quite irrelevant to semantics that the first man to land on the moon has a specific object to refer to in 1973, but the first woman to land on the moon does not. This must be so, since if in 1974 a woman shoudd land on the moon it would not follow that the phrase the first woman to land on the moon would have a different meaning. Thus if reference has to be restricted to the world as we know it, then the general assumption that linguistic semantics is not concerned with problems of reference seems to be correct.

However there is an alternative. The concept of reference could. be generalised to encompass different worlds, or rather different states of affairs, in the following way. If we conceive of the world and the changing events in the world as a series of states of affaixs such that at time ${ }_{1}$ one state of affairs holds, at time ${ }_{2}$ another state of affairs holds, etc then the real world of "now" in which unicorns do not exist but horses do is just one possible state of affairs. ${ }^{4}$ In each of these states of affairs, there will be a set of objects to which the symbols of the language stand in a relation of reference. In the light of this, the relation between meaning and reference could be reformulated: the meaning of a symbol could be defined as a statement of the conditions necessary for a relation of reference to hold in some state of affairs. Thus in talking about meaning, one is not talking about reference itself, but about the (necessary and sufficient)

4. This philosophical concept of 'possible worlds' is most clearly explained by Hintikka (1969): 'It would be more natural to speak of different possibilities concerning our 'actual' world than to speak of several possible worlds .... In our sense, whoever has made preparations for more than one course of events has dealt with several 'possible courses of events' or 'possible worlds'. Of course, the possible courses of events he considered were from his point of view so many alternative courses he considered events might take. However, only one such course of events (at most) become actual. Hence there is a sense in which the others were merely 'possible courses of events' (p.90f). The concept is defined more formal.Iy by A.N.Prior 1962. 
conditions for reference.

Under this interpretation of meaning, it is not so obvious that we need to have recourse to the distinction between sense and reference. 5 It is certainly no longer the dichotomous one that many would have us believe. Let us consider briefly the original argument for the twin concepts of sense and reference. What Frege argued (1892) was that the existence of a relation of symbol to referent was in principle not a sufficient statement of meaning because of the existence of such non-synonymous pairs of sentences as (1) and (2): (1) Noam Chomsky; is Noam Chomsky

(2) Noam Chomsky is the man who wrote Aspects

In order to explain the non-tautologous nature of the second sentence, Frege set up the distinction between sense and reference, where the sense of a word constituted its meaning and reference the relation it held to some referent. But the sense of a word or phrase under the interpretation given here is the specification of the conditions which a referent must meet in ordex for the relation of reference to hold. And in the case of Frege's type of sentence-pair, the conditions of reference are clearly not the same. It is merely a contingent fact that the proper name Noam Chomsky and the phrase the man who wrote Aspects have the same referent. Thus while it is a semantic fact that the (1) is vacuously- true, it is a contingent fact that (2) happens to be true. There is clearly a possible state of affairs in which the man who wrote Aspects was not Chomsky but Enoch Powell. Similarly it is mattex of contingent fact that there are no unicorns at the moment, and the semantic

5. This is suggested by Hintikka (Hintiklka $1969 \mathrm{pp} .87-111$ ) in connection with the semantics of propositional attitudes. 
statement would merely predict that the meaning of unicorn constitutes a set of conditions which specify that the object which unicorn be used to refer to must be like a horse except that it have one horn.

\subsection{Sentence Meaning and Truth}

If meaning were defined in terms of reference conditions, sentence meaning could then be described interpretively by a set of projection rules. There are however several problems over equating meaning and conditions for reference. First there is the problem that the relation of reference must incorporate abstract concepts such as properties, actions, etc, since the problems of coreference in pronominalisation, relativisation etc hold equally for objects, properties and actions, as for example in The happiness that I felt yesterday was overwhelming. The second and more important problem is that the connectives and, or and if-then will not be characterised as having meaning, since they clearly do not refer.

Yet as we shall see immediately, there is a natural connection between reference conditions and sentence meaning, which can lead. us to a definition of meaning that encompasses reference conditions and the truth-table definitions of the connectives. Notice that if for any sentence, the items refer appropriately to objects, and the properties or actions described correspond to the description given, then the sentence will be true. Thus if the sentence The boy ran to hi.s mother is used to describe a male, non-adult human and a female adult human who is his mother, and the relation between them is such 
that he went to her with a particular fast motion that we call running, then each of the conditions specified in the sense of the lexical items contained in the sentence corresponds to its non-linguistic referent, and as a result the sentence is true. It follows from this that we have an alternative characterisation of the meaning of a sentence viz. the meaning of a sentence constitutes a statement of the (necessary and sufficient) conditions under which that sentence would be true. 6 In other words, a statement of meaning in a natural language is a statement of the truth conditions of the sentences of that language. Just as with referential conditions, it is important to note again that it is no more relevant to a statement of sentence meaning whether or not a sentence is actually true in any arbitxaxy state of affairs than it was to a statement of word meaning that the item actually bear a referent. One is not concerned with contingent truthvalue assignments - only with the necessary and sufficient conditions for the truth of sentences. Thus the meaning of I saw a unicorn is no different in kind from I saw a horse. In both cases, the statement of meaning merely gites the conditions under which that sentence would be true. Furthermore this definition of meaning naturally includes the definitions of the connectives, since truth-tables are a statement of truth-conditions.

How does this definition of meaning match up to the conditions on a semantic theory given earlier $(p .8 f)$ - viz, the ability to isolate the infinite set of contradictory sentences and the ability to predict entailment, synonymy, contradiction etc? The prediction of

6. Cf. section 2.4.1 for a discussion of the validity of assigning truth-values to sentences. 
inter-sentence relations follows as an automatic consequence of the definition of meaning. That is, if all the conditions hold that make true John killed an actress last night then it must be the case that both An actress died last night and A woman died last night are of ncessity true, since each of these constitutes a subset of the conditions specified by John killed an actress last night. But this is the logical definition of entailment - that one sentence entails the second if the truth of the second necessarily follows from the truth of the first. Similarly synonymy. Synonymy is defined logically as mutual entailment, and this too is predicted naturally if the meaning of a sentence is a set of truth conditions: if two sentences mean the same, then they will have the same set of truth conditions; thus whenever one is true the other will be. Moreover both will also be false under the same conditions, a second characteristic of mutually entajling sentences. More interesting is the delimitation of the set of contradictory sentences which, I have suggested ( $p .310$ ) should be blocked by the semantic component. If meaning is defined as a statement of the conditions under which a sentence will be true, the oddity of contradictions is automatically captured. What contradictory sentences have in common, and in contrast to all other sentences is that (given that the meanings of words remain constant, and are not interpreted metaphorically) they can never be true: there is no possible state of affairs that they describe. They are therefore unlike other sentences, since the assignment of the value false is not a matter of contingent fact. 
Their separation from other non-deviant sentences as a natural class is thus automatically predicted.

That the prediction of entailment, contradiction etc is an automatic consequence of defining meaning in terms of truth conditions is powerful support for the theory, since these predictions were stated earlier $(p .8 f)$ as a necessary condition on the adequacy of a semantic theory. However these are only two of the conditions I set up for semantic theories to be judged against. In addition, a theory must (a) be recursive and (b) state a systematic relation between the syntactic structure of a sentence and its lexical j.tems. Logicians such as Montague (1970b, 1972) and Lewis (1971), who have expounded a formal version of referential semantics for natural languages, appeax to assume that all linguistic formulations of meaning meeting these two additional conditions are inadequate, and that a truth-based theory of meaning is necessarily mutually exclusive with any semantic theory devised in the framework of transformational grammar. This however seems to me unjustified, in the light of Bierwisch's formulation of a semantic component. On the contrary, Bierwisch's semantic markers (in the form of predicate plus argument(s)) seem non-distinct from a set of abstract truth conditions - with one important caveat: unlike a theory using conceptual semantic markers, a theory of truth conditions is open to falsification. For purposes of formalisation however, this difference is unimportant, and a formulation of truth conditions in the format of Bierwisch's semantic markers seems quite legitimate. Moreover, his rule of negation is naturally interpretable as a rule involving truth conditions. Thus while A boy ran to his 
mother is true if and only if the state of affairs described is such that a male, non-adult human went with a fast motion to someone who was female, adult, and his mother, the negation of that sentence is true just in case any one ox more of those conditions fails to hold in the world described. That is to say, a negative sentence is used to assert that the corresponding positive sentence is false. But A boy ran to his mother can be false for any of several reasons either someone ran to their mother, but not a boy, or a boy went to his mother but didn't run, or a boy did something but not run anywhere, let alone to his mother, etc, etc. And this interpretation matches the output of Bierwisch's rule of negation. Thus what the negation rule states is all the possible ways in which the corresponding positive sentence could be false. And just as it is Irrelevant in stating the meaning of a sentence to specify whether it is actually true or false for any given state of affairs, so it is irrelevant in stating the meaning of a negative sentence to specify which of the conditions of the corresponding positive sentence may have failed in any utterance of that sentence. Finally, a framework such as Bierwisch proposed fulfils the two additional conditions mentioned above (viz. recursiveness and a systematic statement relating the syntax of sentences and the meaning of lexical items). I shall therefore assume that linguistic semantics, more specifically semantics as formulated by Bierwisch, has been implicitly a truthconditional semantics. If this is so, it provides a natural explanation of both the descriptive adequacy of predicate calculus for describing the semantic structure of sentences and also the notational equivalence of de Morgan's law and Bierwisch's rule of negation, since both predicate calculus and de Morgan's laws are defined within a truth-based system. 
There is one apparent internal contradiction in my assumption that Bierwisch's formulation of the semantic component can be used to capture the concepts of truth condition, sense and reference as I have used them. I referred earlier to sense and reference in talking of the semantic properties of words. Yet in my original presentation of Bierwisch's model (ch.I p.30) I stated that reference indices were generated by the base structure as a property not of the lexical item but of the noun phrase node immediately dominating it. This represents a claim that reference is not a property of lexical items in isolation but only within a syntactic structure. This claim appears to be correct. As Alston pointed out (1.964 p.15f) it is by no means clear that pencil of itself refers to anything. If I wish to refer to the class of pencils, or a single object which is a pencil, the item pencil is insufficient - it only becomes a referring expression when it is part of a noun phrase 8 - 1.e. a pencil, the pencils etc. This seems to indicate that the lexical item itself does not refer at all. As a reformulation, let us suggest that $\because$ every sentence is made up of words in a certain relation (defined syntactically), and these words and relations together specify a set of conditions which constitute the meaning of that sentence (a set of truth conditions). A part of these conditions is that there be objects of whom the properties in question are predicated $\therefore$ But it is a part of the conditions set by the meaning of the sentence, not by the individual items. The items themselves specify descriptive conditions and, in the formulation given here,

8. For an independent justification of this extension of the concept of reference to include indefinite noun phrases, cf. ch.5-6. 
the dominating node (ND) is interpreted as providing the conditions of reference. That is to say, an implication of reference to some object is a consequence of a lexical item's entering a syntactic construction. The specification of that object or action is provided by the lexical item. It follows automatically that what are entered in the lexicon are the senses of lexical items and not reference relations. As a lexical item in isolation they do not refer. Bierwisch's formulation thus captures the observation made informally by Alston.

\subsection{The Limitations of a Truth-Based Theory of Semantics: A Criticism and $A$ Defence}

\subsubsection{The Relation Between Sentence and Statement} The major criticism of a truth-based theory of semantics is that such a theory must be restricted to statements, since it is only these which have the property of being true or false. And since not all sentences can be used to make statements, a theory which is restricted to analysing statements is not giving a complete account of meaning for natural languages. There are three common analyses of the relation between sentences and statements. In all three, this relation is defined in such a way that questions and imperatives are excluded (since they are said to be incapable of being true or false), together with some indicative sentences, 0.g. Austin's performatives (I promise to go home, I apologise, I suggest .... etc), which are said by Austin to lack a truth value and therefore also cannot be statements. The least restrictive view excludes only these sentences from the set of sentences which can constitute statements. There is a stricter view which by virtue of defining statements as having just one truth value assignment, true or false, excludes all sentences containing deictic elements from the set of sentences which can constitute statements - for example You are 117 , He came here - 
since it is charactexistio of such sentences that they change their truth value according as the referents (i.e. the speaker and hearer) change. But this relative rather than absolute truth-value assignment ts a general property of natural language sentences, since tense is speaker-relative. Thus in order to constitute a statement under this view, a sentence must be phrased in such a way that it will have one and oniy one possible truth-value assignment: for example Ruth Kempson of 19 King Henry's Road London is tired on 10 August 1973 at $3 \mathrm{pm}$ (c.. for example Quine 1966 and elsewhere). The most stringent view, thet of Strawson (1952, 1964) is that the semantic analysis of sentences cannot in principle be reduced to the concept of truth, since truth and falsity are not properties of sentences at all, but only of statements.

The two most restrictive views can, I think, be side-stepped if we agree with Lemmon (1966), Lewis (1972) and Davidson (1967) that sentences do have a truth value relative to some context of utterance. 9 Thus deictic and all indexical sentenoes will have a truth value relative to a person (the speaker), a ploce and a time. Yet this cleim need not lead us into defining the full range of contexts for each and every person in each and. every possible state of affaixs. The statement of the truth conditions of indexical sentences need be no different in kind from other sentences. The theory is not aiming to predict truth-value assigments of particular utterances, but merely, for every sentence in the language, the necessary and sufficient conditions for its truth. The ectual value a sentence may have relative to any specific context is irrelevant.

9. Cf. Ch.3 (section 3.1.3) for a further discussion of statement and sentence, with respect to the logical definition of presupposition. 
Accordingly I shall assume that predicting conditions on the truth of sentences is not illegitimate and that the problem of handling the truth conditions of deixis can be overcome (cf. Davidson (ibid) and Lewis (ibid) for more detajled analyses).

2.4.2 Performative Verbs, Imperatives, and Questions - A Suggested Solution Two chief criticisms of a truth-based semantics remain: ${ }^{10}$ performatives, and the non-indicatives - imperative and question. It has been claimed by Austin (and others after him) that performatives have no truth value (asserted by Austin in 1962 to be obvious and not in need of argument). These verbs all have two properties: (i) they describe an act which can only be carried out by speaking (or some other form of communication) (ii) in the first person present tense, the action depicted by the speaker is not so much described by his statement as carried out by that statement. Thus I promise to go is not a description of a promise but will itself constitute a promise when it is uttered. The class of verbs is a fairly clear one: what is less convincing is Austin's claim that they cannot be either true or false because they are actions, and not descriptions. ${ }^{11}$ This performative use is notably restricted to first person, simple present. In every other case, a truth-conditional analysis is straightforward and unexceptional. As an example, take promises. John promised to go will be true if the action described constitutes an undertaking (either verbal or written)

10. The claim, widespread among logicians (cf. Strawson $1952 \mathrm{ch} .3$ section II) that the logical connectives '.' ' $v$ ' and ' $J$ ' do not correspond to their natural-language counterparts and, or and if-then, I have not considered here since I shall consider arguments relating to and and or in ch. 4 in connection with presupposition. The relation between ' $'$ and if-then has been discussed extensively by philosophers. Grice (cf. ch.7) argued in lectures in 1967-8 that the difference between the two was solely pragmatic (though his axguments are disputed by Cohen 1971). For an argument that they must be semantically identical, cf. Clark 1971 (with a counter-argument by Young 1972).

11. At several points, Austin more or less withdraws this claim. Cf. 1962, lecture XI particularly pp.134f, $144 f$. 
made by John sometime in the past to carry out some action in the future, namely going, ${ }^{12}$ and these conditions constitute the meaning of the sentence. If these conditions are not met (because John's statement did not constitute such a commitment, because John made no statement at all, etc), then - just as a truth-based semantic analysis predicts - the sentence is false. Now in the case of an utterance of I promise to go, one of the conditions for the truth of the sentence is automatically guaranteed by the utterance itself. And if in addition the speaker is indeed committing himself to an undertaking, it is arguable that the utterance of I promise to go constitutes a true statement. Under this analysis, performative utterances can and do carry a truth value: what is odd about them is that the mere fact of their utterance guarantees the fulfilment of at least part of the conditions for the truth of the proposition conveyed. With the verb say itself we have the limiting case where the very act of uttering "I say that he is sick" guarantees the truth of the statement. As Lewis points out (1972), to utter I am speaking is not only to speak but it is also to speak the truth. The idiosyncratic feature of performative statements is therefore not that they have no truth value but rather that their truth value is at least partially determined by their very utterance. If this is correct, then this class of verbs is not excluded from a truth-based semantics. 13

Some support for this argument is provided by looking at the contradictions that can arise in both performative and nonperformative utterances. If the analysis in which performative utterances are said to carry a truth value is correct, then we should predict that

12. For a more detailed analysis of promises, cf. Searle 1969, ch.3

13. This view has been putforward by a number of people: $c f$. in particular Lewis (ibid) pp.209 ff, who presents the most detailed account. Also Wiggins 1971, p.21 fn.b, Landesman 1972 p.31f. 
constraints which hold on nonperformative utterances by virtue of the meaning of promise will also hold for performative utterances: that is to say, sentences which are contradictory in a nonperformative tense will be contradictory in the simple present. This prediction does not follow from Austin's analysis: since performative utterances have no truth value, there is no theoretical basis for predicting, for example, that what will provide contradictions in sentences capable of being true or false should also provide contradictions in sentences which can never have a truth value. ${ }^{14}$ Yet it seems clear that within each group of sentences (3)-(8), each containing two nonperformative sentences and one performative, all the sentences are equally. odd, and odd for the same reason.

(3a) 8*John warned Mary that the bull was dangerous though he didn't assume it was

(3b) 2*I warn you that the bull is dangerous though I'm not assuming it is (3c)? I'm warning you that the buIl is dangerous though I'm not assuming it is

(4a) *John warned Mary that the bull was dangerous but he didn't say anything

(4b) *I waxn you that the buIl is dangerous but I haven't said anything (4c) *I'm warning you that the bull is dangerous but I'm not saying anything

(5a)?*John promised Mary that he had cleaned the sink though he didn't assume that he had

(5b) $3 * I$ promise you I've cleaned the sink though I'm not assuming I have (5c) $3 * I ' m$ promising you I've cleaned the sink though I'm not assuming I have

(6a) *John promised Mary that he would clean the sink but he didn't say anything

(66) *I promise you I'Il clean the sink but I haven't said anything (6c) *I'm promising you that I'll clean the sink but I haven't said anything

14. If a contradiction is defined as a statement which is necessarily false, then performatives cannot provide contradictions by definition. 
(7a) "John promised Mary that he would clean the sink but he didn't cominit himself to doing so

(7b) *I promise you I'Il clean the sink but I'm not committing myself to doing so

(7c) *I'm promising you that I'II clean the sink but I'm not committing myself to doing so

(8a)?*The Queen ordered the guards to chop off his head but she didn't intend to give the impression that she had insisted that they do so

(8b) $3 * I$ order you to chop. off his head but I don't mean to give the impression that I insist that you do so (8c) 3 *I'm ordering you to chop off his head but I don't mean to give the impression that I insist that you do so

Turthermore there is no difference in deviance between the simple (performative) present tense and the progressive (nonperformative) present tense, as the Austinian account might be expected to predict. It therefore seems reasonable to conclude that the case for excluding performative utterances as not having a truth value is weak and should be dropped. Performative utterances will be analysed as statements like other utterances, and they will not be excluded in principle from a truth-based semantics. 25

There remains the problem of imperative and question. How can they be handled within a formal semantic theory? If as is almost universally assumed, ${ }^{16}$ they cannot have a truth value, then they constitute exceptions to a theory of truth conditions. What consequences does this have for a theory of semantics in which meaning is so defined? There are five possibilities.

(1) The theory should be rejected, since these demonstrate it to be false.

15. It follows from this argument that it is not a necessary condition of a sentence's being a true statement that it constitute a description. The only necessary condition is that it stand in an exact correspondence with some arbitrary state of affairs.

16. One exception is Lewis (ibid). 
Such an outmand-out rejection of a theory would demand the substitution of an alternative more explanatory theory. There are two possibilities: (a) since the interpretation of questions, commands, and indeed assertions, appears to depend on some concept of illocutionary force, a general theory of speech acts should constitute the basis of natural language semantics; (b) since questions and commands undeniably involve the interaction of speaker and hearer, we might attempt to define meaning in these terms rather than in terms of truth conditions. The second alternative I shall discuss (and reject) in detail in chaptex 7, so I sha1I not consider it here. The first alternative is based on a misconception. The existence of questions and commands does not provide any evidence that concepts relating to the speech act such as illocutionary force need to be incorporated into natural language semantics; for interrogative and imperative forms are not indicators of i.l.ocutjonary force. Questions and commands are open to as many interpretations as statements. Thus a question such as Are they thinking of leaving soon? is no more explicit as to its illocutionary force than is the statement They are thinking of Ieaving soon. It can be used either as an implicit command (if for example said by a bored emperor to his officer in front of some subordinates whom he wishes to get rid of), an implicit threat (if the same emperor intends to suggest that if the people in question did leave, they would lose their jobs), or an implicit statement (if the implication is simply one of boredom on the part of the emperor), etc. etc. Furthermore, as these examples demonstrate, the identification of illocutionary force is just as indeterminate with non-statements as with statements. In short, there seems no reason to suppose any one-tomone correspondence between the 
operators assertion, question, and command, and concepts such as illocutionary force. I therefore take it that the existence of questions and commands does not in itself provide any evidence for a theory of meaning based on speech acts. 17

(2) The second possibility is that the theory of truth-conditional semantics should be maintained rigorously with no interpretation of any non-truth-conditional elements. This would exclude any interpretation of the syntactic markers $Q$ and $\operatorname{Imp}$ on the grounds that these are pragmatic operators (cf. ch.7 p.2jo). This would have the disastrous consequence that Are you quiet?, You are quiet and Be quiet would be predicted to be synonymous, since with no interpretation of $Q$ and Imp, the three sentences would have an identical set of truth conditions.

(3) One possible way of incorporating questions and imperatives into a truth-based semantics is to analyse them as having a semantic representation identical to their corresponding performative statement. As such they would (if we assume that performative utterances are truthbearing statements) not only have a truth value on every utterance, but they would correspond to statements which are very generally true. Thus for example (9) would have a semantic representation identical to that of (10), and similarly (11) and (12) would share a semantic representation.

(9) Get out

(10) I order you to get out

(1I) Is John in the bathroom?

(12) I ask you to tell me whether John is in the bathroom

17. For a discussion of illocutionary force within a pragmatic framework cf. ch. 8 section 8.9

18. Since they would be of the type whose truth was guaranteed by its utterance. 
However, this solution is based on the assumption that the paired sentences $(9)-(10)$ and $(11)-(12)$ are synonymous. Yet there are good reasons for thinking that pairs involving an assertion and its corresm ponding performative statement (e.g. John is sick: I tell you that John is sick) are not synonymous: they have different truth conditions. And since one's intuitions about meaning judgements are even less clear on pairs such as $(9)-(10)$ and $(11)-(12)$, there is little justification for claiming synonymy in the cases of commands and questions and their corresponding performative statements if this parallel does not carry over to assertions. This solution must therefore be rejected. (4) A further alternative is to predict truth conditions as a property of the common content of a sentence, question and imperative (a socalled 'sentence-radical') rather than on sentences themselves. This is the analysis proposed by Stenius (1967). He suggests that every sentence be analysed as containing a sentence-radical and a modal element, the former signifying the descriptive content of the sentence and the latter its mood. Thus You be quiet, Are you quiet? and You are quiet all share the same sentence-radical but have different moods. A sentence-radical is further described as true if what it describes is the case, and false otherwise - irrespective of mood. Mood itself is defined in terms of separate semantic rules as follows: Indicative rule: Produce a sentence in the indicative mood only if its sentence-radical is true

Imperative rule: React to a sentence in the imperative mood by making the sentence-radical true

Interrogative rule: Answer the question by 'yes' or 'no', according as its sentence-radical is true or false (cf. ibid pp. 268; 273). 
While an explanation along these lines seems intuitively sound, there are in fact considerable difficulties. Firstly, imperatives will under all normal circumstances be false since truth-value is assigned. to the radical. Second, and more important, is the problem that if the rules given above are semantic rules, then it becomes semantically deviant to tell a lie, and similarly deviant to answer anything other than yes to a question such as Are bachelors unmarried? Yet it is clearly irrelevant to a semantic statenent whether or not speakers tell the truth. Though Stenius attempts to argue against such criticisms, his rebuffs are not I think entirely just and the criticisms remain. A more exact statement of the indicative rule would surely include a weakening to 'only if there are good reasons for believing the sentence-radical is true'. Now I think there are important reasons (which will emerge in ch.4) why any semantic theory which introduces the concept of speaker's belief becomes in principle incapable of fulfilling quite basic conditions on linguistic theories, and as such is untenable. For the moment, I merely enter this reservation together with the previous criticisms as justification for not accepting this alternative.

(5) The final alternative is to have a truthoconditional semantics which gives no account of questions or imperatives except that they are defined, together with the assertion sign, as semantic primitives, not capable of being assessed as true or false. In this formulation, the relationship between Be late and I order you to be late or between Am I wrong? and I ask you to me whether I am wrong is captured indirectly, by defining ask and order in terms of the primitives $Q$ and Imp respectively and stating that ask is followed by embedded 
questions, and order by embedded imperatives. ${ }^{19}$ This alternative differs only from Stenius' suggestion in the definition of the symbols 'F', '?', '!'. Effectively, this framework also separates a sentenceradical on which truth conditions are stated, from a 'modal' element comprising one of the pragmatic mood operators 't', '?', 'I'. Thus the meaning of a yes-no question for example is defined by stating the truth conditions of the proposition being questioned and prefixing the semantic primitive ' 2 '. While the treatment of the actual operators 'f ', '?' and '!' is admittedly ad-hoc, there is strong evidence to suggest that whatever solution is adopted for the interpretation of $Q$ and Imp themselves, the semantic analysis of questions in particular must be in terms relating to truth conditions. The evidence concerns

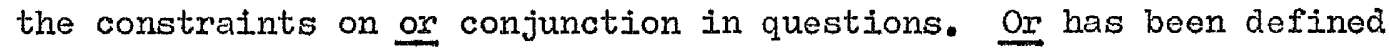
truth-functionally in the following ways:

Inclusive or
\begin{tabular}{ll|c}
$\mathrm{P}$ & $\mathrm{Q}$ & $\mathrm{P}$ \\
\hline $\mathrm{T}$ & $\mathrm{T}$ & $\mathrm{Q}$ \\
$\mathrm{T}$ & $\mathrm{T}$ & $\mathrm{T}$ \\
$\mathrm{F}$ & $\mathrm{T}$ & $\mathrm{T}$ \\
$\mathrm{F}$ & $\mathrm{F}$ & $\mathrm{F}$
\end{tabular}

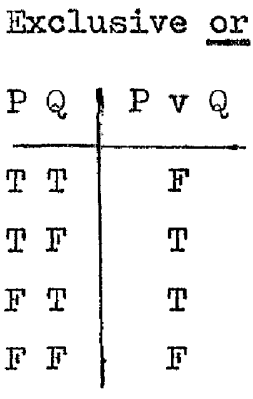

This truth-functional definition of the meaning of or gives us a set of predictions. Since the condition on semantic well-formedness is that a sentence be true in some possible state of affajrs, and since exclusive or demands that the conjuncts $P$ and $Q$ of any conjunction be able to differ in their truth value assignment (in the same way that pregnant demands that the object it is predicated of be female), it follows that where there is a truth dependence between conjuncts, the

19. Cf. Stockwell, Schachter, Hall-Partee who argue (p.543) that complements of ask and order are questions and imperatives respectively for syntactic reasons. 
sentence as a whole will be contradictory. That is, there will be no state of affairs in which either $P$ will be true and $Q$ false, or vice versa; so $P$ and $Q$ in these cases will never jointly fulfil the conditions demanded by or. This prediction of deviance appears to be correct:

(13) ?*Either John left or Bill. noticed

(14) ?*Either John was ill or he wasn't well

(15) ?*tither Mary is dead or John killed her

(16) 3*Iither John's theorem was right or Bill proved that it was right

(17) ?*Either Edward pretended to be sick or he wasn't sick

(18) ?* Either there was an exhibition or the mayor went to the exhibition

In every case, the sentence is odd if or is interpreted exclusively, and in every case there is a relation of dependence between the conjuncts. Exactly the same phenomenon occurs in questions, where the ox appears to be invariably exclusive:

(19) *Did John leave or did Bill notice? 20

(20) *Are you going to stay here or are you not going to leave?

(21) *Was John's theorem right or did Bill prove that it was?

(22) *Was there an exhibition or did the mayor go to the exhibition?

(23) *Did Fdward pretend to be sick or wasn't he sick?

(24) *Is Mary dead or did John bill her?

This ungrammaticality is predicted if the or in questions is given a truth-functional definition. Constraints on conjunction in questions can then be given a natural explanation. It follows that, whatever particular solution is adopted for interpreting the syntactic marker $Q$ itself, the constituents of questions must be interpreted in terms of truth conditions.

$20^{\prime}$. This example is taken from R. Takoff (1971) and is one of a set of examples that she uses to demonstrate the necessity for a performative analysis of questions. The above argument however shows that there is a natural means of predicting this deviance without the need of under. lying higher verbs. 
In summary, I have argued that meaning for natural languages can be defined in terms of conditions on the truth of sentences, and that such a definition need not in principle exclude an analysis of performatives, questions or imperatives. Performative uses of a verb, I have analysed as no different from the remainder of the verb's paradigm. Questions and imperatives I argue must be entered as unanalysed semantic primitives. I cannot and would not wish to pretend that either of these arguments is conclusive. For my purposes however, it has been sufficient to show that an analysis of meaning in terms of truth conditions is not ruled out of court by the mere existence of performatives, imperatives, and questions.

More generally in this first section I have suggested that an interpretive semantic component along the lines envisaged by Bierwisch provides a formal description by recursive procedure of the truth conditions of the sentences of a language. In presenting this specification, I have assumed that the logic on which it is based contains the two values true and false. In the following section, we shall see how this analysis competes with two other analyses:

(a) one in which the meaning of sentences includes reference to the beliefs of speakers

(b) one in which the Iogic on which the semantic mechanism depends is not two-valued but three-valued, containing the extra value neither true nor false. 
CHAPTER 3 : Presupposition: Two Definitions

So far I have outlined a truth-conditional theory of meaning, and have shown how it is naturally compatible with the formulation of the semantic component in Bierwisch 1969, 1971. In the introduction to chapter I, I argued that presupposition constituted a possible falsification of this claim. In this chapter I shall give an account of two ways in which presupposition has been defined, in preparation for considering what issues these definitions raise.

Presupposition was defined by Strawson in an attempt to explain the relation between a definite referring noun phrase and its referent. ${ }^{1}$ It was specifically intended as a refutation of Russell's analysis. Russe11 (1905) made, inter alia, two claims: that The King of France is bald is logically made up of two assertions (i) There is one and only one King of France, (ii) Whoever is the King of France is bald; and that the relation between The King of France is bald and There is a King of France is one of entailment. Strawson on the other hand claimed (1950, 1952, 1964) that The King of France is bald is logically made up of a presupposition that there is a King of France and an assertion that he is bald; and that the relation between the two statements The King of France is bald and There is a King of France is one of presupposition. Presupposition therefore stands in dixect contrast both to assertion and entailment. It is these two contrasts which lead to the two non-equivalent characterisations of

1. The term presupposition was first used by Frege (1892), whose account largely agrees with that of Strawson. I shall restrict myself to Strawson's account as it was this that attacked Russell's analysis. 
presupposition. While strawson talks informally of what a speaker assumes in using sentences containing definite descriptions as opposed to what he actually states (1950), the formal definition of presupposition is in terms of the relation between two statements. By definition then, the concept of presupposition contrasts with entailment.

\subsection{Entailment v. Presupposition}

Intailment I defined earlier $(p .64)$ as a relation between sentences such that the truth of the second necessarily follows from the truth of the first. Thus any statement $S_{I}$ will entail a statement $s_{2}{ }^{2}$ if when $s_{1}$ is true, $s_{2}$ must also be true. It is therefore not possible to assert the truth of $s_{1}$ and deny the truth of $s_{2}$. A different formulation of this same relation is to say that the truth of $\mathrm{s}_{2}$ is a necessary but not sufficient condition for the truth of $s_{1}$; whereas the truth of $S_{1}$ is a sufficient but not necessary condition for the truth of $\mathrm{s}_{2}$. For example, the statement made by uttering That person is a bachelor $\left(S_{1}\right)$ entails the statement made by uttering That person is a man $\left(s_{2}\right)$ since if $s_{1}$ is true, $s_{2}$ must be (demonstrating the sufficiency of the truth of $s_{1}$ for the truth of $s_{2}$ ). On the other hand, $S_{2}$ must be true if $s_{1}$ is to be, though this does not itself guarantee the truth of $S_{1}$ (demonstrating the necessity of the truth of $s_{2}$ for the truth of $s_{1}$ ). It follows from this set of defining conditions that if $s_{2}$ is false, then $s_{1}$ must also be false. However if $s_{1}$ is false, nothing follows $-\mathrm{S}_{2}$ can be either true or false.

2. I am deliberately using statement here and not sentence in accordance with the logical definitions. $\mathrm{Cf}$. Ch.2 for a discussion of truth as a property of sentences, and section 3.3. of this chapter for the justification of ascribing presuppositions to sentences. 
Presupposition differs from entailment in only two ways: the consequence of $\mathrm{S}_{1}$ being false, and the consequence of $\mathrm{S}_{2}$ being false. For $S_{1}$ to presuppose $S_{2}$, the truth of $s_{2}$ must follow from the truth of $s_{1}$, but if $s_{2}$ is false then $S_{1}$ will have no truth value, i.e. will be nelthex true fror false, or it will not constitute a statement at all. 3 It follows from this that if $s_{1}$ is false, $s_{2}$ must be true. Like entailment then, for a presupposition relation to hold between two statements the truth of $\mathrm{S}_{2}$ must be a necessary condition on the truth of $S_{1}$ and conversely the truth of $S_{1}$ must be a sufficient condition on the truth of $\mathrm{s}_{2}$. But in addition, the truth of $S_{2}$ must also be a necessary condition of the falsity of $S_{1}$, and conversely the falsity of $S_{1}$ must be a sufficient condition for the truth of $\mathrm{S}_{2}$. The original example the Kine of France is bald is thus said to presuppose There is a King of France since, as Strawson argues, one judges the truth or falsity of this statement by assuming the existence of the King of France and by assessing on the basis of this assumption whether or not he actually is bald. If there is no King of France, then the statement The King of France is bald is neither true nor false. It follows from this that The King of France is not bald (which asserts the falsity of The King of France is bald) is also said to be either true or false only if there is a king of France. If there is no King of France it is said to be just as odd to say The King of France is not bald as it is to say The King of France is bald. As Strawson would have it, the question of whether these statements are true or false simply does not arise if

3. It is not clear whether the difference between these two consequences is other than terminological Lemmon (1966 p.98) assumes that they are, but Strawson seems normal.Iy to accept the former (1964 p.106). If we accept the former we have to allow a definition of statement which does not demand the property of being either true or false. Since I shall be talking about presuppositions on sentences, the question of whether a statement can have no truth-value will not concern me. I shall adopt the former alternative. 
there is no such person as the King of France. ${ }^{4}$ The difference between entailment and presupposition is summarised in Table I:

Tabie I

Entailment

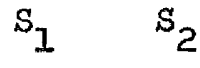

$\mathrm{T} \rightarrow \mathrm{T}$

$F \leftarrow F$

$\mathrm{F} \rightarrow \mathrm{T}$ V $\mathrm{F}$

Presupposition

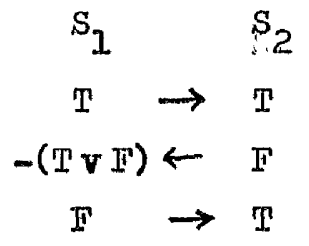

\subsection{Speaker-Presuppositions: Presupposition v. Assertion}

The discerming reader should be wondering at this point how the relation of presupposition - defined as it is in texms of the truthdependence of statements - ould possibly constitute a potential falsifier of truthebased semantics. The answer is - it does not. The trouble arises over the contrast between presupposition and assertion. Strawson's informal discussion of what is stated as opposed to what is assumed led to a characterisation of presupposition in terms of beliefs on the part of the speaker in making a statement. This re-interpretation of the term was first explicitly given by Sellars (1954) who infers from Strawson's initial account ${ }^{5}$ that what is presupposed in some utterance of The King of France is bald is that the speaker believes that there is a king of France and moreover that the hearer does so also. Presupposition is here opposed by definition to what a speaker would assert in uttering a given sentence. This concept is radically different from the logical definition since the defining criterion of presupposition yields quite different results.

4. Cf. Strawson 1950 section III.

5. Strawson 1950 is in fact indeterminate as between a truth-based characterisation of presupposition or a pragmatic one. 
In Sellars' case presupposition bears no relation to truth conditions but relatas to conditions for sucioessful communication. Thus if the presupposition fails to hold, the speaker has in some sense spoken incorrectly. But as Strawson points out in his reply to Sellars (1954), this concept is neither incompatible nor compatible with his own definition - it is merely different. Correct and incorrect usage are not co-extensive with the assignment of the truth-values true and false to statements. In fact, it has been suggested (by Garner 1971) that anyone wishing to use Sellars' concept of presupposition should scrap the term presupposition.

However Sellars' misinterpretation of Strawson is not wholly unjustified, and it is not I think the sole or even the chief source of the widespread conflation of speaker-presupposition and statementpresupposition. There is a very general tendency in describing presupposition to talk about what a speaker would be presupposing in using a particular sentence to make a statement as opposed to what he would actually be asserting. The dangers of this are hinted at by Garner (ibid) who separates the various different uses of the term by philosophers and linguists. 6 Yet even he claims that 'we could always rephrase what I have said (about statements - RMK) by talking explicitly about what, as a performer of an act of a certain kind, or as a producer of an object of a certain kind, a speaker does (or would) presuppose' $(p .27)$. But this is to fall into the very trap he is warning other people of. This rephrasing by Garner is only not a danger if it is recognised as a consequence of the logical definition of presupposition, and not part of the definition itself.

6. He draws attention to this conflation in a footnote (p.27 fn.5) as a 'potential source of trouble'. 
If however, it is taken as a characterisation of presupposition, then it invites conflation with a subtly different use of presupposition, where all that a speaker assumes his hearer knows constitutes his presuppositions and this stands in contrast with what that speakex is informing his hearer of (asserting). Thus the utterance of JOHN seduced Mary with contrastive stress on John, could be said to presuppose not only that there is a man called John but also that someone called Mary was seduced, and to assert that it was John that did it. 7 In a similar way both John SEDUCED Mary and John seduced MARY would have a different set of presuppositions. Now it is fairly certain that neither Strawson nor Garner would wish to conflate these two uses of presupposition, since the latter is not susceptible to any truth-based definition. 8 Indeed, it is essentialiy equivalent to presupposition in terms of speakex-belief. But it is not clear how this use can be excluded by a characterisation of presupposition in terms of what the speakex presupposes in making such a statement. If therefore the logical definition of presupposition is to be kept distinct from presupposition defined in terms of speaker belief or assumption, the former must not be discussed in terms of what a speaker would do in saying a sentence. I shall therefore assume a) that the logically defined presupposition is a relation defined only between two statements 9 and (b) that it stands in contrast to a pragmatically defined speaker presupposition, which is defined in terms of what the speaker assumes in saying particular utterances.

7. Cf. Chomsky 1971, and ch.8 section 8.2 .5 of this thesis.

8. Strawson appears to fluctuate between a position keeping these two separate (cf. p.85 and Strawson 1954) and a position implicitly conflating them (cf. ch.5 section 5.1 of this thesis and Strawson 1964a)

9. This will be extended shortly to include sentences. 


\subsection{Presuppositions of statements and Sentences}

Before we can assess how or whether either of these concepts should be incorporated into a formal model of language, there remain two problems: (1) what is meant by statement?, (2) Can we justifiably speak of sentences bearing presuppositions? We have already seen in chapter 2 that statements are generally defined as abstract entities which are either true or false with respect to some context of utterance (with the possible caveat of footnote 3 of this chapter). It is necessary to maintain a distinction between this definition of statement and the illocutionary act definition of statement. The importance of the distinction rests in the fact that the illocutionary act of stating stands in contrast to the illocutionary acts of promising, warning, boasting etc. The logically defined statement does not. Now it is clear that whatever the presuppositions of the logical statement made by The King of France visited the exhibition, we would not want these to stand in potential contrast to those of utterances where the same sentence is used as a boast, a warnings or a threat. The essential feature of the logically defined statement is that whatever act is purported to have taken place, the statement itself and hence its presuppositions remain constant. The presuppositions of a logically defined statement are thus independent of the illocutionary force associated with it. On the contrary however, the presuppositions of the illocutionary act of stating need not in principle hold for other illocutionary acts. While this distinction is maintained by Strawson, this is not the case with some of his interpretexs, for example Garner (1971). 
Indeed conflation of these two types of statement leads Garner (jbid) to characterise presupposition failure (when $S_{2}$ is false) as a failure to constitute a statement (rather than guaranteeing that the statement in question be neither true nor false) on the grounds that it 'allows a natural generalisation to speech acts of other kinds and their objects, since it seems desirable to speak of the presuppositions of promises, commands, questions, bets, warnings, and so on as well as those of statements' (p.31). He then goes on from this to characterise presupposition in terms of presuppositions on the part of a speaker 'in the performance of an illocutionary act (or the purported performance of one)'(p.42). His failure to distinguish the illocutionary act of stating from the logically defined statement thus leads directly to a conflation of the two different concepts of presupposition which he initially sought to separate. 10

More important perhaps for our purposes is that Garner, like Strawson, condemns discussions of the presuppositions of sentences (pp.38, 42) and he does so on the basis of this conflation of the two uses of the term statement. His reason for not allowing presuppositions to be a property of sentences is significantly different from strawson's. Strawson restricts presupposition to statements because it is only these he says which are true or false, not sentences. Garner however seems to exclude all presuppositions as a property of sentences on the grounds that 'the same sentence .... can be used, on different occasions, to perform different kinds of illocutionary acts' (p.38). But if, as I suggest, presupposition is a property of the logically 
defined statement, then the question of varying illocutionary act potential does not arise. Moreover if, as Lemmon suggests (1966 p.91), it is legitimate to speake of sentences as true or false relative to some context of utterance, an extension implicit in all analyses of meaning as conditions on the truth of sentences (cf. chapter 2 section 2.3), then it follows that to speak of presuppositions (and entailments) of sentences is not illegitimate either.

\subsection{Summary}

I have now outlined two definitions of presupposition, one in terms of a relation between statements or sentences (by definition in contrast to entailment), the other in terms of what a speaker must assume in saying a given sentence (by definition in contrast to assertion). 11 Neither concept is catered for in the linguistic framework I outlined in chapters 1-2. Of the two concepts, logical presupposition possibly presents the lesser difficulty for this framework. The semantic components set up in chapter I were largely justified by their predictive power - viz. the predicting of entailments and contradictions. If now logical presupposition has to be predicted, the logic underlying these predictions will have to be altered to include three values (true, false, and neither true nor false) and this will have to be reflected in either the formalisation of the components themselves or in the formalisation of the projection rules predicting the interpretations of sentences (cf. p. $30 f$ ). Such a change would for example affect the interpretive rule of negation outlined in chapter 1 (as we shall see in chapters 4-5) since this

11. There are several problems in the definition of assertion which I shall return to in detail. Cf. ch.5 p. $144 \mathrm{ff}$ and ch. 8 section 8.6 . 
is based on the de Morgan equivalence

$$
-(P \cdot Q) \equiv-P v-Q
$$

which need not hold in a three-valued logic. However the underIying assumptions about the nature of semantic representation would not be altered with such a revision. In contrast to this, speaker-presuppositions appear to give the lie to the whole framework. If it can be shown that presupposition so defined must be stated as part of the semantic representation, the meaning, of a sentence, then it would appear that meaning itself can no longer be defined in terms of truth conditions. Two issues thus emerge: (1) Should the formalism of the semantic component reflect a threevalued logic rather than a two-valued logic? (2) Is the whole framework outlined in chapters 1-2 in principle based on the wrong premises - i.e. should meaning be defined in some other way, for example in terms of speaker-hearer relations? With these issues in mind, I shall now consider the various ways in which presupposition has been used (or misused) by linguists. 


\section{CHAPTER 4 : Presupposition: Its Use By Iinguists}

We have now seen that the definitions of presupposition appear to provide deciding evidence for two different issues: (a) whether or not the logic of natural language semantics should be two or three valued, (b) whether or not natural language semantics should even be related to logic rather than to some quite different theory involving speaker-hearer communication. In this chapter, I wish to see to what extent the evidence from work in linguistics supports either of these two hypotheses. What I shall argue is firstly that the majority of claims for presupposition in fact turn out to be examples of entailment. This confusion of entailment and presupposition, I suggest, has arisen in linguistics largely by virtue of an incorrect analysis of negative sentences. My argumentation will therefore rest heavily on the outline of negation I gave in chapters 1 and 2. Secondly, I shall argue that those examples which cannot legitimately be analysed as entailment are not properties of sentences which should be predicted by a semantic component of a formal theory at all. Indeed, they cannot be if the theory is to remain predictive. Rather they constitute part of a separate theory, a theory of pragmatics. Thus I shall conclude that none of the purported presuppositions refute the theoretical framework that I outlined in chapters 1 and $2 .^{1}$

1. For reasons of exegesis, I shall only give detailed consideration to discussions of presupposition which seem to have been most influential in determining the use other linguists have made of the term - viz. Fillmore's, the Kiparskys', Keenan's, and the Lakoffs'. The term is now extremely widely used and uses by the many other linguists have been taken into account only peripherally, or not at all. In particular, cf. the articles on presupposition in Kiefer and Ruwet (eds.) 1972, which have come to my attention too recently to be incorporated into the discussion here. 
Unfortunately most recent work done in semantics by linguists appears to have been done without sufficient regard for its philosophical. consequences, and this is effectively to work in a semantic vacuum. For example, most linguists writing on presupposition do not appear to recognise either that there are two distinct concepts of presupposition or that any use of the concept of presupposition raises a central issue for semantic theory in general. Not only are the two concepts of presupposition in general not distinguished, but presupposition is used as an extremely broad cover term which includes examples of entailment (Fillmore 1969, 1971, Keenan 1971, 1972, Kiparsky and Kiparsky 1970, Lakoff 1971, 1972), Jogical presupposition (Keenan ibid), Austin's implication and happiness conditions (Fillmore ibid, Lakoff ibid), Grice's conventional and nonconventional implicature (Lakoff ibid, R.Lakoff 1971, Horn 1969, Chomsky 1971), and also lexical presupposition (Fillmore ibid). These distinctions are not recognised by the writers themselves, and presupposition is very generally defined as that which the speaker assumes to be true as opposed to what he asserts to be true. Given this application of the term to almost every conceivable semantic and pragmatic relation, it is hardly surprising that presupposition has been thought to have considerable explanatory validity.

\subsection{The Introduction of Presupposition to Linguistics: Fillmore} The term presupposition was first used in linguistics by Fillmore $(1969,1971)$ who is one of the few linguists to recognise that there is an issue over how meaning should be defined. In 1969, he attempted to reflect the distinction between entailment and presupposition within a 
semantic feature analysis by dividing the components of meaning of lexical items into the meaning of an item and its presuppositions. His criterion for so doing was a negation test, which in general reflects the defining criterion of presupposition that the truth and falsity of $S_{1}$, the presupposing sentence, be a sufficient condition for the truth of $S_{2}$, the presupposed sentence. This test divides the semantic components of a sentence into two sets - those which may fall within the scope of negation (i.e. which may be interpreted as false when the corresponding positive sentence is asserted to be false); and those which can never fall within the scope of negation (i.e. which must remajn true when the corresponding positive sentence is asserted to be false). In the case of a lexical item, its presuppositions are said to be those elements of its meaning which are unaffected by negation: i.e. they cannot be denied. For example, the item bachelor, in the relevant sense of the word, is claimed to have 'unmarried' as its meaning and the components 'adult' and 'male' as its presuppositions on the grounds that That person is not a bachelor is not used to deny that the person is a male adult, but only to deny that he is unmarried (Fillmore 1969 p.123). However this assumes that negative sentences have a single fully specified interpretation. This, as we have seen (ch.1 section 1.3 .3 ), is false. In fact, each of the components can be interpreted as falling within the scope of negation:

(1) That person is not a bachelor - he's married

(2) That person is not a bachelor - he's only five years old

(3) That person is not a bachelor - it's a woman

(4) That person is not a bachelor - it's a woman, who is married

(5) That person is not a bachelor - it's a spinster

(6) That's not a bachelor - it isn't even a human being - it's a stone made to look like Bill, our only unmarried friend. 
If we take the negation test strictly, this set of sentences provides

five contradictory results:

I bachelor Meaning: unmarried

Presupposition: male, adult, human

II bachelor Meaning: adult and unmarried

Presupposition: male and human

III bachelor Meaning: male and unmarried

Presupposition: adult and human (3), (4)

IV bachelor Meaning: male

Presupposition: unmarried, adult, human (5)

V bachelor Meaning: male, human, unmarried, adult

Clearly this is wrong. What has been ignored is the inherent vagueness of negative sentences and the variability in the interpretation of their scope. Furthermore, since the examples demonstrate that any part of the meaning of bachelor can be interpreted as not matching the state of affairs described then in no case is a component presupposed. On the contrary, the variability in scope of negation is a defining criterion of an entailment relation (cf. ch.3 Table I line 3, p. 84) since the denial of the entailing sentence has no consequence for the entailed sentence, which can be either true or false when the entailing sentence is false. It therefore appears that That person is a bachelor entails the maleness, adultness, etc, of the object described and does not presuppose them. Thus none of the components of bachelor constitute presuppositional components.

This confusion of entailment and presupposition is repeated in Fillmore 1971, as we shall see. However since in this paper he adopts a more fully specified theoretical position which is purportedly contrary to the position being argued for in this thesis, I must make a short digression and consider the theoretical implications first. 
Fillmore explicitly dismisses any form of componential analysis on the grounds that it is often 'completely ritualistic', that there is 'no stopping place' (p.274), and that in unclear cases, the oddness bears little relation to the linguistic properties of the lexical items in question, but stems rather from what we happen to know about the world. As an alternative he suggests that the meaning of sentences should be analysed, along the lines of the ordinary language philosophers, in terms of two levels, the illocutionary and the presuppositional, the latter constituting 'those conditions which must be satisfied in order for a particular illocutionary act to be effectively performed in saying particular sentences $1(\mathrm{p} .276)$. In other words, he is committing himself to a use theory of meaning, and is therefore making exactly the opposite claim to that which is being made in this thesis. He argues that both in philosophy and linguistics the wrong question has been asked; that the question should not be 'What is the meaning of this form?' but rather 'What do I need to know in order to use this form appropriately and to understand other people when they use it?' (p.274). However a framework which equates meaning with aspects of the illocutionary force of utterances is forced to distinguish between There are three bulls in that field said by a farmer to a passing walker, the same sentence said by a farmer to his financial backer, and the same sentence said by a farmer to his assistant, since in the first case, the utterance will constitute a warning, in the second case a boast, and in the third a mere statement. Moreover since Austin alleged that there were an indeterminate number of illocutionary forces, or at least a very large number (cf. Austin $1962 \mathrm{p.149}$ ), it follows that a strict speech act theory of semantics must predict that every sentence is if not indeterminately ambiguous at least ambiguous 
in anything up to one thousand ways. As we shall see in section 4.4, this leads to consequences which no linguist would wish to accept. Fillmore only avoids these consequences by two ad-hoc caveats: first, the illocutionary level is called the 'explicit' level of communication, ruling out ad-hocly the fact that a statement may be used to boast, warn, etc - i.e. ruling out that aspect of communication which is a central part of a use theory of meaning; and second, at the presuppositional level he claims to be concerned 'only with those (conditions - RMK) that can be related to facts about the Iinguistic structure of sentences' (p.277), ruling out some of the conditions which are normally seen as an indisputed part of a speech act theory of meaning (cf. the preparatory and sincerity conditions on promi.sing etc given in searle 1969).

In this form, it is not obvious that Fillmore's formulation is more than a terminological variant of a feature or component analysis of meaning. Indeed an analysis explicitly in terms of conditions on the use of linguistic items given his caveats meets just the same problems as componential analysis, over just the same border-line cases. Thus it is as inappropriate to say of a three-week old baby John's child is not a virgin as to say John's child is not a human being but it is not clear that the oddity of the former can be related to facts about the linguistic structure' of the sentence. In addition, it is not clear what criteria Fillmore has for distinguishing what is part of the meaning of a lexical item, the illocutionary level, and what is not. And yet componential analysis which, according to Fillmore, assigns meaning in a ritualistic way, in principle provides criteria as follows: if a postulated component of meaning in a sentence can be 
denied without forming a contradiction, then it is not part of the meaning of that sentence. If it cannot, then it is. If furthermore the component can never be interpreted as being included in the scope of negation when that sentence is negated, then it will constitute a presuppositional component (cf. line 3 Table I p.84 ). Given that Fillmore's criticisms of componential analysis are not entirely justified and moreover that his alternative analysis of meaning, with two quite ad-hoc caveats, comes up against exactly the same problems as a componential analysis, it is by no means certain that componential analysis is shown to be fundamentally at fault. There remains only the possibility that his analysis predicts a different and more sound description of a given set of data, and therefore could be said to provide a plausible alternative framework.

As a demonstration of his theoretical position, Fillmore gives an analysis of a set of verbs of judging in terms of their 'illocutionary' and 'presuppositional' aspects (their meaning and presupposition). of these verbs I shall consider in detail only criticise and accuse, ${ }^{2}$ but even this small amount of evidence demonstrates that componential analysis and Fillmore's are no more than terminological vaxiants, except in cases of presupposition where Fillmore's own criterion (that of negation: cf. p. 93 ) contradicts his analysis. Thus we shall see that not only is Fillmore's theoretical position not a real alternative to an analysis in componential terms of truth conditions but his use of presupposition is again a confusion of this term with entailment. Fillmore's specification of criticise and accuse is as follows:

2. There are a number of criticisms of detail that could be made of the other verbs. The most obvious mistake is perhaps the analysis of blame into three lexical items, apparently dependent on stress assignment, in exactly the manner of my pseudo-analysis of bachelor (cf. p.94). That this cannot be correct can be shown by considering John KICKED Ruth v. John kicked RUTH where in the former there is no doubt that he did something to her and in the latter that he kicked somebody, but which would not lead us to set up two lexical items kick (analogous to blame) one in which the entire lexical content was presupposed. 


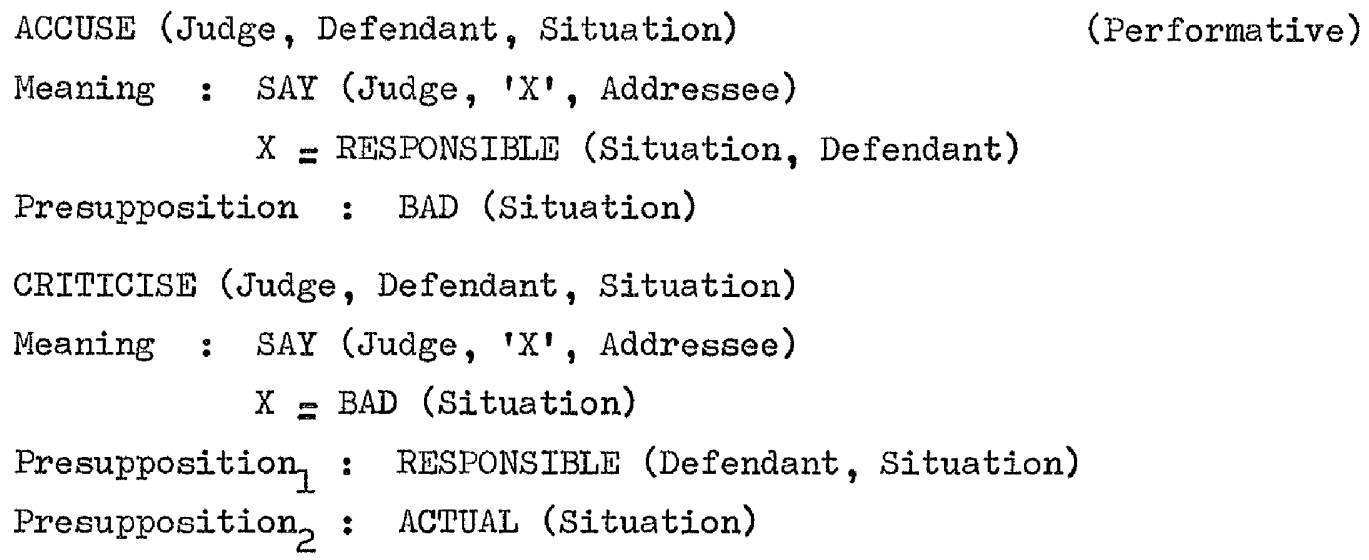

These in effect claim that for $X$ (the judge) to be described as accusing Y (the defendant) of $Z$ (the situation), $X$ must say to someone, not necessarily the defendant $Y$, that $Y$ is responsible for $Z$, and it must in addition be presupposed that the situation is bad. Conversely for criticise, with the additional presupposition that $z$ actually happened. It is not easy to test this analysis because of an equirocation over who does the presupposing. Fillmore allows the following formulae (where $\mathrm{x}$ is what is presupposed): 'Suppose there's no question in anybody's mind that $x^{\prime}(p .285)$, 'There is no question about $x^{\prime}(p .282)$ and 'If I say (36), I presuppose that $x$ ' (p.282) (both the latter are used with respect to criticise). Thus it is not clear whether the presupposed element has to be true, to be generally assumed to be true (whether it is or not), or to be assumed to be true by the hearer. However both analyses would presumably use data of the following sort: (7) *John accused Mary of taking his books but he didn't say anything (8) *John accused Mary of taking his books but he didn't say she'd done so (9)?*John accused Mary of taking his books but he wasn't assuming anybody had taken them

(IO) ?*John accused Mary of taking his books but he wasn't assuming it was a bad thing to have done

(11) John accused Mary of taking his books but I couldn't see anything wrong in it 
(12) John didn't accuse Mary of taking his books: he merely suggested that she had

(13) John didn't accuse Mary of taking his books because he knew she hadn't done so

(14) John didn't accuse Mary of taking his books: he didn't say anything

(15) John didn't accuse Mary of taking his books because he assumed he'd lost them

(16) *John criticised Mary for taking his books but he didn't say anything

(17) *John criticised Mary for taking his books but he didn't say there was anything wrong in it

(18)?*John criticised Mary for taking his books though he was assuming that she hadn't done so

(19)?*John criticised Mary for taking his books though he was not assuming that anybody had taken them

(20) John didn't criticise Mary for taking his books because he knew there was nothing wrong in doing so

(21) John didn't criticise Mary for taking his books because he knew she hadn't done so

(22) John didn't criticise Mary for taking his books: he didn't say anything

(23) John didn't criticise Mary for taking his books, because he assumed he'd lost them

These sentences fall into two categories, apparent contradictions, and apparent non-contradictions. In each case, where an apparent contradiction arises, (7)-(10), (16)-(19), I have tested whether a suggested basis for the contradiction holds when the statement John accused/criticised Mary of/for taking his books is denied, i.e. whether when the statement is asserted to be false, the purported presupposition must remain true. Thus for example, sentences such as John criticised Mary for something she hadn't done suggest that Fillmore's presupposition $n_{2}$ on criticise is not an absolute presupposition 
but relative to the criticiser (confirmed by (18)); ${ }^{3}$ but the fact that this component can be interpreted as falling within the scope of negation in (2I) indicates that it is not a presuppositional component. The main conclusion to be drawn from this set of examples is that none of the apparent presuppositions necessarily holds under negation: in each case the statement can be asserted to be false by virtue of the purportedly presupposed statement being taken to be false (cf. (12)(15) and (20)-(23)). In brief, I think the data provide evidence against Fillmore's analysis and in favour of the following:

ACCUST : Judge say defendant responsible for situation
Judge assume situation bad
Judge assume situation actual
CRITICISE : Judge say situation bad

Judge assume defendant responsible for situation
Judge assume situation actual

Moreover I think this procedure of testing a purported presupposition by seeking interpretations of negative sentences which deny it (an impossibility for a true presupposition) shows that there is no such thing as lexical presupposition. Every case of lexical presupposition that Fillmore suggests can be interpreted as falling within the scope of negation, and these lexical properties seem to be no more than reflexes of entailment ${ }^{4}$ in just the way that the semantic components of Leech (1969), Katz and Fodor (1963), Bierwisch (1969, 1970, 1971), etc., are set up on lexical items by virtue of entailment relations between sentences in which the items occur. Since with respect to the non-presuppositional components of meaning the two analyses of criticise and accuse do not conflict, and since only ad-hoc caveats save Fillmore's

3. Cf. ch..9 p.297f for further justification for describing this relationship as an entajiment.

4. This conclusion has been demonstrated independently by Cohen (1973). 
analysis from undesirable consequences, I suggest (a) that each of the cases Fillmore puts forward as presupposition are in fact cases of entailment and (b) that Fillmore has not demonstrated the relevance of aspects of the speech act to the semantic analysis of lexical items. On the contrary, I assume - along with Austin (cf. Austin 1962 p.100) - that the level of illocutionary force is quite separate from the level of meaning. 5

5.2 Factive Verbs: Kiparsky and Kiparsky.

An important premise of my criticism of Fillmore's hypothesis of 'lexical presupposition' was that negative sentences could be shown to have variation in scope without this corresponding to a variation in meaning of the sentence itself. Thus I suggested that all the components of meaning in criticise and accuse are reflexes of entailment, and not presupposition, because they may be interpreted as constituting part of what is negated. The Kiparskys (1970) make some gesture towards this position in recognising that 'it is the SET of assertions that is operated on by ... negation' (p.I5I) where the assertions of a sentence are 'all those propositions which follow from it by virtue of its meaning' (p.148). Any one of these assertions, they state, may fall within the scope of negation. Thus they give the following set of examples (p.152) as possible interpretations of Mary didn't clean the house:

(24) Someone may have cleaned the house, but not Mary

(25) Mary may have done something, but not clean the house

(26) Mary may have cleaned something, but not the house

(27) Mary may have done something to the house, but not clean it

(28) Mary may have been cleaning the house, but it didn't get clean

However they would not accept the full consequences of my analysis since they maintain Fillmore's test for presupposition that the presuppositions

5. Cf. Ch. 8 section 8.9 for an analysis of illocutionary force within a pragmatic frameworli. 
of a sentence are constant under negation. Thus the above sentence is said to presuppose that the house was or has been dirty. This negation test has one important caveat: the presuppositions of a sentence may be denied, but this does not constitute the straightforward denial of an event or situation, but rather the denial of the appropriateness of the word in question' (p.151). Thus certain interpretations of negative sentences are excluded by fiat as not constituting 'straightforward denial'. With their particular example, clean is said to presuppose that the object of which it is predicated was or has been dirty, and it follows that (29) would be described as an example of straightforward denial, but (30) by contrast apparently would deny the appropriateness of the word clean:

(29) The boy didn't clean the room - the woman did (30) The boy didn't clean the room - he made it dixty

I find this distinction dubious. We have seen earlier (ch.2,.p.66) that to deny some proposition 'P' is to claim that the conditions specified by 'P' do not correspond to the state of affairs in question. Informally, one might say that it is not appropriate to use 'P' unless there is an exact correspondence between ' $P$ ' and the state of affairs. 6 Thus in the examples cited, it is just as inappropriate to the situation to say 'John cleaned the room' if in fact Mary did as it is to say 'John cleaned the room" if in fact he made it dirty. To deny some proposition, for example John cleaned the room IS to say it is inappropriate to relate the predicate in question to the particular subject, whatever the cause of the noncorrespondence.?

6. Cf. the pragmatic maxim introduced in ch. 7 p.202 "Do not say what you believe to be false".

7. Cf. Ch. $7 \mathrm{p} .214 \mathrm{f}$ for an argument against postulating the more special kind of denial even as a separate pragmatic type. 
The Kiparskys characterise this 'special' type of negation as characteristically having contrastive stress. But if one legislates against the type of negation in (30) as being merely a denial of the appropriacy of the word clean, one is bound to legislate against all contrastive stress negations, and such an exclusion would have also to exclude (29). In this example the scope of negation was interpreted as being restricted to the set of conditions represented by boy. Since it is precisely these conditions which fail, one might say - parallel to (30) - that the word boy is inappropriate in this context. This exclusion seems quite unjustified. Moreover, allowing presupposition to be included within the interpretation of negation at all contradicts the logical definition of presupposition that it is not possible to assert that the presupposing sentence is false (i.e. deny it) if the presupposed sentence is false, since the former will be neither true nor false under these conditions. In (3), denying the appropriacy of clean, this is clearly not so: there is nothing 'special' about this case.

The Kiparskys' discussion of presupposition is by way of introduction to the semantic and syntactic properties of the verbs they call 'factive' (cf. also Lees 1960), e.g. regret, realise, be angry. These they claim presuppose the truth of their complements. However, like criticise and accuse, I think it can be shown that sentences negating these verbs can be interpreted as negating their complements as well:

(31) I don't regret causing trouble because I diơn't

(32) He can't have realised I've been unfaithful to him because I haven't (33) He shouldn't be furious that I've failed because I haven't

(34) I didn't regret that John was leaving because I knew it wasn't true (35) I don't regret that I was alone because I wasn't

In other words, if it is false to say that I have been unfaithful to my 
husband then it is also false to say that he realises that $I$ have been unfaithful to him; it's false to say that John regrets going to the party because he never went; etc. 8

Moreover there are some puzzling complications under their analysis. The Kiparskys capture the distinction between the presuppositions of a sentence and its assertions by claiming 'the assertions of a proposition $\left(\mathrm{P}_{\mathrm{k}}\right)$ are made relative to that proposition within its context of dominating propositions. Presuppositions on the other hand, are relative to the speaker' (p.155). If presuppositions induced byese verbs are relative to the speaker, then they should hold irrespective of the sentences they are contained in. Yet in if-then sentences, they are clearly not presupposed to be true by the speaker:

(36) If you go to the party, you will regret it

(37) If you go to the party, you will realise what a mistake it was And in counterfactual conditionals, ${ }^{9}$ they are taken to be false:

(38) If you had been to the party, you would have regretted it

(39) If you'd seen John you would have realised it

In addition, Lakoff points out (1972) that when factive verbs are embedded as complements of verbs such as pretend and dream, their complements are no longer presupposed to be true:

(40) I dreamt I realised my mother was dying and I couldn't get to her in time

(4I) Sue pretended that her boss realised she had an IQ of 180

8. Tor a logical argument supporting this data (using the factive verb know), cf. Wilson 1972.

9. Counterfactual conditionals have themselves been said to presuppose the falsity of their consequent and antecedent (cf. Morgan 1969). This has been shown to be wrong on the one hand by Karttrumen (1971) who demonstrates, by examples such as If Harry had known that Sheila had survived he would have gone home, which he did anyway, that the consequent is not presupposed to be false (though he assumes the antecedent is) and on the other hand by Thomason (1973 fn.9) who gives the example If the patient had taken arsenic, he would be exhibiting just the symptoms he does now to show that the antecedent is not presupposed to be false either. 
(42) I pretended to realise I was dying of cancer though I had just been told I only had pleurisy

(43) I pretended to regret that John was leaving though I knew he wasn't (44) John refuses to realise he's dying of cancer, so maybe he won't That is, in for example (41) (Lakoff's e.g. 22a of section V), it is not necessarily true that Sue has an IQ of 180 in order for (4.1) itself to be true. As Lakoff reports (ibid. p.575) 'there are some speakers who find it hajd to make judgments about (22a)'. Yet if realise and regret induce presuppositions which are speaker-relative these should hold irrespective of the constxuction in which they are contained. Lakoff is forced to postulate dialect differences in these cases, an outlet which is in this case quite unjustified. 10

Verbs such as pretend do not however merely constitute complications for the Kiparsky analysis of factives as presupposing the truth of their complement. They provide direct evidence against such an analysis. Pretend is a verb which very generally implies the falsity of its complement. ${ }^{11}$ Now if sentences containing a factive verb are embedded as a complement of pretend, that complement will be implied to be false. But on the hypothesis that sentences containing factive verbs presuppose the truth of their complement it should follow that the complement of the factive verb must still be implied to be true, even though the sentence containing the factive verb is itself implied to be false. On the hypothesis that positive sentences containing factive verbs entail the truth of theix complement,

10. I shall. not give Lakoff's analysis in detail since in a footnote, he admits that 'the treatment of presupposition in this section is woefully inadequate'. One specific error is his analysis of pretend as presupposing the falsity of its complement, but having the curious property that under negation it has no presupposition with respect to its complement. This curious property guarantees that the relation cannot be one of presupposition!

11. It is arguable that this property is based on an entailment relation between any assertion containing pretend and the complement of the verb; but examples such as John pretended that he was $i 11$ and he found out later that in fact he had been ill for a very long time suggest that the relation is not that strong. (I am grateful to J.Iyons for pointing out to me examples of this type.) Cf. Ch.9 p.297f for a further discussion of the nature of this relation. 
this prediction will not of course follow since if the entailing sentence is implied to be false (as it will be when embedded as the complement of pretend) the entailed sentence (the complement of the factive verb) may be either true or false. As we have seen in examples (41)-(43), the prediction made by the presupposition analysis is not borne out. Each of these examples can be interpreted in one of two ways - with the complement of the factive verb taken to be true or taken to be false:

(45i) Sue pretended that her boss realised she had an IQ of 180 in order to get a better job

(45ii) Sue pretended that her boss realised she had an IQ of 180 though in fact he didn't know how clever she was

(46i) I pretended to realise I was dying of cancer though I knew it was only sciatica

(46ii) I pretended to realise I was dying of cancer though in fact I couldn't make myself believe it

(47i) I pretended to regret that John was leaving when I knew he had no intention of doing so

(47ii)I pretended to regret that John was leaving because I didn't want anyone to see how relieved I was

Moreover this variability in implication extends to the entire range of factive predicates, as witness $(48)-(49):^{12}$

(48i) The teacher pretended that he was angry that Pete was late though he knew that Pete was there on time

(48ii)The teacher pretended that he was angry that Pete was late so that Pete would be frightened

(491) Gerald pretended that it was most unfortunate that Ann was pregnant though he knew in fact it wasn't true

(49ii)Gerald pretended that it was most unfortunate that Ann was pregnant though secretly he was very pleased

12. In fact it extends to the entire range of purported presuppositions as we shall see. Cf. Karttunen 1973 who notices that judgments seem to differ in such cases. What Karttunen, like Lakoff, fails to point out is that this variability is an unambiguous indication that the relation in question is not one of presupposition, but of entailment. 
This evidence suggests fairly unambiguously that the relation between positive sentences containing factive verbs and the complements of those verbs is not one of presupposition at all, but is a relation of entailment. Moreover the anomalies which arise in a presuppositional analysis with negation and conditionals no longer remain if the relation between factive verbs and their complements is analysed as based on entailment. ${ }^{13}$ If John regrets that he went to the party $\left(S_{1}\right)$ entails John went to the party $\left(s_{2}\right)$, then the following predictions arise:

(a) If $S_{1}$ is negated, then there are at least two possible interpretations, one in which $\mathrm{S}_{2}$ is assumed to be true, and one in which it is not. (b) In a construction such as If $S_{2}$, then $S_{1}$ - where any speaker uttering a sentence of this type would not be asserting eithex constituent conjunct - since $S_{1}$ is not asserted to be true, there is no reason to assume that $\mathrm{S}_{2}$ must be. ${ }^{14}$ Furthermore exactly the same prediction could be made for sentences conjoined by or, and this turns out to be the case. Thus there is nothing odd about (50)-(52) despite the fact that the truth of the factive complement is not assumed.

(50) Tither John regretted going to the party or he didn't go

(51) Either Bill was annoyed that Mary was late or she managed to get there on time

(52) Either the President realises that he faces impeachment or the the charge has been dropped

The reason is again the same: since the truth of neither conjunct would be asserted in any utterance of this sentence, there is no reason for

13. I do not mean to imply by criticising the Kiparskys' use of the term presupposition that their entire analysis is thereby falsified. On the contrary, as we shall. see in ch.6, section 6.4 , the evidence they provide suggests fairly conclusively that a syntactic class of factive predicates needs to be distinguished, but these are a subset of predicates which entail the truth of their complement propositions.

14. Cf. Ch. 8 section 8.6 for a pragmatic account of assertion. 
the truth of the factive complement to be necessarily assumed. On the contrary, the truth of the factive complement will only be a necessary consequence if the first conjunct turns out to be true (in which case the second conjunct will be false). Thus each of the oddities for a presupposition-based analysis of factives follows as an automatic consequence for an entallment-based analysis of the same set of verbs.

One final piece of evidence provides further confirmation of this analysis. Both Lakoff (1972) and Horn (unpublished Ph.D. thesis) have clajmed that presuppositions can be suspended under certain conditions. 15 one of these is that the presupposing sentence be negated. Thus we have:

(53) John doesn't realise Sue loves him, if indeed she does

(54) *John realises Sue loves him, if indeed she does but not

(55) John doesn't regret having his money stolen, if in fact it was but not

(56) *John regrets having his money stolen, if in fact it was

In each case, the implication need not be held to be true if the apparently presupposing sentence is negated. But again, this is prohibited by definition for presupposition, and constitutes the hallmark of entailment. 16 Hence we have still not seen evidence for the necessity of changing the original framework of chapters 1-2 to accommodate a different logical relation of presupposition.

1973

15. Karthunen/generalises this 'suspension' procedure, setting up ad-hoc 'filtering' conditions which can be used to account for both this type of example and the examples above, with if-then and or. But this is to concede the point I am making that purported presuppositions of the constituent sentence are not a necessary implication of all sentences in which they occur but only of sentences in which the presupposing sentence is implied (or asserted) to be true.

16. Cf. Karttunen $1971 \mathrm{~b}$ for a different analysis of sentences such as these. 
4.3 Some Remaining Examples of Logically Defined Presupposition: Keenan Keenan (1971) provides a laxge range of examples which are said to demonstrate the reality of the relation of logical presupposition in natural language, but all his examples can I think be handled as entailments, in a way similar to the examples of Fillmore and the Kiparskys. Keenan himself would not consider this counter-evidence since, unlike Strawson, he explicitly claims that presupposition is a type of entailment. However, so far we have had reason to suggest that presupposition as linguists : use it is non-distinct from entailment. The defining criterion of presupposition is that the truth of $\mathrm{S}_{2}$ follows from the falsity (negation) of $s_{1}$ as well as from the truth of $s_{1}$, His examples include "factive" predicates, "definite" names, "cleft" sentences, selectional restrictions, temporal subordinate clauses, nonrestrictive relatives, certain aspectuals, iteratives and presuppositional quantifiers' $(p .46 f) .17$ Factives I have already dealt with; definite noun phrases I shall consider in some detail in chapter 5, when I shall turn to some problems in Strawson's analysis; selectional restrictions I argued in chapter 1 must be formulated as mere components of the lexical items in question and not as a separate entity (cf. p. 15ff) - thus anticipating the discussion here. The remaining constructions are exemplified in(57)-(62).

(57) It was John who was sick

(58) John left before Margaret came

(59) Fred ate another helping

(60) John stopped working
(Presupposition: Someone was sick) (Presupposition: Margaret came) (Presupposition: Fred ate at least one helping )

(Presupposition: John was working ${ }^{18}$

17. I shall not discuss quantifiers such as any, every, many, some, either here or in chapter 5 , since the interpretations of quantified, plural and generic noun phrases provide too many additional problems to be able to incorporate them in this thesis. For some indication of the general treatment of noun phrases cf. p. $174 \mathrm{f}$.

18. These are among the examples which Karttunen (1973) shows to be problematical. 
(61) Only Fred shot himself

(Presupposition: Fred shot himself)

(62) John, who saw Bill, burst out laughing (Presupposition: John saw Bill)

These involve various problems. Some of them do not have straight-

forward negations for syntactic or semantic reasons, and are thus not

amenable to the negation test (e.g. nonrestrictive relatives, adverbial

constructions and only constructions). But it is not clear that even in

these cases the falsity of the presupposing sentence necessarily implies

the truth of the presupposed one. Consider the following examples,

contextualising denials of the truth of the above examples:

(63) It is false to say that the King, who opened the exhibition in:

January, was assassinated in February, since

the exhibition wasn't opened until March

(64) It is false to say that it was John who caught the thief since the thief got away

(65) It is false to say that John left before Margaret came, because Margaret never came 19

(66) John has not stopped working. How can he have w he hasn't even started.

(67) Fred didn't eat another helping - he even refused the first one.

(68) It is false to say that only Fred shot himself because he was the only one that did not

Furthermore, almost all these cases allow an interpretation when embedded below a verb such as pretend in which the presupposition fails to hold: 20

(69) Bill pretended that it was John who was sick though he realised that none of them were

(70) Bill pretended that he had eaten one flower. Then he pretended that he had eaten another flower. Then he pretended to stop eating.

19. In some dialects of English this relation is not entailment either. An announcement on the news, 1.8.72, was that 'They defused the bomb before it exploded'

20. The two exceptions are (58) and (62). The sentence adverbial and the non-restrictive relative clause cannot be interpreted as falling within the scope of pretend for independent reasons. 
(71) Bill pretended that only Fred shot himself when in fact it was Bob and not Fred that did.

As we saw in the case of the factive verbs, this interpretation is predicted by an entailment analysis but not by a presuppositional one. This predicts, against the evidence, that the purported presupposition of the constructions in question must be implied to be true when, as here, the presupposing statement is implied to be false.

Moreover these purported cases of presupposition meet momalies similar to those demonstrated by the factive predicates in conjoined sentences (either by and, or, or if-then). In none of the following cases conjoined by and is the purported presupposition of the subordinate sentence presupposed by the example as a whole: if the apparently presupposed sentence is false then the entire sentence is presumably false, not truth-valueless and 'odd' as presupposition failuce is supposed to guarantee.

(72) Somebody killed John and it was Bill that did

(73) Someone was sick and it was John that was

(74) John ate one helping and then he ate another helping

(75) John was working and then he stopped working

(76) Margaret came and John left before Mary came

(77) Fred and only Fred shot himself

A.1. these examples of Keenan, therefore seem - like the factives more naturally explicable as relations of entailment, an analysis which makes exactly correct predictions.

The case for which this seems perhaps the least plausible is nonrestrictive relatives (cf. my prefixed question-mark to e.g. (63)). But there is independent evidence for not andysing these clauses as presupposed. Consider examples (78)-(80). 
(78) The King, who opened Parliament on January 10th, was assassinated in Trebruary

(79) The King, who was assassinated in February, opened Parliament on January loth

(80) The King opened Parliament on Jamuary 10th, and he was assassinated in February

If non-restrictive relative clauses are analysed as presuppositional, these three sentences will not be synonymous since they will have different truth conditions. Yet in terms of propositional content, these seem identical. It would surely be counter-intuitive to say that in a state of affairs in which the King was assassinated in February but Parliament wasn't opened until March, one would be bound to analyse utterances of (78) and (79) differently, assigning the value 'Neither true nor false' to (78) and the value 'False' to (79). The relation between the statements (78)-(80) and the state of affairs in question is surely the same - viz. a mis-match of exactly the same order. Thus if one is false, as indeed both (79) and (80) are, then (78) must be false too. I therefore see no reason for analysing (78) and (79) as non-synonymous. 21

In general then, though Keenan's examples are somewhat more intractable and border-line than the Kiparskys' or Fillmore's, we have not yet come across any strong evidence that semantics of natural language should be based on a three-valued logic incorporating presupposition. In chapter 5, I shall consider further reasons why such a logic should NOT be taken as the corner stone of semantics.

21. To analyse non-restrictive relative clauses in terms of presupposition is in any case counter to the Fregean analysis (cf. p.73 of each and Black (eds)). 
4.4 A Pragmatic Concept of Presupposition: Robin and George Lakoff Each of the arguments I have considered so far in this chapter has been formulated within a framework compatible with a componentbased semantic a nalysis. Fach has therefore been compatible with, or nondistinct from, a theory of meaning based on a definition of truth. A11 I have been presenting evidence gainst is the need to relate such a theory of meaning to a three-valued logic (rather than the traditional two-valued logic). However, presupposition has been discussed by the Lakoffs in terms of speaker-hearer relations which are neither terminologically equivalent to nor even compatible with the framework that is proposed in this thesis. In her article on conjunction (1971), Robin Lakoff makes two claims:

(a) that there is evidence of a constraint on co-ordination which can only be explained in terms of presuppositions on the part of the speaker and deductions that he might make upon those presuppositions. Hence the concepts of speaker-presupposition and deduction must be included in the grammar;

(b) that there is evidence that not only has and two uses which differ in their presuppositions, but also that all co-ordinate conjunctions have two such uses.

If (a) is correct, a semantic theory based exclusively on truth conditions must be inadequate because it will. be unable to capture such a constraint. In arguing for (b) she claims that but differs in meaning from and by virtue of additional presuppositions, and that or has solely an exclusive meaning: both claims conflict with a truthcondition based: analysis.

Her argument is based on the premise that My grandmother wrote me a letter yesterday and six men can fit in the back seat of a Ford is 
very odd and should be excluded by the grammar. In order to explain this apparent constraint, she suggests the following solution. If two sentences are to be conjoined, they must share a common relevance or topic. This may be self-evident (and lexically definable) as in John is a bore and Harry's not very interesting but may not be, as in John wants to make Peking Duck and I know that the $A$ and $P$ is having a sale on hoisin sauce. In this lattex type of case, she argues one may need to know 'presuppositions' with respect to either conjunct in order to deduce a common topic: in this case that hoisin sauce is the accompaniment to Peking Duck, that a sale is a good time to buy things, and that now would therefore be a good time to make Peking Duck 'making Peking Duck' thus being the common topic. Biy this means, she claims, one can assess the relative grammaticality of a sentence. The harder and more culturally specific the presuppositions, the more likely a speaker is to reject it. Hence the assumed relative acceptability of each of the following groups:

(81a) John eats apples and his brother drives a Ford

(81b) 3John eats apples and many New Yorkers drive Fords

(8Ic) 3John eats apples and I know many people who never see a doctor

(82a) The police came in and everyone swallowed their cigarettes

(82b) ?The police came in and everyone started eating their applesauce

(83a) John has a yacht but Bill has a large mortgage to pay off on his house (83b) ?John has a house but Bill has a sore toe

(84a) John is a Republican but you can trust Bill

(84b) *John is a Republican but Bill will take out the rubbish for you For example, (8la) involves the presupposition that one's brother has something to do with one, whereas $(81 \mathrm{~b})$ demands a less obvious presupposition that John is a New Yorker; and in order to judge (81c) grammatical, she claims that one needs to presuppose knowledge of the proverb 'An apple a day keeps the doctor away, enabiting the deduction of a common topic along the following lines: 
The proverb means that if you eat apples you will be healthy and you will not need to visit doctors

People who never see doctors are people who are healthy

Common topic : being healthy

Hach of the pairs (82)-(84) is analysed in a similar way, involving presuppositions about drugs in (82a), about what constitutes riches in (83a), about the moral standard of Republicans in (84a). (82b), $(83 b)$ and $(84 b)$ are all said to be odd because they lack any such common topic. In each case, the meaning of the conjuncts, their common topic, and hence the assessment of grammaticality are dependent on what information the sentence is intended to convey. Since this involves the presuppositions of a given sentence, the presuppositions must be part of its underlying semantic representation.

She then gives a descriptive account of and, but and or in these terms (of. ibid p.1.26-149), and she claims that the symmetric, reversible and differs from the asymmetric, non-reversible and of temporal sequence in that in the latter, the first conjunct is presupposed. Analogous claims are made for but and or. This descriptive analysis can be criticised quite independently of her theoretical. assumptions. For example, the claim that the and of temporal sequence and the reversible and differ with respect to presuppositions is simply false. Her examples are (37) What a night we had last night: the fuzz came in during the party, and the cat kept dropping the kittens into the punch bowl, and Mary screamed when Bill tried to abduct her, and the strobe light never did arrive, and (38) Well, the story is as follows: the police came in, and everyone swallowed their cigarettes, and Bill choked on his, and they had to take him to the hospital, and his mother just about went frantic when she heard, and I had to placate her by lending her my copy of Portnoy's Complaint. She claims that if 
the first (or any non-final) conjunct in (38) is denied 'the result is bizarre, and renders the whole discourse somehow nonsensical, the usual result of denying a presupposition' (p.128). But compare the following as responses to (38):

(85a) No, that's not true: the police didn't come in. Mary suggested we try a new way of taking pot, and everyone swallowed their cigarettes. Otherwise the story's correct.

(85b) No, that's not true: Bill didn't choke on his cigarette - he wasn't even smoking. He'd swallowed a fly just as the police came in, and they had to take him to the hospital. Otherwise the story's correct.

(85c) No, that's not true: Bill's mother wasn't frantic. She was amused and sajd it sounded like an Ed McBain novel.

Thus the entire statement is false if any one conjunct is false, as the truth-functional definition of and predicts. The interpretation of and as having temporal sequence therefore does not rest on the notion of presupposition, given any standard definition of that term. Moreover it is not clear that sequence of time is part of the meaning W. $\rightarrow$ of and at all, since the same implication occurs when there is no and: ${ }^{22}$ (86a) The Lone Ranger mounted his horse and rode off into the sunset (86b) *The Lone Ranger rode off into the sunset and mounted his horse. (87a) The Lone Ranger mounted his horse. He rode off into the sunset. (87b) *The Lone Ranger rode off into the sunset. He mounted his horse. So however the implication is achieved, it is not due to the presence of a particular sense of and, unless a full stop is also given a semantic characterisation of this kind! It seems therefore that the interpretation of time sequence between sentences, whether conjoined or not, is a property of discourse interpretation and not a semantic property of the conjunction itself. 23

22. This observation is due to Deirdre Wilson. 23. Cf. Ch. 8 section 8.7 for a pragmatic characterisation of this implication. 
Robin Lakoff analyses but as eithex presupposing between the conjuncts some contrast which can be lexically specified ('semantic opposition but') or as presupposing an expectation on the paxt of the speaker of the opposite of the second conjunct ('contrary-toexpectation but') (p.133). Her examples are (57) John is tall but Bill is short and (60) John hates icecream, but so do I. There are several problems here. She herself discusses counter-examples which necessitate envisaging at least two additional meanings for but (p.136142). In general though; for those cases where there is no lexical opposition, she sets up this second 'contrary-tomexpectation' sense of but. So she analyses (60) as having the interpretation 'one would not expect that I would hate icecream'. But paxallel examples need not have this interpretation: consider the utterance of John wants an icecream, but so do I in a situation where there is not enough money to buy us both icecreams, so neither of us can have one. It is (a) not obvious how her analysis of but can handle this case, and (b) how it would predict that these two examples apparently involve a different sense of but. More generally, if there is a semantic component of contrastiveness in but then this should automatically enable one to predict a set of environments in which but may not occur, by virtue of there being no requisite contrast (analogous to what man is pregnant where the environment does not meet the condition specified by pregnant). The above examples should be prima facie cases; but they are not. And to retreat to a different but merely makes the original claim untestable. Moreover this account of but should in addition predict that examples such as John is rich but John is poor are grammatical because they meet the requisite condition 
of contrastiveness. There is no obvious way to block these sentences, as Robin Lakoff herself points out ( $\left.p .134 f^{\circ}\right)$. It thus seems doubtful whether a semantic analysis can predict any contrast in meaning between but and and. (Their synonymy is of course what is predicted by a truth-functional analysis.) $)^{24}$

Her claim that natural language or has solely an exclusive interpretation is also false. In analysing or, she sets up two uses of exclusive or one of which is asymmetric, e.g. Either jittle Seymour eats his dinner or his mother complains to the neighbours. This she states makes no implication that if Seymour eats his dinner his mother will not still complain; i.e. both conjuncts can be true - by definition, inclusive or. So much for its non-existence in natural. language. 25

More important than any of these points of description, is an assessment of her claim that 'two sentences may be conjoined if one is relevant to the other, or if they share a common topic', where the deduction of a common topic may depend on presuppositions on the part of the speaker. 26 I think this argument can be shown to be false, on two accounts: first, on the grounds that every sentence she cites as ungrammatical, odd or unacceptable (the terms are used interchangeably) can be contextualised as a perfectly appropriate utterance (and she

24. Cf. ch. 8 p.253f for a pragmatic account of but and ch. 9 for a discussion of the problem this account raises for the delimitation of the over-all linguistic theory.

25. For an argument supporting the opposite claim, that EXCLUSIVE or does not constitute a separate use of or, cf. Barrett and Stenner (I971).

26. This claim is marred by an unpardonable equivocation over the concept of grammaticality. Throughout the article, she consistently uses the terms grammatical, ungrammatical and grammaticality to refer to semantic judgments on sentences (pp. 116, 125, 127, 128, 130, 139, 142). However in the first footnote she states 'Let us try to reserve the term ungrammatical (as I may not consistently do in this paper) for anomalies that arise out of violations of syntactic rules alone: John and Bill is here'. This might as well read as an instruction 'Please ignore everything I say'. To give her the benefit of the doubt, I shall assume that the footnote is a sop to critics of her position, and I shall henceforth ignore this caveat. 
would surely agree that the grammar must predict every possible sentence of the language and not merely the more likely ones); and secondly, on the grounds that her position demands that meanings of sentences are unpredictable independent of the actual speech act and hence the grammax itself is non-predictive (essentially equivalent to Bloomfield's conclusions about semantics - cf. Bloomfield 1933 p.139f.). It is a straightforward matter to disagree with every example brought forward. Consider the following:

(88) We've been wondering how many people can get into the back seat of a Ford and my grandmother decided to try the experiment. She tried it two days ago and she wrote me a letter yesterday and six men can fit in the back seat of a Ford.

(89) I'm going to tell you two very peculiar facts. Some people eat thistles and yesterday Mary killed a python with a stone. In the second contextualisation any conjoined sentence is acceptable, given that the conjuncts themselves are not in some way anomalous or mutually contradictory. But if all sentences can be construed to have some sort of link, or common topic, then the inclusion of this concept in the grammar to determine grammaticality constraints is vacuous. More interesting are the consequences of her position. She herself points out one of them - namely that sentences which under all traditional analyses of ambiguity would be unambiguous may have different presuppositions, reflected in different semantic representations, and are therefore by definition ambiguous. This new type of ambiguity she calls 'contextual' (p.l2l). It arises because if presupposition is defined as broadly as she allows, no sentence will have a unique set of presuppositions. She suggests that ambiguity of this type only arises in border-line cases: the worse the sentence is, the more interpretations people will strain to produce (p.I2lf.). The example she demonstrates this with is John wants to make Pelsing Duck and I know 
that the $A$ and $P$ is having a sale on hoisin sauce, which can be interpreted with more than one set of presuppositions leading to different common topics. But this possibility is not restricted to the border-line cases. It is merely that if there is a common interpretation, people will not naturally seek an uncommon one. For example, she suggests that a possible common topic of a sentence like John owns a yacht and Bill has a lovely house in Knightsbridge is derived from the presuppositions that owning a yacht is an example of 'conspicuous consumption' and so is owning a lovely house in Knightsbridge. But in a situation where both speaker and hearer are very rich, the speaker might well not have these presuppositions and might continue 'but since most of our friends either have oceangoing vessels or live abroad, I think they won't fit in', where the earlier presuppositions are in fact implicitly contradicted, and the common topic is the insufficient wealth of John and Bill. In her terms, this sentence would therefore need two different semantic representations to reflect this. But do we want to say that by virtue of its use in two different situations the sentence has two different meanings? In any case, to own a lovely house in Knightsbridge is not a necessary sign of 'conspicuous consumption' a it might be very small; or suppose fashion changed, and Knightsbridge became a slum area. Would we want to say that the meaning of Bill has a lovely house in Knightsbridge is different in each of these cases? It is clear that in principle every sentence can be analysed with at least as many different sets of presuppositions as here, and if furthermore the sentence were used with an illocutionary force other than that of statement, e.g. promise, boast, etc., the sets of presuppositions fast become indeterminate. 
This is not the only problem. In characterising presupposition as part of the underlying semantic representation, if presuppositions are not stated as part of the meaning of lexical items, one must give up the standard claim that the meaning of a sentence is a function of the meaning of its constituent parts. Though she is not explicit on this point, it would seem that she is relinquishing this claim, since presuppositions are not claimed to be a property of the lexical item. But if the interpretation of presuppositions is not related to the lexical items, how are they to be derived? They are presumably part of the beliefs of the speaker, or derive from his knowledge about the situation. But if this is so, the meanings of sentences cannot be determined independent of the speaker of a sentence in a particular speechmact situation. 27 We are thus faced with an analysis of meaning which claims that every sentence has an indeterminate number of indeterminable meaning representations. And if the meanings of sentences are indeterminable, then meaning-relations between sentences such as implication, contradiction, by definition cannot be predicted. Moreover, in her terms, it follows that the grammaticality of sentences cannot be determined either, independent of the situation in which they are uttered, But this has the immediate consequence that one's grammar is not predictive. We are thus faced with the conclusion that a theory which incorporates a speaker-relative concept of presupposition as part of its semantic representation is in principle unable to fulfil any of the four conditions ${ }^{28} \mathrm{I}$ set up initially (cf p.8f)

27. Similar consequences follow from describing the requisite presupposition as a property of the lexical item in question: cf. e.g. (84b) and the necessary specification of Republican.

28. Namely (a) the ability to predict sentence meaning (b) the ability to predict the set of grammalrical sentences and (c) the ability to predict entailments etc by (d) a finite set of rules. 
as a premrequisite for any semantic theory. This impasse stems from defining presupposition in terms of assumptions on the part of the speaker. If presupposition is to be a useable term in semantics, it seems clear that it cannot be defined in these terms.

George Lakoff's article in the same volume (1971c) as the Robin Lakoff article I have just discussed argues along similar lines. His arguments concern the interaction of but, either, too, and contrastive stress placement, with presuppositions and deductions on those presuppositions. For example he analyses too (along the lines of Georgia Green, 1968) as having two uses (cf. p.64f.), one where there is an explicit point of similarity between the two conjuncts, another where some point of similarity is presupposed of deduced (analogous to Robin Lakoff's analysis of all conjunctions): e.g. John's honest and Bill's honest too, The mayor's a Republican and the used-car dealer is honest too. Thus in the second example, one must either presuppose that all Republicans are honest or that the mayor is the used-car dealer. Given these presuppositions, simple rules of inference allow identity of either predicate or subject to be deduced, as Lakoff demonstrates. In a comparable way, reciprocal contrastive stress can be predicted in conjoined sentences under two conditions: (a) where the conjuncts are identical except for a subject-object switch, and (b) where there are presuppositions from which such an identity can be deduced by formal rules of inference: e.g. JOHN insulted MARY and then SHE insulted HIM, JOHN called MARY a virgin, and then SHE insulted HIM. 29 This latter example is therefore only grammatical relative to the presupposition that to call someone a virgin is to insult them. So, like Robin Lakoff in the case with but, Lakoff draws the conclusion 29. Cf. Ch.8 p.279f for a pragmatic explanation of these examples. 
that the interpretation and hence the grammaticality of the sentences depends on presuppositions about the sentence, and deductions following from those presuppositions, which are not part of the meaning of the lexical items in the sentence. His argument is thus open to the same criticisms as his wife's, and seems to be heading for a theoretical contradiction. In order to explain the distribution of the elements in language, one is forced to set up a non-predictive theory.

He attempts to avoid this contradiction by arguing (1971b) that the task of the grammar is to generate sentence and presupposition pairs: the judgment of whether or not a sentence is grammatical is thus he claims not context or speaker relative but merely relative to a particulax presupposition which is, like the sentence itself, a construct of the competence model. But this attempt to avoid the consequence of non-predictability is not successful. Consider the power of such a grammar in connection with Robin Lalsoff's data. It has to generate pairs, or n-tuples, such as:

John wants to make Peking Duck and $I$ know that the $A$ and $P$ is having a sale on hoisin sauce

Pelking Duck is an item of Chinese cookery Hoisin sauce is used for cooking Peking Duck from which the common topic of 'cooking Peking Duck' can by some extra mechanism be deduced. Yet it must not generate as a well-formed pair the above sentence and the presupposition 'Hoisin sauce is used to kill fleas which collect in ducks' feathers' (unless of course there are additional presuppositions such as 'Ducks become edible when fleas are removed from their feathers'). As it stands, this sentence-presupposition pair is not grammatical: speakers know that kj.lling fleas on ducks has nothing to do with cooking. But the 
semantic specification of both the sentence and the presupposition contains the word duck and therefore there seems no way of preventing the deductive mechanism from predicting that this sentence-presupposition pair is grammatical. The problem is not restricted to this particular sentence-presupposition complex. Consider (90) and (91). (90) S: Pope John is dying and the cat's in the bath

Pr: I have a brother who is a schitzophrenic Catholic and whenever he hears a Catholic is sick he puts the cat in the bath

(91) S: Pope John is dying and the cat's in the bath Pr: I have a schitzophrenic brother who puts the cat in the bath when he has a turn

In the case of (90), a relatively simple deduction process allows us to predict a common topic between the conjuncts of the sentence since from both conjuncts one can deduce, via the presupposition, that a Catholic is sick. But it is equally possible to deduce a common topic in (91) via its presupposition where the predicted existence of a common topic does not match our intuitions; for the first conjunct entails that someone is sick and from the second conjunct, via the presupposition, we can deduce that since John is sick, someone is sick. Thus the mechanism is forced to predict a common topic and hence the grammaticality of (91). The point is this: if the mechanism has sufficient power to predict the required sentence-presupposition pairs, it will have absolute and unconstrainable power. It is thus not a valid means of avoiding the charge of unpredictability. The problem thus remains: speaker-relative presuppositions cannot be incorporated into the linguistic model without giving up all of the foux essential premrequisities on one's formal model (cf. fn.28 of this chapter). 


\subsection{Summary}

What sort of conclusion can be drawn from this medley of negative criticisms? First, I have argued that none of Fillmore's, Kiparskys' or Keenan's examples provide counter-examples to an entailment analysis, since among other reasons in each case the purported presupposition can be interpreted as denied when the presupposing sentence is denied, a possibility excluded by a presupposition analysis. Secondly, I argued that speaker-relative concepts cannot be included in a predictive semantic theory because if they are, then the semantics automatically loses its predictive power. I therefore concluded that speakerrelative concepts must be excluded by fiat. On the one hand, I have rejected every linguistic account of logical presupposition as confusing presupposition and entailment: on the other hand, I have legislated against speaker-presuppositions. The concepts of presupposition thus seem to be being squeezed out of theoretical existence. So, on present evidence, the framework outlined in chapters $I$ and 2 does not appear to require revision.

Three main forms of rejoinder could however be made. First, I have still not touched on the problem of reference, for which presupposition was first introduced. Thus a semantic theory has still to predict a presuppositional relation in order to explain the nature of the relation between a definite noun phrase and its referent. Secondly, in analysing the Fillmore-Keenan-Kiparsky examples as entailment, I have excluded the possibility of capturing what constitutes a 'natural interpretation', a concept which is captured by their use of presupposition. Each of the cases I constructed as a falsifier to a presupposition-based 
analysis constituted a 'less likely' interpretation as opposed to the 'most likely' interpretation. Thus for example I didn't regret going to the party because I didn't go is clearly not the 'natural' interpretation of I didn't regret going to the party.

These two complaints can however be met on the first trivially, since I shall consider Strawson's analysis of presupposition in the following chapter. Less trivially, I think arguments along the lines of earlier sections of this chapter can be extended to the whole concept of presupposition. The second complaint claims in effect that an analysis in terms of entailment could not be correct since it does not distinguish between more and less likely interpretations. Presupposition on the other hand can be used to distinguish between these two. 30 However this is to misuse the term presupposition. The definition of presupposition is in terms of necessary implication, and it is clear I think that the falsity of the apparently presupposing sentence does not of necessity guarantee the truth of the presupposed sentences, in all the cases we have considered. Furthermore, one of the aims of a semantic theory outlined initially was to predict all possible interpretations of every well-formed sentence of the language. Thus a semantic theory is not only committed to predicting the obvious interpretations of sentences but all possible interpretations. Analogously, it is now standard to reject a syntax which only describes the obvious sentences of any language on the grounds that it would not only be a very uninteresting one but it would also not capture the necessary generalisations. It is however arguable that a complete account of natural languages should contain some form of prediction as to what constitutes a natural interpretation; but I shall argue in chapters 7-9

30. Notice how Keenan (1972) in discussing presupposition is careful to refer to 'natural denial' (p.49). 
that this is naturally explained with the domain of a theory of communication (pragmaties) as part of an over-all theory of performance. The explanation of why a sentence such as I didn't regret going to the party because I didn't go is extremely unlikely ever. to occur will thus be comparable in status to the explanation of the impossibility of I met the man the girl the boy the dog bit seduced kissed.

There is one final over-all criticism which should be made. My analysis dismissed somewhat off-handedly contrastiveness of but, temporal sequence and and, and the concept of common topic, yet each of these clearly contributes to the interpretation of sentences in some sense. Moreover, I offered no explanation whatever of Lakoff's examples of stress asignment. What these examples have in common is that none of them can be explained in terms of conditions for the truth of sentences. Furthermore, there is the more general problem of contrastive stress, 31 which I argued explicitly in chapter 3 (p.86) could not be accounted for by a logical definition of presupposition because it could not be explained in terms of truth conditions. This group of examples together seem to constitute the falsifying counter-examples to my claim that meaning for natural languages can be explained in terms of truth conditions. However, the exclusion of most of these examples from semantic theory can be justified ( $\mathrm{c} f$. the reasons given in analysing but (p.117) and and (p. 116 ). There is one yet more serious counter-example. At least one lexical item has a meaning which cannot be explained at all in terms of truth conditions: even.

31. The phenomenon of contrastive stress is a well-known one, and has been discussed in some detail recently by Chomsky 1971. Cf. ch. I section 1.3.4.1 and ch.8 section 8.61 for a discussion and re-analysis of Chomsky's data. 
Even, like many other items, has been analysed in terms of presupposition. 32 It has been sajd for example that in saying Even Max tried on the pants a speaker asserts that Max tried on the pants and presupposes (a) that other people tried on the pants and (b) that it is surprising that Max tried on the pantis. However Fraser (1971) points out that presupposition is not the right relation to describe the properties of even. In particular the implication that 'other people tried on the prints', though a semantic property of the sentence in question, is not a presupposition and nor is it an entailment. For as Frasex points out 'there is certainly something very strange about (2) (Even Max tried on the pants - RMK) if Max turned out to be the only one to try on the pants, but I think we can still assert that (2) is either true or false depending on the empirical evidence' (p.153). He suggests that the implication that ather peopletried or the parts is rather an implication as defined by Austin (cf. Austin 1962 p.48). Similarly for the implication of surprise (cf. p. 154). But this is the relation which holds between my saying Max tried on the pants and my believing that Max tried on the pants, which is generally agreed to be pragmatic and not a semantic relation. Even therefore constitutes a clear counter-example to the claim that the contribution lexical items make to the meaning of sentences can be defined in terms of truth conditions. It is no coincidence that the exceptions I have listed here have at some stage been labelled as involving presupposition, since they are 32. Cf. Horn 1969 and Fraser 1971. 
all naturally explicable in terms of what a speaker presupposes (or assumes) as opposed to what he asserts. I do not however believe, despite the evidence which these counter-examples present, that the theory of truth conditions has thereby been shown to be false and should be replaced by a non-predictive speaker-oriented semantics. On the contrary, I hope to show in chapter. 8 that these apparent counter-examples are not falsifying examples, and that the generalisations captured within the framework put forward here can and must - be maintained. As with the concept of 'natural interpretation' I shall explain these apparent counter-examples within the framework of a theory of pragmatics - viz. a theory which seeks to characterise how speakers use the sentences of a language to effect successful communication. 
CHAPTER 5 : The Problem of Reference and The Semantic Interpretation of Noun Phrases

In chapter 4 I argued that despite certain counter-examples which remained to be explained, there was strong evidence to suggest that presupposition had not only been misused by linguists but appeared to be nondistinct from entailment in all the examples I considered. Before taking into account the exceptions to my hypothesis that have already accumulated, I wish to consider what evidence there is either for or against strawson's analysis of definite noun phrases. 1 I shall therefore consider in more detail the problem of definite noun phrases for which Strawson (and Frege before him) set up the logical relation of presupposition. In brief, I shall argue that the same type of evidence which was used in the previous chapter to demonstrate the entailment basis of certain semantic relations is available also in the case of definite noun phrases, and that they too stand in an entailment relation to their referent. In consequence, the separate logical relation of presupposition does not exist. In addition there is independent evidence concerning the truth-functional definition of the logical connectives which leads to the same conclusion. In this chapter I shall therefore be arguing that the framework set up in chapters $1-2$ can in principle predict the reference properties of definite noun phrases without the addition of some reflex of a presuppositional relation. Turthermore, we shall see in the light of this analysis that there is evidence to suggest that definite and indefinite (specific) noun phrases should be identical in their semantic representation.

1. Initially I shall assume that definite noun phrases constitute a homogeneous set, as philosophers have done. But cf. $p_{.152} \mathrm{ff}$. 
5.1. The Referring Properties of Definite Noun Phrases:

Entailment or Presupposition?

First let us recapitulate the main differences between Russell's analysis and that of Strawson. Russell (1905) claimed that sentences such as The King of France is wise should not be analysed in a simple subject-predicate form but as the conjunction of:

There is a King of France

There is not more than one King of France

There is nothing which is the King of France and not wise Since every conjunction of the form $\underline{P} . Q$ entails $\underline{P}$ (and $\underline{Q}$ ), it follows that The King of France is wise entails There is a King of France. Thus when There is a King of France is false and there is no such man, then The King of France is wise is also false. Strawson however sets up a new logical relation of presupposition to handle this relation. He argues that it is only false to say that the King of France is wise, if he is not wise. If there is no such man, then it is neither true nor false to say that he is wise. Conversely The King of France is not wise is only true if there is such a man. If there isn't, then - like its positive congener - it is neither true nor false.

Thus these examples constitute the prima facie cases for the negation test discussed in chapter 4 . That is, in both the positive and negative forms, The King of France is wise and The King of France Is not wise, the implication of the existence of the King of France is held constant. Or so it appears. On this account it should therefore be contradictory to negate a sentence containing a definite phrase and to simultaneously imply that the existential sentence corresponding to the implication of reference on the noun phrase is 
false. But consider the following:

(1) The moon wasn't hidden by the clouds because there weren't any

(2) A: Did the neighbours break the window?

B: No, it wasn't the fault of the neighbours - we haven't got any neighbours.

(3) The exhibition was not visited by the King of France - France hasn't got a King

(4) Jones has not spent the morning at the local swimming pool - there isn't a swimming pool in this town

(5) Neither Aristotelian nor Russellian rules give the exact logic of any expression of ordinary language; for ordinary language has no exact logic. ${ }^{2}$

Examples (1)-(4) are modified examples from Strawson 1964a, and he points out ( $p .112)$ that 'it may seem natural enough to say that it is quite untrue, or is falise that Jones spent the morning at the local swimming-pool, since there isn't one; that, however Jones spent the morning, he did not spend it at the local swimming-pool, since there's no such place.' The linguistic corollary to this statement is that these examples demonstrate how, among the possible interpretations of negative sentences, there IS one in which the reference properties of a noun phrase fall within the scope of negation. These thus constitute countermexamples to an analysis of reference in terms of presupposition. Notice moreover that they are not counter-examples to an entailmentbased analysis of reference, since the difference between presupposition and entailment is that in the case of entailment but not presupposition, the falsity of the entailing sentence allows the entailed sentence to be either true or false (cf. ch. 3 Table I line 3 p.84).

2. This is the concluding sentence of 'On Referring': Its existence as a counter-example to the analysis presented in that article is pointed out by Bar-Hillel (1954). 
What examples (1) ow (5) have in common is that the definite noun phrase in question is not in subject position; and, as Strawson points out (1954 p.226), it is much less natural to interpret the implication of existence on a noun phrase as falling within the scope of the denial if that noun phrase is in subject position. However, I think it is fairly cleax that counterparts to examples (1)-(4) in which the relevant noun phrase is in subject position can be interpreted as having their existence denied. (Such an interpretation will noxmally demand contrastive stress.)

(6) The CLOUDS weren't hiding the moon - there weren't any clouds (7) No, the NEIGIBOURS didn't break it - we haven't got any neighbours (8) The King of FRANCE didn't visit the exhibition - France hasn't got a king

(9) The swimming pool at BLY wasn't closed - there isn't a swimming pool there

Compare also:

(10) My HUSBAND didn't come to meet me - I'm not maxried. Now clearly, as before, these examples provide 'unnatural' interpretations of negative sentence. However I would argue again (cf. p.126) that negative sentences have a semantic representation which allows a disjunct. set of interpretations and that the initial aim of the semantic model must be to predict what the logical limits to the possible number of interpretations are before it can characterise which is more or less likely. These examples therefore suggest that the implication of reference of definite noun phrases may fall within the scope of negation though clearly it need not. This being so, the relationship of reference would seem to be an entailment relation and not one of presupposition. 
This analysis is supported by further examples of Strawson's (1964a) where he points out that if the predicate of the sentence is explicitly stated to be the topic of conversation, then it becomes more natural to deny the truth of the statement by virtue of the nonexistence of the subject:

(11) A: What outstanding events have occurred recently in the social and political fields?

B: The King of France married again.

A: No, that's not true - there isn't such a person.

(12) A: What examples if any are there of famous contemporary figures who are bald?

B: The King of France is bald.

A: No, that's not true. There's no such man.

Thus in the context where being bald is the topic, it is quite natural. to deny the truth of The King of France is bald on the grounds that he does not exist.

Each of these examples provides evidence against an analysis in terms of presupposition. It is thus incumbent on someone wishing to maintain this position to explain away these examples. Strawson attempts to defend his position by analysing the concept of truth and truth-assignment in terms of 'topic', where the 'topic' of a statement is what the statement is about. What he claims is that 'assessments of statements as true or untrue are commonly, though not only, topic-centred in the same way as the statements assessed; and when, as commonly, this is so, we may say that the statement is assessed as putative information about its topic.' (p.116). Thus he claims that since in the case of for example (3) the exhibition is the established topic then it can be the case that it is false 
to say of the exhibition that it was visited by a non-existent person. But if the King of France is claimed to be the topic, as in The King of France visited the exhibition, and this noun phrase does not have a referent, there is no topic about which to assess the truth-value of the predicate. In this case, it has no truth-value. It follows that a passive form of a sentence may be false while, under the same circumstances, the active form has no truth value at all. Furthermore, the same active sentence may be false in one speech-act situation and truth-valueless in another while the state of affairs to which the sentence refers remains constant. What has been varied is the speaker's choice of topic. Thus The King of France visited the exhibition will lack a truth value if the King of France is the topic and there's no such man, or if the exhibition is the topic and there was no exhibition. If however the King of France is the topic and there is such a man, but there was no exhibition, then the statement will merely be false. Similarly if the exhibition is the topic and the speaker is correct in thinking there was an esthibition but mistaken in thinking there was a King of France.

But such an analysis is untenable. This constitutes a radical change in the conception of truth: it is no longer defined as a relation between an abstract statement (or sentence) and a particular state of affairs but rather in relation to a speaker, a hearer, and a state of affairs. That is, the assignment of truth value is dependent on what information the speaker is intending to convey to the hearer. Notice first that a large body of contradictions will no longer be labelled as such since the conjunction of any sentence containing a definite noun phrase with its negative counterpart will not be 
necessarily false. It may be neither true nor false. 3 Notice secondly that if this definition of truth were correct, the statement of meaning of a sentence as a set of truth conditions would have to be abandoned, since the truth of a sentence under this characterisation would not depend solely on the relation between the constituent parts of the sentence and the objects and relations to which they refer, but also on what information the speaker was intending to convey. It follows from this that sentences, on a truth-condition account of meaning, could not be said to have a particular meaning independent of the context in which they are spoken. The meaning would be dependent on what information was already known beforehand by the speaker and his audience. This consequence follows because, since truth is dependent on the information a speaker is intending to convey, the meaning of an utterance must also be dependent on the speakex's intentions. But if this holds, sentences become indefinitely ambiguous, the limits on a semantic theory are not definable, and semantics thereby becomes an inoperable discipline. Exactly the same consequences follow as follow from the incorporation of speakerpresupposition into semantics.

Moreover the argument seems unavoidably circular. The definition of truth is dependent on a concept of topic. Topic itself is more or less undefined. However, informally, a characterisation of topic will depend on what a speaker assumes to be true, and is thus in some real sense dependent on the notion of presupposition. But presupposition is defined in terms of truth: hence the circle.

3. Cf. Hochberg 1970. 
A definition of truth which avoids this circularity is given by Dummett (1958/59). According to his definition,

'A statement, so long as it is not ambiguous or vague, divides all possible states of affairs into just two classes. For a given state of affairs, either the statement is used in such a way that a man who asserted it but envisaged that state of affairs as a possibility would be held to have spoken misleadingly, or the assertion of the statement would not be taken as expressing the speaker's exclusion of that possiblitity. If a statement of the first kind obtains, the statement is false; if all actual states of affairs are of the second kind, it is true. It is thus prima facie senseless to say of any statement that in suchand-such a state of affairs it would be neither true nor false."

This analysis casts doubt on the premises of a presuppositional logic, the possibility of a truth-valueless statement. If the definition provided by Dummett is in the main correct, as I believe it is, the counter-examples (1)-(12) raised earlier remain unexplained. The philosophical literature on this problem is extensive, and I shall not consider it all. 4 However, further evidence has been provided by Nerlich (1965) that the relation between a sentence containing a uniquely referring noun phrase and the appropriate existential must be one of entailment. It is well-known that entailment is a transitive relation such that for any sentences $s_{1}, s_{2}$ and $s_{3}$, if $s_{1}$ entails $S_{2}$ and $s_{2}$ entails $s_{3}$, then it follows that $s_{1}$ entails $S_{3} \cdot A$ straightforward example is This rose is crimson entails This rose is red. The latter in its turn entails This rose is coloured and hence This rose is crimson entails This rose is coloured. Nerlich points out that by the rule of transitivity The King of France

4. Cf. Geach 1958-9, Caton 1959, Odegard 1963, Roberts, 1969, Cassin 1970a,b, Jacobson 1970, Hochberg 1970, Schnitzex 1971, to name but a few. 
in 1965 is bald must entail There is a King of France in 1965, since the former entails There is a bald King of France in 1965 which itself entails There is a King of France in 1965. To postulate a separate logical relation of presupposition to account for this is therefore a matter of legislation, and the law of transitivity will have to be relinquished. Moreover both he and Iinsky (1967) noticed that if a statement $S_{1}$ is a necessary condition of the truth and falsity of a statement $s_{2}$, then it must by definition be a necessary condition of the truth of $S_{2}$. This in its turn entails that $S_{2}$ is a sufficient condition for the truth of $S_{1}$. But this defines entailment. Hence, whatever presupposition is, it must be an entaxilment. .

In earlier chapters I used two main types of evidence to demonstrate the entailment basis of the postulated presupposition: (i) the interpretation of negative sentences (ii) the interpretation of sentences with pretend and dream as the superordinate verb. This second test provides further indication here of the entailment nature of the implication of reference. In sentences in which the falsity of the embedded sentence is implied, a presupposition analysis should predict that a definite noun phrase in that sentence should be bound to imply the existence of a referent. This prediction is not korne out: (13) John pretended that the King of France seduced his sister (13) can clearly be true even if there is no King of France. Thus it does not necessarily imply the existence of the King of France. A similar phenomenon occurs in sentences with believe and dream as the superordinate verbs. These have no commitment to a specific truth-value - they can be either true or false, whatever the truthvalue of the subordinate sentence.

(14) Bill dreamt the Queen of Germany was dying

(15) Amahl believes that Franklin Roosevelt is the King of America. 
The truth or falsity of each of these sentences is not dependent on any constituent of its complement sentence: so even though these contain proper names or definite noun phrases which in present circumstances have no referent, the entire sentence may be true. For a presuppositional analysis, these examples are embarrassing. If however the referring property of definite noun phrases were analysed as one of entailment, such a situation would follow as an automatic consequence. Because dream and believe have complements which are uncommitted as to truth value, all meaning properties (viz. entailments) may or may not hold. Hence the opaqueness of reference under these conditions. More strongly, pretend as we have seen generally implies the falsity of its complement (unless it is negated). If a sentence containing pretend is true, then since the complement sentence will be implied to be false, it follows from an entailment analysis of reference that implications of existence may or may not be true. The indeterminacy of noun phrases in that environment is the hallmark of entailment.

\subsection{Presupposition and Three-Valued Logic}

Pexhaps the most damaging evidence against a presuppositionbased framework however comes not from arguments as to whether or not opaque and negative sentences containing definite noun phrases possess certain properties, as both cases are complex and controversial, but on the contrary from drawing out the consequences of accepting as a basis for natural-language semantics a logic which contains the three values True, False, and Neither True nor False. We have already seen some of the problems which arise in the definition of truth if a three-valued logic is assumed. Yet it may seem nevertheless that 
in the case of simple sentences the concept of $1-(T \vee F)$ matches the native speaker's intuition about the oddity of saying either "The King of France is bald" or "The King of France is not bald" when there is no such man. Whatever the clearness of this intrition, it does not extend into complex propositions. 5 Take for example any proposition of the form $\underline{P}$.Q. Presumably we would be prepared in principle to agree with Keenan (1972) that if either conjunct is neither true nor false, then the whole claim will be nether true nor false: it is just as odd to make the complex claim (16) The King of France is coming to the exhibition and Mary has got a headache

if there is no such man as it is merely to assext the first conjunct. Thus we might suggest the following three-valued truth-table for $\underline{P . Q}$ :

\begin{tabular}{ll|l}
$\mathrm{P}$ & $\mathrm{Q}$ & $\mathrm{P} \cdot \mathrm{Q}$ \\
\hline $\mathrm{T}$ & $\mathrm{T}$ & $\mathrm{T}$ \\
$\mathrm{T}$ & $\mathrm{F}$ & $\mathrm{F}$ \\
$\mathrm{F}$ & $\mathrm{T}$ & $\mathrm{F}$ \\
$\mathrm{F}$ & $\mathrm{Z}^{6}$ & $\mathrm{Z}$ \\
$\mathrm{Z}$ & $\mathrm{F}$ & $\mathrm{Z}$ \\
$\mathrm{T}$ & $\mathrm{Z}$ & $\mathrm{Z}$ \\
$\mathrm{Z}$ & $\mathrm{T}$ & $\mathrm{Z}$ \\
$\mathrm{Z}$ & $\mathrm{Z}$ & $\mathrm{Z}$
\end{tabular}

However this truth-value assignment does not always match one's intuitions as neatly as it appeared to in (16). Compare (17) and (18) (17) John beats his wife and his children (18) John is married and he beats his wife

5. For a discussion of some of the problems connected with presupposition and the various definitions of and within a three-valued logic, cf. Kartunnen 1973.

6. I am following the notation of Keenan (ibid) in labelling the third value ' $Z$ '. 
(17) is like (16) in matching neatly our intuitions that if a presupposition of one conjunct is false, the entire sentence will be odd. Thus - one might argue - it is odd (not merely false) to say (17) if John has no wife. However in (18), this is not so: if John is not married, then the claim is simply false. Furthermore it is not odd at all to say It is false that John is married and he beats his wife if he is not married: on the contrary it is true. But we cannot allow the truth-functional definition of and to depend on the semantic properties of its parts. Thus we are faced with a contradiction. When one of the conjuncts of $\underline{P . Q}$ is neither true nor false, we appear to need to assign the entire statement sometimes the value neither true nor false, but sometimes the value false.

There is a further problem associated with the definition of and given in the truth table. Suppose I bet example (19). (19) In 1975, the Pope will not give the annual address but it will be the Prefect of the Sacred College of Rites who gives it. What in fact happens is that the Pope dies in 1974 and they do not replace him. So in 1975, the Prefect of the Sacred College of Rites gives the address. Do I win my bet? It seems clear that I do. Yet this intuition cannot be captured in a presuppositional threevalued logic. A presuppositional logic claims that both the positive and negative claims containing a definite noun phrase are vitiated and are neither true nor false if there is no referent corresponding to the definite noun phrase. Thus the claim that the Pope will not give the annual address must turn out to be neither true nor false if there is no Pope. But since $\underline{P \text { but } Q}$ can only be true (like $P, Q$ ) if both conjuncts are true, a presuppositional logic must predict 
that under the circumstances described, I do not win my bet. None of these problems arise if we assume the validity of a two-valued logic. A conjunction of $\underline{P} \cdot Q$ will be false if either conjunct is false and thus (16)-(19) will all be false if one of the definite noun phrases in either conjunct fails to refer. And the fact that I win the bet stated in (19) if it turns out there is no Pope and the Prefect of the Sacred College of Rites delivers the address is naturally predicted. If there is no Pope, then the prediction that the Pope will not give the annual address will turn out to be true. Thus two anomalies which arise in a three-valued Iogic are naturally explained within a framework based on a twovalued logic.

Anomalies of this kind arise with each logical connective. Consider a three-valued truth table for $\mathrm{P}$ or $\mathrm{Q}$. What happens when one conjunct is true and the other conjunct neither true nor false: is the entire proposition, true, or neither true nox false? Some cases suggest one assignment, some the other. If we maintain the intuition that a third value is used to enable us to capture what a speaker assumes in uttering sentences, then presumably of (20) we would wish to say that There is a mayor of Iondon is presupposed - it would certainly be assumed to be true by anyone who spoke it under all normal conditions: (20) Wither the Mayor of Iondon visited the exhibition or the organiser was very upset

Along these lines then, we would want to say that if there was no mayor of London then the entire proposition made by (20) is neither true nor false. In contrast to (20) consider (21). 
(21) Either there wasn't a mayor of London or the Mayor of London visited the exhibition

If in this case the first conjunct is true, then it seems clear that the whole claim is true, despite the fact that the second conjunct is necessarily neither true nor false. Again we are facing a contradiction. Either we have to depart from the intuition for which presuppositions were set up in the first place by defining or in such a way that $\underline{P V Q}$ wi.l. be true just in case either conjunct is true (ignoring the assumptions speakers make in uttering sentences) ${ }^{7}$ or we have to allow more than one definition of or (quite apart from the problem of exclusive or).

Moreover, es with and, we face problems with bets. Suppose John bets (22),

(22) Either the Mayor of Inglesham won't go to the meeting or the meeting will be postponed

and what in fact happens is that the mayor dies shortly before the meeting, but the meeting is still held. Does John win his bet? Or if he bets (23),

(23) On December 1st 1975, either the Pope will not give the anmual address, or America wi.l工 drop 100 bombs on Vietnam what is the outcome when it turns out that America doesn't drop any bombs on Vietnam but since the Pope is dead somebody else gives the annual address? Are the bets successful? Though these cases are less clear than the case of conjunction by and, it seems to me that there is little doubt that strictly speaking in both cases John has won his bet. 8

7. This is the option taken by Keenan (ibid).

8. Whether these bets could be upheld in a court of law is not relevant since the legal doctrine of frustration which is relevant here is not defined in terms of the semantics of the statement (contract) in question but refers to extra-linguistic knowledge concerning the particular circumstances involved (e.g. a tanker contracted to carry oil from A to. B will not be in breach of contract if when $B$ is at war, it refuses so to do, unless of course this is specifically provided for in the contract). 
But a three-valued logic cannot account for this intuition. Since in both cases one conjunct is false, and one conjunct is truthvalueless, whatever the value the entire proposition may have it cannot be true. But if John wins his bets, then the propositions ARE true. And just as before with and/but, what provides an anomaly for a three-valued logic is automatically accounted for by a two-valued logic. A two-valued logic predicts that if there is no object for a definite noun phrase to refer to then a negative statement containing it must be true. Thus the first conjuncts of (19) and (20) are true under such conditions and the whole proposition will therefore be true even if the second conjunct is false. Finally let us consider $P \supset$ Q. Herespeakers' intuitions are notoriously hazy. In a three-valued logic, one of the problems we have to decide is what value to give the whole proposition if $\underline{P}$ is neither true nor false and $Q$ is false. If we wished to seek parallelli.sm with the two-value definition of $P \supset Q$, we might want to say that in this case the entire proposition should be true. Some examples seem to support this. If I say (24): (24) If the Regent of Lithuania visited Enid's art gallery, then I'm a Dutchman 9

since the expression If $X$, then I'm a Dutchman is commonly used to suggest the absurdity of $x$, then it seems reasonable to suggest that (24) is true if there's no Regent off Lithuania and I'm not a Dutchman. The problem arises with the negative statement The Regent of Lithuania did not visit Enid's art gallery. According to a three-valued logic this will have the same truth value as its positive counterpart if

9. This type of example was pointed out to me by Deirdre Wilson. 
there is no such man as the Regent of Lithuania - neither true nor false. So a three-valued logic predicts that the substitution of the negative statement for its positive counterpart in (24) should not alter the truth value of the whole. But it seems clear that it does. If there is no Regent of Lithuania and I am not a Dutchman then the claim made in (25) is surely false. (25) If the Regent of Lithuania did not visit Enid's art gallery, then I'm a Dutchman.

To put it another way, if you promise that if the Regent of Lithuania does not visit Enid's art gallery, then you'dz eat your hat, when it transpires that he didn't because there's no such man then you should feel forced to eat your hat. That is to say, the antecedent of both conditionals is true, and thus the entire proposition is true only if the consequent is true. Otherwise it is false. Thus the claim in (25) is false if there is no Regent but I am not a Dutchman. This is precisely the result predicted by a two-valued logic - but not by a three-valued logic, which predicts that in both the cases (24) and (25) the entire proposition will be true if I'm not a Dutchman. Ijike the examples with or and and, this prediction does not match the native speaker's intuition.

There is one further example involving $\underline{P \rightarrow Q}$ which concerns a counter-argument given by Strawson (1964a) to an attempt to disprove the validity of a three-valued logic. The argument strawson cites runs as follows. Let $\mathrm{g}$ be a statement which is neither true nor false. Then the statement $\mathrm{P}$ is true is false. If it's false that $\mathrm{P}$ is true, then $\mathrm{P}$ must be false. But the statement $\underline{P}$ is false is also false. If it's false that $P$ is false, then $P$ is true. Therefore $P$ is both 
true and false. Since this is self-contradictory, the three-value theory is false. Strawson's counter-argument (ibid p.109) is that if $\underline{P}$ lacks a truth value, then any statement assessing it as true, or any statement assessing it as false similarly lack a truth value. But this counter-argument will not I think do. Consider (26) (26) If John has won his bet, then it is false that the mayor opened the exhibition

in conjunction with a state of affairs in which (a) John bet that there was no mayor and (b) John won his bet. A three-valued logic has three alternatives (i) to say that (26) is neither true nor false since the antecedent is true and the consequent neither true nor false, (ii) to say that $P \supseteq Q$ can be true when the arrtecedent is true and the consequent neither true nor false, (iii) to admit that if it is true that there was no mayor then the statement It is false that the mayox opened the exhibition is true. I take it that no-one would be prepared to support the second alternative. But the first does not match one's intuitions. (26) seems true, given the state of affairs in question. Thus we seem bound to accept alternative (iii). But this is an admission that the relation between the two statements The mayox opened the exhibition and There was a mayor is one of entailment and not presupposition.

Thus we find that despite its initial apparent ability to capture certain properties of definite noun phrases, an analysis based on a three-valued logic not only makes a considerable number of wrong predictions with respect to negation and opaque environments such as pretend, but faces a number of embarrassing anomalies. Yet for each of the cases raised against a presuppositional analysis, an analysis of the referential properties of definite noun phrases in terms of 
entailment makes predictions consonant with the native speaker's intuitions. Thus the sum conclusion of the evidence I have presented is that definite noun phrases, as delimited by Russell. (cf. Russell 1905), entail the existence of their referents and do not presuppose their existence.

The main burden of my arguments has rested on the interpretation of negative statements, which I argued were unspecified as to scope of negation, allowing even interpretations in thich the existence of objects referred to by definite noun phrases was denied. One could however retort that in criticising Strawson's account of presupposition I have in addition depaxted from Russell's account. In On Denoting, Russell claims ( $p .489 f_{.}$) that the negation of a sentence containing a definite description is not a disjunction but is ambiguous. This is pointed out by Schnitzer (1971) who draws attention to some awkward consequences created by this claim. In particular, as he points out, if negative sentences are said to be ambiguous, then The King of France is bald can be shown either to entail or to presuppose that there is a King of France, depending on how the scope of negation is construed. If the IKing of France is not bald is understood as 'It is false that the King of France exists (and is bald)' then The King of France is bald will entail There is a King of France (since if the latter is false, the negation as understood above will be true). If however the King of France is not bald. is understood as 'The King of France exists and is not bald' The King of France is bald will presuppose that there is a King of France since the negation of The King of France is bald still, under this interpretation, implies that there is a King of France. Schnitzer shows furthermore 
that if the negative sentence is assumed to be ambiguous, The King of France is bald will neither entail nor presuppose Whoever is the King of France is bald. However none of these consequences arise if negative sentences containing definite descriptions are analysed as vague or unspecified with respect to their scope, like all other negative sentences. Further evidence in support of this is provided by the linguistic test of vagueness the do so test (cf. ch.1 p.37). To recapitulate, vagueness in sentences is preserved across sentence pronominalisation, and so is ambiguity. That is to say, a vague sentence which is pronominalised will allow independent specifications of the vague attributes in its two occurrences. An ambiguous sentence on the other hand, must share the same interpretation with its pronominalised counterpart. Negative sentences in general allow independent specifications of a pro-form; and they do so even when this pro-form involves a definite referring noun phrase. Thus we get not only (27) but also (28) and (29). (27) John didn't run away, and Bill didn't either. John walked as slowly as he could, whereas Bill stayed where he was. (28) Bill didn't see the satellite through the telescope and Joan didn't either. Bill didn't because there wasn't a satellite by the time he got there and Joan didn't because she couldn't focus the telescope properly.

(29) The King of France didn't visit the Duke's world-famous exhibition and Prince Ivan didn't either. Prince Ivan didn't because he was in prison on a treason charge; and the King of France didn't because there is no such person. The interpretation of negative sentences as vague - even allowing an interpretation in which definite noun phrases fall within the negation's scope - thus seems justified. 


\subsection{Assertion: Strawson v. Russell}

All my arguments have led in the same direction, that presupposition, as a new logical relation, is in natural language not distinct from entailment. Natural language therefore appears to be analysable in terms of a two-valued logic and not some other logic; and I have suggested that any argument to the contrary is based on a false analysis of negative sentences. The foundation stone of either argument is what constitutes a possible interpretation of negative sentences. This is not however the source of Srawson's disagreement with Russel1. Their disagreement can I think be traced to a confusion over the term assertion. Assertion is not used by strawson in the same sense as Russe11, though Strawson appears to assume that there is no radical difference. The distinction is analogous to the distinction I made earlier $(p .87 f)$ between statement defined logically and statement defined as an illocutionary act. Assertion is used by Russell in the sense of a commitment to the truth of certain conditions. Thus searle (1969) defines assertion as 'a (very special kind of) commitment to the truth of a proposition' (Searle 1969 p.29). This definition has as an automatic consequence that if a speaker asserts (is committed to the truth of) some sentence then he is automatically asserting (committed to the truth of) all the entailments of that sentence. To infer that anyone who asserted $S$ (The King of France is wise - RMK) would be asserting that (1) There is a king of France (2) There is not more than one king of France (3) There is nothing which is king of France and is not wise' (Strawson 1950 p.324) is therefore not an incorrect inference, given the above characterisation of assertion. 
But this concept of assertion is clearly not equivalent to assert in the sense of 'to give information of some kind to an audience'. Only the latter stands in contrast to what a speaker assumes. This latter sense is used by Strawson. He claims that 'To use the sentence (The table is covered with books - RMK) is not to assert, but it is (in the special sense discussed) to imply, that there is only one thing which is both of the kind specified (i.e. a table) and is being referred to ${ }^{10}$ by the speaker' and '.. referring to or mentioning a particular thing cannot be dissolved into any kind of assertion. To refer is not to assert, though you refer in order to go on to assert.' (Strawson 1950 p.333). Yet Strawson appears to assume that there is no difference between his sense of assertion, and that of Russell. He argues that one of the false things that Russell claims is that in asserting The King of France is wise a speaker would also be asserting that there at present existed one and only one luing of France. Further he argues that since all a speaker would be asserting is the wiseness of such a man, then it is only on the grounds of his putative wiseness that that assertion can be assessed as true or false. It is this claim which conflates the two uses of the term assert and it leads directly to the incorporation of some undefined notion of topic into the definition of truth, a procedure which I have already argued leads to circularity.

The argument in svour of presupposition seems therefore to be founded on a misconception. Clearly Russell would not accept the characterisation (and the consequences) of assertion that Strawson assumes. Such a characterisation is indistingujshable from a non-truthfunctional use of assertion, in which JOHN hit Mary asserts that it 
was John that hit Mary but assumes (presupposes) that someone hit Mary. (Cf. ch.3 p.86). The conflation of an illocutionary definition and a logical definition also emerges in Strawson's use of the word state. He claims in On Referring' that 'to use the word the is ... to imply that the existential conditions .. are fulfilled. But to use the in this way Is not to 'state' that these conditions are fulfilled' (p.332). Here he appears to use state in an illocutionary sense. But this sense of state is not of the same class as a logically defined statement, to which Russell was seeking an explanation. This type of confusion is best (i.e. most crudely) displayed not by Strawson, but by Searle, who claims that Russell's analysis is incorrect on the grounds that 'it is absurd to suppose that someone who asks "Does the queen of England know the king of France?" makes two assertions, one of them true and one false' (Searle 1969 p.162). The absurdity lies rather in Searle's refusal to recognise that assertion is being used in two quite separate ways. Moreover it is not so obvious that the supposition he outlines is incorrect, given the Russellian use of assertion. Indeed Geach (1965) - along the lines of Russell - claims exactly this. He suggests not only that the assertion John is aware of the fact that his wife is unfaithful is equivalent to the pair of assertions. John is convinced that his wife is unfaithful and John's wife is unfaithful but that in asking the question Is John aware of the fact that his wife is deceiving him? 'I am not just asking a question; I am asserting that John's wife is deceiving him' (p.454). Since I have argued earlier that meaning is quite separate from aspects of the speech act (cf. ch.2 section 2.4 .2 and $\mathrm{ch} .4$ section 4.1 ) and moreover that meaning on a truth-conditional basis therefore relates directly not to the speech act of stating, to which it is logically prior, but to the logical statement, I shall therefore assume that an analysis 
of reference for definite noun phrases cannot be in terms of what a speaker assumes in uttering sentences. This assumption, together with the earliter arguments given against an analysis of reference in terms of a three-valued logic, commit me to asserting that presupposition, as Strawson defines it, is not part of a semantic explanation of natura.l language, since it appears to have been conceived on the basis of a conflation of the logical structure of statements and their illocutionary function.

\subsection{Anaphora: The Problem of Coreference}

I have assumed so far that the property of reference of the definite noun phrase is a unitary phenomenon (of. fn.l of this chapter). This is clearly an oversimplification. There are three main functions of the definite article as an indicator of definite reference:

1) anaphoric: I saw a man hanging around this morning and when I came back the man had moved

2) definite description with relative clause:

John annoyed the man he had dismissed.

The man who I met yesterday came back ggain today

3) nonlinguistically anaphoric: Did you wind the clock?

The King of France is bald.

The moon was hidden behind the clouds

In all that precedes, I have only discussed type (3) and I have argued that this implication of reference can be interpreted as falling within the scope of negation. But this is the only one of the three types which can be. The other two types are neither of them negatable. John didn't annoy the man he had dismissed always implies John had 
dismissed a man just as $A$ dog and a cat ran across the road and the dog wasn't chasing the cat implies the existence of a specific dog and a specific cat. One might argue that these constitute a cleax case of presupposition (as Keenan does -1971 ). However this would not I think be justified. Let us look at the evidence more closely.

A descriptive account of the in these two types of example is relatively straightforward. The function of the is as a linguistic coreference indicator to some noun phrase previously occurring. The Iinearity involved in the distribution of a and the is essential to the interpretation of the definite article. Consider examples (30) $-(33):$

(30) Someone came into the room and told a boy that the poljuce were outside, while the boy was talking to a pretty girl

(31) While a boy was talking to a pretty girl, someone came into the room and told the boy that the police were outside

(32) Someone came into the room and told the boy that the police were outm side, while a boy was talking to a pretty gixl

(33) While the boy was talking to a pretty girl, someone came into the room and told a boy that the police were outside

In both (30) and (3i) the indefinite noun phrase is to the left of the lexically identical definite noun phrase ${ }^{11}$ and this allows a reading of coreference. When this condition is not fulfilled as in (32) and (33) the readings are that these two instances of boy do not refer to the same object. Thus (30) and (31) axe synonymous but (3i), (32) and (33) are not. But it is sentence-pairs (30) and (33), and (31) and (32), which are identical morpheme for morpheme and which would - other things being equal - have identical representations (both semantic and syntactic). Thus, however the distribution of a and the is to be

11. There are numerous problems about this statement of identity. For some discussion, cf. Lakoff 1968,p.63ff, and Kartunnen 1971a. 
predicted, it is clearly dependent not on deep structure order but on surface structure. Moreover, if an intexpretation of coreference is required, the is obligatory. If a is substituted for the in (30) and (3l), there is a necessary implication that two boys are involved, not one. The evidence therefore suggests that we explain these occurrences of the as indicating a second-mention instance of the noun phrase it modifies, and analyse definite and indefinite noun phrases as differing only in that a definite noun phrase is a second instance of the indefinite noun phrase, stnce this would provide an automatic means of explaining the synonymy of (30) and (31) despite their non-identity morpheme for morpheme.

Definite noun phrases with relative clauses are exactly comparable to non-modified definite noun phrases: the function of the definite article is to establish anaphoric coreferentiality:

(34) A man with a moustache was talking to a man who was bald on the pavement at the side of the road when suddenty the man who was bald took out a gun

Here, as with the simple definite noun phrase (type 1), the occurrence of the must be analysed as differing from the indefinite noun phrase only in that it constitutes a second occurrence of the noun phrase, since again the is obligatory if an interpretation of coreference is required.

If this analysis is correct, and both these uses of the definite article are a reflex of a second mention of the object to which the noun phrase is referring, then there is an automatic explanation of why this use of the definite noun phrase cannot be interpreted as falling within the scope of negation. The law of contradiction predicts that a sentence cannot be simultaneously both true and false. So for 
example, the semantic interpretation of a sentence such as John saw a girl at the party predicts that the sentence will be true if, among other things, there was a girl at the party. But the sentence John didn't dance with the girl because there weren't any girls there is true under contrary conditions. Thus general pxinciples of contradiction rule out the conjunction John saw a girl at the party but he didn't dance with the girl because there weren't any girls there. Similarly A man with a moustache was talking to a man who was bald at the far end of the room but the man who was bald was not replying must imply that there was such a bald man, since to interpret The nan who was bald was not replying as true because there was no such man provides a contradiction with the preceding conjunct. On these grounds, a noun phrase with linguistically anaphoric the can never be interpreted as falling within the scope of negation, since to do so will always set up a contradiction with the preceding instance of that noun phrase. Non-linguistically anaphoric the differs from anaphoric the in just this respect. There is no prior explicit commitment to the existence of some object in the former case, and so a necessary contradiction does not arise - this use of the is interpreted as falling within the scope of negation. Hence the nondeviance of (35) I didn't wind the clock because we haven't got one (36) The moon wasn't hidden by the clouds, because there weren't any It therefore seems that the natural explanation for anaphoric definite noun phrases, with or without relative clauses, is that they constitute second mention of the object the noun phrase describes, thus automatically providing an account of why they are not interpretable as falling within the scope of negation. If this is a correct explanation, then there are no grounds for setting up a new logical relation of presuppositjon just to account for these cases. 
Evidence that this general analysis is correct is provided by the contrastive interpretations of indefinite, anaphoricmdefinite and nonanaphoric-definite noun phrases when embedded in a complement sentence below pretend, the verb whose use commonly implies the falsity of its complement. We saw earlier that the implication of existence of non-anaphoric the could be interpreted as false within a pretend complement. Thus John pretended that the King of France seduced his sister (e.g. (12) p.138) does not depend for its truth on there being a king of France. This may, or may not be, true. Thus (37) is not a contradiction.

(37) John pretended that the King of France seduced his sister though there is no such man.

Compare also

(38) John pretended that the clouds were hiding the moon though there weren't any

(39) John pretended that he was winding the clock, though there wasn't one there

By contrast the anaphoric uses of the cannot normally enter sentences in a similar way without contradiction:

(40a)?*John pretended that he was strolking the woman beside him though there was no-one there

(40b) John pretended that he was stroking the woman beside him though he never touched her

(4la). John pretended that he was stroking a woman beside him though there was no-one there

(4ib) John pretended that he was stroking a woman beside him though he never touched her

(42a)?*John pretended that he was stroking the woman who was standing beside him though there was no-one there

(42b) John pretended that he was stroking the woman who was standing beside him though he never touched her 
(43a) John pretended that he was stroking a woman who was standing beside him though there was no-one there (43b) John pretended that he was stroking a woman who was standing beside him though he never touched her

In each of these cases an account of the contrast between interpretations with indefinite and definite noun phrases in terms of first and second mention of some object predicts this distribution in the following way.The indefinite noun phrase can be interpreted as false since there is no prior commitment to the truth of the the existence of the object to which the noun phrase refers. The definite noun phrase cannot, as there is such a prior commitment - it constitutes a second mention of some object previously referred to and because the previous mention of this object is not explicitly included with the scope of pretend in these example, it is understood to be outside the scope of the verb. Hence, as in the other cases (cf. p.154f) general rules of contradiction block such an interpretation.

A presupposition-supporter might well retort at this point that to eliminate presupposition only to bring in a notion of 'prior commitment' is in effect to bring presupposition in again by the back door. But this would be quite unjustified. This notion of prior commitment is not in these cases relative to the world which guarantees the truth of the sentence in which the definite noun phrase occurs (as a presuppositional analysis would predict): rather it is relative to the world in which the first mention of the noun phrase in question was asserted ${ }^{12}$ Consider the following sentences:

(44) John pretended there was a woman beside him and that he was striking the woman

(45) John dreant that he seduced a woman, and the woman fought him (46) John wants to buy a car which is convertible and the car must be green (47) John wants to catch a fish this afternoon when the tide is out and then eat the fish he has caught for supper 
(48) My great-grandfather seduced a woman and the woman therefore became a nuas

(49) John will catch a fish this afternoon and we shall make sure that the fish is shared amongst us all.

Wach of the above sentences contains an indefinite noun phrase and a definite noun phrase which are coreferential. However none of them unambiguously imply a specific referent to whose existence the speaker must be committed in asserting the sentence. On the contrary, al of them constitute opaque contexts: that is to say, they describe worlds or states of affairs which may be compatible with the actual world but which need not (in some cases, must not) be co-extensive with the real worl.d. Thus for example John may want something which exists, but he mass want something which only exists in the hypothetical state of affairs that he envisages and desires. ${ }^{13}$ so it is that in each of the above examples, the referent that the two noun phrases refer to may be a real-world referent, but it may not be. Thus for example (49) is true under two possible interpretations - either if John is going to catch a specific fish, which - say - he has seen, or if there is going to be a state of affairs such that there is a fish which he catches. Analogously, (48) can be true whether or not there is a specific woman who my great-grandfather seduced alive at the time of utterance. It does not affect the truth conditions of the sentence if in fact there is no such woman to refer to in the world relative to the speaker. 14 But these opaque contexts are not restricted to a particular set of verbs. They include future and past tense, as we have seen. Each of

13. This is the concept of 'possible world' which I introduced in ch.2 cf. p. 60 .

14. This appears to be the basis of Chomsky's suggestion (1971) that Einstein taught John physics would be used if Einstein were dead, as opposed to Einstein has taught John physics which presupposes that he is alive. An account more in line with the analysis here would be that past tense is an opaque context describing a world which is necessarily nd coextensive with the present, whereas perfect aspect does not provide an opaque environment but is interpreted as co-extensive with the present. 
these examples is an embarrassment for a presuppositional analysis, since they constitute cases where there is no implication of an actual referent to which the definite noun phrase refers. Moreover, like negation, each of these opaque operators is vague with respect to its scope and not ambiguous. ${ }^{15}$ Each passes the vagueness test (cf. p. 37 ) in allowing verb-phrase pronominalisation without demanding agreement in the specification of whether or not the noun phrase in question has a specific referent.

(50) My great grandfather seduced a woman, and so did my grandfather. Only my grandfather's woman is alive today.

(51) John wants to buy a car and so does Bill, but only Bill knows exactly the car he wants.

(52) John dreamt a woman was sleeping in bed beside him, and so did Bill. Bill wolse up to find there was.

For all these cases, an analysis of reference in terms of entailment predicts as an automatic consequence that opaque and negative contexts will be unspecified as to whether any of the entailments of the constituents of that context hold. A presupposition analysis has to legislate against these case.

Now in the cases I considered previously - in which I claimed there was a 'prior commitment' - the definite noun phrase has no precursor within the opaque context. This being the case, its precursox is generally understood to be outside the opaque context, ${ }^{16}$ preventing

15. Despite numerous claims to the contrary. Cf. Baker 1966, Jackendoff 1971, Hall-Partee 1972.

16. Actually the relation between worlds is considerably more complex than this. Coreference may either cross into an opaque world as in (i.) or from an opaque world to the real world as in (ii) or remain within the opaque world as in (iii):

(i) John met a girl and he dreamt he seduced her

(ii) Yesterday John dreamt that he hurt a girl and today she came round (iii) John dreamt that he hurt a girl and she cried In the two cases where coreference is across worlds, the two worlds must agree in the interpretation given to that referent. In terms of referential indices the constraints are as follows: if within one world an object can be referred to by more than one name, each of these references must bear the same index. This is true for both real-world coreference and corefexence in an opaque world. Where coreference occurs across worlds, these worlds must agree in assigning the same index to a particular object. Cf. Hintikka 1969, 1972. 
the definite noun phrase from being interpreted as within the opaque state of affairs. The exceptions to this general position are cases where the predicate responsible for the opaque environment is repeated in a discourse. Thus examples in (40a) and (42a) do not imply the actual existence of a referent if they occur in the following environment: ${ }^{17}$

(53) John pretended that there was a woman beside him. Then he pretended that he was stroking the woman beside him though in fact there was nomo there

(54)?John pretended there was a woman standing beside him. Then he stood up and pretended to stroke the woman who was standing beside him, though in fact there was no-one there.

These examples, particularly (53), provide us with further evidence that the implication of reference on an anaphoric definite noun phrase is not based on a relation of presupposition, but on entailment since only the latter predicts the variability of reference implications within opaque environments. The evidence thus suggests that all definite noun phrases entail the existence of thejr referent, despite the fact that in negative sentences they divide into two classes, only one of which allows an interpretation that denies the existence of the referent. The other class - those whose existence has already been implied by a preceding indefinite (or definite) noun phrase canot do so on account of the contradiction that would be set up. The nature of this relation between two noun phrases which are lexically identical save that where one has an indefinite article and the other a definite

17. For some reason that I cannot explain the occurrence of an explicit tense marker within the definite noun phrase in (54) makes it worse than (53). Since I have not given any detailed consideration of the enormous problems involved in the semantics of tense, this remains an anomaly. 
article can be formally captured simply by means of the linear representation of sentences. It would therefore be redundant to add any additional inherent specification to definite noun phrases to distinguish them from their corresponding indefinite noun phrases. It follows that definite and indefinite noun phrases have an identical semantic representation.

The question then arises as to whether the non-Iinguistically anaphoric definite noun phrases should be distinct from their corresponding indefinite noun phrase. Russell assumes that they are, by virtue of an implication of uniqueness. That is The King of France visited the exhibition entajls, in his analysis, that there is one and only one king of France, whereas A King of France Visited the exhibition does not. It is doubtful however whether this relationship is one of entailment. If it were, and the semantic representation of the King of France visited the exhibition had to include a conjunction of the statements There is one and only one of King of France and The King of France visited the exhibition (I ignore the noun phrase in the predicate), then it should follow that the statement will be false if either one of its conjuncts is false (an argument which is by now familiar). However the statement It is not true that the King of France visited the exhibition because there is more than one king of France seems quite as incoherent as the same sentence with an indefinite noun phrase, where uniqueness is clearly not entailed:

(55) It is not true that a king of France visited the exhibition because there is more than one king of France

The truth of the statement in question in both cases is quite unaffected by whether or not there is more than one king of France. Compare (56) It is not true that the head of school came to see me because we have two heads of school

(57) It is not true that a head of school came to see me because we have two heads of school 
It is simply irrelevant to the truth of the statement The head of school came to see me that there may be more than one head of school. Similarly with (58):

(58) The glass has fallen on the floor

This does not entail that only one glass has fallen on the floor since if in fact seven other glasses fell on the floor as well (58) would not thereby be false. Rather the conditions under which $(58)$ be true are exactly those which guarantee the truth of A glass has fallen on the floor. What is additionally implied in the use of the definite noun phrase is however that the object referred to by the definite noun phrase is uniquely identifiable by the hearer; but this implication is not an entailment either. The truth of any of the statements The King of France visited the exhibition, The head of school came to see me, The glass has fallen on the floor is clearly not affected by whether or not the hearer is in fact able to identify the particular objects referred to in any speaker's utterance of the sentences. Thus, as we would predict of a relation involving speaker-hearex interaction, the implication of uniqueness on non-anaphoric definite noun phrases is not a truth-conditional implication and hence is not merely not an entajlment relation but is arguably not even a semantic relation. Since, as we have seen, this is the only putative distinction between (non-anaphoric) definite noun phrases and indefinite noun phrases, I shall therefore assume that, like the anaphoric the, the non-anaphoric the is nondistinct in its semantic representation from the indefinite article. One important exception to this conclusion is the predicative use of the indefinite noun phrase, which does not enter into a relation 
of reference at all. It is also an exception to the generalisation adopted in the formalism described in ch. I (cf. p. 30) that all noun phrases bear a referring index. It is not at all obvious how to deal with these examples except possibly by setting up two mutually exclusive indefinite articles, one referring and one not. This solution is not entirely ad-hoc since their behaviour is importantly different. (It does not however explajn the anomaly in the formalism of referring indices.) Notice for example that a referring use of the indefinite article cannot occur after the definite article and maintain an implication of coreference. Thus The man came into the room and a man immediately did up his coat cannot imply that the same man both came into the room and did up his coat. This is not so with the non-referring use:

(59) The man is a big lout

(60) John hit the man, a big lout of a fellow

The indefinite noun phrase clearly does indicate properties of the object referred to by the definite noun phrase, and not some other object. For reasons such as these I shall assume that the predicative use of the indefinite article has to be represented as quite distinct from its referring use. And in all that follows, I shall only be concerned with this referring use of the indefinite noun phrase. 18

\subsection{Summary}

The central argument of this chapter has been - like that of the previous chapter - a negative one: I have suggested that the logical.

18. I shall also not take into account here the generic use of either the indefinite or the definite article. While the concept of reference as I have used it here might reasonably be expected to include reference to a whole class, generics provide additional problems of their own which are not relevant to the main arguments of this thesis. I have also omitted the use of the definite article in superlative constructions on the grounds that this is an extended and not a central use. 
relation necessaxy to describe the implication of reference in definite noun phrases is entailment, and not presupposition. Thus the conflation by linguists of presupposition and entailment (cf. ch. 4) is not merely a foolish and philosophically insensitive mis-use of relations defined within logic but stems from the fact that in natural language presupposition is not logically distinct from entailment, despite Strawson's claim to the contrary. What I am in effect suggesting is that the discussion of presupposition within a formal linguistic framework has been a red herring, since the arguments originally establishing the need for such a new logical relation are not valid. A consequence of my argument is that both definite and indefinite noun phrases entail the existence of the object to which they refer and should therefore be given the same semantic representation. We shall see in the following chapter how the conclusions of this chapter can be characterised in our formal framework.

The list of counter-examples or anomalies to a truth-based semantics has grown longer with each chapter. This chapter has added to the list not only the extremely 'marked' nature of the interpretations: of negative sentences which include the implication of reference in the scope of negation, but also (more seriously perhaps) the implication in definite noun phrases of the hearex's ability to uniquely identify the object described, an implication which is the basis of the distinction between definite and indefinite noun phrases. However on the basis that a semantic theory must not only be predictive but must also make the correct predictions (cf. p.8f), I suggest that the restriction is a legitimate one and the apparent anomalies which arise can be naturally 
$-165-$

explained by a theory of pragmatics. Two large problems thus remain:

I) the further specification of our linguistic framework to predict

the data we have discussed in this and the preceding chaptex

II) the specification of a theory of pragmatics.

These form the burden of the four remaining chapters. 
CHAPTER 6 : The Formalisation of The Solution

The conclusions reached in chapters 4 and 5 provide two main problems of formal description:

(1) How should the theoretical account reflect the demonstrated relations of entailment - (a) between a non-opaque sentence containing a factive verb and its complement (b) between a non-opaque sentence containing a specific noun phrase (definite or indefinite) and the consequent claim of existence of the referent of that noun phrase (2) How can the distribution of the definite article be predicted (a) where the two co-referring noun phrases (of which the second contains the definite article) are within the same sentence (b) when the co-referring noun phrases are not within the same sentence (c) when there is no explicit prior noun phrase for the definite noun phrase to co-refer to. As we shall see, there is reason to suppose that cases such as factive verbs which entail the truth of their complements should be analysed as containing a definite noun head. This being so, the formal representation of factives depends on the analysis given to definite noun phrases. I sha1l therefore discuss first the means of capturing the distribution of the definite noun phrase - i.e. problem (2).

6.1 The Syntactic Relation Between Definite and Indefinite Noun Phrases I have already argued that definite and indefinite noun phrases should have an identical semantic representation. On this basis, some linguists have argued that they should be given the same underlying syntactic 
representation, deriving the definite article by a rule of 'Definitisation' from an underlying indefinite article. ${ }^{1}$ on semantic grounds, Kuroda for example axgues that co-referential noun phrases should have an identical deep-structure representation on the grounds that if they did not, then examples (1) and (4) would have an identical deep structure, and so would examples (2) and (3); but (1) and (2) would not. 2 If however, the were derived transformationally from a second instance of some noun phrase by a rule of definitisation which follows adverb preposing, then identical deep structures would be assigned to (1) and (2), but not to (3) and (4).

(1) Someone came into the room and told a boy that the police were outside, while the boy was talking to a pretty girl

(2) While a boy was talking to a pretty gixl, someone came into the room and told the boy that the police were outside

(3) Someone came into the room and told the boy that the police were outside, while a boy was talking to a pretty girl

(4) Wile the boy was talking to a pretty girl, someone came into the room and told a boy that the police were outside

A transformational derivation of anaphoric the thus correctly describes two occurrences of the same noun phrase in (1) and (2) and different noun phrases in (3) and (4).

What syntactic justification is there for this analysis? According to the principles suggested in chapter I, the evidence would have to show that indefinite and definite noun phrases did not differ in their syntactic constraints. Two putative counter-examples to this claim are the hypotheses that only definite noun phrases can take nonrestrictive relative clauses (henceforth $\mathrm{NRRCs}$ ), and that indefinite noun phrases cannot occur in negative sentences. 3 Thus one might

1.Cf. Annear 1965, Robbins 1968, Kuroda 1968. 2. These examples are repeated from ch.5 for convenience. 3.Cf. C.Smith (1.964) who distinguishes between two uses of the indefinite noun phrase, only one of which can take NRRCs, and Baker 1966. 
argue that of the following examples, (5), (7), (9), (10), (12) and

(14) are acceptable, but (6), (8), (11), (13) and (15) are not:

(5) The book, which is about linguistics, would be very helpful

(6) *A book, which is about linguistics, would be very helpful

(7) A book which is about linguistics would be very helpful

(8) *Any book, which is about linguistics, would be useful

(9) And book which is about linguistics would be useful

(10) He is an anthropologist who studies Indian tribes

(11) * He is an anthropologist, who studies Indian tribes

(12) The halfback didn't run with the ball

(13)*A halfback didn't run with the ball

(14) John didn't see the salesman

(15) *John didn't see a salesman. 4

The evidence given is insufficient. There are circumstances in which an indefinite noun phrase can take a NRRC and does enter negative sentences:

(16) John didn't see a lorry which was coming round the corner

(17) John didn't see a Iorry, which was coming round the corner

(18) John didn't buy a car which was convertible

(19)3John didn't buy a car, which was convertible

(20)*A picture, which has a gold frame, may soon be painted by John

(21) A book, which was written by Paisley, was publicly burned by Catholics today

(22) A man didn't see me and stepped off the pavement in front of the car. The negation constraint is shown by these examples to be simply wrong. 5 So too is the constraint on NRRC formation. (17), (19) and (21) all contain NRRCs modifying indefinite noun phrases. What then is the nature of the relation between indefiniteness and negation on the one

4. Examples (13) and (15) are from Baker 1966.

5. Stockwell et al (1973) wisely disagree with Baker's data (cf. p.72). 
Land, and NRRC formation on the other? (17) appears to contain a referring instance of an indefinite noun phrase in a negative sentence, with a NRRC modifying it. So does (19). (16) and (18) are of the same negative construction (containing an indefinite noun phrase with a restrictive relative clause) but their interpretations do not seem parallel. (16) seems to suggest that there was a specific lorry but (18) does not suggest the existence of a specific convertible. These four examples indicate that an indefinite noun phrase in a negative sentence can either be interpreted as referring to a specific object or as not doing so. 6 If this evidence is correct, it should enable one to predict that John didn't see a lorry has two possible interpretations: (23) John didn't see a lorry $\left\{\begin{array}{l}\text { - in fact he didn't see any traffic } \\ \text { and it nearly ran him down }\end{array}\right.$ Similaxly with examples (13) and (15): (24) A halfback did not run with the ball $\left\{\begin{array}{l}\text { - he didn't even touch it } \\ \text { - you don't have halfbacks in Rugby }\end{array}\right.$ The hallmarks of entailment are in evidence. An indefinite noun phrase implies the existence of some object and this implication may but need not fall within the scope of negation. John saw a lorry thus entails There is a Ioxry, I am therefore assigning to indefinite noun phrases the property of referring to some object, 7 a conclusion which provides additional support for the semantic analysis of a and the in the preceding chapter. The postulated negation constraint thus seems nonexistent.

What of constraints on NRRC formation? Notice that in each of (17), (19) and (21) the interpretation of the indefinite noun phrase

6. (17) also demonstrates the incorrectness of a constraint suggested by C.Smith (ibid) that NRRCs cannot occur with either the or a in the predicate of negative sentences. The deviance of her example, He didn't write a novel, which was publi.shed by McGraw-Hill, is particular to verbs such as write which take objects of result. $\mathrm{Cp}$. eg (20). For some discussion of these, ef. Fillmore $1968 \mathrm{p.} 4 \mathrm{f}$, and also Vendlex 1967a. (pp.97-121) who calis them 'accomplishment' verbs.

7. This analysis has to some extent been anticipated by Barbara Hall-Partee (1972) who talks about the referring properties of indefinite noun phrases. 
must imply the existence of some referent, even (as in (17) and (19)) when the indefinite noun phrase is contained in a negative sentence. Moreover examples (8), (11) and (20), which are all. clearly deviant, contain indefinite noun phrases which do not imply the existence of a specific referent. A first explanation for this distribution is that there is a constraint on NRRC formation such that NRRCs can only modify noun phrases which imply a specific referent. Restrictive relative clause (RRC) formation has no prohibition of this kind since (10) and (18) are grammatical though ... only the latter is even able to carry a referential intexpretation. Since I have argued that negative sentences with an indefinite noun phrase are open to more than one interpretation, this entails that examples (6) and (19) which contain NRRCs, are deviant only if they are not given an interpretation in which the noun phrase in question has a referent. Though this interpretation may be difficult to evoke in some cases, 8 for example (19), the sentence (and others like it), must be allowed a referential interpretation on the grounds of its interpretation when embedded in a sentence such as (25): 9 (25) In the end John decided not to buy a cax, which then stayed in the showrooms for six months

Moreover, the constraint on NRRCs as reformulated should predict that whenever an noun phrase is open to either a referring or a nonreferring interpretation, a modifying NRRC will disambiguate the sentence, though a RRC will. not. There are two types of environment in which indefinite noun phrases have two interpretations, negative sentences and opaque environments. Negative sentences we have already seen are indeterminate as

8. This is particularly difficult in (6) which contains the modal would, an opaque operator like will. cí. p.157ff.

9. The referential interpretation is the natural one in this type of example if a is replaced by one. Cf. Perlmutter 1970 for an argument that a is the unstressed variant of one. 
to an implication of reference for indefinite noun phrases, unless that noun phrase is modified by a NRRC. Opaque environments present exactly the same phenomenon.

(26) John is looking for a car

(27) John is looking for a car which is convertible

(28) John is looking for a car, which is convertible

(26) and (27) are indeterminate as to whether John has a specific car he wishes to buy, but (28) must mean that there is a particular object. These examples of relative clause modification demonstrate that the constraints involved in NRRC formation are dependent not on the form of the article but on the referring properties of both definite and indefinite noun phrases. 10

However the analysis given above is simplistic for exactly the same reasons as a description of definite noun phrases as necessarily implying a specific real-world referent is simplistic (cf. ch.5). Thus, though a NRRC implies a specific referent in the examples (17), (19) and (21) above, it need not. Consjder (29).

(29) John dreamt he seduced a woman, who fought him

Here, as in the examples with a definite noun phrase on p.157f, and unlike the earlier examples in this section, the INRRC allows an interpretation in which the action described takes place within the dream. The referent it modifies is therefore not necessarily a specific, realworld referent. The reason for this is straightforward. The syntactic evidence for deriving NRRCs from an underlying conjoint structure is reasonably convincing (cf. Laksoff $1968 \mathrm{pp} .4 \mathrm{lff}$ ). This being so, sentences of the form John bought a car, which is green will be derived from the structure underlying John bought a car and the car is green. But NRRCs therefore correspond to the second-mention anaphoric

10. The existence of this constraint (though yet to be modified: cf. $p_{0} 172$ ) provides added support for this rather wider use of the term reference than is common among philosophers. 
definite article. It follows automatically that NRRCs should have the same constraints as the definite article. 11 This prediction is borne out by examples $(30)-(33)$.

(30) *Any book, which is about linguistics, would be useful

(31) *Any book would be useful and the book is about linguistics

(32) *John is an anthropologist, who hit me

(33) *John is an anthropologist, and the anthropologist hit me.

Neither anaphoric definite noun phrase nor NRRCs can occur where the preceding noun phrase has no implication of a referent. Their shared constraint is therefore that the noun phrase in question must imply the existence of a referent in some world, and that where coreference is across worlds, the worlds must agree in their interpretation at this point. It follows from this (by virtue of their underlying conjunct structure) that the NRRCs lie outside the scope of negation. in examples (17) and (19) above, and outside the scope of look for in (28). They will have an underlying structure of the following form:
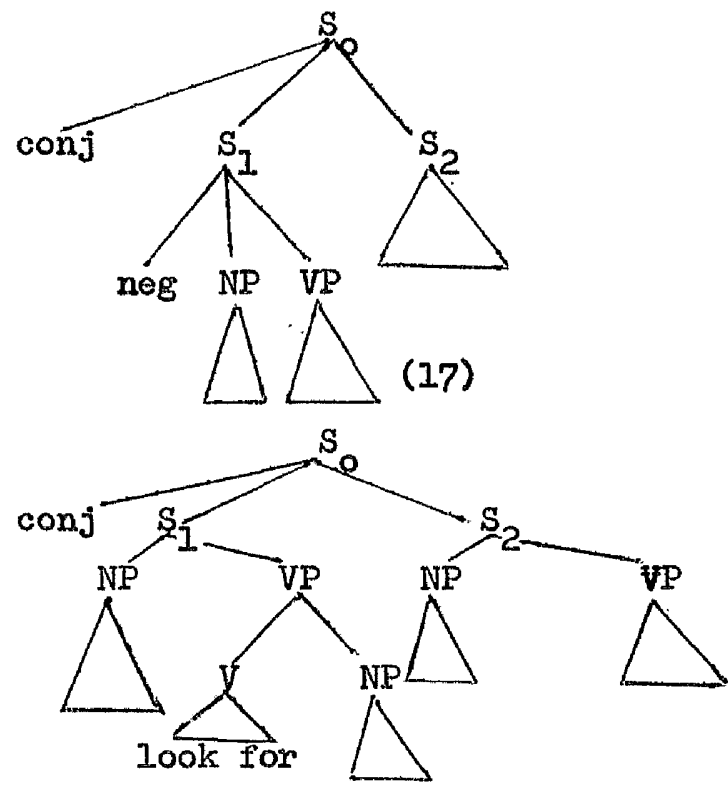

(28)

11. Cf. also pronominalisation which occurs in a similar range of environments. Though cf. Hall-Partee 1972 for a discussion of the many problems involved. 
The interpretation of $\mathrm{S}_{2}$ in both cases is therefore relative to the speaker (by virtue of the deictic property of the tense). To avoid contradiction, the interpretation of the indefinite noun phrase in $S_{1}$ of (17) as having a referent must therefore not be included in the scope of negation. Thus not only do NRRCs occur with definite and indefinite noun phrases under the same conditions, but these conditions are exactly those which allow the occurrence of anaphoric definite noun phrases.

In this section, we have seen how two apparent distinctions in the behaviour of definite and indefinite noun phrases were incorrectly formulated, and specifically that constraints on NRRC formation which appeared to demand some property of reference were met by both definite and indefinite noun phrases. Moreover this reference constraint turned out to be exactly the condition which is demanded by anaphoric definite noun phrases (incidentally confirming the correctness of the analysis of NRRCs as underlying conjuncts). We can therefore, after a somewhat circuitous route, conclude in the absence of further putative counterexamples that syntactic constraints on definite and indefinite noun phrases are identical. 12

\subsection{Definite and Indefinite Noun Phrases: A Preliminary Formulation of Their Syntactic and Semantic Properties In a formulation of the above analysis, we have to reflect the following facts:}

12. This conclusion has of course the same caveats as did the corresponding conclusion in ch. 5 about the semantic representation of definite and indefinite noun phrases. Cf. ch.5 g.162f. 
Fact 1: Noun phrases, both definite and indefinite, will be interpreted as having a specific referent if they are not within the scope of a modal operator or a negation operator. If they are, they may retain the implication of a specific referent, but they may not. Fact 2: Definite noun phrases in general constitute second mention indefinite noun phrases. The second fact I shall capture in the standard way within a sentence by postulating a rule of definitisation assigning the feature $[+\mathrm{Def}]$ to the second of two coreferential noun phrases, to take place after adverb movement (cf. p.167 and Kuroda 1968, Stockwell et al 1973). The morphological rules then guarantee that any noun phrase marked [+Def] acquires the and any noun phrase not so marked remains with a. The exceptions - non-anaphoric definite noun phrases - will arbitrarily have the in underlying structure, with a syntactic feature [-Def]. For further details of this formulation, see the next section, where more difficult counter-examples are also considered.

The formalisation of the semantic properties of noun phrases is not so straightforward. The form of the interpretation will depend to a large extent on how the interpretation of quantified, plural and generic noun phrases is formalised. Yet each of these constitutes a study of its own and I cannot go into these problems here. Bierwisch (1971) has argued that the quantification theory of modern logic is not suited to an analysis of quantification in natural language on the grounds that unlike the existential and universal quantifiers, which characterise sets by enumerating the individuals in those sets, the quantifiers (and plural noun phrases) of natural language appear to operate with sets as primitive terms. Evidence for this is given by (a) sentences such as 
(34) The boys saw the girls

(35) The boys hit the girls

since only the former necessitates that each boy stands in the specified relation to each girl, and an interpretation in terms of logical quantifiers would therefore have to distinguish between the two sentences; and (b) sentences such as The Romans destroyed Carthage where the act of destroying Carthage is not even understood as applying to each or indeed any one Roman individually but rather to the group a whole. On the basis of evidence such as this Bierwisch sets up a different type of semantic element from that considered in chapter 1 - namely, a semantic element which delimits the set substitutable for the variable $X_{i}$ in the semantic reading of a noun phrase, and I shall adopt his formulation here. Unlike the predicating features already discussed which specify the conditions to be met by the objects of the set referred to, the delimiting features apply to the set as a whole. Bierwisch suggests two ways in which these features might be formulated: an operator $\left(Q X_{i}\right)$ is formed by combining the delimiting feature $Q$ with the variable $\mathrm{x}_{i}$ and this operator is elither prefixed to the reading of the whole sentence (or the next higher constituent) or it is prefixed to the reading of the noun phrase itself. As in logic, brackets indicate the scope of the operator. The two alternative formulations are then as follows for some sentence containing a two place predicate: (i) $\left(Q \mathrm{X}_{1}\right)\left([\mathrm{B}] \mathrm{x}_{1} \cdot\left(\mathrm{Q \textrm {X } _ { 2 }}\right)\left([\mathrm{C}] \mathrm{x}_{2} \cdot[\mathrm{S}] \mathrm{x}_{1} \mathrm{X}_{2}\right)\right)$ (ii) $[\mathrm{S}]\left(Q \mathrm{X}_{1}\right)\left([\mathrm{B}] \mathrm{X}_{1}\right)\left(\mathrm{QX}_{2}\right)\left([\mathrm{C}] \mathrm{X}_{2}\right)$

Though Bierwisch does not choose between these two formulations, we shall see that alternative (i) allows for a correct prediction of the interpretation of negative sentences (with one additional rule for interpreting negation 
in combination with such an operator) whereas alternative (ii) does not.

Let us assume then that each noun phrase is assigned a reference index in its underlying structure (needed for syntactic purposes such as relativisation) and that whether a noun phrase has the feature [fDef] or not, ${ }^{13}$ the semantic representation of the noun phrase will include the operator (Spec $x_{i}$ ) to characterise the fact that a single fixed object is referred to by that noun phrase. The interpretation of a sentence such as $\mathrm{A} / \mathrm{The}$ King bought $\mathrm{a} /$ the chandelier will then (ignoring tense) be along the lines of one of the following schema: 14

(a) $\left(\operatorname{SpecX_{1}}\right)\left([\mathrm{K}] \mathrm{X}_{1} \cdot\left(\operatorname{SpecX}_{2}\right)\left([\mathrm{C}] \mathrm{X}_{2} \cdot[\mathrm{B}] \mathrm{X}_{1} \mathrm{X}_{2}\right)\right)$

(b) $[\mathrm{B}]\left(\mathrm{SpecX}_{1}\right)\left([\mathrm{K}] \mathrm{X}_{1}\right)\left(\operatorname{SpecX}_{2}\right)\left([\mathrm{C}] \mathrm{X}_{2}\right)$

The interpretation of the negation of such a sentence must then be able to predict that the positive statement could be false for at least any one of the following reasons: that the King sold the chandelier, that he sold a candlestick, that he bought a candlestick, that the duke bought or sold the chandelier, that there was no chandelier, or that there was no king. To what extent are either of the above formulations successful in predicting such a disjunction of possibilities? Before answering this question we need some formulation of the interaction of negation and (SpecX $\left.X_{i}\right)$ and I tentatively suggest the following addition to the negation rule given in chapter $1:^{15}$

$\operatorname{Neg}\left(\operatorname{SpecX}_{i}\right)\left([S] x_{i}\right)=A /\left(\operatorname{SpecX}_{i}\right)\left([S] x_{i}\right)$ $A /\left(\operatorname{SpecX}_{i}\right)\left([S] X_{i}\right)=\left(A / S p e c X_{i}\right)\left([S] X_{i}\right) v\left(\operatorname{SpecX}{ }_{i}\right) A /\left([S] x_{i}\right)$ In the limiting case where [S] is a single predicate: A $\left(\operatorname{SpecX}_{i}\right)\left([S] \mathrm{x}_{i}\right) \equiv\left(A / \operatorname{SpecX}_{i}\right)\left([S] \mathrm{X}_{i}\right) v\left(\operatorname{SpecX}_{i}\right)\left([\mathrm{A} / \mathrm{S}] \mathrm{X}_{i}\right)$

13. It is only non-anaphoric definite noun phrases which have [+Def] present in deep structure. Cf. p.174.

14. [K] represents the complex of features characterising king, [B] the complex of features characterising the two-place relation buy, and [C] the complex of features characterising chandelier.

15. [S] represents any complex of features whose arguments contain the variable $X_{i}$ bound by the operator $\left(\operatorname{SpecX}_{i}\right)$. ' $A /$ ' is the antonymy operator: cf. ch.I p. 33 . 
Informally what this rule states is that if it is not true that some fixed object has the attribute (or complex of attributes [S], then either there is no such fixed object (with the attribute [S]) or there is some fixed object but it does not have the attribute [S]. The negation rule then applies to the sentence reading (a) (alternative (i)) as follows:

A) $\left(\operatorname{specX_{1}}\right)\left([\mathrm{K}] \mathrm{X}_{1} \cdot\left(\operatorname{SpecX}_{2}\right)\left([\mathrm{C}] \mathrm{X}_{2} \cdot[\mathrm{B}] \mathrm{X}_{1} \mathrm{X}_{2}\right)\right)$

$=\left(A / \operatorname{SpecX}_{1}\right)\left([K] X_{1} \cdot\left(\operatorname{SpecX}_{2}\right)\left([C] X_{2} \cdot[B] X_{1} X_{2}\right)\right) v$

$\left(\operatorname{SpecX}_{1}\right) \mathrm{A} /\left([\mathrm{K}] \mathrm{X}_{1} \cdot\left(\operatorname{SpecX}_{2}\right)\left([\mathrm{C}] \mathrm{X}_{2} \cdot[\mathrm{B}] \mathrm{X}_{1} \mathrm{X}_{2}\right)\right)$

$=\left(\mathrm{A} / \mathrm{SpecX}_{1}\right)\left([\mathrm{K}] \mathrm{X}_{1} \cdot\left(\operatorname{SpecX}_{2}\right)\left([\mathrm{C}] \mathrm{X}_{2} \cdot[B] \mathrm{X}_{1} \mathrm{X}_{2}\right)\right) v$

$\left(\operatorname{SpecX}_{1}\right)\left([\mathrm{A} / \mathrm{K}] \mathrm{X}_{1} \vee \mathrm{A} /\left(\operatorname{SpecX}_{2}\right)\left([\mathrm{C}] \mathrm{X}_{2} \cdot[\mathrm{B}] \mathrm{X}_{1} \mathrm{X}_{2}\right)\right)$

$=\left(\mathrm{A} / \mathrm{SpecX}_{1}\right)\left([\mathrm{K}] \mathrm{X}_{1} \cdot\left(\mathrm{SpecX}_{2}\right)\left([\mathrm{C}] \mathrm{X}_{2} \cdot[\mathrm{B}] \mathrm{X}_{1} \mathrm{X}_{2}\right)\right) v$

$\left.\left(\operatorname{SpecX}_{1}\right)\left([\mathrm{A} / \mathrm{K}] \mathrm{X}_{1} \vee\left(\mathrm{A} / \operatorname{specX}_{2}\right)\left([\mathrm{C}] \mathrm{X}_{2} \cdot[\mathrm{B}] \mathrm{X}_{1} \mathrm{X}_{2}\right) \vee\left(\operatorname{SpecX_{2}}\right) \not(\mathrm{C}] \mathrm{X}_{2} \cdot[\mathrm{B}] \mathrm{X}_{1} \mathrm{X}_{2}\right)\right)$

$=\left(\mathrm{A} / \operatorname{SpecX}_{1}\right)\left([\mathrm{K}] \mathrm{X}_{1} \cdot\left(\operatorname{SpecX}_{2}\right)\left([\mathrm{C}] \mathrm{X}_{2} \cdot[\mathrm{B}] \mathrm{X}_{1} \mathrm{X}_{2}\right)\right) v$

$\left(\operatorname{SpecX}_{1}\right)\left([\mathrm{A} / \mathrm{K}] \mathrm{X}_{1} \vee\left(\mathrm{A} / \mathrm{SpecX}_{2}\right)\left([\mathrm{C}] \mathrm{X}_{2} \cdot[\mathrm{B}] \mathrm{X}_{1} \mathrm{X}_{2}\right) \vee\right.$

$\left.\left(\operatorname{SpecX}_{2}\right)\left([\mathrm{A} / \mathrm{C}] \mathrm{x}_{2} \vee[\mathrm{A} / \mathrm{B}] \mathrm{X}_{1} \mathrm{X}_{2}\right)\right)$

This gives exactly the result we need - namely that a given statement will be false if one or any combination of the semantic properties is not met in the state of affairs it describes. In particular it allows the combination of $[\mathrm{A} / \mathrm{K}] \mathrm{X}_{1}$ and or $[\mathrm{A} / \mathrm{C}] \mathrm{X}_{2}$ and $/ \mathrm{or}[\mathrm{A} / \mathrm{B}] \mathrm{X}_{1} \mathrm{X}_{2} \cdot B i e r w i s c h \mathrm{~s}$ alternative (ii) cannot predict this range of possibilities. It would predict the following reading:

Af $[B]\left(\operatorname{SpecX}_{1}\right)\left([\mathrm{K}] \mathrm{x}_{1}\right)\left(\operatorname{specX}_{2}\right)\left([\mathrm{C}] \mathrm{x}_{2}\right)$

$=[\mathrm{A} / \mathrm{B}]\left(\operatorname{SpecX}_{1}\right)\left([\mathrm{K}] \mathrm{X}_{1}\right)\left(\mathrm{SpecX}_{2}\right)\left([\mathrm{C}] \mathrm{X}_{2}\right) \vee$

[B] $A /\left(\operatorname{SpecX}_{1}\right)\left([K] X_{1}\right) \vee A /\left(\operatorname{SpecX}_{2}\right)\left([C] X_{2}\right)^{16}$

16. The negation rule I have applied here is the equivalent to that given above, viz: $A /[S]\left(\operatorname{SpecX}_{j}\right)=[A / S]\left(\operatorname{SpecX}_{i}\right) \vee[S]\left(A / \operatorname{SpecX}_{i}\right)$ 
$=[\mathrm{A} / \mathrm{B}]\left(\operatorname{SpecX}_{1}\right)\left([\mathrm{K}] \mathrm{X}_{1}\right)\left(\operatorname{SpecX}_{2}\right)\left([\mathrm{C}] \mathrm{X}_{2}\right) v$

[B] $\left(\mathrm{A} / \operatorname{SpecX}_{1}\right)\left([K] \mathrm{X}_{1}\right) \vee\left(\operatorname{SpecX}_{1}\right)\left([\mathrm{A} / \mathrm{K}] \mathrm{X}_{1}\right) \vee\left(\mathrm{A} / \mathrm{SpecX}_{2}\right)\left([\mathrm{C}] \mathrm{X}_{2}\right) \vee$ $\left(\operatorname{specX}_{2}\right)\left([A / C] x_{2}\right)$

But this formulation does not allow the combination of $[A / B]$ and either

$[\mathrm{A} / \mathrm{C}]$ or $[\mathrm{A} / \mathrm{K}]$ a combination clearly demanded by sentences such as

The King didn't buy the chandelier: what happened was that the Duke sold the candlestick. I shall therefore assume that the first

alternative is the correct one.

In addition to such a negation rule, analogous rules will be needed for the interpretation of opaque contexts, since these provide exactly the same indeterminacy in the interpretation of the reference of noun phrases within theix scope as negation (cf. ch. $5 \mathrm{pp} 138 \mathrm{f}, 156 \mathrm{ff}$ ).$^{17}$

These rules will differ according as for example the operator demands that the 'world' it describes not be co-extensive with the real world (of which a possible example is pretend, though cf. ch.4 fn.11), or whether the operator allows the ase where the 'world' it describes is co-extensive with the real world (e.g. look for, believe). I shall not provide a formalisation of these since the details are not central to the argument

17. For a different proposal, cf. Jackendoff 1971 who argues that any formalism which uses quantifiers whose scope is as large as an entire proposition (e.g. traditional quantificational logic) is in principle incapable of capturing the appropriate interpretation of sentences containing opaque contexts, on the grounds that for example John is trying to find a pretty girl does not mean that 'John is trying to cause there to be a pretty girl such that he finds her' since he is not trying to make someone exist. His translation of the predicate calculus formula is not however correct. It should read 'John is trying to cause it to be true that there is a pretty girl such that he finds her' which does not entail that John is trying to cause the girl's existence. (For a related discussion of operators like cause which do not 'penetrate' to the entailments of their propositional argument, cf. Dretske 1970) . In any case, when his own analysis of the referential properties of noun phrases is extended to entire sentences, Jackendoff's system falls prey to all the problems of quantificational logic, and is thus no more than a terminological equivalent. 
of this thesis. However I think the existence of these rules in principle cannot be doubted. Furthermore these rules will only affect the interpretation of the noun phrases and their indices: they will not constitute deletion rules. The syntactic function of the index for relativisation etc will therefore be unaltered despite the fact that the interpretation of the index may be that there is no realworld referent (as in for example: John did not buy a car which is convertible - he bought a lorry). 18

\subsection{Inter-Sentence Relations - Which Solution?}

I have so far argued about and formalised the relation between definite and indefinite noun phrases within the framework of a sentencebased grammar, and I have more or less ignored the problem of relations between indefinite and definite noun phrases across sentence boundaries. Yet it is well-known that anaphora is not restricted to the confines of the single sentence, and the critical reader may have doubted my conclusions on the strength of these examples. This problem must now be faced. There are three possible solutions:

(A) to treat definite noun phrases as always constituting a second mention of some indefinite noun phrase and as therefore containing either in the underlying structure or in the semantic interpretation the information that there was a prior mention of that noun phrase; (B) to treat sentences with only a definite noun phrase as different in principle from sentences containing co-referring pairs of indefinite and definite noun phrases;

\footnotetext{
18. This avoids the problem pointed out by Baker (1966) that a noun, though it have no referent, may still allow restrictive relative clause modification which apparently demands coreference between the superordinate noun phrase and the noun phrase in the embedded sentence.
} 
(c) to treat indefinite and definite noun phrases identically, and to treat sentences with only a definite noun phrase ad-hocly on the basis that inter-sentence relations are excluded by fiat, since they constitute part of a theory of discourse, not a theory of semantics. Alternative (A) has occasionally been put forward. 19 However it is in my view untenable. The syntax of a simple sentence cannot be allowed to have a conjoint sentence as part of its underlying structure for two reasons: (i) there is no syntactic evidence to justify such an underlying structure - I can conceive of no relevant syntactic constraints which a simple sentence such as A man hit the gixl would share with a conjoint structure such as There is a girl and a man hit the girl (cf. ch.I section 1,2,1) (ii) general conditions on recoverability prohibit such an analysis, since the details of the sentence preceding the occurrence of any given definite noun phrase are quite undecidable. It is not even possible to predict that the preceding sentence contain an indefinite noun phrase since it may not. The preceding noun phrase might itself be definite, or a pronoun (as in (36)):

(36) A man came. He sat down and eventually a girl came. At that point the man left.

Similar reasons militate against a semantic rule stating as part of the interpretation of a simple sentence that the preceding sentence has contained in it an indefinite noun phrase. To incorporate either type of rule into the grammar would be to transform the grammar from a grammar predicting the sentences of some language into a grammar

19. Cf. Bakex 1966 Jackson 1971. 
predicting the discourse of some language. But, as the example above shows, the structure of a discourse is not predictable in the way that the structure of a sentence is. One cannot predict what sentence will precede or follow any given sentence. Thus any attempt to incorporate such a prediction into the grammar is in principle doomed to failure.

The second alternative, (B), treats definite noun phrases with no preceding coreferential noun phrase as different in kind from definite noun phrases which form such a pair. This is in effect a weaker form of a presupposition-based theory. Definite noun phrases with no preceding indefinite noun phrase (whethex with a relative clause or not) would be said to presuppose the existence of the referent, whereas in co-ordinate structures where the constraints are naturally explicable in terms of entailment, an analysis of the definite noun phrases in question as entailing the existence of their referent would seem more appropriate. 20 Such an analysis is not however satisfactory, since the very general claim that intersentence relations are in principle different from intra-sentence relations would follow as a consequence. This solution - despite its superficial attractiveness in accounting for certain constraints on sentences (e.g. the protection of definite noun phrases with restrictive relative clauses from the scope of negation) seems therefore to lead to a highly counter-intuitive conclusion. It is not the case that all inter-sentence relations are different in kind from relations within a sentence. Indeed, coreference causes this theoretical difficulty just because it is the same phenomenon which is operating both between and within sentences. A framework which treats one and the same

20. This solution is not in fact adopted by anyone, but unless some such solution is adopted the examples given here in preceding sections provide an embarrassing wealth of counter-examples. 
phenomenon in the form of two quite different statements, referring to two different logics, is not one to be accepted lightly.

The third alternative, (c), is to admit the limits of one's model openly, to provide a mechanism which deals with the counter-examples albeit ad-hocly and which provides a general theory within which the ad-hoc distinction can be explained away. It is this final alternative which - in the face of no adequate alternative solution - I wish to put forward. Definite noun phrases which have no preceding noun phrase with which they explicitly corefer, must be entered in the underlying structure of the sentence as definite noun phrases. To effect this, we shall say that all noun phrases have a referring index in underlying structure and they may optionally have an additional syntactic feature [+Def]. This feature does not take part in any transformation and is not interpreted by the semantic rules operating at the base. The definitisation rule then operates on coreferential noun phrases, without taking these [+Def] features already in the phrase marker into account. That is, it applies ixrespective of whether the first noun phrase of the co-referring pair is marked [t-Def] and it applies redundantly where a [Def] feature was assigned in the base on a coreferential noun phrase. The morphological rules then guarantee the spelling out of the and a. The feature [+Def], like the feature [FPro], will not be given any interpretation by the grammar, which will predict synonymy between The man hit me and A man hit me. This is arguably not counter-intuitive. The distinction between The man hit me and A man hit me is, as we have already seen (cf. ch.5 p. 162 ), explicable in terms of the speakex's assumption of what the hearer knows. The man hit 
me implies that the hearer knows who is being referred to, while A man hit me does not. But as I have already argued in chapter 4 ( $p$ 12lff) this type of relation cannot and should not be handled within a formal model and so must be excluded by fiat.

\subsection{The Formulation of Factive Complements}

In the light of the formulation given to definite noun phrases in the last two sections, we are now in a position to discuss a possible formulation of the interpretation of the factive verbs. We saw in chapter 1 that some predicates take propositions as arguments e.g. [CAUSE]; and from the discussion of factives in chapter 4, it becomes clear that propositions which operate as arguments must be divided into at least two types - those whose truth is entailed by the superordinate predicate and those whose truth-value assignment is independent of the superordinate predicate. The factive predicates delimited by the Kiparskys (1970) constitute a subset of those predicates which entail the truth of their (propositional) argument, and the Kiparskys argued on syntactic and semantic grounds that sentences containing factive predicates plus that complements or gerunds should be derived from an underlying structure identical to sentences containing an explicit definite noun phrase complement - i.e. that John regretted that Mary was sick and John regretted the fact that Mary was sick should have the same underlying structure. The syntactic evidence that they offer for the distinction between factive and non-factive verbs is: (i) Only factives can take the full range of gerundives (without tense or adverbial constraints) as object complements - hence the distribution 
(37) John regretted Bill's having whipped the dog so hard

(38) John resented Edward's seeing his sister every day

(39) *John thought Bill's whipping Mary

(40) *Edward assumed Alice's creating a fuss in each lecture

(ii) Only non-factives allow the transformation of 'raising' 21 to

object position:

(41) *John regretted Mary to be right

(42) *Edward resented Bill to be the winner

(43) John believed Mary to be right

(44) Edward expected Bill to be the winner

(iii) Only non-factives allow the rule of negative transportation

(cf. R.Lalsoff 1969) - thus

(45) John thought that Bill wasn't there

is equivalent to

(46) John didn't think that Bill was there

but this is not true of the pair (47)-(48)

(47) John didn't regret that Bill was there

(48) John regretted that Bill wasn't there

(iv) Only factives can be followed by the fact that $S$ construction, which

is synonymous with a simple that complement

(49) John regrets the fact that Mary came early

(50) John resents the fact that Mary came early

(51) *John thinks the fact that Bill is right

(52) *Jo imagined the fact that Peter was thexe

To this list we can add two further criteria: (v) the sequence of tense constraint and (vi) adverb preposing. 22 Non-factive verbs share the

21. This rule has also been referred to as pronoun-replacement (Rosenbaum 1967) and it-replacement (Jacobs and Rosenbaum 1968).

22. These criteria were mentioned in a different connection by Ross in a lecture in Cambridge, April 1973. 
property that the tense of the embedded complement clause must agree with the verb complements the normal tense contrast of present and past.

(53) At first my parents deeply regretted that $\left\{\begin{array}{l}I^{\prime} v e \\ \text { I'd }\end{array}\right\}$ decided not to have any more children (54) My parents eventually realised that $\left\{\begin{array}{l}I ' m \\ I \text { was }\end{array}\right\}$ determined not to have

(55) At first my parents thought/believed/imagined that $\left\{\begin{array}{c}\text { *I've } \\ \text { I'd }\end{array}\right\}$ decided not to have any children

(vi), Adverb preposing, concerns the ease with which an adverb of the embedded complement clause can be moved to the front of the superordinate clause. Non-factives allow this; factives do not. Thus we get

(56) I think he'll be in York tomorrow

(57) Tomorrow I think he'II be in York

(58) I imagine that Mom will give the game away tomorrow

(59) Tomorrow I imagine that Rom will give the game away

(60) I suggest we go to Windsor tomorrow

(6I) Tomorrow I suggest we go to Windsor

(62) I realise that Mary is leaving tomorrow

(63) *Tomorrow I realise that Mary is leaving

(64) I resent it that Mary is leaving tomorrow

(65) *Tomorrow I resent it that Mary is leaving

(66) I'm suprised that Mary is leaving tomorrow

(67) *Tomorrow I'm surpirised that Mary is leaving

In the light of this evidence ${ }^{23}$ I shall assume - together with the Kiparskys that factive and non-factive complements differ in that the former is assigned an underlying structure of the form:

23. There are several verbs which do not fulfil all the criteria of the semantic class to which they helong, but in each case the verb will fulfil a majority of the conditions: e.g. imagine which takes the full range of gerundives but which allows negative transportation ( $I$ don't imagine he'll come) and adverb preposing (cf. eg's (58)-(59)), requires sequence of tense agreement (*They imagined that you are sick) and cannot take the fact that $S$ constructions. 


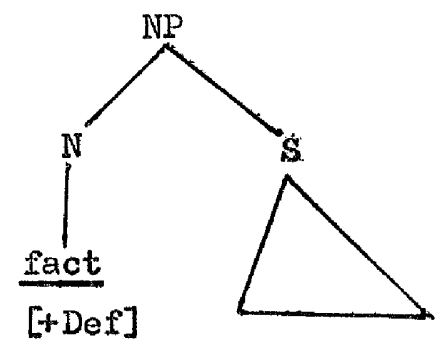

The problem we now meet of formaljsing the semantic interpretation of factive complements thus becomes one of formalising the interpretation of those definite noun phrases where the head noun and the entire modifying proposition are co-referential.

Bierwisch (1971) has argued ( $p .425)$ that these 'fact' noun phrases should be interpreted along lines indicated by Reichenbach (1947) - as involving the specification of a given fact where the proposition expressed is the name of that fact. 24 Formally, this is expressed as $\left(\mathrm{SpecX}_{i}\right)\left([\mathrm{P}] \mathrm{X}_{i}\right)^{25}$ for some proposition $P$ whose truth is entailed by the statement in which it is embedded as a complement. 26 For example, if we represent the semantic components of regret schematically as [REGRET], those of king as [K] and those of the Queen is sick as $[\mathrm{P}]$, then the semantic representation of The King regrets that the Queen is sick will be:

$$
\left(\operatorname{SpecX}_{1}\right)\left([K] \mathrm{X}_{1} \cdot\left(\operatorname{SpecX}_{2}\right)\left([\mathrm{P}] \mathrm{X}_{2} \cdot[\mathrm{REGRET}] \mathrm{X}_{1} \mathrm{X}_{2}\right)\right)
$$

Now, in the case of the Kiparskys' factive verbs, there is a close correspondence between the deep-structure syntactic representation

24. Cf. Keenan 1972 p. $419 f$ for a similar formal characterisation of factive predicates.

25. This formulation assumes the position argued earlier (ch.5 section 5.3) that definite and indefinite noun phrases are semantically nondistinct.

26. Definite noun phrases containing relative clauses are distinct from this since there is no variable ranging over the proposition itself. Thus the ambiguity of the fact that Mary wrote is reflected schematically in two different semantic representations:
(a) for the relative: $\left(\operatorname{SpecX}_{1}\right)\left([\mathrm{F}] \mathrm{X}_{1} \cdot\left(\operatorname{SpecX}_{2}\right)\left([M] \mathrm{X}_{2} \cdot[W] \mathrm{X}_{2} \mathrm{X}_{1}\right)\right)$
(b) for the non-relative: $\left(\operatorname{Specx}_{1}\right)\left(\left[\left(\operatorname{Specx}_{2}\right)\left([M] x_{2} \cdot[W] x_{2}\right)\right] x_{1}\right)$ 
and the semantic representation, the syntactic representation reflecting the syntactic behaviour of this class of items. Yet this form of semantic representation is not restricted to the factive predicates: It is general to all semantic predicates which take a proposition as argument whose truth is entailed. Thus [CAUSE] for example, which in positive statements entails the truth of its complement proposition, will be of the form represented here. So The King of France killed the Queen of Persia, which contains the predicate [CAUSE] and entails the truth of the Queen of Persia died, will have a semantic representation which is not

$$
\left(\operatorname{SpecX}_{1}\right)\left([K] X_{1} \cdot\left(\operatorname{SpecX}_{2}\right)\left([Q] x_{2} \cdot[\operatorname{CAUSE}] X_{1}\left([D I E] X_{2}\right)\right)\right)^{27}
$$

where the second argument of [CAUSE] is a proposition, but rather $\left.\left(\operatorname{SpecX}_{1}\right)\left([K] X_{1} \cdot\left(\operatorname{SpecX}_{2}\right)\left(\left[\left(\operatorname{SpecX}_{3}\right)\left([Q] \mathrm{X}_{3} \cdot \mathrm{DIE}\right] \mathrm{X}_{3}\right)\right] \mathrm{X}_{2} \cdot[\mathrm{CAUSE}] \mathrm{X}_{1} \mathrm{X}_{2}\right)\right)^{28}$ Implicit in this formulation is the claim that the relation between a true proposition and the state of affatrs which it expresses can be explained by means of the same formal mechanism as the relation between a symbol and the specific object to which it refers. There are many philosophical problems attendant on this claim: and suggestions which have been put forward along these lines have proved controversial cf. particularly Reichenbach's 'fact functions' (Reichenbach 1947 p.269 ff ) and Frege's concept of truth-value being the referent of a proposition (Frege 1892, translated 1966 p.63). I cannot enter here into all the issues which such a formulation implies. However, should the claim that objects and facts can legitimately be treated as the same type of

27. I assume here and elsewhere in this section for simplicity that [DID] is primitive, since its internal structure is not germane to the arguments here.

28. It might seem that the semantic representation should have the quantifier scope of $\mathrm{X}_{2}$ and $\mathrm{X}_{3}$ reversed so that the existence of the Queen of Persia in the above example is outside the range of the [CAUSE] predicate. Arguments to this effect have been given by Jackendoff 1971. For arguments against this alternative, cf. fn. 17 of this chapter. 
formal object prove too strong, it would be a straightforward matter to allow another form of quantifier which ranged only over propositions. Since this would be a veakening of the theory, I shall maintain the more restrictive form in the absence of further evidence. 29 Some confirmation of the correctness of this analysis can however be gained by seeing how this formal mechanism interacts with the rule of negation. Given the solnematic semantic representation of The King of France killed the Queen of Persia suggested on the previous page, and given the rule of negation:

$$
A /[P . Q] \equiv[A / P \vee A / Q] \quad(c f . p .33)
$$

and its subparts

$[A / P] \equiv[-P]$ where $P$ is the sole member of a set (cf. p.33) $A /\left(\operatorname{SpecX} X_{i}\right)\left([S] X_{i}\right) \equiv\left(A / S p e c X_{i}\right)\left([S] X_{i} \vee\left(\operatorname{SpecX}_{i}\right)\left([A / S] X_{i}\right) \quad\left(c f_{0} p_{1} 176\right)\right.$ the negation rule would predict that The King of France did not kill the Queen of Persia be assigned a semantic interpretation as follows: A/ $\left(\operatorname{SpecX}_{1}\right)\left([K] X_{1} \cdot\left(\operatorname{SpecX}_{2}\right)\left(\left[\left(\operatorname{SpecX}_{3}\right)\left([Q] X_{3} \cdot[D I E] X_{3}\right)\right] X_{2} \cdot[\right.\right.$ CAUST $\left.\left.] X_{1} X_{2}\right)\right)$ $=\left(\mathrm{A} / \mathrm{SpecX}_{1}\right)\left([\mathrm{K}] \mathrm{X}_{1} \cdot\left(\operatorname{SpecX}_{2}\right)\left(\left[\left(\operatorname{SpecX}_{3}\right)\left([\mathrm{Q}] \mathrm{X}_{3} \cdot[D I E] \mathrm{X}_{3}\right)\right] \mathrm{X}_{2} \cdot[\mathrm{CAUSE}] \mathrm{X}_{1} \mathrm{X}_{2}\right)\right) \mathrm{v}$ $\left(\operatorname{Speax}_{1}\right) A /\left([K] x_{1} \cdot\left(\operatorname{SpecX}_{2}\right)\left(\left[\left(\operatorname{SpecX}_{3}\right)\left([Q] x_{3} \cdot[D I E] \mathrm{X}_{3}\right)\right] \mathrm{X}_{2} \cdot[\right.\right.$ CAUSE $\left.\left.] \mathrm{X}_{1} \mathrm{X}_{2}\right)\right)$ $=\left(\mathrm{A} / \mathrm{SpecX}_{1}\right)\left([\mathrm{K}] \mathrm{X}_{1} \cdot\left(\operatorname{SpecX_{2}}\right)\left(\left[\left(\operatorname{specX}_{3}\right)\left([Q] \mathrm{X}_{3} \cdot[D I R] \mathrm{X}_{3}\right)\right] \mathrm{X}_{2} \cdot[\mathrm{CAUSH}] \mathrm{X}_{1} \mathrm{X}_{2}\right)\right) \nabla$ $\left(\operatorname{SpecX}_{1}\right)\left([\mathrm{A} / \mathrm{K}] \mathrm{X}_{1} \vee \mathrm{A} /\left(\operatorname{SpecX}_{2}\right)\left(\left[\left(\operatorname{SpecX}_{3}\right)\left([\mathrm{Q}] \mathrm{X}_{3} \cdot[\mathrm{DIE}] \mathrm{X}_{3}\right)\right] \mathrm{X}_{2} \cdot[\mathrm{CAUSE}] \mathrm{X}_{1} \mathrm{X}_{2}\right)\right)$ $\equiv\left(\mathrm{A} / \mathrm{SpecX}_{1}\right)\left([\mathrm{K}] \mathrm{X}_{1} \cdot\left(\operatorname{SpecX}_{2}\right)\left(\left[\left(\operatorname{SpecX}_{3}\right)\left([\mathrm{Q}] \mathrm{X}_{3} \cdot[\mathrm{DIE}] \mathrm{X}_{3}\right)\right] \mathrm{X}_{2} \cdot[\mathrm{CAUSE}] \mathrm{X}_{1} \mathrm{X}_{2}\right)\right) \quad v$ $\left(\mathrm{SpecX}_{1}\right)\left([\mathrm{A} / \mathrm{K}] \mathrm{X}_{1} \vee\left(\mathrm{A} / \operatorname{SpecX}_{2}\right)\left(\left[\left(\operatorname{SpecX}_{3}\right)\left([\mathrm{Q}] \mathrm{X}_{3} \cdot[D I E] \mathrm{X}_{3}\right)\right] \mathrm{X}_{2} \cdot[\mathrm{CAUSE}] \mathrm{X}_{1} \mathrm{X}_{2}\right) \mathrm{v}\right.$ $\left(\operatorname{SpecX_{2}}\right) A /\left(\left[\left(\operatorname{SpecX}_{3}\right)\left([Q] X_{3} \cdot[D I E] X_{3}\right)\right] X_{2} \cdot[\right.$ CAUSE $\left.\left.] X_{1} X_{2}\right)\right)$ $\equiv\left(\mathrm{A} /\right.$ SpecX $\left._{1}\right)\left([K] \mathrm{X}_{1} \cdot\left(\operatorname{SpecX}_{2}\right)\left(\left[\left(\operatorname{SpecX}_{3}\right)\left([Q] \mathrm{X}_{3} \cdot[D I E] \mathrm{X}_{3}\right)\right] \mathrm{X}_{2} \cdot[\right.\right.$ CAUSE $\left.\left.] \mathrm{X}_{1} \mathrm{X}_{2}\right)\right) \mathrm{v}$ $\left(\operatorname{SpecX}_{1}\right)\left([A / K] X_{1} \vee\left(A / \operatorname{SpecX}_{2}\right)\left(\left[\left(\operatorname{SpecX}_{3}\right)\left([Q] X_{3} \cdot[D I E] X_{3}\right)\right] X_{2} \cdot[C A U S E] X_{1} X_{2}\right) v\right.$ $\left.\left(\operatorname{SpecX}_{2}\right)\left(\mathrm{A} /\left[\left(\operatorname{SpecX}_{3}\right)\left([Q] \mathrm{X}_{3} \cdot[D I E] \mathrm{X}_{3}\right)\right] \mathrm{X}_{2} \vee[\mathrm{A} / \mathrm{CAUSE}] \mathrm{X}_{1} \mathrm{X}_{2}\right)\right)$

29. For some discussion of this question, cf. Martin 1971a, who first argues agajnst Reichenbach's use of the same operators over facts and objects, but who later (p.129f.) admits that a perfectly satisfactory formal system would also hold if the distinction between the two were not taken as primitive. For support of the weaker view that propositions should legitimately be quantified over, cf. Vendler 1967 $\mathrm{b}$. 


$$
\begin{aligned}
& \equiv\left(A / \text { SpecX }_{1}\right)\left([K] X_{1} \cdot\left(\operatorname{SpecX}_{2}\right)\left(\left[\left(\operatorname{SpecX}_{3}\right)\left([Q] \mathrm{X}_{3} \cdot[D I E] \mathrm{X}_{3}\right)\right] \mathrm{X}_{2} \cdot\left[\text { CAUSE]X } \mathrm{X}_{2} \mathrm{X}_{2}\right)\right) \mathrm{v}\right. \\
& \left(\operatorname{SpecX}_{1}\right)\left([\mathrm{A} / \mathrm{K}] \mathrm{X}_{1} \vee\left(\mathrm{A} / \mathrm{SpecX}_{2}\right)\left(\left[\left(\mathrm{SpecX}_{3}\right)\left([\mathrm{Q}] \mathrm{X}_{3} \cdot[\mathrm{DIE}] \mathrm{X}_{3}\right)\right] \mathrm{X}_{2} \cdot[\mathrm{CAUSE}] \mathrm{X}_{1} \mathrm{X}_{2}\right) v\right. \\
& \left(\operatorname{specX}_{2}\right)\left(\left[\left({\mathrm{A} / S p e c X_{3}}_{3}\right)\left([Q] \mathrm{X}_{3} \cdot[D I E] \mathrm{X}_{3}\right) \vee\left(\operatorname{SpecX}_{3}\right) \mathrm{A} /\left([\mathrm{Q}] \mathrm{X}_{3} \cdot[D I E] \mathrm{X}_{3}\right)\right] \mathrm{X}_{2} \mathrm{v}\right. \\
& \left.\left.[\mathrm{A} / \mathrm{CAUSE}] \mathrm{x}_{1} \mathrm{X}_{2}\right)\right) \\
& \text { 虽 }\left(\mathrm{A} / \mathrm{SpecX}_{1}\right)\left([\mathrm{K}] \mathrm{X}_{1} \cdot\left(\mathrm{SpecX}_{2}\right)\left(\left[\left(\operatorname{SpecX}_{3}\right)\left([Q] \mathrm{X}_{3} \cdot[D I E] \mathrm{X}_{3}\right)\right] \mathrm{X}_{2} \cdot[\mathrm{CAUSE}] \mathrm{X}_{1} \mathrm{X}_{2}\right)\right) v \\
& \left(\operatorname{SpecX}_{1}\right)\left([\mathrm{A} / \mathrm{K}] \mathrm{X}_{1} \mathrm{v}\left(\mathrm{A} / \mathrm{SpecX}_{2}\right)\left(\left[\left(\operatorname{SpecX}_{3}\right)\left([Q] \mathrm{X}_{3} \cdot[D I B] \mathrm{X}_{3}\right)\right] \mathrm{X}_{2} \cdot[\mathrm{CAUSE}] \mathrm{X}_{1} \mathrm{X}_{2}\right) \mathrm{v}\right. \\
& \left(\operatorname{SpecX}_{2}\right)\left(\left[\left(A / \operatorname{SpecX}_{3}\right)\left([Q] X_{3} \cdot[D I D] X_{3}\right) \vee\left(\operatorname{SpecX}_{3}\right)\left([A / Q] X_{3} v[A / D I E] X_{3}\right)\right] X_{2} v\right. \\
& \text { [A/CAUSE } \left.] \mathrm{X}_{1} \mathrm{X}_{2}\right) \text { ) }
\end{aligned}
$$

This is just the result we want. We have (at least) seven possible interpretations, ${ }^{30}$ each of which is exemplified in the following contextualisations. (corresponding in order to the order of the disjuncts): (68) The King of France didn't kill the Queen of Persia - there's no such person as the King of France

(69) The King of France didn't kill the Queen of Persia - it was the Shah who did

(70) The King of France didn't kill the Queen of Persia - she's here

(71) The King of France didn't kil] the Queen of Persia - there's no such person as the Queen of Persia

(72) The King of France didn't kill the Queen of Persia - he killed the queen of Ithiopia

(73) The King of France didn't kill the Queen of Persia - he merely made her very ill

(74) The King of France didn't kill the Queen of Persia - nobody did, she just died

Informally, the rule states that the King of France did not kill the Queen of Persia is true just in case any one or more of the predicate terms falls within the scope of negation and hence the property to

30. There are more than seven possible interpretations, since the ' $v$ ' of the negation rule is inclusive. 
which it corresponds fails to hold in the state of affairs being described. Furthermore, it states that if any of the delimiting argument features is interpreted as falling within the scope of nepation, then all the components which depend on the argument in question must of necessity fail. Thus if theie mo referent corresponding to $x_{1}$ not only is there no King of France but there cannot have been a killing of the type described; if there was no fact corresponding to $\mathrm{X}_{2}$, then either there was no Queen of Persia or she didn't die; and conversely if there was no Queen of Persia then there cannot have been a fact corresponding to $\mathrm{X}_{2^{*}}$. Thus our independently justified negation rule predicts correctly that (a) if the statement There is a King of France is false then of necessity The King of France did not kill the Queen of Persia is true; (b) if the entailed fact is false then either it is false because she did not die, or because there is a queen of Persia is false; and (c) if There is a Queen of Persia is false indeperdently of whatever action the King of France may or may not have taken, 31 them not only is it of necessity false that the queen of Persia died at the time specified, but also it is of necessity true that the King of France did not kill the Queen of Persia.

As a further example, take The King regrets that the Queen is sick, which we represented schematically before as:

$$
\left(\operatorname{SpecX}_{1}\right)\left([K] \mathrm{X}_{1} \cdot\left(\operatorname{SpecX_{2}}\right)\left([P] \mathrm{X}_{2} \cdot[\mathrm{REGRET}] \mathrm{X}_{1} \mathrm{X}_{2}\right)\right)
$$

If we now break down the semantic structure of ' $P$ ' giving the components of queen as [Q] and those of sick as [S] we get:

31. The complication caused here by the use of the verb kill in this example is irrelevant to the general point. 
$\left(\operatorname{SpecX}_{1}\right)\left([K] X_{1} \cdot\left(\operatorname{SpecX}_{2}\right)\left(\left[\left(\operatorname{SpecX}_{3}\right)\left([Q] X_{3} \cdot[S] X_{3}\right)\right] X_{2} \cdot[R E G R T T] X_{1} X_{2}\right)\right)$ The semantic representation of The King does not regret that the Queen is sick is then predicted to be A/ $\left(\mathrm{SpecX}_{2}\right)\left([\mathrm{K}] \mathrm{X}_{1} \cdot\left(\mathrm{SpecX}_{2}\right)\left(\left[\left(\mathrm{SpecX}_{3}\right)\left([Q] \mathrm{X}_{3} \cdot[\mathrm{S}] \mathrm{X}_{3}\right)\right] \mathrm{X}_{2} \cdot[\mathrm{REGRET}] \mathrm{X}_{1} \mathrm{X}_{2}\right)\right)$ $\equiv\left(A / \operatorname{SpecX}_{2}\right)\left([K] X_{2} \cdot\left(\operatorname{SpecX}_{2}\right)\left(\left[\left(\operatorname{SpecX}_{3}\right)\left([Q] X_{3} \cdot[S] X_{3}\right)\right] X_{2} \cdot[R E G R E T] X_{1} X_{2}\right)\right) v$ $\left(\operatorname{SpecX}_{1}\right) A /\left([K] X_{1} \cdot\left(\operatorname{SpecX}_{2}\right)\left(\left[\left(\operatorname{SpecX} X_{3}\right)\left([Q] X_{3} \cdot[S] X_{3}\right)\right] X_{2} \cdot[R E G R E P] X_{1} X_{2}\right)\right)$ $=\left(A / S p e c X_{1}\right)\left([K] X_{1} \cdot\left(\operatorname{SpecX}_{2}\right)\left(\left[\left(\operatorname{SpecX}_{3}\right)\left([Q] X_{3} \cdot[S] X_{3}\right)\right] X_{2} \cdot[R E G R E M] X_{1} X_{2}\right)\right) v$ $\left(\operatorname{SpecX}_{1}\right)\left([\mathrm{A} / \mathrm{K}] \mathrm{X}_{1} \vee \mathrm{A} /\left(\operatorname{SpecX}_{2}\right)\left(\left[\left(\operatorname{SpecX}_{3}\right)\left([Q] \mathrm{X}_{3} \cdot[\mathrm{S}] \mathrm{X}_{3}\right)\right] \mathrm{X}_{2} \cdot[\mathrm{REGRET}] \mathrm{X}_{1} \mathrm{X}_{2}\right)\right)$ E. $\left(A / \operatorname{SpecX}_{1}\right)\left([K] X_{1} \cdot\left(\operatorname{SpecX} X_{2}\right)\left(\left[\left(\operatorname{SpecX}_{3}\right)\left([Q] X_{3} \cdot[S] X_{3}\right)\right] X_{2} \cdot[R E G R E T] X_{1} X_{2}\right)\right) v$ $\left(\mathrm{SpecX}_{1}\right)\left([\mathrm{A} / \mathrm{K}] \mathrm{X}_{1} \mathrm{v}\left(\mathrm{A} / \mathrm{SpecX}_{2}\right)\left(\left[\left(\operatorname{SpecX}_{3}\right)\left([\mathrm{Q}] \mathrm{X}_{3} \cdot[\mathrm{S}] \mathrm{X}_{3}\right)\right] \mathrm{X}_{2} \cdot[R E G R E T] \mathrm{X}_{1} \mathrm{X}_{2}\right) \quad \mathrm{v}\right.$ $\left.\left(\operatorname{SpecX}_{2}\right) A /\left(\left[\left(\operatorname{specX}_{3}\right)\left([Q] x_{3} \cdot[S] X_{3}\right)\right] X_{2} \cdot[R E G R T] X_{1} X_{2}\right)\right)$

$\left.=\left(\mathrm{A} / \mathrm{SpecX}_{1}\right)\left([\mathrm{K}] \mathrm{X}_{1} \cdot\left(\operatorname{SpecX}_{2}\right)\left(\left[\left(\mathrm{SpecX}_{3}\right)[\mathrm{Q}] \mathrm{X}_{3} \cdot[\mathrm{S}] \mathrm{X}_{3}\right)\right] \mathrm{X}_{2} \cdot[\mathrm{REGRET}] \mathrm{X}_{1} \mathrm{X}_{2}\right)\right) \mathrm{v}$ $\left(\operatorname{SpecX}_{1}\right)\left([\mathrm{A} / \mathrm{K}] \mathrm{X}_{1} \vee\left(\mathrm{A} / \mathrm{SpecX}_{2}\right)\left(\left[\left(\operatorname{SpecX}_{3}\right)\left([Q] \mathrm{X}_{3} \cdot[\mathrm{S}] \mathrm{X}_{3}\right)\right] \mathrm{X}_{2} \cdot\left[R E G R T T \mathrm{X}_{1} \mathrm{X}_{2}\right) \vee\right.\right.$

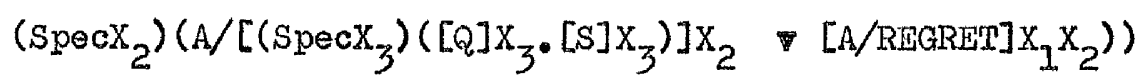

$\equiv\left(\mathrm{A} / \mathrm{SpecX}_{1}\right)\left([\mathrm{K}] \mathrm{X}_{1} \cdot\left(\operatorname{SpecX}_{2}\right)\left(\left[\left(\operatorname{SpecX}_{3}\right)\left([\mathrm{Q}] \mathrm{X}_{3} \cdot[\mathrm{S}] \mathrm{X}_{3}\right)\right] \mathrm{X}_{2} \cdot[\mathrm{REGRET}] \mathrm{X}_{1} \mathrm{X}_{2}\right)\right) \mathrm{v}$ $\left(\operatorname{SpecX}_{1}\right)\left([\mathrm{N} / \mathrm{K}] \mathrm{X}_{1},\left(\mathrm{~A} / \mathrm{SpecX}_{2}\right)\left(\left[\left(\operatorname{SpecX}_{3}\right)\left([Q] \mathrm{X}_{3} \cdot[\mathrm{S}] \mathrm{X}_{3}\right)\right] \mathrm{x}_{2} \cdot[\mathrm{REGRET}] \mathrm{X}_{1} \mathrm{X}_{2}\right) \mathrm{v}\right.$ $\left(\operatorname{SpecX_{2}}\right)\left(\left[\left(A / \operatorname{SpecX}_{3}\right)\left([Q] x_{3} \cdot[S] X_{3}\right) \vee\left(\operatorname{SpecX}_{3}\right) A /\left([Q] x_{3} \cdot[S] X_{3}\right)\right] x_{2} v\right.$

$\left.\left[A / R E G R H T X_{1} x_{2}\right)\right)$

$\equiv\left(\mathrm{A} / \mathrm{SpecX}_{1}\right)\left([\mathrm{K}] \mathrm{X}_{1} \cdot\left(\operatorname{SpecX}_{2}\right)\left(\left[\left(\operatorname{SpecX}_{3}\right)\left([\mathrm{Q}] \mathrm{X}_{3} \cdot[\mathrm{S}] \mathrm{X}_{3}\right)\right] \mathrm{X}_{2} \cdot[R E G R E T] \mathrm{X}_{1} \mathrm{X}_{2}\right)\right) v$ (a)

$\left(\operatorname{SpecX} X_{1}\right)\left([A / K] X_{1} \vee\left(A / \operatorname{SpecX}_{2}\right)\left(\left[\left(\operatorname{SpecX}_{3}\right)\left([Q] X_{3} \cdot[S] X_{3}\right)\right] X_{2} \cdot[R E G R D I] X_{1} X_{2}\right) v\right.$ (b) (c)

$\left(\operatorname{specX}_{2}\right)\left(\left[\left(\mathrm{A} / \mathrm{SpecX}_{3}\right)\left([\mathrm{Q}] \mathrm{X}_{3} \cdot[\mathrm{S}] \mathrm{X}_{3}\right) \vee\left(\mathrm{SpecX}_{3}\right)\left([\mathrm{A} / \mathrm{Q}] \mathrm{X}_{3} \vee[\mathrm{A} / \mathrm{S}] \mathrm{X}_{3}\right)\right] \mathrm{X}_{2} \mathrm{v}\right.$ (d)

(e)

$\left.[A / R E G R E T] x_{1} x_{2}\right)$ )

\section{(g)}

As before, the output of the rule predicts that if any of the quantifiers is negated, and hence there is no specific argument to which to attribute the respective predicates, then all the predicate features 
which depend on that argument must also fail to correspond to properties in the state of affaixs being described. Thus if there is no King, then The King does not regret that the Queen is sick must be true since the regret predicate must also fail to hold (though it may still be true that the Queen Is sick, since the specification of $x_{2}$ itself does not depend on $x_{1}$ ); if there is no fact $x_{2}$ then either there is no queen or she isn't sick and of necessity the King cannot have regretted it; and if there is no queen corresponding to $x_{3}$ then there can be no fact $x_{2}$ since $x_{2}$ is solely dependent on a conjoint set of properties pertaining to $\mathrm{X}_{3}$ and hence again the King cannot have suffered regret. This is - exactly the result we need - specifically that if there is no fact corresponding to $x_{2}$ and The Queen is sick is false, then (of ecessity) The King does not regret that the Queen is sick is thereby true; and if there is no Queen, then (a) The Queen is sick is false and (b), as before, The King does not regret that the Queen is sick is therefore true. It thus seems that our independently motivated formal mechanism gives the correct result in a nonm vacuous way.

Some details of the formulation must now be made more explicit. All propositional arguments in the semantic interpretation of a sentence whose truth is entailed are represented as falling within the scope of the 'Spec' quantifier, which also binds object-variables, according to the schema $\left(\operatorname{SpecX}_{i}\right)\left([P] \mathrm{X}_{i}\right)$. Their semantic representation is thus closely analogous to specific noun phrases. In the case of factive verbs and adjectives, this semantic parallel is explicitly reflected in the syntactic representation, which contains an underlying, 
definite noun phrase. The feature of definjteness is specified at the level of deep structure since the definite article in phrases such as the fact that Mary came are never anaphoric (cf. p.182). Indeed this type of construction demands the definite article: a fact that Mary came is ungrammatical as a noun-phrase construction. 32 A syntactic subcategorisational restriction on the lexical entry fact 33 will therefore guarantee that a rule assigning [-Def] to noun phrases optionally will in this case be obligatory. The semantic intexpretation of the entailed complements of factives in both positive and negative sentences is then predicted by rules of interpretation which are independentiy justified.

\subsection{Summary}

We have seen in this chapter how if we assume (a) that definite and indefinite noun phrases are in Beneral non-distinct both in their underlying syntactic representation and in their semantic representation and (b) that factives are non-distinct from definite noun phrases of the type the fact that $S$ in their underlying syntactic and semantic representation, then the already existing framework proposed by Bierwisch, with only minor extensions (cf. p.176), makes all and only the predictions the data demand. While the prediction of correct interpretations only provides functional justification for the analysis in hand, I take it that such predictive success provides at least strong partial confirmation of the philosophical assumptions on which it is

32. It is not of course in sentences such as It's a fact that Mary came but these constitute cases where extraposition has taken place. 33. Of the form $[+\operatorname{Def}$ S] 
based. Thus concepts such as Reichenbach's 'fact functions' receive some confirmation.

More generally, in this central section, I have considered what evidence there is for the incorporation into natural language semantics of either a logical or a speaker-oriented concept of presupposition. The conclusions were however negative: the evidence suggests on the contraxy that the semantic component of the grammar should not be revised to allow for the concept of presupposition, whichever way it is defined.

One of the most important assumptions I have made throughout has been the need to predict all the possible interpretations of negative sentences (given the agreement that 'interpretation' be understood in a truth-conditional sense). So there has been no attempt to predict in the specification of negative sentences what constitute likely interpretations and what much less likely ones - either in the case of sentences containing factive verbs or in the case of sentences containing definite noun phrases. In both, the rule of negation merely predicts all the logical possible ways in which negative sentences can be true. It might be argued (as I suggested on $\mathrm{p}_{0} 125 \mathrm{f}$ ) that likely interpretations (as the more 'natuxa1') should be distinguished from unlikely ones, and that this becomes a problem only if a relation of presupposition, however it is defined, is not recognised. But we shall see in the following section that an explanation of this problem is not a semantic matter. 
CHAPTER 7 : Towards a Pregmatic Theory

Throughout chapters 4-6 I. have had constant recourse to a theory of pragmatios. Whenever I faced counter-examples, both more and less serious, my excuse has been that this is a phenomenon which it is the function of a pragmatic theory to explain, and not that of a semantic theory. This excuse is little more than a lame fudge if there is no pragmatic theory to carry out the task assigned to it. We must now therefore ask what form such a pragmetic theory could take. Unfortunately there are as many divexgent delimitations of pragmatics as there are of semantics. 'When Morris first introduced the trichotomy of syntax, semantics and pragmatios $(1938,1946)$, pragmatics was charocterised as the study of the relation between an utterance and its intexpreters (speaker and hearer). But since Bar-Hillel sugrested in 1954 that pragnatios concern itself with the intexpretation of indexical expressions, there have arisen two quite separate applications of the tem pragmatics. It can be applied to the study of speech acts (cf. Stalneker $1972 \mathrm{p} .383 f$ ), or to an interpretation of indexical sentences (cf. Stalnaker ibid p.383ff, Montegue 1972). However in arguing that the semantics of a natural language involves a statement of the necessary and sufficient condition for the truth of the sentences of that language, I have already assurned (of. p.69f) that such a statement in the case of indexical sentences is part of semantios (as argued by Davidson 1967, Lewis 1972, Wiggins 1971). In any case I have referred to the need for a pragmatic theory at the points where the interpretation of sentences in natural language appears to involve phenomena which do not play any part in a truth definition for that language. And a pragmatics such as Montague's (Montague 1968, 1972)

1. Cf。 Hintikka 1968, Martin 1971b, Stalnakex 1972, Thomason 1973. 
which assigns a truth value to indexical. (and other) sentences (relative to some arbitraxy world) is no nearex to explajnjng these phenomena than a semantios stating necessary and suffictent conditions for truth. I am not thexefore using pragmatios here in the sense of Bar-Hillel, Montague and others. In the sense to be adopted here, pragmatios refers to the study of sentences in use, and I shall be assuming that a pragmatic theory is a theory which has to explain how a language is used to enable any speakex to oommunicate with any hearex (c. Thomason 1973 and Wiggins 1971, who make an equivalent use of the term). Such a, theory is put forwaxd by Gxice (1957, 1961, 1968, 1969), and in the remainder of this thesis, I shall attempt to show how the problems and implications pertaining to non-txuth-conditional properties of utterances (or sentences) can be explained within the theory of conversation set out by Grice. Since the concept and status of a pragmatic theory within an over-a.1]. theory of language is still quite uncleax, the greater part of what follows must be assumed to be in the nature of a tentative initial suggestion. Despite this caveat howevex, what I hope minimally to show is that Grice's framework can provide a natural explanation of the phenomena to which both linguists and logicians have given the label presupposition. If this explanation is at least in part correct, I shall take it that the restriction of semantios to a fxamework which is both truth-conditional and based on a two-valued logic receives double confirmation - (a ) from intermal. arguments such as the prediction for any given sentence of its entailments and contradictions arising from those entaijments, and (b) from the demonstration that those phenomena which are not a,coounted for by this form of semantics appear to be naturally explicable within a more general theory of communication (pragmatios). 


\subsection{Grice's Theory of Meaning}

Grice's theory has two parts: (i) a definition of speaker's meaning (ii) the setting up of maxims of behaviour to explain the co-operative nature of communication. ${ }^{2}$ With respect to speaker's meaning ('meaning ${ }_{n n}$ '), Grice argues that (roughly speaking) in uttering ' $x$ ', a speaker $(S)$ is intending for indicative utterances 3 (a) that the hearer (H) should believe that $S$ believes some proposition $\mathrm{p}$ and (b) that by virtue of his belief that $S$ believes p. H should also believe p. In more formal terms, Grice gives the following definition: 4

For some specific occasion, a speaker $S$ makes an utterance ' $\mathrm{X}$ ' to a hearer $H$ indicating that $p$ if he intends that:

(1) H should think $x$ has $f$ (where $f$ is a feature)

(2) II should think that he $S$ intends $H$ to think $x$ has $f$

(3) If should think $f$ is correlated in way $c$ with the state of believing that $p$ (where $p$ j.s the propositional content)

(4) H should think that $S$ intends that he (H) thinks $f$ is correlated in way $c$ with the state of believing th t $p$

(5) H should think he $S$ intends $H$ (via $I$ and 3) to think that $S$ believes that $p$

(6) on the basis of (5), H should think that in fact $S$ does believe that $p$ (7) H should think that S intends (6)

2. In all that follows, I shall give references wherever possible to the published accounts of Grice's work. Where the only account is the mimeo version of Grjee's William James lectures 1967/8, I have had no option but to give references to this unpubitshed but widely circulated account. I have not given detailed page references in this case.

3. Cf. p.209ff for a generalisation of Grice's definition of meaning to include imperatives and questions.

4. This definition (given in the William James lectures) combines the revisions to the 1957 account outlined in Grice 1969, with one omission which is not essential here (cf. in particulax Grice 1969 p.165), with the change made in the 1968 account that $H$ believe $p$ only from his belief that $S$ believes $p$, rather than directly from $S$ 's intentions (cf. Grice 1968 a p.230). 
(8) on the basis of (6) H should believe that $p_{0}^{5}$

That is to say, there is a general convention which all speakers

(and necessarily therefore al1 hearers) know (and moreover know that they all know) ${ }^{6}$ that in communicating some proposition $\mathrm{p}$, a speaker is communicating his belief that $p$ with the assumption that the hearer, knowing that the speaker only says $x$ if he believes that $p$, will also believe p.?

The obscure part of Grice's definition of somcalled 'meaning ${ }_{n n}$ ' is the relation between ' $x$ ', ' $f$ ', ' $c$ ' and ' $p$ '. The weaker one is that the relation between ' $x$ ', ' $f$ ', ' $c$ ' and ' $p$ ' is that conventionally provided by the rules of the language. 8 This weaker thesis j.s straightforwardly compatible with the framework suggested in this book. The interpretation which Grice intends is however a stronger thesis: ' $x$ ', ' $f$ ', ' $c$ ' and ' $p$ ', as part of a definition of utterancemeaning, are intended to cover what on any occasion an utterer may mean by using a sentence. And - as Grice points out - what a sentence means ('timeless meaning") is not necessarily the same as what an utterer might mean (speaker's meaning) in saying that sentence on a particular occasion. In saying for example 'He's a fine friend' of

5. I have not adopted Schiffer's revision of Grice's definition here (cf. Schiffer 1972), since this revision depends on the assumption. that the regress involved in this definition is not harmless. Cf. section 7.2.2 of this thesis for an argument that this is not the case.

6. Hence the constant inclusion of a defining criterion is intends that $H$ should think $X$ ' with a following criterion 'S intends that $H$ should think that $S$ intends $H$ to think $X$.

7. This definition of utterancemeaning depends on the assumption that wo all speak the truth, a problem to which I shall return on $p_{.} 202$

8. Cf. Apostel's (1971) paraphrase of Grice's condttions which includes the condition that the perception of the event is' (caused by the speaker.A) by the ane $B$ ' causes the epistemio state in $B$ about $A$ because $B$ believes that $E^{\prime}$ belongs to a set of events $\left\{\mathrm{I}^{\prime}\right\}$ whose structural description is such that only systems behaving in accordance with certain rules $R$ (speaking a certain language) will produce elements of $\left\{\mathrm{E}^{\prime}\right\}$. Moreover $B$ believes that these rules are such that only believing $p$ and wishing others to know $f(p)$ will produce $\mathrm{E}^{\prime}$ ' (p.14). 
somebody who has just left you in the lurch, you do not mean to indicate the proposition $\underline{p}$ which is correlated by the rules of the Janguage to the sentence you have uttered.

In its strongest form, Grice's explanation of meaning is not compatible with a truth-based definition of semantics, but is rather in direct conflict with it. What Grice has aimed to show (with Strawson as his articulate second - cf. Strawson 1964a, 1964b, 1971b and also Schiffer (1972)) is that (a) occasional (utterance meaning) can be defined as above in terms which do not presuppose the concept of linguistic meaning, and (b) linguistic meaning can then be defined in terms of occasional meaning. It follows from this that - if Grice, Strawson and Schiffer are correct - Iinguistic meaning can and should be defined in terms of the speaker's belief and intention in saying sentences.' The clarification of ' $x$ ', ' $f$ ', ' $c$ ' and ' $p$ ' in Grice's definition are therefore essential to an assessment of his claim.

While I am by no means certain that my interpretation of Grice is the correct one, I should like to consider some problems which appear to arise under the strong version of Grice's definition. We have already seen that to incorporate into a linguistic theory what a speakex might mean in saying a sentence on some particular occasion is to face the consequence that the meaning of sentences is unpredictable (cf. ch. 4 p.12uf 0 . Now, if sentence meaning is claimed to be derived from a definition of utterer's meaning, and this definition allows 'f', ' $c$ ' and ' $p$ ' to range over features, modes of correlation and propositions respectively which axe not conventionally indicated by the utterance ' $x$ ', then it is by no means clear how the consequence of nones

9. Cf. Strawson 1971b, where he argues that the notion of truth condition if it is not taken as primitive - can be defined in terms of communicationintention. 
predictability can be avoided. One possible way to avoid it would be to restrict ' $f$ ', ' $c$ ' and ' $p$ ' precisely so that they range': over features, modes of correlation and propositions respectively in a way which is comextensive with a previously defined linguistic system. But if this linguistic system is to be used as a necessary part of the definition of what it means for a speaker to utter ' $x$ ', then sentencemeaning can no longer be defined in terms of speaker-intentions since such a step would make the hypothesis circular and no longer explanatorily valid. Now it seems to me that the restrictions Grice places on his occasion-meaning are implicitly of the type I have suggested. In discussing how a speaker (U) might intend by a hand-wave (H-W) to indicate 'I know the route' Grice suggests that one condition of this being successfully conmunicated is that 'it is U's policy (practice, habit) to utter $\mathrm{H}-\mathrm{W}$ if $\mathrm{U}$ is making an utterance by which $U$ means that $U$ knows the route' ${ }^{10}$ If this type of condition is applied to linguistic utterances, it seems that it can mean no more and no less than for an utterance $\underline{x}$, to communicate one's belief as speaker (U) in a proposition $p$ it must be 'U's policy (practice, habit)' to utter ' $x$ ' if $U$ is making an utterance by which $U$ means that $p$. But unless $U$ is idiolectal, his policy will be decided by the linguistic conventions of the language he is speaking. Thus the correlation between ' $x$ ' and ' $p$ ' reduces to a linguistic convention. If this interpretation is correct, then the clain that sentence meaning can be explained in terms of speaker-meaning cannot be maintained. I shall therefore assume that the stronger claim - maintained by Grice, Strawson

10. Cf. Grice 1968ap.232f. In fact this definition is there dismissed in favour of the formulation ' $U$ has in his repertoire a certain procedure' but the difficulties with this latter phrasing seem to be no different. 
and Schiffer - is not correct; and that the characterisation of what a sentence means for particular speakers on particular occasions is dependent on a prior definition of linguistic meaning independent of the use of sentences in communication.

Once the strong form of the thesis is relinquished, Grice's definition of meaning can be seen as a pragmatic characterisation of the way in which speakers and hearers use a previously specified Iinguistic system. However Grice's account goes much further than this. A basic condition for a pragmatic theory is that it explain ot only how speakers use sentences of the language in a way which corresponds to their meaning, but also how they succeed in using those sentences to communicate information which is not specified by the meaning of the sentences in question (for some examples, cf. R.Lakoff's examples of common topic discussed in $\mathrm{ch} .4$ ), and Grice provides a framework in which this is explained. Grice's hypothesis rests on one basic principle - that most of our conversations are not random exchanges of disconnected remarks but that conversation involves - in general - a comperative effort between speaker and hearer. That is, participants are expected to contribute to a conversation under conventions which Grice labels generally as the Co-operative Principle. This Co-operative Principle (henceforth CP) subsumes a number of maxims which specify the conventions which participants of a conversation should obey. These are as follows: Quantity

(1) Make your contribution as informative as is required (for the current purposes of the exchange). 
(2) Do not make your contribution more informative than is required. ${ }^{1 I}$ Quality

(I) Do not say what you believe to be false.

(2) Do not say that for which you lack adequate evidence.

\section{Relation}

Be relevant.

Manner $^{12}$

This maxim has an overmall instruction 'Be perspicuous'. Grice subdivides this general instruction into four further maxims:

(1) Avoid obscurity.

(2) Avoid ambiguity.

(3) Be brief.

(4) Be orderly.

Tach of these constitutes a convention that is normally obeyed. In a conversational exchange, one generally expects for example that one's fellow conversationalists are telling the truth and one assumes that they will extend the same courtesy to oneself. Conversations would not follow the pattern they do if every statement made was assumed to be false.

One striking characteristic of these 'rules' is that - unlike linguistic rules ingeneral w they are often broken. There are many liars and there are many conversations which change their subject abruptly as someone makes a statement quite irrelevant to what was said before. These are simple breakages of the maxims. There is

11. Cf. the equivalent 'platitudes' of Strawson 1964a - 'The Principle of the Presumption of Ignorance' and 'The Principle of the Presumption of Knowledge'.

12. The maxim of manner is of less importance than the others, and $I$ shall not consider it in detail. However cf. ch.8 section 8.7. 
however a much more interesting way in which the maxims can be broken. They may be deliberately and flagrantly broken, in such a way that the speaker knows and intends that the hearer shall recognise that a maxim has been broken. The hearer then has two alternatives: one is to say 'You're a liar' or 'That's irrelevant' or whatever, in which case, the CP has broken down. But he may - and characteristically does choose a second alternative. He assumes that the speaker is in general observing the $C P$ and reasons in the following way: 'If he is doserving the CP and if he is flouting a maxim in such a way that I shall notice the breakage, then he is doing so in order to convey some extra information which is in accordance with the $\mathrm{CP}$, and moreover he must know that I can work out that infowmation'. Let us take for example Grice's case of a man who is asked to give a reference for a past student who is applying for a lectureship in Philosophy. The man writes: 'Dear Sir, Jones' command of English is excellent, and his attendance at tutorials has been regular. Yours faithfully,'. The writex of the letter is clearly and openly violating the maxim of Quantity (if not that of Relation too): he is offering absurdly little information. The receiver of the letter, faced with this blatant violation, will not however throw the letter away: he will assume that its sender is trying to convey information other than what his letter strictly says - namely that Jones is no good at Philosophy. Since if the recipient makes this assumption the man's letter no longer violates the Co-operative Principle, and since the man clearly intends that the recipient of the letter will deduce precisely this information, this is therefore what his 
letter implies: or as Grice labels it, this is the implicature of what he has written. These 'conversational implicatures' of an utterance are by definition assumptions over and above the meaning of the sentence used which the speaker knows and intends that the hearer will make in the face of an apparently open violation of the $C P$ in order to interpret the speakex's sentence in accordance with the $\mathrm{CP}$. Grice's own characterisation. (from the William James lectures) is as

\section{follows:}

'A man who, by (in, when) saying (or making as if to say) that $p$ has implicated that $q$, may be said to have conversationally implicated that $q$, provided that: ( 1 ) he is to be presumed to be observing the conversational maxims, or at least the co-operative principle, (2) the supposition that he is aware that, or thinks that $q$, is required in order to make his saying or making as if to say $p$ (or doing so in those terms) consistent with this presumption, and (3) that the speaker thinks (and would expect the hearer to think that the speaker thinks) that it is within the competence of the hearer to work out, or grasp intuitively, that the supposition mentioned in (2) is required'.

Other examples are provided by (1), which flouts the maxim of relation and (2), which flouts the maxim of quality:

(I) The police came in and everyone swallowed their cigaxettes

(2) You're the cream in. my coffee

Someone hearing an utterance of (1) and not lsnowing about the illegality of maxijuana might think that swallowing cigarettes is a stupid pastime and what did it have to do with the police anyway? However, anyone saying that in 1973 would assume that the hearex was able to work out that the second sentence is relevant if one assumes that the people would only swallow their cigarettes when the 
police came in if those cigarettes were illegal. Since people smolking illegal cigarettes are generally smoking marijuana (not opium, cocaine or other drugs) one interprets the sentence as 'implicating' that everyone was smoking marijuana. (2) is an example of categorial falsity, and metaphor, and Grice's implicatures provide a natural explanation of how metaphor is interpreted (and why it commonly involves nonmlinguistic assumptions about the world). In order to interpret an utterance of (2) as not breaking the maxim of quality, the hearer must assume that the speaker is trying to convey something other than the literal meaning of the sentence. Since cream is something which is not only a natural accompaniment to coffee, but a perfect accompaniment, the speaker is perhaps saying that the hearer possesses similar attributes. He is therefore paying the hearer a great compliment.

Five charactexistics of conversational implicature stand out:

(I) They are dependent on the recognition of the Co-operative Principle (CP) and its maxims

(2) They will not be part of the meaning of the lexical items in the sentence since thejr interpretation depends on a prior understanding of the conventional meaning of the sentence.

(3) The implicature of an utterance will characteristically not be the sole possible interpretation of that utterance. There may well be more than one possible assumption which will reinstate the CP in the face of an apparent breakage. Since these assumptions are not explicit, they are often indeterminate (for example, the interpretation of (2) above).

(4) The working out of an implicature will depend on assumptions about the world which the speakex and the hearer share (for example the interpretation of (1) above). They will therefore not in general be predictable. 
(5) They are cancellable. That is, an interpretation which is not part of the conventional meaning of the utterance can be explicitly denied without contradiction. Thus for example our referee might have written a letter such as 'Dear Sir, Jones! command of English is excellent, and his attendance at tutorials has been regular. Moreover his ability at and enthusiasm for Philosophy are quite adequate for the job. Yours faithfully'. Similarly I might say 'The police came in and everyone swallowed their cigarettes though they were doing nothing illegal', or 'You're the cream in my coffee but since I don't like cream, that's a dubious complement'.

So far I have assumed that there is a dichotomy between what is part of the conventional meaning of an utterance and what is super. imposed on that meaning on specific occasions. As Grice points out in his lectures it is not that simple. The total signification of an utterance can be divided in two different ways. Firstly, there is the distinction between what is part of the conventional meaning and what is not; secondly there is the distinction between what is said or asserted and what is implicated. This cross-classification leads to three possibilities: what is said, what is conventionally implicated and what is nonconventionally and hence conversationally implicated. Grice in fact allows for a fourth possibility, generalised conversational implicature, which is dependent for its prediction on the CP and which fulfils the conaitions stated above for conversational implicature, but which unlike the conversational implicatures considered already is not necessarily dependent on features of the context for its interpretation - it may be generally interpreted as part of the total signification of such an utterance. We thus have 
four distinctions: what is said, what is conventionally implicated, what is generally but conversationally implicated, and what is conversationally (occasion-specific) implicated. 13

What is the justification for this classification - in particular for the distinction between conventional implicature and generalised conversational implicature? Grice argues that there is a range of examples which appear to contain implications that the speaker is committed to, without those implications being strictly what is part of the meaning. That is, they are determinable, non-contradictable and not dependent on the CP for their interpretation. His example is John is an Englishman; he is therefore brave. In saying this he suggests a speaker is certainly committed to there being a causal connection between the two statements but if it turned out that both statements were true but there was no connection, the speaker's statement as a whole would still be true. Moreover the speaker cannot say (if he is to retain his credibility) John is an Englisho man; he is therefore brave - though I don't believe there's any connection between the two'. ${ }^{14}$ Conventional implicatures are thus those elements of meaning which are not truth-functional, but which are not contradictable. They are in effect an admoc way of labelling within a pragmatic framework counter-examples to the semantic framework I have argued for. General conversational

13. These distinctions are introduced briefly in Grice 1961 (Section III) but they are not referred to there by the term implicature. 14. Cf. ch.9 for a discussion of the validity of this example (p.302fP). 
implicatures on the other hand are common accompaniments to the meaning of a sentence but they can be contradicted. To make a statement of the form $P$ or $Q$ for example generally implicates that the speaker does not know which of $\mathrm{P}$ or $\mathrm{Q}$ is true. Thus the statement It's either in your bedroom or the attic said in response say to the question Where's my book? will generally imply that the spealsex does not know exactly where the book is. But this implication is not a necessary part of the meaning: It's either in your bedroom or the attic, and I'm not saying any more than that does not have this implication, yet is clearly not a contradiction, Moreover, this implicature has a natural explanation on the basis of the CP. Since the maxim of quantity militates that a speaker shall give as much information as is required, and the maxim of quality that he should have adequate evidence for what he claims, a speaker is or should be committed to making the strongest statement he can. A hearer of an utterance of the form $\mathrm{P}$ or $\mathrm{Q}$ will know (and know that the speaker knows) (a) $\underline{P}$ or $Q$ is true just in case either of $P$ or $Q$ is true, and (b) that the speaker is making the strongest statement he can. If then he is complying with the maxim of quantity, the speaker must be uttering ' $P$ or $Q$ ' on the basis that he only has evidence for $P$ or $Q$ and not suffictent evidence to claim just $\underline{P}$ or just $Q$ (to claim $\underline{P}$ or $Q$ if one knows that $P$ is to break the quantity maxim). Hence the spealser is jmplicating that he does not know which of $P$ or $Q$ is true. Since the calculation of such implicatures depends on a prior specification of the meaning of the sentence, it follows that conversational implicatures - unlike conventional implicatures os are demonstrably not part of the representation of the meaning of sentences. 
7.2 On Criticisms of Grice

Before we can go further and consider the ways in which Grice's theory provides an account of the phenomena generally labelled presuppositions, there are two important factors to consider. First this formulation of the basis of communication must be extended to all forms of utterance, i.e. to imperatives and questions: otherwise the framework will not be sufficiently general. Secondly, and more importantly, it is essential that we take into account the various criticisms of Grice's theory. The most important of these are those which attack the theory in principle, since it is only if these can be rebutted that the use of Gricean principles to be given here will retain any explanatory value. I shall consider two such criticisms:

I: Grice's formulation of meaning involves an infinite regress of conditions. This being so, it is not stateable in a finjte form. II: The conversational maxims are so vague and general that they allow the prediction of any implication whatever - specifically those which do not occur as well as those that do. The theory is therefore unfalsifiable, vacuous, and of no explanatory value.

\subsubsection{Speaker's Meaning and Non-Indicative Utterances}

Grice himself generalises the definition of meaning to include imperatives by defining meaning on an utterance ' $x$ ' signifying $' * \psi p$ ' where $* \psi$ is a dummy for a specific mood operator corresponding to the propositional attitude of $\psi$-ing (cf. Grice 1969 p.I71). Thus the definition I gave on p.ig7f should be reformulated as: For some specific occasion, a speaker $S$ makes an utterance ' $x$ ' to a hearer $H$ indicating ' $\psi \mathrm{p}$ ' if he intends that: 
(1) H should think $x$ has $f$ (where $f$ is a feature)

(2) H should think that he $S$ intends $H$ to think $x$ has $f$

(3) $H$ should think $f$ is correlated in way $c$ with the state of $\psi$-ing that $p$ (where $p$ is the propositional content)

(4) II should think that $S$ intends that he (H) thinks $f$ is correlated in way $c$ with the state of $\psi$-ing that $p$

(5) H should think he S intends $H$ (via (1) and (3)) to think that $s y-s$ that $p$

(6) on the basis of (5), $H$ should think that in fact $S$ does $\psi$ that $p$

(7) H should think that $S$ intends (6)

(8) on the basis of (6) H should $\psi$ that $p$.

If we define assertion and imperative as follows -

if $p$ ' is conventionally correlated with a belief that $p$

' ! ' is conventionally correlated with an intention (with respect to some audience) that that audience make $p$ true -

Grice's definition of pragmatic meaning then provides an account of the basis on which a speaker will successfully convey his belief or intention that $\mathrm{p}$.

The definition has however to be modified somewhat for questions (both wh and yes-no), since unlike imperatives ox indicatives, the speaker is not indicating a positive attitude or intention with respect to $p$. Yet it is clear that a similar explanation must apply to questions. Suppose we characterise yes-no questions ('3p') as conventionally correlated with an intention (with respect to some audience) that that audience tell the speaker the truth value of $\mathrm{p}$ (equivalently, tell him etther ' $p$ ' or ' $-p$ '). Then just as in the imperative case, where the speaker succeeds in conveying his intentions 
by virtue of the hearex's recognition of those intentions, so in

the case of ' $2 p$ ', $S$ intends

(A) that $\mathrm{H}$ should think ' $\mathrm{p}$ ' has a feature $f$ which is correlated in way $c$ with intending with respect to some audience that that audience say either ' $p$ ' or ' $p$ ' (the relation between $f, c$, and $p$, being given by the conventions of the language) (corresponding to conditions (1)-(3) of the definition)

(B) that $H$ should think that $S$ intends $H$ to think via their common knowledge of the correlation $c$ that $s$ intends that $H$ say ' $p$ ' or ' $-p$ ' (condition (5) of the definition)

(C) on the basis of this, that $\mathrm{H}$ should think that $S$ does in fact intend that $\mathrm{H}$ say ' $\mathrm{p}$ ' or ' $\mathrm{p}$ ' (condition (6))

(D) on the basis of knowing that $H$ intends (C), H should form the intention to say either 'p' or ' $-p$ '.

In other words the communication of meaning in yes-no questions can be described (as is intuitively correct) as no different in kind from the communication of any other utterance. This type of analysis extends naturally to wh-questions with slight modjfications. In

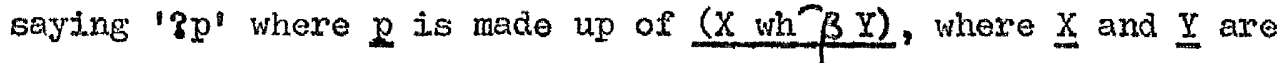
variables, $S$ Intends that $H$ should think that $\underline{?\left(X w^{-} \beta Y\right)}$ is correlated in way $c$ with intending with respect to some audience that that audience say ' $\alpha$ ', where $\alpha$ is a member of the set indicated by $\beta$. The process of deduction then goes through in exactly the same way, giving the conclusion that on the basis of $S$ saying ' $(x w h-\beta y)$ ' H forms the intention to say ' $\alpha \cdot 15$ That is to say, each type of

15. The characterisation of wh-questions has only been given informally here, since it is not a central concern of this thesis. It is arguable that a pragmatic characterisation of questions should give an account which applies equally to yes-no and wh questions. I shall leave this problem for another time. 
utterance is based on an intention on the part of the speaker which is itself based on an anticipation of the hearex's strategy on hearing that utterance (cf. the concept of 'comordination problem' outlined by Lewis, to be discussed on p. $216 \mathrm{ff}$ ).

To what extent do the maxims apply equally to all types of utterance? Clearly just as statements have pragmatically to be uttered sincerely, so do imperatives and questions have to be uttered with a sincere intent to receive a response and the maxim of quality has to be generalised to apply equally to the three types of utterance. In addition, the maxim must apply to the implicatures of an utterance as well as what is stated. It is just as misleading to say 'I'm tired' if you:.. Intend your hearer to construe from your utterance that you have a headache even though you do not have one as it is to say explicitly 'I've got a headache' in the same circumstances. Thus the maxim must require that one not only beljeve or sincerely request one's utterance but one must believe (and have adequate evidence for) any jmplicatures consequent upon that utterance. The maxims of quantity and relation apply equally to all types of utterance even as they stand. In the case of the quantity maxim for example, as we shall see in more detail in chapter 8 section 8.2, it is just as important to give sufficient information in asking a question or giving a command as it is in making a statement. Furthermore the maxim of quantity guarantees that questions be answered, and answered appropriately: at least one major interpretation of the first maxim is not that the speaker should merely give as much information as the situation requires, but more specifically that the 
speaker should give as much information as the hearer requires, should the hearex make a request for information. 16 It is this more narrow interpretation of the quantity maxim which applies in the case I have already discussed where an utterance of $\mathrm{P} \mathrm{Q}$, will normally implicate that the speaker does not know which of $P$ or $Q$ holds. For example, suppose $H$ asks 'Where is my book?' and $S$ replies 'It's either in your bedroom or the attic' $S$ knows that he is bound by the pragmatic convention on wh-questions and by the corresponding quantity maxim to provide a specification of the place where the book is. However he is also constrained to say only that for which he has adequate evidence. If therefore he gives a disjunction of two possible places he knows and knows that $H$ will recognise that he is not fulfilling the exact requirement on the question posed by $\mathrm{H}$. On the assumption that he is in fact complying with the $\mathrm{CP}$, he knows that $\mathrm{H}$ will deduce that he does not have adequate evidence to choose between the two possibilities he has put forward. He knows therefore that his utterance will be construed as indicating that he has evidence only for the disjunction Either the book is in your bedroom or the attic. and not for either disjunct.

In this section I have considered informally how Grice's account of meaning can be generalised to all forms of utterance, whether statement, imperative, yes-no question or wh-question. This has given us three (or possibly four) mood indicators ' $t$ ', 'I' and ' $?$ ' (plus an operator for wh-questions, though cf. p. 211).

16. For a discussion of an apparent countermexample to this interpretation of the maxim, cf. p. 233 . 
With this generalisation, I take it that the limitation on Grice's account of pragmatics that it apply only to statements cannot be raised as a criticism of principle.

It might on the other hand be argued that this list of pragmatic mood operators is not long enough since it should contain at least a pragmatic operator of denial. If this were so, negative sentences which were not mexe negative descriptions would be distinguished semantically from those that were, by prefixing to denials a pragmatic moodmoperator characterising denial of a positive statement (whereas the negative descriptions would be preceded by the assertion operator). It might be argued further that if this solution were adopted, many of the arguments given in this thesis against the logical relation of presupposition fall to the ground since the marked cases of negation which have been brought up can only sensibly be uttered as denials of a foregoing positive statement. I have already argued (p.102) that there is no semantic justification for distinguishing two such types of negation. There are in any case severe problems involved in incorporating a pragmatic operator of denial within this framework. First notice that since pragmatic mood-operators are merely entered into the semantic formalism here as primitives, a denial. that $p$ (as opposed to the negative assertion 'f $-p$ ') will we semantically identical to the assertion that $\underline{g}$ except for the difference in roodm operator. The second problem created by the addition of a moodoperator characterising denial is that the pragmatic framework would have one mood-operator which was different in kind from all the other operators. We have already seen (p.74) that the mood-operators 
'P', ' $\mathrm{'}$ ' and ' $:$ ' are not illocutionary force indicators since each can be used with a wide range of illocutionary forces. Not so denial. If in the face of some positive statement $\mathfrak{L}$, a speaker denies $\mathfrak{p}$, his illocutionary act constitutes only a denial. It is not simultaneously a threat, promise, request, warning et. Furthermore, and more seriously, positive statements can also be used as denials. 17 Consider the following two conversations:

(3) A: John has passed his exams B: He hasn't.

(4) A: John hasn't passed his exams. B: He has.

It is arguable that the illocutionary force of B's statement is the same in both conversations: he is denying (or contradicting) A's statement. But we would surely not wish to conclude that the semantic representation of the sentence used by $B$ in conversation (4) corresponds even approximately to:

'Denial' (-John has passed his exams) This would have the unfortunate consequence that every positive statement is at least two ways ambiguous. These various problems suggest that the concept of dental does not have the status of a pragmatic mood-operator but is simply one of the uses (along with warnings, threats, promises, etc) to which sentences can be put. I have therefore not increased the list of pragmatic mood-operators beyond three.

17. For further arguments against conflating negation and denial, cf. Gale 1970. 


\subsubsection{The Infinite Regress Prbblem}

Much more important than the problem that the theory has only been articulated to apply to statements are the accusations against it of infinite regress and vacuity. The first criticism has been pointed out by Grice himself as well as others (Grice 1969 p.156fr, Schiffer 1972, Mackay 1972) ${ }_{4}^{18}$ though he suggests that the regress, if it exists, is not a serious one. I think he is correct in thinking the regress not serious, but not for the reasons he appears to hold. I take it however that the criticism of the harmfulness of infinite regress would be seriously eroded if it could be shown that this form of infinite regress was part of the very nature of convention, and hence of any analysis of the conventions for use of a Iinguistic system. This has been done by Lewis (1969), whose analysis of convention depends on such regress.

Briefly, this analysis depends on the notion of 'comordination problems', 19 and their solution. These are exemplified in the following way (to take Lewis' initial example). Suppose you and I both want to meet. It doesn't matter where - we each merely want to choose to go where the other is most likely to go. Comordination is achieved if we succeed in meeting. In order to do this, each of us has to work out a strategy, and each of us knows that if one succeeds in his strategy then the other will also have done so, since we are both planning to the same end (namely to succeed in meeting). This being so, I shall try to work out where to go on the basis of what you will do; and the way to work out where to go is therefore

18. MacKay's claim of infinite regress alternating with a claim of adhocness of the conditions is based on a mistaken notion of justification and a misunderstanding of the central nature of the Gricean derinition of meaning. I shall therefore not consider it in detail. In any case, the first of two conditions which he objects so stronglyto, does not appear in the 1967/68 Iecture version I have adopted here.

19. The term is Lewis' own, but the problems are also developed by Schelling 1960. 
to replicate your reasoning. Like me, you will work out where to go on the basis of where you think I shall go. Since where I go is determined by where I think you will go, i.t follows that you will be trying to anticipate where you think I think you will go. But since where you go depends on where you think I shall go, it follows that you will be trying to anticipate where you think I think you think I shall go. etc. etc. This attempt to replicate the expectations of the other member in a co-ordination problem automatically sets up an infinite chain of expectations. ${ }^{20}$ Given only this overly brief exemplification of a co-ordination problem, one might wondex why communication (or more spectfically a Gricean theory of meaning $\mathrm{gnn}_{n}$ ) should have anything to do with co-ordination problems. The answer, as Lewis suggests, is that all conventions involve the solution of co-ordination problems. 21 More formally,

'a regularity $R$ in the behavior of members of a population $P$ when they are agents in a recurrent situation $S$ is a convention if and only if in any instance of $S$ among members of $P$

1) everyone conforms to $R$

2) everyone expects everyone else to conform to $R$

3) everyone prefers to conform to $R$ on condition that the others do, since $S$ is a coordination problem and uniform conformity to $R$ is a coordination equilibrium in $S$ ( the best strategy for successful coordination RMK)' (p.42)

Thus a convention is in effect a standard solution to a co-ordination problem. Having sophisticated this definition of convention and given a definition of a conventional signalling system on the basis of this

20. It is important to note that this is a chain of implications, not of steps in anyone's actual reasoning. Cf. $p_{0} 218$.

21. This is disputed by Schiffer (1972 p.151). 
definition, Lewis then goes on to give a proof that Grice's definition of meaning is a consequence of his own definition of conventional signalling - i.e. is a solution to a co-ordination problem (the problem In the case of statements being roughly the transmission of a certain belief by uttering a certain signal - co-ordination is only successful If the hearer does in fact gain the belief in question). ${ }^{22}$ He does this by showing that Grice's definition of what it is for a speaker to mean $_{n n}$ something by a symbol * can be derived by examining the reasoning that justifies his saying '*': this reasoning replicates exactly the characteristic structure of an agent's justification within a conventional signalling system (cf. Lewis p.136 ff). Since conventions of meaning ${ }_{n n}$ are shown to constitute a conventional signalling system, it follows that any analysis of the basis of these conventions will by definition involve infinite regress in the way that all solutions to co-ordination problems do. Furthermore, this regress is not, as the original Gricean regress seemed to be, a sexious one, since there is no claim that anyone's actual reasoning to a co-ordination equilibrium involves an infinite number of steps. The infinite regress concerns rathex a chain of implications which follow from any finite (and normally very limited) number of steps. As Lewis points out, there is therefore nothing improper about its infinite length (p.53). On the basis of Lewis' arguments (which I have presented here regrettably in a highly impoverished form for reasons of exegesis), I shall therefore assume that any attempt to 
explain what a speakex does in using his conventional (1inguistic) system is bound to set up a regress whtch is in principle infinite, though in practice it never exceeds more than three or four steps. The characteristic of infinite regress in Grice's theory of meaning does not therefore raise objections in principle to the theory, but is part of the very essence of convention itself. 23

\subsubsection{The Vacuity of the Maxims}

That the maxims of the Co-operative Principle are too vague to be anything but vacuous has been argued by Kroch (1972), who provides two examples which purport to demonstrate that the maxims can in the one case and must in the other generate contradictory implicatures. On these grounds, he concludes that the theory is unfalsifiable.

His first and main consideration is with time adverbs. He points out that there are adverbials which are sometimes interpreted as synonymous, sometimes not.

(5a) Before the arrival of the army, the government controlled the town

(5b) Until the arrival of the army, the government controlled the town

(6a) During one period before the arrival of the army, the government controlled the town

(6b) *During one period until the arrival of the army, the government controlled the town

(7a) John died before dawn

(7b) *John died until dawn

That until and before clauses cannot have the same semantic representation is demonstrated by the contradiction inherent in $(6 \mathrm{~b})$ and $(7 \mathrm{~b})$, though

23. The arguments of Lewis do however suggest the correctness of the position adopted here, that Grice's theory of meaning can only be a basis for a pragmatic theory and not for a linguistic theory of semantics - it is hardly the burden of the semantics of any conventional. system to explain not only the interpretations given to the elements of the system, but also the nature of convention per se. 
they clearly are synonymous in (5). On the basis of these examples, Kroch analyses until and before as:

until = at all times prior to NP

before $=$ at some time(s) prior to NP

(where NP is the object of the adverb phrase)

To these definjtions, he adds a rule of interpretation (a putative general. conversational implicature) that adverbs containing an existential quantifier will be interpreted universally when the action modified is durative, given thet the context does not prohibit it. Hence the synonymy of $(5 a)$ and $(5 b)$. He points out however that If there is an explicit existential quantifier in the time adverbial, then there is no such implication.

(8) At some time before the arrival of the army, the government controlled the town

Unlike (5a), (8) is not normally interpreted with some read as all. On the contrary, there is an opposite implication that the government did not control the town for the entire period before the arrival of the army. Yet, Kroch argues, the only difference in the meaning of (8) and (5a) is that there is an explicit quantifiex in (8). Since they have the same basic meaning, these sentences should have the same conversational implicatures. These examples therefore appear to constitute a case where either the theory must allow for two contradictory implicatures, or we have to admit an implication which is not predictable by implicature.

Notice however that Kroch's argument only goes through on the assumption that ( 8$)$ and $(5 a)$ have the same semantia representation. If they do not, then the theory has a natural basis for predicting 
different implicatures. Kroch's analysis of before I shall at the moment accept as containing an existential quantifier, since parallel to the interpretation of $I$ ', it allows for the entire range from one moment in the time specified (e.g. (7a)) to every moment in the time specified (e.g. (5a)). I suggested earlier however (following Bierwisch - cf.p.174f) that the interpretation of noun phrases in general should not be based on the existential and universal quantifiers of predicate calculus, and it seems not unreasonable to suggest along the lines put forward by Bierwisch 1.971. that the some of natural language should be described in terms of a subset of some whole (where the notion of set is taken as primitive) rather than in terms of a collection of one or more individuals (in the formalisation of predicate calculus). 24 Thus, while (5a), containing before, correctly involves a paraphrase 'at least one time prior to NP', (8), containing some, does not. The distinction is I suggest analogous to the following pair:

(9a) They took some of the girls

(9b) They took at least some of the girls Notice that $(9 \mathrm{~b})$, with at least, allows the implicature that they took more than some girls, namely all, whereas (9a) does not. More generally, any sentence containing at least will carry an implicature which we must somehow capture as 'one or more notches up the scale in question. 25 Thus for example Her jewels cost at least two thousand pounds implicates that they probably cost more. By contrast, sentences

24. For a more formal and much moxe detailed discussion of some other aspects of plural noun phrases, cf. Blerwisch 1971 pp.414 ff.

25. This implicature is straightforwardly deduceable on the basis of the maxims of quantity and quality. 
without at least, such as (9a) and (8), which are to be interpreted as involving a subset of the members of the whole set in question, implicate that that subset is not comextensive with the whole set. 26 While I grant that these observations are informal, and I have no suggestions to make here as to their formalisation, they seem to provide a natural basis for the distinction between (5a) and (8). I take it then that there is some evidence to sugeest that (5a) and (8) should have semantic representations which differ at least in. that (5a) will have a representation which relates it to other sentences containing at least explicitly.

Kroch's other attack on the maxims is his claim that they have the power to predict on the same utterance both the implicature which does not exist and the one which does. Thus for John ate the apple, he gives two parallel arguments:

(A) Iff the spealkex had meant that the whole apple was eaten, then he would have said, "John ate all of the apple" in order not to violate the maxim of quantity ... by giving too little information. Since he left out the word "ali", he must have been obeying the maxim of quality ... and avoided saying more than he knew. Therefore, all that the speaker was saying is that at least part of the apple was eaten.'

(B) "The speaker would have said "John ate at least some of the apple" if that were all he knew (by the maxim. of quality - RMK). Since he left out the qualifying phrase, he mist have meant to convey that the whole apple was eaten. Otherwise he would have been giving too little information.' 
However only (B) exists as an implication of John ate the apple. From this he concludes that the theory, in allowing both for the Case which does and for the case which does not exist, is in principle unfalsifiable and therefore vacuous.

Unfortunately his example is not a good one. If the interpretation of John ate the apple corresponds roughly to 'There is some specific apple which John chewed and swallowed', it is not obvious that John ace his apple but only some of it is not a contradiction. 27 Compare John has eaten his food but not all of it which seems a clear case of contradiction. This being so, the semantic interpretation of the sentence will predict that the interpretation that Kroch aims to predict by (A) is not a possible intexpretation of this sentence.

Nonetheless I grant that answers of the kind just given to attacks in principle are merely fending off the day when a better example will be thrown up (cf. p.248f for a discussion of further examples which appear to suggest the same conclusion). To disagree over data does not alter the force of the criticism. The dojection remains an important one: if Grice's Co-operative Principle is to provide a substantive explanation of the basis on which communication is conducted, we must restrict it in such a way that it constrain the nature of communication processes as narrowly as possible. Otherwise

27. I assume that it is not a linguistic matter that in eating objects there is a convention that only certain edible parts are relevant. Thus the fact that James has eaten his cake though there are a lot of crumbs on the floor and John has eaten his apple but he's left the core are not contradictions does not alter the point being made here. 
the apparent naturalness with which the framework appears to explain the varying phenomena is merely a consequence of the vacuity of the framework. Since, as I shall. argue, the Gricean maxims seem to allow a natural explanation both of occasion-specific implications on utterances (such as Robin Iakoff's speaker-presuppositions) and also of more general implications (such as arise in the use of definite noun phrases and factive verbs), one of my chief concerns in the following chapter will be to consider to what extent the maxims can be given a greater degree of content.

My main concern in this chapter has been the exposition of the two facets of Grice's theory - his concepts of meaning ${ }_{n n}$ and the Co-operative Principle. We have not yet considered how Grice's theory can be used to explain the apparent anomalies which have arisen during the course of this thesis. Yet clearly its validity as part of an over-all linguistic theory depends on whether it can provide a natural explanation of these apparent anomalies. Since this explanation, as we shall see, rests on the concept of the Co-operative Principle, its maxims, and the consequent implicatures, I shall restrict my attention in the remainder of this thesis to the maxims and shall not considex the details of meaning ${ }_{n n}$ further. 
CHAPTER 8 : The Application of Grice's Theory

We saw in chapter 7 that Grice's theory of meaning and communication provided a potential basis for a theory of pragmatics. In section 7.2 of that chapter, I defended Grice's theory against specific criticisms of infinite regress and vacuity. Our troubles would not be over however, even if it were certain that Grice's hypothesis could be presented in a testable way. The general problem that remains is to explain how Grice's framework can capture the insights which presupposition has been used by linguists in the past to capture. This can be broken down into six parts:

(i) We have to be able to explain the concept of a natural interpretation as opposed to an unnatural one - viz. Why some interpretations of negative sentences are so much more likely than others. Connected with this problem is a second problem, which has so far not been discussed at all. In general, linguists arguing for presupposition have claimed that in negation and questions the presuppositions of a sentence will be preserved. Since the basis for presupposition was in terms of the truth-value assignment to statements, my discussion of linguists' use of the term was restricted to negative sentences. Yet questions share with negation the property that certain entailments of the corresponding positive statement are normally assumed to be true when that statement is questioned. Thus Does John regret going? implies in isolation that he went, and Is The King of Rumania coming to the coronation? implies that there is a King of Rumania. However, as in negation, this implication can be 
cancelled without creating a contradiction: in (1)-(7) there is no assumption either of the truth of the factive complement or of the existence of the referent corresponding to the particular definite noun phrase.

(1) Does John regret going or didn't he go in the end?

(2) Did PETE regret doing an MA - I didn't think he was accepted fox the course.

(3) Was the teacher annoyed that sue was late or did she manage to get there on time?

(4) Was the teacher annoyed that SUE was late - I thought she got there on time.

(5) Is the King of Rumania coming to the coronation, or doesn't Rumania have a king?

(6) Did the Duke of PLAZIrORO come to the opening ceremony - I didn't think there was such a place as Plazitoro, let alone that it had a Duke.

(7) Is the King of Rumania coming to the exhibition - I thought Rumania was a republic.

So it seems that in both negation and question, we have to be able to explain how an implication which normally appears to be part of the meaning of the sentence can be cancelled out without contradiction, a possibility which is by definition sot open to central core meaning of sentences. Since this problem arises only within an over-all theory which does not incorporate a logjcal concept of presupposition, I consider this one of the chief remaining tasks of the thesis. (ii) We have a heterogeneous collection of lexical problems to explain viz. the non-truth-conditional idiosyncrasies of the (cf. p. 161f), but (cf. p.117f), and (cf. p.116), and even (cf. p.128). (iii) We have to be able to characterise presupposition in the sense 
of Chomsky (1971) and others - i.e. what is assumed in an utterance of a sentence, as opposed to what is asserted.

(iv) We should be able to predict why stress assignment and the interpretation of sentences are interdependent.

(v) There must be some explanation of Robin Lakoff's suggested constraint of common topic on comordination.

(vi) Finally there is a somewhat different problem which, like the problem of questions, I have not considered in detail so far os the status of Austin's concept of illocutionary force. Since I have argued (p.70 ff) that, semantically, performative statements are no different in kind from other statements, the burden of explanation of such concepts as illocutionary force wust fall on a pragmatic theory.

\subsection{The Concept of Relevance}

Since it is evident that the validity of a Gricean pragmatics depends initially on giving the theory sufficient content to render It non-vacuous, the first hurdle to overcome is to see to what extent Kroch's criticism (cf. p.222 $\mathrm{ff}^{1}{ }^{1}$ can be answered more generally. Since it is the maxims of relation and quantity which are largely responsible for the Comoperative Principle's enormous power of application, it is these for which I shall attempt to give a more precise definition. I shall turn initially to Robin Lakoff's concept of common topic, which concerns the problem of relevance.

To recapitulate, she argued that no sentences could be conjoined unless they shared a common topic, and she pointed out that the harder the topic was to construe, the more varjous became the interpretations

\footnotetext{
1. Echoed by many colleagues informally.
} 
informants found. However I argued ( $\operatorname{ch}_{0} 4 \mathrm{p} .119$ ) that every conceivable sentence containing two conjuncts could be construed as having some common ground and that the constraint was therefore vacuous. Moreover it appeared that any sentence contajning two conjuncts could be given more than one interpretation. Each of these characteristics is predicted if the interpretation of the specific common topic is analysed as a consequence of the conversational implicatures of an utterance. Thus for example our speaker (S) says 'John owns a yacht and Bill has a house in Knightsbridge' and he knows that the hearer (H) will reason in the following way: 'S has said both that John owns a yacht and that Bill has a house in Knightsbridge, and since he is biding by the Comoperative Principle (CP) he must be assuming that the second sentence is relevant to the first, despite the fact that it appears not to be. But $S$ knows and knows that I know that yachts are vexy expensive and so is property in Knightsbridge, particularly houses. John and Bill must therefore hich, and this = together with the two assumptions necessary to reach this conclusion - is what $S$ is implicating.' But this interpretation depends on the assumption of shared knowledge made by $\mathrm{S}$ and $\mathrm{H}$. If our speaker and hearer operate with a different set of assumptions, then the interpretation of the sentence will, as we saw in chapter 4, be different. Along similar lines, every conjoint sentence can both be construed as having some common point of relevance and as having more than one interpretation. And this is the result that our analysis should predict: jmplicatures by definition are open-ended, different assumptions providing different 
interpretations (cf. the third characteristic listed on p.215), and hence the interpretation of common topic is unpredictable in isolation (cf. condition (4) on p.215). Prediction of the shared knowledge of speaker and hearex is not possible without knowing both participants. Furthermore these results follow only if such implicatures are analysed as quite separate from the lexically specified meaning of the sentence.

Now it is clear I think that Robin Lakoff's concept of common topic can be extended to discourse structure in general. From her account I argued that given a sentence containing $S_{1}$ and $S_{2}$, the hearex must be able to deduce some form of (partial) identity if the two conjuncts are to be seen as possessing a common relevance ( $c$. Lakoff 1971 p.118 $f$ ) - either by virtue of the semantic interpretation of the two conjuncts, or if not, via some extra assumptions or implicatures. Thus in our example above, the hearer deduced that the speaker was implicating that yachts are very expensive, that Knightsbridge is an expensive area, and hence that both John and Bill are rich. A more general form of the constraint would be that in order for any $S_{1}$ to be relevant in a given conversation, it must carry at least one implicature or entailment that is implicated by $S_{i-1 .}$. To see that this is at least in part correct, consider a conversation between $A$ and $B$ :

A : John has a yacht

B : Bill has a house in Knightsbridge

A : Which do you think is the richer?

Parallel to the conjoint sentence, A implicates that John is rich. On the basis of this implicature, B makes a statement which implicates

2. Cf. the parallel difinition of relevance given by Apostel (1971 p.18): ' $p$ is relevant if the belief in $p$ is held to be logically connected with some statement that occurred not too long before or that will. not occur too much later'. 


$$
-230-
$$

that Bill is rich. This common topic is then made explicit in A's question. Alternatively, to give a case where the second utterance ontails the implicature of the first, consider the following discourse: A says 'John's late' implicating that he's rude, and B replies 'He takes great pleasure in being rude'. Thus as we would expect, the apparent constraint on co-ordination seems to be a property of discourse structure in general, and the maxim of relation can be reformulated with this in mind as:

'Only say any sentence $S_{i}$ made up of '* $\psi p$ ', if $p$ either entails or implicates some proposition $q$ which is also implicated by $\mathrm{S}_{\mathbf{i}-1}$ " $^{\prime}$

This characterisation of relevance in conversation is of course only a first approximation, and is in any case absurdly limited. In any detailed account of conversational relatedness, it is clear that the interdependence between implicature and entailment must be specified. Notice first for example that it is not a sufficient condition of relevance that a sentence $S_{i}$ should share at least one entailment with the preceding sentence $S_{i-1}$ in the discourse, since both the sentences John went to London yesterday and John's mother has got cataract entail the sentence There is someone called John yet the latter could only be seen as relevant to the former on the basis of some further assumption, for example that John's mother lives In London. Thus we do not want to say that any sentence $S_{1}$ which entails $\mathrm{S}_{2}$ will also implicate $\mathrm{s}_{2}{ }^{3}$ However one might reasonably hypothesise that a relation of implicature does hold between two sentences $S_{1}$ and $S_{3}$ when $S_{1}$ is used to implicate a sentence $S_{2}$ which entails $S_{3}$.

3. Cf. ch. 4 p.124, where examples such as these were seen to provide problems for Lakoff's mechanism predicting sentence-presupposition pairs. 
This would predict that John doesn't regret running until he was sick $\left(\mathrm{S}_{1}\right)$ normally implicates that John went until he was sick $\left(\mathrm{S}_{3}\right)$ since $S_{1}$ normally implicates that John ran until he was sick $\left(S_{2}\right)$ (cf. section 8.5 of this chapter), which in its turn entails that John went until he was sick $\left(\mathrm{S}_{3}\right)$.

But this is only the tip of the iceberg. There are undoubtedly many such relations which must be formalised in any pragmatic account which makes reference to both entailment and implicature. Moreover, this is particularly important in view of the tentatively proposed definition of relevance since the definition - if it is even approximately correct - now allows that any sentence $S_{i}$ will be relevant in a discourse if an entailment of any one of the propositions it may be used to implicate is also implicated by the preceding utterance of the discourse.

I shall not go further into this area here, since my main purpose has been merely to consider a possible way of constraining the notion of relevance so that it become open to empirical investigation. We shall see in any case in section 8.6.1, that it is not obvious that the notion of relevance can be so constrained, if our pragmatic constructs are to account for the whole range of data (paxticularly problems of stress).

\section{8:2 The Maxim of Quantity: Some Preliminaries}

Having taken a few tentative steps towards making the maxim of relation more specific via a consideration of Robin Lakoff's data, I shall now consider the maxim of quantity, for discussion of this maxim is a necessary preliminary for the pragmatic account I shall give of definite noun phrases, factive-verb complements, and the assertion-presupposition contrast. This maxim has in Grice's formulation two subparts: 
(i) Give as much information as is required

(ii) Do not give more information than is required

Grice himself suggested (in his 1967/68 lectures) that the second part of the maxim is either unnecessary (since it is not a violation of the CP to say too much, merely a waste of time) or it is covered by the maxim of relation since if you give more information than is required, this additional information will of necessity be irrelevant. For these reasons I shall restrict my attention to the first part of the maxim.

There are several problems with the maxim 'Give as much information as is required'. Like the maxim of relation, its formulation allows for an extremely wide interpretation. First the agentless passive form of 'as is required' allows for an interpretation so open that it is almost entirely without content, since it allows the requirement to be forced by either the semantic or pragmatic content of the previous discourse, or by the hearer, or by more general elements of the situation. Secondly, the constraint of 'being informative' seems to need two quite different statements (as we shall see), and as It stands, the maxim is simply neutral between these, allowing in fact the addition of any further interpretation which may be required in the face of countermexamples.

While I am by no means certain that the following analysis is anything more than an interim measure? I shall argue for the need of at least two separate sub-maxims of quantity to cover (i) the requirement that one answer questions appropriately (ii) the requirement of presenting sufficient information in questions.

4. One would presumably wish ultimately to give a unified account of informativeness where this has two separate parts. 
and imperatives to enable one's requests to be successfully carried out (iii) the general requirement of not saying what is familiar. Since in each case, the requirement of informativeness can be stated with at least a certain amount of precision, the specification of further maxims would appear to go some way towards increasing the content of the CP.

I have already suggested ( $p .2 I 2 f)$ that one interpretation of the maxim is that the speaker should 'give as much information as the hearer requires', and I argued that this was equivalent to an instruction that one answer a wh-question according as the semantic interpretation of the question (or a corresponding imperative) determines. One apparent counter-example to this is provided by comparing the two following conversations, which let us assume take place in Malet Street:

(8) A: How long does it take by taxi to Russell Squaxe? B: One minute.

(9) A: How long does it take by taxi to Russell Square? B: You don't need a taxi - it's only two minutes walk. According to the above interpretation of the maxim, the conversation in (8) is well-formed (and informative) whereas that in (9) is not. Yet clearly the conversation in (9) is the more informative one: in (8) $B$ is being, under all normal circumstances, misleading or at least unhelpful. It thus might seem that one cannot constrain the concept of 'required information' to anything less general than elements of the situation. However this conclusion is not I think warranted. In the situation created by $A^{\prime}$ s utterance in Malet street, $B$ is faced with a conflict between the given maxim of quantity and the maxim of quality that one believe one's utterance and its implicatures. 
A's utterance implies that one goes by taxi to Russell Square. If therefore B answers the question in the way it strictly requires, he will also be implicating that one goes by taxi to Russell Square. But he knows that this is false, and to answer thus would therefore violate the maxim of quality. Since this is the fundamental maxim on which all the others depend, the maintenance of the maxim of quality overmides the maxim of quantity, thus predicting that the only communicatively helpful answer to a question in which the questioner makes a mistaken assumption is one which corrects the assumption. Examples such as these are therefore not counter-examples to this analysis, since they can be naturally explained in terms of a conflict between the proposed maxim and the maxim of quality.

However this is not the only counter-example. Assume that you are standing at a crossmroads in Salisbury and someone drives up in a car and asks you 'How long does it take to get to London?' Now clearly the answer you should give is one which incorporates information from the situation (viz. that the questioner is in a car) - something like 'Three hours' being an appropriate answer. Tet the maxim merely makes reference to the content of the question. So, according to the maxim, a perfectly straight answer would be 'A week'. Moreover, it might be a true answer, on the basis that one was walking. Thus there appears to be no violation of either the maxim of quantity or the maxim of quality on the part of the hearer. What has gone wrong? Is this evidence that we cannot constrain the maxim of quantity so that it apply only in terms of responding to the request strictly made by the question? Again I think the answer is 'No', though the reason is not the same as before. What I suggest is the basis of the difficulty 
here is that the questioner has provided too little information to al.1ow his question to be answered without making further assumptions. That is, he knows (and knows that the hearer knows) that a whquestion is a request for information with respect to a certain variable, in this case of time. 5 Moreover, he knows (and knows that the hearer knows) that the time an action takes is dependent on the speed of the action. ${ }^{6}$ Since his question makes no mention of how he is getting to London, he knows that the hearer will not have sufficient information offered him to make a proper answer. The hearex might thus construe that he the speaker is violating the maxim of quantity. However he knows that the hearer knows that he is in a car and will therefore be able to work out that since he is in a car he is likely to wish to drive to London. Since if $H$ makes this assumption $S$ 's utterance no longer violates the maxim of quantity, $s$ therefore assumes that if he utters the sentence 'How long does it take to get to London?', H will take him to be implicating that he will be going by car. This form of analysis suggests that the reliance on facts of situation is not part of the definition of the quantity maxim but an implicature which arises from apparent violation of the maxim. That this is correct is suggested by the fact that the utterance 'How long does it take to get to London?' allows for differently appropriate answers according as different assumptions are made. The variability of

5. Cf. p231 for an informal discussion of wh-questions.

6. I assume that this fact should at least follow as a consequence of the semantic representation of duration adverbials. However the formal semantic representation of duration adverbials is quite unclear to me, and I shall not give further detalls. 


\section{$-236-$}

interpretation by virtue of changing assumptions is as we have seen (p.205) a defining criterion of conversational implicature. It therefore seems at least the analysis is on the right lines. But what version of the quantity maxim has been invoked? What is involved in being constrained to give surficient information to enable your question to be answered? The problem is not restricted to questions: it also arises with imperatives. If $\mathrm{A}$, a business man, asks B, his secretary, 'Please get Smith on the phone' and at the end of the day she has still not done so, he will no doubt round on her and say 'Why haven't you got Smith on the phone?' But she is technically in the right if she says 'But you didn't tell me when to get him on the phone - I was going to do so tomorrow'. However, in fact A knows that she will recognise that he has given insufficient information for her to know exactly in what way she should obey the command and on the basis that he is in fact obeying such a quantity maxim, she will make the further assumption that he wants it carried out at the time of utterance. Thus it is only on the basis of an implicature that the command be carried out now that $A$ can be construed as obeying the quantity maxim that he give sufficient indication to enable his hearer to know exactly how to meet his request. So it seems that with both imperatives and questions we must be able to state what constratins speakers to give sufficient information for hearers to obey them. How is this constraint to be stated? Is it covered by 'Give as much information as the hearex requires'? In one sense it is: the hearer does require a certain minimum of information in order to be able to reply to a question or 


\section{$-237-$}

respond to an imperative. The problem is that the maxim does not apply in the same way that it did in the case of answering questions. In the earlier case, the maxim covered the fact that speakers must answer questions appropriately by supplying information with respect to the variable already indicated by the questioner. Now we have the converse, that questioners must give information which will enable their hearer in the one case to provide information solely on the variable in question, and in the other case to carry out the command precisely. The question then arises: are these two forms of explanation correctly collapsed into one maxim? If the maxim applies to both these cases, the problem of over-generality raises its ugly head again. Is the notion of 'what the hearex requires' any less all-embracing than 'what the situation requires'? If it is not, then any explanation which depends on the maxim of quantity is in dangex of being no more explanatory than the maxim itself. If however the concept of what the hearer requires can be explained in terms of the semantic and pragmatic content of either the speaker's utterance ox preceding utterances, then it would seem that hearer-requirements can be given a reliable degree of content. I think in the case of Imperative and question, the requirement of informativeness can be traced to the interpretation given to commands and wh-questions. In the formex case, since propositions can only be true relative to a specific state of affairs at a specific point in time, it is arguable that a command to make some proposition true is pragmatically inadequate unless a specification of the time at which it should be made 
true is included. Wh-questions, on the other hand, as requests for information with respect to a particular variable, are pragmatically inadequate if they do not imply the truth of propositions which must be believed in order to give a value to the vaxiable in question. Thus in the case of How Iong does it take to get to London?, the question itself gives no implication of the manner of travel. Yet the semantics of duration is such that the hearer must know the manner of travel if he is to provide a specification of duration. ${ }^{7}$ so the only way to construe the questioner as not breaking the maxim of quantity is to make some further assumption which would reinstate the maxim. Hence the implicature that the speaker is travelling to London by car. It seems then that if we wish the maxim of quantity to be maximally spectfic, we should add separate maxims of quantity guaranteeing that inadequacies of this type do not arise. Since all of this is extremely tentative I shall not give further specification to the maxim here. What I hope however to have indicated is how in principle the concept of hearer's requirement of informativeness (whether as a questioner or questionee) can be defined in terms of the semantic or pragmatic content of the discourse.

\subsection{The Maxim of Quantity and The Pragmatic Universe of Discourse} Constraints on iuformativeness are not however fully covered by the maxim 'Give as much information as the hearex requires'. In addition, there is a more general constraint of informativeness which applies to all forms of utterance. I pointed out earlier (p.212) 
in a footnote that the maxims demanding that the speaker's contribution be as informative as required but not more so corresponded to strawson's 'Presumption of Ignorance' and 'Presumption of Knowledge' (Strawson 1964 a p.97f). These 'presumptions' capture on the one hand the assumptions on the part of the speaker that the hearer does not already know what the speaker is telling him and on the other hand the speaker's assumption that the hearer knows certain 'empirical facts relevant to the particular point to be imparted in the utterance' (p.97). What this latter presumption. suggests is that there is a certain body of facts which in any discourse a speaker will presume that his hearer lnows. Now if we are to give any content to the maxim of quantity construed in a general sense and give an account of the oddity of uttering tautologies or statements which are generally recognised to be true, we must give an explicit characterisation of the concept of 'assumed knowledge'; since if a sentence is to be informative it must not merely tell the hearer what he already knows nor what both the speaker and the hearer already know each other knows. And more importantly perhaps for the specific hypotheses presented in this thesis, we shall that a formal definition of 'assumed knowledge' provides a natural basis for explaining the pragmatic behaviour of definite noun phrases and factive complements, which is one of our chief remaining concerns.

\subsubsection{The Pragmatic Universe of Discourse: A Definition}

What we have to capture is that in any conversation, there is a body of facts which both speaker and hearer believe they agree on and which is therefore not in dispute: this set of propositions constitute their shared knowledge - knowledge which they know they share. That is, for any 
individual $S$, there is a fund of knowledge which may be represented. as a set of propositions $K_{i}$. When this arbitrary individual communicates to any other individual $\mathrm{H}$, who also possesses a fund of knowledge $\mathrm{K}_{\mathrm{j}}$, there will generally be a subset of $\mathrm{K}_{i}$ which is also a subset of $\mathrm{K}_{\mathbf{j}}$. More formally we can say that for every conversational exchange in which $S$ is the speaker and $H$ the hearer, the set of propositions which constitute the knowledge which two such speakers will believe they share must meet the following four conditions:

(I) $S$ believes $P_{\mathbf{i}}$

(2) $S$ believes H knows $P_{1}$

(3) $S$ believes $H$ knows $S$ believes $P_{i}$

(4) $S$ believes $H$ knows $S$ believes $H$ knows $P_{i}^{8}$

I shall call this set of propositions the Pragmatic Universe of Discourse. 9 For any proposition $P_{i}$, if it fulfils these conditions it will constitute a proposition which both speaker and hearer will (or will expect each other to) assume. Moreover, if a proposition $P_{1}$ fulfils these conditions then the entailments of $P_{i}$ must also fulfil these conditions. This follows from the general rule of doxastic logic (logic of belief statements) that for any speaker $S$, if he believes that $p$ and $p$ entails $q$, then he is

8. I have characterised these conditions in terms of belief or knowledge in the way that seemed the most satisfactory, though there is independent evidence that this formulation is correct (cf. p.247f). A more precise formulation would depend on theorems of epistemic and doxastic (belief) logic. Cf. Hintikka 1962 where he defines a logic for statements of knowledge and a logic for statements of belief. Cf. also p.24l fn.10.

9. This concept of a Pragmatic Universe of Discourse is close to the concept of 'mutual knowledge' defined independently by Schiffer 1972 (p.30f): $S$ and $A$ mutually know* that $p$ iff $K_{S} p, K_{A} p, K_{S} K_{A} p, K_{A} K_{S} p$, $K_{S} K_{A} K_{S} p, K_{A} K_{S} K_{A} p, K_{S} K_{A} K_{S} K_{A} p, K_{A} K_{S} K_{A} K_{S} p \ldots \ldots$ 
committed to the belief that $\mathrm{q}^{20}$

The Pragmatic Universe of Discourse (henceforth PUD) is not, as this formulation might suggest, a static one. On the contrary it changes (increases) its membership as a conversation progresses. This changing content of the Pragmatic Universe of Discourse is a necessary consequence of the information-bearing nature of making a statement. Once you have made a statement $S_{i}$ which by the maxim of quality you know the hearex will assume you know to be true - you will assume (by virtue of the definition of speakex's meaning - cf. p.197f) that the hearer now also belieres $S_{1}$ (and all its entailments and implicatures). So if both you and your hearer are obeying the $\mathrm{CP}, \mathrm{S}_{\mathbf{i}}$ will - after your utterance be a statement you both share knowledge of. But our definition of the Pragmatic Universe of Discourse predicts exactly this process of enlargement: according as the conversation progresses from $S_{1}, S_{2} \ldots$ $s_{n}, s_{1}$ (and its consequent commitments) will become a proposition which fulfils all four of the defining conditions. That is, the speaker believing $S_{1}$ (condition 1 ) tells it to the hearer. On the assumption that his communication is successful, he then believes the hearer knows $S_{1}$ (condition 2) and moreover he believes (by the quality maxim) that the hearer knows he believes $S_{1}$ (condition 3) and similarly that the hearer knows that he believes the hearer knows (condition 4 ).

It may seem that the definition of the Pragmatic Universe of Discourse (PUD) is unnecessarily: unwieldy and that the two conditions (1) and (2) are sufficient to characterise what will constitute the assumptions made

10. Hintikka's doxastic and epistemic logics were set up to formulate criteria of consistency for statements of belief and knowledge resepectively parallel to the eriteria of consistency provided by standard logics. Thus to take the example provided here, it would be inconsistent (or in Hintikka's sense 'indefensiblo') for any speaker A who believes that $p$, where $p$ entails $q$, to deny that he believes that $q$. In Hintiklsa's more general formulation: $B_{A} p \supset B_{A} q$ whenever $p \supset q$. Notice that by this rule condition ( 1 ) of the PUD follows from condition (2): 1 knows $P_{i}$ entails $\underline{P}_{i}$ and hence if $S$ believes $H$ knows $P_{i}$, he is committed to believing $\mathrm{P}_{i}$. 
by two speakers at any one point in a conversation and will therefore not be part of their conversation at that point. But this is not always so. There are cases in which the CP is being maintained, and conditions (1) and (2) hold, but the propositions in question are not part of what we want to say are the assumptions of that utterance. Take for example a situation in which an examiner says to a student 'What is a transformational rule?' Now the student may assume that the examiner knows that a transformational rule is a rule which states a relation between two phrase-maxkers, but he may still say 'A transformational rule is a rule which states a relation between two phrase-markers'. This is not assumed in the PUD of that conversation. What the student does not believe is that the examiner knows he knows that a transformational rule is as described (i.e. condition (3) is not fulfilled). Likewise a persohell officer (PO) talking to a new man in the firm may believe that the new man knows that no information about the firm may be given to outsiders (condition 2) but he does not believe that the man knows that he the Po knows that the man knows this (condition 4) - the new man may therefore think he can break the rule. Thus the PO may say 'No information about the firm may be given to outsiders.' The failures of conditions (3) and (4) are clearly not the normal reasons why a proposition is not part of the PUD, but rather what is stated. The general condition on saying something is that you believe that the hearer does not know what you are telling him - that is, condition (2) is not met. And if condition (2) is not met, then it is not possible that condition (4) be fulfilled. If condition ( 1 ) is not met, then clearly the proposition in question cannot, trivially, be part of the Pragmatic Universe of Discourse since the speaker does not believe it. 


\subsubsection{The Maxim of Quantity II}

My initial aim in delimiting the Pragmatic Universe of Discourse was to incorporate into the maxim of quantity some general constraint on being informative. I suggest the following maxim as a first approximation:

Do not assert ${ }^{12}$ any proposition $p$ which is a member of the Pragmatic Universe of Discourse' or, more generally:

'For any proposition $p$, and any mood operator ' $\psi \psi$ ' (i.e. 'F', '!' or '?'), do not say '* $\psi \mathrm{p}$ ' if $p$ is a member of the Pragmatic Universe of Discourse.' But $\mathrm{p}$ will only be a member of the PUD if sufficient conditions for the truth of $\mathrm{g}$ are themselves members of the PUD. Equivalently, if $p$ is known to be true, the conditions which guarantee the truth of I will also be known to be true. The maxim can thus be given the further specification:

Tror any proposition $\mathrm{p}$ whose truth is minimally guaranteed by n conditions, and any mood operator ' $\psi$ ' ', only say '* $\psi$ p' if $\leq n-1$ of those conditions are members of the PUD.' As a first indication of how this maxim might operate, let us look first at positive assertions, imperatives and questions. The maxim was defined to exclude as conversationally inadequate saying what is mutual knowledge between speaker and hearer. It also excludes ordering one's audience to carry out some action which is already clearly true. Thus one should not tell someone to shut the door if

11. Cf. section 8.6 of this chapter for a discussion of assertion. 
It is already shut, nor to kill somebody ${ }^{12}$ if that person is already dead. 13 Along similar lines, one should not ask a question to which one knows the answer if moreover one knows that the hearex knows the answer. The position is further complicated here by the fact that ' $p$ ' indicates a request for either the utterance 'p' or the utterance '-p'. Unlike imperatives which indicate a simple intention, '?p' expresses a complex intention (containing a disjunctive or) and it is therefore conversationally inadequate to say '?p' if either $\mathrm{p}$ or -p are members of the PUD. How do negative statements obey this maxim? We have seen in previous chapters that the semantic representation of some statement $=p$ is a disjunct of semantic features, say,

$$
[\mathrm{A} / \mathrm{M}] \vee[\mathrm{A} / \mathrm{N}] \vee[\mathrm{A} / \mathrm{P}] \text { etc. }^{14}
$$

Any one of these disjuncts is a sufficient condition for the truth of $-p$ but no one of them is a necessary condition. What the maxim claims is that if any one of these disjuncts is a member of the PUD, it will be otiose for any speaker to inform his hearex of the statement $=$. And this is what we find. As an example, let us assume a very approximate schematic representation of John didn't kill Mary $^{15}$ to be

$$
[\mathrm{A} / J] \mathrm{x}_{1} \vee[\mathrm{A} / \mathrm{M}] \mathrm{x}_{2} \vee[\mathrm{CAUSE}] \mathrm{X}_{1}\left([\mathrm{~A} / \mathrm{DIE}] \mathrm{x}_{2}\right) \vee[\mathrm{A} / \mathrm{CAUSE}] \mathrm{X}_{1}\left([D I E] \mathrm{X}_{2}\right)
$$
(a)
(b)
(c)

If it is common knowledge between any speaker and hearer either that

12. I am ignoring the moral constrajnts that might operate in this latter case.

13. In fact the constraint is stronger than the maxim indicates, since a generalisation of the maxim of quality should forbid one to command something if it is already true (whether or not this is known by the hearer.

14. $A / M_{i}$ is the antonymy operator for a member $M_{i}$ of a set $M_{7}, M_{2}, M_{3}, \ldots M_{n}$ such that $A / M_{1} \equiv M_{1} \vee M_{2} \vee \ldots M_{-1} \vee M_{-1} \ldots$ i $\vee M_{1}$ (cf. ch.I $\left.p .33\right)$.

15. This representation is misleading in that ali problems of quantification are ignored. These details do not however affect the point being made, so I have excluded them for the sake of clarity. For a fuller representation of negative sentences of this type, cf. ch.6 p.188f. 
someone other than John killed Mary (cf. (a)) or that John killed

someone other than Mary (cf. (b)) or that Mary died but John definitely was not the cause of it (cf. (d)), or that John raped Mary but she didn't die as a result (cf. (c)), then the maxim predicts that the utterance of this sentence will flaunt the Comoperative Principle and therefore be conversationally inadequate, in just the way that 'John killed Mary' is an inadequate utterance if the speaker and hearer both know that this is so.

\subsubsection{Some Putative Counter-Arguments}

It might seem that there are immediate and obvious counter-examples both to the maxim and to the general definition of the PUD. On the one hand, the newly defined maxim appears to exclude the possibility of repeating, recapitulating or summarising what one has said, since one is only conventionally allowed to say what is not part of the PUD and everything that is said in an exchange becomes in its turn paxt of the expanding PUD. And on the other hand - along similar lines one often tells children things which they already know, an activity which appears not to be allowed. More generally, it is not obvious as the account of the PUD presunes - that communication is based on the assumption that as a result of some utterance $P_{i}$ by a speaker, the hearer then himself believes $P_{i}$ (which is then part of the PUD). Rather the effect of the speaker's utterance might be only that the hearer believes that the speaker believes $P_{i}$, in which case the predicted expansion of the PUD as the conversation progressed does not take place since one member (the original hearex) does not believe $P_{1}$. 
$-246-$

None of these criticisms however seem to me to be justified. Let me take first the case which I suggest is theoretically the least interesting = that of the child, for whom one may often repeat oneself. Now in all that has been said so far, it has been assumed that the pragmatic conventions, like the linguistic conventions, are part of our mastery of the use of our language. The child, by contrast to adults, may well not have mastery of its language and it seems that is precisely and only at the age when the child is learning the language that it most delights in being told what it knows. 16 This suggests that it has not learnt the pragmatic maxim I suggested. This seems to be confirmed by the fact that it is at just this age when the child in the role of speaker will repeat itself over and ovex again. Thus in both its role as speaker and as hearex the child has not yet acquired the pragmatic convention in question. The evidence of repetition to and by children is thus irrelevant to the point in hand.

More interesting for my purposes is the problem of conversations in which the hearer is not convinced by the speaker's statement $P_{i}$ and is not led by this utterance to believe $P_{i}$ himself. Should such instances, which are surely common enough, be included within a theory of communication as one form or result of communication? I think the answer is 'No' for the following reason. If convincing one's hearer that one believed some proposition $\underline{P}$ were a sufficient end in itself for communication, one would anticipate that conversations

16. My stepmson of five intensely dislikes being told what he knows. 
could proceed in an orderly fashion on this weaker assumption. But they cannot. Suppose the hearex of $\underline{P}$ only believes that the speaker of $\underline{P}$ believes that $P$ without himself being committed to the truth of $\underline{P}$. If he then makes a statement which depends on $\underline{P}$, he is breaking the Co-operative Principle (viz. the maxim of quality). In order to develop the conversation on the basis of $\underline{p}$, he must be committed to the stronger belief that $P$. So we can see that if a hearer assumes that mere belief that the speaker believes that $P$ is a sufficient basis for communication, he immediately violates the $C P$ on which communication is based. It follows that a belief in $\underline{P}$ on the part of the hearer of $\underline{P}$ is a necessary condition of successful communication. With this in mind, we have a natural explanation of the third criticism that summarising, recapitulating and other repetitions appeared to be excluded by fiat by the newly specified maxim. Consider the function of a summary or a recapitulation. In each case they serve to ensure that the statement in question has been successfully communicated: they are generally made in the face of doubt on the part of the speaker as to whether his communication was successful in the first instance. That is to say, they are made to prevent the situation we have just discussed, where the hearer was not himself convinced that $P$, he merely believed that the speaker believed that $P$.

In all cases, though the speaker has already indicated that $\mathrm{P}$ and hence he should believe that the hearer knows that $P$, in fact he doubts this and makes the weaker assumption, and believes only that 
the hearer believes that he the speaker believes $P$. This being the case, repetitions fail to meet the conditions spectified by the Pragmatic Universe of Discourse (in particular its condition (2)) and hence they are not excluded by the maxim 'For any proposition $p$, and any mood operator ' $*$ ' do not say '* $\psi \mathrm{p}$ ' if $\mathrm{p}$ is a member of the PUD'. They are therefore not counter-examples to this analysis. ${ }^{17}$

\subsubsection{Exclamations and The Requirement of Informativeness}

In all the discussion of the maxims of the Co-operative Principle so far, I have restricted my attention to statements, questions and (briefly) imperatives. There remains however a further class of utterance - exclamations. 18 Utterances such as Isn't she clever! Isn't the view lovely: Didn't she sing beautifully! appear to constitute much clearer counter-examples even than repetitions and summaries to the constraint that speakers should not say what is known and known to be known by the participants in a conversation. There is little doubt that two people can stand in front of the Mona Iisa and knowing both that it's a beautiful painting and that each other knows it is a beautiful painting they can still naturally turn to each other and say 'Isn't it a beautiful painting:'

These examples are interesting for a further, and potentially more damaging, reason. Unless the maxim of quantity is given greater content than is provided by Grice, examples of this type show up its vacuity since the maxim enables one to pxedict either that they should be deviant or that they are not. If the maxim 'Give as much information

17. For a much more detailed refutation of apparent counter-examples of this type with a concept of 'activated belief', cf. Grice 1969 p.169f.

18. These examples were pointed out to me by R.A. Hudson. 
as is required' insists, as it suggests, that all utterances must have some information content, where information is measured in terms of what is not agreed between speaker and heaxer (corresponding to the definition of the PUD: cf. p.240) then since these utterances neither offer nor seek informatjon, they are predicted to be conversationally deviant. If however the maxim allows for a situation in which no information being required, no information need be given then the theory predicts that exclamations of this type do not violate the maxim. However if this interpretation of the maxim is allowed, it is not clear what conceivable situation it could exclude. It is therefore vacuous, and without content. This criticism does not however extend to the reformulation of the maxim I have given; but the examples instead become counter-examples.

There are at least two ways in which these counter-examples might be treated. The first is to claim that the prediction made is correct in excluding these from a theory of communication since they are essentially noncommunicative. On this view they are not counterexamples. While this approach is tempting, I think it has to be discarded. It is tempting because there is a sense in which utterances such as 'She IS Iovely', 'He DOES sing well' are not communicative utterances but involuntary expressions of belief which do not seek to further conversation. But even if such an explanation could be given any content, it does not seem to be applicable to exclamations in the form of a negative question. These genuinely seek a response of some sort, and are not the natural form of exclamation uttered in the 
absence of an audience. The second explanation of such exclamations is that they are not mere statements of fact but are communications of the strength of the speaker's commitment to the statement in question. It has been pointed out by Quirk et al (1972: p.4.0079 that exclamatory questions of this type are only possible if the question contains a gradable term, the interpretation always being that the speaker is committing himself to an assessment of the gradable term as at the extreme end of the scale of gradation. Thus Isn't she lovely? Didn't she sing badly? Didn't she sing a beautiful song? can all be exclamations, whereas Isn't he coming tomorrow?, Wasn't she your secretary last year? and Didn't he do the washing-up? can never be. Though the spealser may know that the statement itself is known by the hearer to be agreed by him and the speaker, what the speaker does not assume is that his hearer knows the strength of his commitment. Hence part of the information conveyed by such utterances is not mutually agreed by the participants. The problem with this form of explanation is its informality, an informality which seems unavoidable given the problems involved in stating a predictable interpretation for negative questions of this kind. They are unique in being sentence forms which do not allow a cumulative interpretation of their constituent parts. The interpretation of Isn't she lovely! is not a questioning of the negative proposition she is not lovely. ${ }^{20}$ Thus it bears no relation

19. Cf. also Hudson 1973.

20. This is unlike true negative questions such as Isn't she coming? which can be analysed as querying She isn't coming. Indeed these are characteristically uttered in the face of their corresponding statement (or an implication of it). 
either to its sentence operator, the negative element, or to its pragmatic operator, the question element. It seems clear that until we have a nonmadwhoc way of giving an interpretation to such utterances, we have no means of testing the validity of explaining their message-content in terms of a considerable degree of commitment on the part of the speaker. With reservations of this sort, I shalI accept this explanation pro tem.

In this section, we have seen how a formal characterisation of the notion of 'assumed lonowledge' (in terms of a Pragmatic Universe of Discourse) can be used to give greater specification to one of the central maxims, the maxim of quantity. This now contains two subparts: (i) Give as much information as the hearer requires (ii) Only say ' $* p$ ' if $p$ is not a member of the Pragmatic Universe of Discourse'. Both the maxims of relation and quantity are now at least partially defined in terms of the semantic and pragmatic content of the utterance and, in being xestricted in this way, are less open to universal. application. One large problem however remains: should they be restricted in this way? As we shall see in section 8.6.1, there is evidence that at least the maxim of relation cannot be restricted merely to the content of the utterance since the interpretation of stress depends not merely on utterance content but on its form. Furthermore the problem is not restricted to merely predicting the available data. As I shall take up in the final chapter, the question of how the maxims should be specified may depend on the theoretical status of pragmatics within an over-all theory of language. For the moment however I shall simply assume that the restriction of the maxims 
to the pragmatic and semantic content of utterances can only be beneficial in giving them greater content and thus greater explanatory val.ue. We shall see in any case that the restrictions placed on the maxims and the setting up of a Pragmatic Univexse of Discourse are not merely ad-hoc methods of saving the theoretical framework, but enable us to give a natural explanation of definite noun phrases, factive complements, and the postulated assertion-presupposition distinction.

\subsection{Definite Noun Phrases and The Pragmatic Universe of Discourse} In chapter 5 I argued that there are two implications in the use of definite noun phrases. These are for any object described with the use of the that there is such an object, and that the hearer knows of the existence of the object (in so far as he can uniquely identify it for the purposes of the particular discourse). I argued however that only the first of these implications was semantic, since to say 'the $x$ ' does not entail that the hearer be able to uniquely identify the object referred to by the $x$, though this is a normal. implication of its use (cf. p.161f). It is this latter implication that wo have to characterise in pragmatic terms. This is not the only problem which definite noun phrases present. In addition we have to explain the natural. interpretation of definite noun phrases in questions and negatives that they be protected from the scope of negation.

In chapter 7 I defined two categories of standard implicature, conventional implicature and generalised conversational implicature, and we are now in a position to assess the explanatory value of these 
categories. As a preliminary to doing so, let me briefly recall examples which demonstrate the central properties of general conversational implicature and conventional implicature. The first was exemplified by ' $P$ or $Q$ ' which normally implicates in response to a wh-question that the speaker does not know which of $\underline{p}$ or $g$ holds, since by virtue of the maxim of the $C P$ that one must give the information that the hearer requires (cf. p.233ff), the hearer deduces that if the speaker knew that $\underline{P}$ was true he should be comnitted to stating that $\mathrm{P}$ : the speaker will therefore be taken to be Implicating that he does not know which of $\underline{P}$ or $\underline{Q}$ is true. The reasons why this category is not a conventional implicature are (a) that the implicature is cancellable either explicitly or by virtue of the situation in which it is uttered and (b) it is deduceable from the maxims of the CP in conjunction with the linguistic specification of the sentence in question. Conventional implicature by contrast fails both these criteria - it is not cancellable and it is not deduceable from the CP. It is thus in effect not explicable by means of the pragmatic constructs. One of Grice's standard examples of conventional implicature is the implication in but of a contrast between its two conjuncts (cf. Grice 1961), which I demonstrated in chapter 4 was unformalisable in semantic terms since it was not possible to predict any contrast (either semantic or syntactic) which was a necessary premrequisite of but's occurrence. This implication of contrast carxies all the hallmarls of conventional implicature: it is not strictly speaking part of the word's meaning for reasons already given, but it seems in some sense always a consequence of the word's use - to say 'X but $Y$, but I don't 
mean to imply there's any contrast between the two' is indefensible 21 in the same way as it is indefensible to say ' $X$ but $I$ don't believe it': and it is not dependent on the CP for its interpretation. ${ }^{22}$ since in the case of but, the semantic arguments against distinguishing but and and are undeniably strong, the ad-hocness of the pragmatic mechanism guaranteeing that but conveys a particular implication does not provide a serious flaw in the theoretical framework. However it seems clear that unless the use made of the concept 'conventional implicature' is extremely restricted, the over-all explanatory value of the pragmatic framework could be cast sexiously in doubt. Thus though in principle we have two possible ways of explaining the pragmatic implications of definite noun phrases, it would be a reasonable criticism to suggest that if either implication had to be analysed as a conventional. implicature, this would constitute a much more serious counter-example than but to the general position adopted in this thesis.

We have already seen that the relationship between I saw the Mayor of Bristol and a statement such as You know who I am referring to by the phrase 'the Mayor of Bristol' is not one of entailment, since I saw the Mayor of Bxistol can be true whether or not the hearer knows - of the existence of such a man. Is it a generaI conversational. jmplicature? If so, we should be able to derive it by means of our

21. Cf. howevex, ch.9 p. $305 f$.

22. One might try to interpret a speaker saying ' $X$ but $X$ ' as reasoning (I) $H$ knows I am obeying the $C P$ and making the strongest statement possible (2) Since $I$ am not saying ' $X$ and $Y$ ' I must be implicating something further (3) Therefore I am implicating that $\mathrm{X}$ is in contrast to $Y$. This is not however a valid argument (even using such weak forms of the maxims), since there is no justification for the jump from (2) to (3). The only means of making this step is to know that but indicates a contrast. But this means that in ordex to predict the contrastiveness of but by means of the $\mathrm{CP}$ we have to assume that but is contrastive. This implicature is therefore not dependent on the $\mathrm{CP}$. 
general principles of communication. Let us take the anaphoric use of the definite noun phrase first. In saying the sentence I saw a man today who was patting a dog despite the fact that the dog looked remarkably vicious, a speaker might reason that the hearer (H) knows and knows that $S$ knows (a) the semantic convention that The dog looked remarkably vicious entails There was a specific dog (b) the syntactic convention that [+Def] is a feature which occurs automatically on a noun phrase when it is in an environment which contains a preceding coreferring noun phrase (cf. p.153ff) and (c) the pragmatic convention that any proposition, or set of propositions, once stated will, if the communication is successful, become part of the agreed Pragmatic Universe of Discourse (PUD) (cf. p. $2^{4}, 0 f$ ). Since the statement I saw a man today who was patting a dog involves at least the proposition that there was a specific dog and a specific man such that I saw the man was patting the dog, the effect of an utterance of that statement will be to add to the PUD the proposition There was a specific dog that $S$ saw a man pat. $S$ therefore knows that if the first mention of the dog, as part of the utterance, successfully achieved an addition to the PUD, then $H$ will recognise (by virtue of the linguistic and pragmatic conventions of the language just listed) that the second mention of the dog, with the formal reflex [+Def] must be an acknowledgement of what is already within the PUD - simply by virtue of its being a second mention. But since the definition of the PUD is that all its members are propositions which the speaker believes the hearer knows (among other things), it follows that in using the definite noun phrase the dog in the 
utterance in question, the speaker - unless he is deliberately giving information which he does not believe - will be implicating that he believes that the hearer knows which dog he is referring to namely the dog that $S$ saw a man patting. As the hearer assumes that the quality maxim is being obeyed, the anaphoric definite noun phrase will therefore implicate that the hearer knows which object is being referred to.

From this deduction, we can predict that those environments where the definite article is not anaphoric will also bear the same interpretation. We have seen that [+Def] occurs obligatorily for formal syntactic reasons in an environment where, as a consequence of the pragmatic definition of meaning and the definition of the PUD, the object to which the noun phrase refers is automatically construed as corresponding to a member of the PUD. Moreover in chapter 6 (p.166ff) I argued that definite noun phrases are syntactically and semantically identical at deep structure except that the syntactic feature [+Def], which has no semantic interpretation, may be arbitrarily assigned by optional rule (cf. p.182). Despite this semantic identity, we know that the spealser (S) must be intending to convey some extra information by the use of the feature [+Def] where it is optional. But [+Def] has no semantic representation. So $\mathrm{S}$ can only be interpreted as conveying extra information if he is deliberately seeking to convey that implication which is an automatic consequence of the obligatory use of the definite article.

Take for example the utterance 'I saw the mayor of Bristol'. In saying this, our speaker $S$ might argue 'I know and I know that $H$ (the hearer) knows that (a) I saw the mayor of Bristol entails There is a mayor of Bristol, (b) [+Def] occurs both optionally on noun phrases, and obligatorily just in case it is an environment which contains a preceding coreferring noun phrase and (c) information given and 
received becomes progressively part of the PUD shared by me and $H$. Moreover I know that H knows that where [+Def] ocurs obligatorily it always carries an implicature that the object to which the noun phrase bearing [ + Def] refers is known by both me and $H$ (1.e. it corresponds to a proposition in the PUD $S$ and $H$ share). We both know this by virtue of the $C P$ and the definition of pragmatic meaning, since if I tell him something I know then I can assume he knows it too. But I know that $H$ will expect that I use the feature [+Def] where it is not obligatory only if I intend to convey some extra information. But both $H$ and I know that the feature has no semantic interpretation, and that it can therefore only be construed as offering extra information if it is used to convey the same information as its obligatory use. I therefore know that $\mathrm{H}$ will take my utterance of I saw the mayor of Bristol as implicating that we both know there is a mayor of Bristol.'

There is one problem in this deduction - in what way do the maxims apply to demand that the speaker offer extra information in his use of the definite article? If we invoke the maxim of quantity, then it appears to be applying in its most general form. Certainly nothing the hearer has said or will say affects the speaker's choice of the definite article, so the revised form of the maxim of quantity does not apply. And in the form adopted in section 8.1, the maxim of relation also concerns preceding utterances of the discourse and this is not relevant to the problem we have here. However I indicated there ( $p .231$ ) that the maxim of relation would have to be extended to accommodate problems of stress. To anticipate what is 
argued for in detail in section 8.6.1, it appears that the maxim of relation needs a separate sub-maxim which applies to the relation between form and content for any utterance, viz: 'Make the form of your utterance relevant to its content'. Now if this maxim is justified - and I argue in section 8.6.1 (p.276ff) that it is the only way to accommodate stress phenomena without reducing the maxims to vacuity - it has a natural application in the case of definite noun phrases. If the speaker uses a noun phrase whose syntactic and semantic specification is identical to that of an indefinite noun phrase except that it bears the feature [iDef] arbitrarily assigned (by optional rule) at deep structure (cf. p.182), he will be breaking this maxim of relation unless he intends the use of this feature [+Def] to be relevant to the content of his utterance. And the only way to construe it as having relevance is to deduce that the speaker must be deliberately invoking that implication which is an automatic consequence of the obligatory use of the definite article. So it seems that where the use of the definite noun phrase is non-anaphoric, the deduction of its implicature depends on the pragmatic definition of meaning (Grice's meaning ${ }_{n n}$ ), the quality maxim, the definition of the PUD, and a not yet justified. extension of the maxim of relation.

This account of the pragmatic implication on definite noun phrases extends naturally both to other types of sentence and across utterance boundaries. In a conversation in which $H$ says 'I saw a man yesterday' and S responds with the question 'Did the man speak to you?' S will argue 'I know that $\mathrm{H}$ knows the conventions (a), (b) and (c) (as before p.256f). Moreover I know that on the basis of (b), (c) and the deductions already given that $\mathrm{H}$ will deduce that definite noun phrases in effect occur obligatorily 
when the noun phrase is interpreted as being a member of the PUD. Since I am using the definite article, $\mathrm{H}$ will therefore deduce that I am implicating that the man to which I refer is part of our PUD. But if I were referring to some man other than the one $H$ has just alluded to, I would be breaking the maxim of relation, ${ }^{23}$ since my question would have nothing to do with his utterance. Since to do so would therefore be to break the pragmatic maxims, and since $\mathrm{H}$ will assume that I am obeying these, II will take my question as referring to the same man as his utterance. So H will take my utterance of the man as implicating that it has a preceding coreferent and is therefore part of our PUD by definition.' As this example demonstrates, we now appear to be able to account for cases of coreference not only within and across sentence boundaries, and within different sentence types, but even between sentences with different speakers. The ability to predict this range of coreference potential arises directly from the delimitation of the PUD. Once any noun phrase corresponds to a proposition of the PUD by virtue of either speaker's assertion, then reference by the can be made to it irrespective of who was responsible for the information about the noun phrase. This prediction, which is an anomaly within any sentence or speaker based framework, arises naturally from the analysis given here. 24 More generally, I have shown how an implicature on definite noun phrases depends on a prior specification of the Jinguistic system (conditions (a) and (b)), and on quite general constraints on communication (condition (c) and the maxims of the Comoperative Principle).

23. This invocation of the maxim of relation refers to the maxim defined in section 8.1 'Give as much information as the hearer requires'.

24. The same phenomenon arises with pronouns and can be explained along similar lines. 
These properties are the essence of conversational implicature. In addition, as an analysis in terms of conversational implicature would predict, this implicature is cancellable, either explicitly or by virtue of the context in which it is uttered. Thus one can say: (10) The King of Ruritania came to my exhibition, though I don't suppose you knew I was having one, let alone that there was a King of Ruritania - did you?

Contextual cancellation of the implicature is provided by the examples which are central to this thesis:

(11) The King of Ruritania didn't visit the exhibition, because there's no such man

That is to say, if there is no King of Ruritania - as the speaker of (II) asserts and hence must believe - then the situation is such that the speaker cannot believe in using a definite noun phrase that the hearer knows of his existence. More formally, we have already seen (p.240f, and fn.10) that The speaker believes that the hearer knows P doxastically implies that the speaker believes that $P$. If therefore it is not the case that the speaker believes that $P$ it follows (as with entailment) that it must also not be the case that the speaker believes that the hearer knows that $P$. If we consider the converse, we can see exactly why both examples (10) and (11) are cases.... where the implication on definite noun phrases of assumed knowledge is cancelled. Since The speaker believes that the hearer knows that $P$ doxastically implies that the speaker believes that $P$, it follows that -(The speaker believes that the hearer knows that P) is (like entailment) consistent with either The speaker believes that $P$ or - (The speaker believes that $P$ ). In the case of (10) we have the former possibility while in (11) we have the latter. In both cases 
the pragmatic implication on the definite noun phrase that the speakex believes the hearer knows that there is a specific King of Ruritania is cancelled out: i.e. we have (schematically) $-(S$ believes that $H$ knows that $P)$. In (10) the pragmatic implication that the speaker believes that there is a specific King of Ruritania is maintained ${ }^{25}$ (schematically, S believes that $P$ ); while in (II) it is not (schematically $=(S$ believes that $P)$ ). In the light of this over-all explanation of definite noun phrases, we can conclude that the implication on definite noun phrases that the speaker believes that the hearer knows of the existence of the referent to which the noun phrase refers possesses the following characteristics: (i) it depends for its deduction on (a) general pxinciples of communication and (b) a separately specified linguistic system; (ii) it is a normal non-situation-specific accompaniment to the relevant utterances; and (iii) it is explicitly cancellable. And these characteristics are the defining characteristics of a general conversational implicature. It thus seems that the implication of definite noun phrases that the speaker believes that the hearer knows the referent in question is not an inherent property of the definite noun phrase, but is a generalised conversational implicature.

The significance of this conclusion does not however stop here. The status of generalised conversational implicatures as normal accompaniments to the interpretation of sentences which possess them provides an automatic explanation of the marked nature of negative sentences containing definite noun phrases where the implication of

25. On the assumption that an utterance of $\underline{P}$ pragmatically implies that the speaker believes that $P$. 
a specific referent of the noun phrase in question is included within the scope of negation. It is because definite noun phrases generally implicate the hearer's knowledge of the existence of the specific referent that interpretations of such negative sentences will normally maintain the implication of the existence of that referent. It is only if this implicature of the hearer's knowledge does not hold, the marked case, that the existence of the referent in question can be consistently denied. On this basis, one would predict that the utterance of The King of France did not visit the exhibition would normally implicate that there was an exhibition, that there was a King of France, and moreover that the speaker believed that the hearer knew both that there was an exhibition and that there was a King of France. But since these implicatures are 'generalised conversational' implicatures and not 'conventional' ones, they can be cancelled, these constituting the marked case. And one way of cancelling such an implicature is to deny a statement on which the implicature depends. Hence to include the existence of the specified referent within the scope of negation necessitates a cancelling of the speaker's belief in the existence of the referent (if the speaker is being honest), which in its turn necessitates a cancelling of the speaker's belief in the hearer's knowledge of the referent in question. So with the statement The King of France did not visit the exhibition, if there is no King of France, and the speaker believes that there is no such man, then it cannot be true that the speaker believes that the hearer knows that there is such a man. So the marked cases of negation we considered in chapter 5 are examples where a second general implicature is cancelled out. 
And with general conversational implicature defined as it is, the theory predicts that such cases constitute the marked cases. Since moreover the implicature of assumed mutual knowledge is directly dependent on the syntactic property of the definite noun phrase as a coreference marker, it follows that the markedness of the particular interpretations of negative sentences which have been central to this thesis can be traced not to the semantic properties of definite noun phrases (as one might at first expect) but to the pragmatic interpretation given to the syntactic feature [+Def]. An exactly parallel explanation can be given to questions, where again both the existence of the referent and the hearer's knowledge of the existence of the referent are normally assumed. The implication that the definite noun phrase corresponds to a proposition in the PUD (and is thus part of the knowledge agreed and assumed by both speaker and heared is cancelled out just in case the proposition itself is doubted or questioned by the speaker.

(5) Is the King of Rumania coming to the coronation, or doesn't Rumania have a king?

(6) Did the Duke of PLAZITORO come to the opening ceremony - I didn't think there such a place as Plazitoro, let alone that it had a Duke.

(7) Is the King of Rumania coming to the exhibition - I thought Rumania was a republic.

Examples (5)-(7) (repeated here for convenience) do not imply that there is a specific referent corresponding to the definite noun phrase in question and therefore they cannot be taken to imply that such a referent is a member of the PUD which speakex and hearex share. 
In general terms, what this section has - hopefully - demonstrated is that an independently motivated pragmatic framework appears to provide a natural explanation of one property of definite noun phrases, which we have already seen from semantic evidence is different in kind from other semantic properties of such noun phrases. Since in addition this pragmatic explanation of definite noun phrases automatically predicts (a) the possibility of negative and interrogative sentences in which the existence of the referent of a noun phrase is denied or questioned respectively, and (b) that such interpretations are extremely marked, I think we can reasonably conclude (as long of course as the explanation is correct) that it provides reassuring confirmation of the semantic and pragmatic frameworks adopted here.

\subsection{The Pragmatic Interpretation of Factive Complements}

We saw in chapter 6 that there was semantic evidence for an interpretation of factive sentential complements in a way that corresponds to specific noun phrases, and that there was syntactic evidence that the underlying syntactic structure of such factive complements should contain an explicit definite noun head such that the sentences The King regretted the fact that the Queen was sick and The King regretted that the Queen was sick possessed the same deep structure. Two consequences follow from this analysis which are relevant to the problem we face here of explaining the marked status of negative sentences and questions incorporating the complement of factive verbs within the scope of negation or question. First, in 
giving factive verb complements a specification at deep structure which contains the feature [-Def] (cf. ch.6 p.1.23), one is committing oneself to a specific prediction about the pragmatic behaviour of these complements - since the pragmatic behaviour of definite noun phrases is triggered by the syntactic feature [tDef], factive complements should have the same pragmatic properties as definite noun phrases. Thisfirst prediction leads to the second. There are verbs which entail the truth of their complement but which do not share many of the syntactic characteristics of factives. Take for example prove, This cannot take the full range of gerunds, and it allows both the for-to construction and the accusative plus infinitive construction. 26 If we distinguish between Jones repretted that Einstein was right and Jones proved that Einstein was right by assigning only to the former a deep structure definite noun head, our formal mechanism will automatically lead to a prediction that the pragmatic behaviour of regret and prove should be different, since it is the feature [tDef] on the head noun of the complement sentence which causes the pragmatic interpretation of factives. Both these predictions are matched by the evidence.

We have already seen in part that the first prediction is fulfilled. Both factives and definite noun phrases have occupied a central part in my arguments here because they share the property of having certain logically possible but highly marked interpretations in negative environments. Moreover this shared property carries over to questions (cf. examples $(1)-(4)$ p.226). Secondly there is an implication in 
the use of factives which I have not yet drawn attention to. (12) and (13) characteristically imply that the speaker assumes that the complement is true, (hence the common use of presupposition) in other words the spealser believes the hearer knows that the complement is true.

(12) John regretted that Mary was sick

(13) Edward realised that his mother was dying

But this implication on factives parallels the implication on definite noun phrases that the speaker believes the hearex knows the referent to which the noun phrase refers. Now the implication on definite noun phrases was, I argued, a general conversational implicature since, among other things, it was cancellable - either explicitly or by virtue of negating the entailment on which the implicature depended. The implication on factive complements behaves in exactly the same way: it can be cancelled, either explicitly as in (14) or - in the case of negative and interrogative sentences such as (15) and (16) - just in case the truth of the complement is also denied or doubted. Corresponding to examples (10) and (11) (p.260) we have (14) I regretted/ didn't regret going to see your mother, though you never knew until now that I ever went to see her, did you?

(15) John didn't regret that Mary was sick because she was not sick (1.6) Does Felicity regret taking a BBC audition - I thought she'd always refused to take one.

Thus both pragmatic properties of definite noun phrases - that in negative sentences and questions the implication of existence of the noun phrase will not be included within the scope of the operator, and that in all sentences there is a general implicature that the speaker believes the hearer knows the referent in question - appear 
to stand in a one-to-one correspondence with the pragmatic properties of the complements of factive verbs.

Our second prediction was that by virtue of the different syntactic analyses of prove and regret, the pragmatic behaviour of these verbs would be correspondingly different. And so it is. As we would expect, two properties distinguish verbs such as prove from the factive set. Unlike factives, the complement of prove is normally interpreted as falling within the scope of negation if the verb itself is. Though the natural interpretation of John didn't regret that Mary was sick is not that given in (15) but is that Mary was sick, there is no such parallel in (17):

(17) Jones didn't prove that Einstein was wrong

Here there is no indication of whether or not Einstein was wrong. Similarly the natural interpretation of questions containing prove is that the complement of prove is being questioned. Thus in (18) there is certainly no assumption that Generative Semantics is vacuous rather this is just what is being questioned.

(18) Has Chomsky proved that Generative Semantics is vacuous? Secondly, the complements of prove carry no implication of assumption. of their truth on the part of the hearer. That is, a sentence such as John proved that Einstein was wrong does not carry an implication that the speaker beljeves the hearer already knows that Binstein was wrong. All these predictions are exactly consonant with the analysis given and they provide independent bonfirmation not only of the semantic and pragmatic account offered here but also of the syntactic analysis accorded to factives by the Kiparskys. 
It thus appears that in collapsing the pragmatic account of factive verbs with that of definite noun phrases, we have to hand a natural means of explaining marked and unmarked interpretations for a large range of negative and interrogative sentences - the marked interpretations arise just in case a separate general implicature is cancelled out. And in a more general perspective, this joint account of factive complements and definite noun phrases togethex with the pragmatic constructs independently defined by Grice provides an automatic explanation of the apparent discrepancy between the semantics of negation and its use.

\subsection{The Assertion-Presupposition Contrast}

So far in this chapter, I have been fosuing my two chief aims: firstly to reformulate Grice's maxims so that they can reasonably be said to have explanatory value; second to use these maxims to explain why it is that some interpretations of negative sentences are 'natural' and unmarised while others are highly 'unnatural' and marked. I wish to turn now to the notion of assertion, since in predicting the relationship between what a speaker assumes (presupposes) and what he asserts, queries, etc, where this correlates with stress assignment, we shall see that there is evidence to suggest that the maxims cannot be restricted solely to messagecontent. We shall therefore be forced to reconsider the problem of the extreme power of the maxims.

Up to this point in the thesis, the term assertion has been used in two different ways. First I introduced (cf. ch.2 p. 78) a pragmatic assertion mood operator, which conventionally indicates 
a belief in the truth of the proposition it attaches to. But then in chapter 3, I argued that there were two uses of presupposition, one associated with statements and one associated with the speaker of an utterance, of which the latter stood in contrast to assertion in the sense of what the speaker is actually asserting. The first use of the term assertion, as a mood operator, applies to a sentence as a whole, the second, in contrast to presupposition, applies to some subpart of an utterance. In chapter 5, I argued that it was a confusion between these two separate senses of assertion that underlay the disagreement between Strawson and Russe1l. It might therefore seem that these two constructs should be distinguished not only theoretically but terminologically, as say entailment and implicature are.

There is however a parallel problem with imperatives and questions, as Searle has pointed out (1969 p.162). In ordering someone to visit the King of France, you are not ordering him to cause the existence of the King of France, and in asking whether the King of France is married you are not (normally) querying the King of France's existence. In both cases, the command and the query respectively are restricted to a subset of the conditions necessary for the truth of the proposition in question. In the one case, the scope of the imperative is restricted to the relation between your audience and the King of France, viz. that your audience visit the King of France; in the other, the scope of the question is restricted to whether the man in question has the property of being marxied. If then we proliferate terminology for the two senses of assertion, we shall have also to do so for command and for question. But in this way, we shall not be providing any explanation of the homogeneous behaviour of the three utterance 
types. If we are to give any general account of this phenomenon, we must provide a uniform explanation of the varying scope interpretations associated with the three mood operators.

The explanation can be found in the concept of the Pragmatic Universe of Discourse (PUD) and the associated maxim of quantity. In section 8.3 I argued firstly that the PUD was defined as a set of propositions which the speaker believed the hearer knew the speaker believed the hearer knew (the other three conditions being derivable from this) and that secondly, the maxim of quantity should be given greater content by adding a further maxim:

'Only say '* $\psi \mathrm{p}$ ' if, of $\mathrm{n}$ conditions minimally guaranteeing the truth of $p, \leq n-1$ conditions are members of the PUD.'

The relation between the mood operators as applied to the proposition as a whole and the part of the utterance which is in fact being asserted/queried/commanded is deduceable from this maxim. The speakex believes the hearer knows (and knows that the speaker knows) a certain body of propositions (i.e. there is a PUD) and in making a certain utterance ' $* \Psi_{\mathrm{p}}$ ' he believes that the hearer, knowing the conventions of the language and hence the conditions for the truth of the proposition in question, will recognise a subset of those conditions as being part of the PUD and hence neither assertible, deniable or queriable (without violating the quantity maxim), and a second mutually exclusive subset of the conditions as being outside the PUD. This latter set, he will interpret as being asserted, denied, commanded or queried. Thus what the speaker asserts in making some statement ' $p$ ' will be precisely those conditions of $\mathrm{p}$ which he believes are not in the PUD since the hearer does not know (or does not know that he knows) them. What he commands in saying 'Ip' will be those conditions of $p$ that 
he believes are not currently true, and hence by definition are not part of the PUD. What he questions in saying ' $2 \mathrm{p}$ ' will be those conditions which he believes are not members of the PUD, in this case not because the hearer doesn't know their truth value, but because he, the speaker, doesn't. In each case, because the body of propositions which makes up the PUD varies from context to context, the assertion-presupposition (or question-presupposition or commandpresupposition) distribution for any sentence will vary according as the context varies (given the limits imposed by the semantic structure of the sentence in question). What now becomes self-evident is why the entailments on factive verbs and definite noun phrases (for example) were mistakenly construed as being necessarily part of what the speaker assumes (presupposes) as opposed to what he asserts. Since, as we have seen, both factive verbs and definite noun phrases generally implicate respectively that the proposition expressed by complement and the proposition claiming existence of a specific referent are members of the PUD, it follows by definition that in any assertion (whether negative or positive), question, or command, these propositions would generally be assumed to be true. The mistake of presupposition supporters lay in setting down a requirement that such an assumption necessarily hold. As we have seen in earlier chapters, this implication is context-dependent, and as such is not a semantic property of the sentence in question. On the contrary, the fluctuating nature of the assertion-presupposition, question-presupposition distribution in different utterances of the same sentence is a characteristic of pragmatic generalisations and is predicted naturally under this analysis. 
8.6.I Speaker-Presupposition, Stress Assignment and The Maxim of Relation

To have given a working definition of the utterance phenomena of assertion-presupposition, question-presupposition etc is not however the end of the story. As many writers have pointed out, there is a conventional correlation between stress assignment and the interpretation of the assertion-presupposition (positive or negative) and question-presupposition distribution. The stressed item is (roughly) interpreted as the sole item falling within the scope of the mood operator, everything else being assumed to be true. The problem as we have seen earliex (ch.3 p.86) is that this phenomenon cannot be truth-conditional since it has no effect on the truth value of a statement in the positive case. 26 It therefore lies outside the domain of what I have argued is semantics. Yet Chomsky (1971) has argued that focus (or scope) of the question or negation is entirely predictable given the stress assignment, both in the case of normal and contrastive stress assignment. Two questions then arise: is this claim correct, and if so what is the nature of the rule which encapsulates it?

The claim Chomsky makes is that the presuppositions of the sentence can be read off by replacing the focussed item (where the focus is any phrase containing the intonation centre) by a variable. Thus for example the presuppositions of the assertion John didn't meet Mary in the garden (with normal stress assignment on garden) are either that John met Mary somewhere (in the garden being the focus of negation), or that John met someone somewhere (Mary in the garden being

26. Actually this is a simplification, since in all opaque contexts, stress can lead to a change in the truth value of a statement (cf. Dretske 1972). I assume however that interpretations of opaque environments are like negation and contain a disjunct set of conditions (cf.ch. I p.36ff), and that stress does not alter meaning in these cases, but rathex provides a pragmatic means of drawing attention to those conditions which are construed as falling within the scope of the operator in question. Cf.p. $276 \mathrm{ff}$. 
focus), or that John did something (the entire verb phrase being the focus). I have already argued (ch.1 p.46f) that this claim is inadequate if stress is normally assigned on the grounds that the full range of scope possibilities is available with normal stress assignment and this range cannot be predicted by considering the phrase containing the intonation centre. However, if stress is contrastive (i.e. not placed on the final lexical item in a sentence), then the interpretation of the scope of negation or question is not in general left open, but is restricted to the lexical item (or phrase containing the lexical item) which is stressed. Since this phrase is often not the end-placed item, contrastive stress assignment will not therefore allow an interpretation in which every part of the sentence is interpreted as falling within the scope of negation, question etc. Thus Chomsky's formulation of focus-presupposition correctly predicts that The man in the GREEN coat didn't ask a question has the following possible interpretations: either that A man in some sort of coat asked a question is presupposed (focus = Adjective), or that Some man asked a question is presupposed (focus = Prepositional Phrase) or that Someone asked a question is presupposed (focus $=$ Subject). But these possibilities represent only a subset of the scope possibilities for this sentence, and do not include for example verb or verb phrase scope (where respectively the presuppositions would be The man in the green coat did something with a question, e.g. answex one, or The man in the green coat did something, but not ask a question). Bresupposition in this sense is, as we have seen (p.270), that part of the semantic interpretation of a sentence which corresponds to propositions which are in the Pragmatic Universe of Discourse (PUD). 
Now Chomsky's generalisation could be incorporated directly into the pragmatic framework elaborated here in the form of a pragmatic instruction:

'For any utterance '* $\psi \mathrm{p}$ ', only assign stress within that syntactic construct which corresponds to conditions for the truth of $p$ which are not in the PUD.'

Thus in the case of a question such as 'Did JOHN kill Mary?', if stress is assigned to John, the rule predicts that John will be the only constituent corresponding to conditions not in the PUD, the remainder (viz. that kill Mary is true of someone) thus being construed as within it and hence assumed to be true. The same phenomenon applies, though more weakly, for imperatives. 'Play with the ball in the GARDEN' implies, as the rule predicts, that the fact that the hearer plays with the ball somewhere is assumed and not in question, but what is commanded is the place in which the audience is to play. Finally, negation. Take by way of example the utterance 'JOHN didn't kiII Mary' with an approximate schematic semantic representation: $[\mathrm{A} / J] \mathrm{X}_{1} \vee[\mathrm{A} / \mathrm{M}] \mathrm{X}_{2} \vee[\mathrm{A} / \mathrm{CAUSE}] \mathrm{X}_{1}\left([\mathrm{DII}] \mathrm{X}_{2}\right) \vee[\mathrm{CAUSE}] \mathrm{X}_{1}\left([\mathrm{~A} / \mathrm{DIE}] \mathrm{X}_{2}\right)^{27}$
(a)
(b))
(c)
(d)

The rule says only assign stress to a condition (in the case of this utterance (a)) which does not correspond to a member of the PUD. One might thus assume that the other conditions in the representation (viz. (b)-(d)) are members of the PUD, a result which would be counter to the actual intexpretation of the sentence. However, we already have a maxim 'Only say ' $* \psi p$ ' if $\leqslant \mathrm{n}-1$ of $\mathrm{n}$ sufficient conditions for the truth of $p$ are members of the PUD'. And if any one of the

27. Cf. p.I88f for a more detailed representation of negative sentences containing kill. Cf. also p.244 fn.15. 
conditions $(\underline{b})-(\underline{d})$ are members of the PUD then this maxim is violated (since each is a sufficient condition for the truth of the utterance). On the assumption that the speaker is not violating this maxim, it thus follows that in obeying our new rule, a speaker would by saying 'JOHN didn't kill Mary' be implying that all other sufficient conditions for its truth (viz. (b) $-(\underline{d})$ ) are not met and that therefore someone killzed Mary.

As it stands, this rule is ad-hoc: it does not fit in any natural way into the theory. It clearly is not a maxim of behaviour. So if such a rule is to be explained naturally within this pragmatic framework, either it should be deduceable from the maxims and as such be a generalised conversational implicature, or it has to be listed as a conventional implicature. As we have already seen in the case of negation, compliance with this rule depends on complying with the maxims, and this suggests that the rule itself is derivable from the maxims. Notice moreover that contrastive stress has a second characteristic which is a criterion of conversational (as opposed to conventional) implicature. The implicatures consequent upon contrastive stress are cancellable. There is no contradiction in the following utterances, where the standard implicatures are contextually cancelled out:

(19) Though I don't wish to imply that Mary was necessaxily hurt, what is absolutely certain is that JOHN didn't hurt Mary

(20) Though we do not as yet know whether the mayor was murdered, what is absolutely certain is that his WIFE didn't kill him

(21) Though we cannot be sure Smith was even in the hospital that night, the question we need the answer to is 'Was he at any time in the OPERAIING theatre?'

(22) Though we cannot be sure that anyone was cheating, what we have to check is whether any LAW students had books with them in the exam room. 
The evidence of these examples suggests that the implication derived from contrastive stress cannot be considered to be an inherent one in any case, since it is not a necessary part of the interpretation of sentences with contrastive stress assigned. On the contrary however, such variability is a defining characteristic of a general conversational implicature.

How then could an implicature consequent upon stress assignment be derived from the maxims? There are two ways in which this could be done: either via a combination of the maxims of relation and quantity, or by setting up a new maxim. The problem with the first alternative is that in the reformulation I have given to the maxim, the notion of relevance relates solely to the pragmatic and semantic content of the utterance (and that of the preceding discourse). But stress is not part of the semantic or pragmatic content of the utterance and moreover its relevance relates only to the utterance itself and not (or not necessarily) to the preceding discourse. Yet if we loosen the restrictions imposed on the maxims and resurrect the old maxims, we face yet again the problem that they have very little content and therefore correspondingly little explanatory value. Suppose that we seek to demonstrate the conversational nature of implications consequent upon stress assignment by deducing them from an assumption of the maintenance of the old maxim of relation and the maxim of quantity. This could be done in the following way if we merely assume that stress is a conventional means of emphasis. Thus if a speaker $S$ says 'A MAN hit Mary', he knows the hearer If will deduce that since stress is a conventional means of emphasising and since he $S$ is committed to asserting the utterance 'A MAN hit Mary' only if at 
least one of its conditions is not in the Pragmatic Univexse of Discourse, his emphasis will only be relevant to his utterance of 'A MAN hit Maxy' if he is seeking to draw H's attention to one of these conditions. Since $H$ assumes that $S$ is obeying the maxim of relation, he therefore assumes that man corresponds to conditions (a set of conditions), one of which is not in the PUD. Moreover, since $S$ has not drawn his attention to any other part of the utterance, ${ }^{28} \mathrm{H}$ will further deduce that $S$ must be implying that that is the only part of the utterance which is not in the PUD. H will therefore deduce that $S$ is implicating that the remainder of the utterance does correspond to propositions in the PUD. S will therefore be taken to be implicating that $\mathrm{H}$ knows that someone hit Mary, and that $\mathrm{H}$ knows that $S$ knows that someone hit Mary. The problem with this form of deduction is that the umbrelia maxim 'Be relevant' in its most general interpretation does not strictly speaking apply to the concept of relevance here. 'Be relevant' is normally construed as the relation between utterance and event, or between utterance and utterance; but the notion of relevance used here is an intra-utterance notion, relating utterance form to utterance content. Thus if we are to claim an explanation of stress assignment in terms of the maxim of relation, not only do we have to return to the highly general original form, but we have to construe it as applying more generally still. I take it that in view of what I have argued earlier (p.223f), this analysis is not therefore a possible one.

28. Contrastive stress is not merely uniquely assignable within one sentence. Consider BILI didn't KTSS Mary which implies (a) that someone kissed Mary and (b) that Bill did something to Mary. Since it seems that in principle, any item could be contrastively stressed, the fact that an item is not stressed in an environment containing contrastive stress is adequate evidence for the hearer to deduce that anything which is not stressed corresponds to a proposition which is in the PUD. 
However, if we admit that the choice of the form of utterance may be relevant to an interpretation of that utterance (given that the choices range only over those options which do not alter the meaning) 29 then a plausible alternative is to maintain the maxim of relation in its strict form, viz. 'Only say a sentence $S_{i}$ if it either entails or implicates some sentence $s_{n}$ which is also implicated by $s_{j-1}$ (cf. p.230), and to add a further maxim of relation 'Make the form of your utterance relevant to its content'. With this second maxim of relation, the deduction of the implicature goes through exactly as before, but we have not reduced the predictive content of the other maxim of relation. A similar explanation will apply in the case of negation and question. Thus if $S$ asks 'Did a MAN hit Mary?' he knows that $H$ knows that by the maxim of quantity he must be assuming that at least one of the propositions entailed by A man hit Mary is not in the PUD and is the focus of S's query. Moreover, his emphasis on man will only be relevant to the content of his question if it corresponds to a condition which is being questioned. Since moreover, it is the only stressed item, $S$ knows that $H$ will deduce that it is the only item in question and that hit and Mary correspond to conditions which are part of the PUD and hence not in question. H therefore takes it that by his utterance of 'Did a MAN hit Mary?'S is implicating that $H$ knows both that someone hit Mary and that $S$ knows he knows this. On the basis of this form of explanation, I shall assume the existence of an additional Relation maxim, 'Make the form of your utterance relevant to its content'.

To see how this form of explanation has a natural general application, let us look at the sentences which Lakoff (19716) posed as problem sentences for anyone not incorporating a notion of pragmatic presupposition

29. Cf. its application in the case of the syntactic feature [+Def], p.258. 
into the grammax: 30 John called Mary a lexicalist and then SHE insulted HIM. As Lakoff points out, these are normally interpreted as implying that to call someone a lexicalist is to insult them, and within the framework here we would expect that such an implication be derivable as a conversational implicature. We saw in connection with the earlier utterances that on the basis of the maxims of quantity and relation, 1tems which were not assigned contrastive stress in an utterance were implicated as corresponding to conditions which were members of the Pragmatic Universe of Discourse. In the type of case posed by Lakoff, the hearer is presented with an apparent dilemma. Mary's insulting John is not a member of the PUD (if it were the wpeaker would be flaunting the quantity maxim by uttering it) and yet the speaker's stress assignment assunes that the insulting does correspond to a proposition in the PUD, since it has not been assigned contrastive stress, though other items in the utterance have. Thus what appears to be being assumed in the speaker's sentence is that someone insulted someone. If the speaker is not intending this to be an assumption then he is flaunting the newly-defined second maxim of relation. If however the hearer makes a further assumption, namely that to call someone a lexicalist is to insult them, the stress assignment, and the consequent implicature that Someone insulted someone is a member of the PUD are predictable in the following way. On stating John called Mary a lexicalist, the speaker assumes by definition (cf. p.240f) that both his utterance and its entailments, specifically Someone called

30. Cf. ch.4 p.122 of this thesis. 
someone a lexicalist, become members of the PUD. The further assumption, that to call someone a lexicalist is to insult them, implies an equivalence between Someone called someone a lexicalist and Someone insulted someone, or at least a relation of implication. With this assumption, it would follow automatically that if Someone called someone a lexicalist is a member of the PUD, Someone insulted someone would also be a member of the PUD. Since on this assumption the maxim of relation is being observed and the speaker's stress assignment on She insulted him is predictable, the spealker must therefore be implicating that to call someone a lexicalist is to insult them.

We have now seen that stress assignment and the consequent interpretation of questions, negative and positive assertions can be predicted within a Gricean framework, with the addition of one maxim. Since the addition of this maxim preserves the content of the other maxim of relation, I assume that taking this step strengthens the explanatory power of the theory. This is presumably preferable to allowing a generaljsation of the single maxim of relation, which would guarantee a reduction in the explanatory adequacy of the concept of the Co-operative Principle on which all my explanations have depended.

\subsection{And and the Maxim of Manner}

I have so far restricted my attention to problems axising with the maxims of relation and quantity. In explaining the pragmatic behavioux of and however, I shall have to refer to the maxim of manner which has an over-all instruction 'Be perspicuous' (cf. ch.7 p.202). In chapter 4 I argued (against Robin Lakoff) that the sequence of time 
implied in such sentences as The police came in and we swallowed our cigarettes was not a presuppositional Implication and indeed not an inherent property of and at all since sentences not joined by and caxried the same implication (cf, p.135f). What explanation would such an implication have within a Gricean framework? It clearly cannot be a conventional implicature since this construct characterises inherent non-truth-functional properties of linguistic items, and we have already seen that this is not merely a property of and. 31 But it cannot be a conversational implicature either since in order to be so, it must be deduceable from the maxims, and there is no obvious way in which this could be done. What solution is there? One possible solution is to suggest that the implication of time sequence is analogous to the implication on every statement that the speaker believes the proposition it expresses. Grice explicitly claims (in the 1967/68 lectures) that this implication is not itself an implicature since it is not an assumption needed to preserve the Co-operative Principle but rather arises as a direct consequence of preserving the maxims straightforwardly. In the case of time sequence, the maxim one might invoke is the sub-maxim of manner 'Be orderly' 32 with the interpretation 'Unless you explicitly mark the time relation, make your narration of events reflect their sequence'. If such an interpretation of the maxim is justified, then the implication of sentences is automatically predicted. Moreover since sentences joined

3.1. Cohen argues ( 1971 p.54ff) that this implication is not merely an inherent property of and but a truth-conditional one. His examples however conflate causality and time sequence, making the case appear stronger than it is.

32. Cf. Cohen's report of the 1967/68 lectures by Grice (Cohen ibid p.55). 
joined by or or if....then do not constitute the 'narration of events' they will, predictably, not carry the implication in question.

Is this solution entirely ad-hoc? The answer seems to be that in some respects it is, but others not. First, let us look at its disadvantages. The chief of these is that unlike the other maxims, it is not clear that a flagrant violation of this maxim would lead to a re-interpretation of the sentence uttered. Take as an example (23): (23) Rob Roy rode away and jumped on his horse. An utterance of this sentence could not I think be rewinterpreted in such a way as to give the utterance a plausible interpretation (in the way that You're the cream in my coffee can). If this criticism is right, we thus have a maxim which does not take part in the interpretation of implicatures (at least by flagrant violation of the maxims). To this extent it is ad-hoc. On the bonus side however, such a maxim provides an automatic explanation of the oddity of both (23) and (24). (24) Rob Roy rode away. He jumped on his horse. In both cases, $S_{1}$ entails that at time $Q$ (such that Rob Roy was riding away) Rob Roy was on some animal (or at least some moving object). $S_{2}$ entails that at time $P$ immediately prior to the time when he jumped on his horse, Rob Roy was not on his horse. If the maxim of manner ensures that utterances with no explicit time dependence between them will be interpreted as reflecting the sequence of events, then it ensures that (23) and (24) will be interpreted as contradictions. This is because $S_{2}$ entails that at a time $P$ before the event at time $Q$ that it describes, Rob Roy was not on his horse. But $S_{1}$, which by the maxim depicts the event at time P, describes Rob Roy as on some animal at that time. Thus at time P, Rob Roy is implied to be both on his horse and not on his horse. Hence the contradiction. 
Like all the other maxims we have considered, this interpretation of 'Be orderly' raises yet again the two problems of (i) the power of the maxims (ii) whether the maxims should in principle be so stated as to apply solely to the linguistic instances of communication. (cf. p.25if). At every point, we seem to have found that it is possible to stretch the maxims so that they apply to anything, and yet with each extension of their predictive power, we reduce the chances of their possessing any explanatory power. In this particular case I have resisted this temptation, and have on the contrary interpreted a maxim so narrowly that it apply to a specific problem. But in doing so, I have given it a linguistically specified interpretation which it could be argued is too naxrow. I shall return to these problems in the final chapter. For the moment $I$ assume that the jmplication of time sequence on certain utterances can be predicted without any difficulty by a particular specification of the maxim of manner.

\subsection{Bven Remains}

There is just one more problem left if the general Gricean framework is to provide some sort of explanation for all the nontrutheconditional 'presuppositional' phenomena which have emerged during this thesis - the problem of even. Let me briefly recapitulate the problem it creates. As Braser points out in his discussion of even (Fraser 1971), a sentence such as Even Max tried on the pants has two implications specifically due to the presence of even: (i.) Other people tried on the pants (ii) One would not expect Max to try on the pants 
Neither of these is logically related to Even Max tried on the pants since if the sentence were uttered on an occasion in which neither (i) nor (ii) were true, it might still be true (even though odd) to say 'Even Max tried on the pants'. But if this is so, then it appears that the conditions for the truth of Even Max tried on the pants and Max tried on the pants (and too Max even tried on the pants) are identical. Thus the theory of semantics outlined in previous chapters predicts that these three sentences are synonymous, and that even is a meaningless particle (since it does not affect the truth conditions of sentences it occurs in). Intuitively this seems unfortunate.

In one sense however, this prediction is correct. It is correct in so far as it predicts that whatever contribution even makes to the sentences in which it occurs, this contribution is different in kind from the contribution most words malse to sentence meaning. This is certainly so. In fact the properties of even are so odd that they do not naturally fit into the Gricean pragmatic framework either. One might expect that implications such as (i) and (ij) would constitute conventional implicatures - they certajnly are not derivable in any natural way via the maxims. But these implications have a further characteristic which seems to militate against such an analysis they are to some extent cancellable. Consider the following utterance: (25) All the kids tried on something. Mary tried on a pair of trousers, Sue a long shawl. Iven Max tried on a fancy tie. But then it's not really surprising. Now that his mother has narried again, he joins in with things much more. What does even contribute to this utterance of Even Max tried on a fancy tie? It is not at all clear. The utterance certainly does not imply that the speaker assumes that other people tried on a fancy tie. 
But nor is the speaker assuming that one would expect him not to try on a fancy tie. He is rather making the weaker assumption that some people (including the hearer?) might expect him not to try on a fancy tie. This type of problem can arise with every case of even. (26) presents a similar case.

(26) Each member of the group did one thing towards getting publicity: May wrote to her bank manager, Bill to his local newspaper. Adrian even wrote to the Prime Minister. But then I suppose it's not surprising when one considers how adventurous he is. Here too, the speaker is clearly not intending to imply that Adrian did a number of things including writing to the Prime Minister. Nor is he implying that it is surprising that he did so. All he is implying is that his audience might expect Adrian's action to be surprising. Yet this implication is not itself a necessary property of even. There is nothing odd in saying (27).

(27) I know you won't find this surprising since you know John better than anyone but he's even read Aristophanes of Byzantium In this case, what seems to remain is the implication that John has read other things. Thus what we appeax to be faced with is a disjunction of properties: even either implies that the constituent to which it is prefixed should be construed as one of a group ${ }^{33}$ or that there is some element of surprise involved (either on the part of the speaker or on the part of hearer). Other than an ad-hoc formulation of these properties, we have no means of stating these characteristics

33. For aidiscussion of scope phenomena and even, cf. Frasex 1971, Anderson 1972, and also ch.2 p.40 fn.35 of this thesis. 
either within the semantic or the pragmatic framework. It therefore remains an anomaly. Since however its behaviour is so idiosyncratic, I think one is justified in assuming on the basis of the evidence considered elsewhere in the thesis that the over-all framework set up here is not seriously disturbed by the counter-example which even presents.

\subsection{Illocutionary Force: Its Status Within Pragmatics} Finally there is one general problem which I have more or less ignored throughout this thesis - that of illocutionary force. My earlier suggestion (p.74f) that illocutionary force and the analysis of speech acts did not form part of semantics was on the grounds that they provide all the problems of indeterminacy which render semantics non-predictable. But if concepts such as illocutionary force are to form part of a pragmatic theory, then we must be able to demonstrate that they are compatible with the pragmatic framework given here. Otherwise they will be problems which have merely been swept under the pragmatic carpet, and left there.

While I do not intend to give a detailed characterisation of this very large area, it can be quite straightforwardly shown that an $a_{\text {alysis }}$ of illocutionary force is dependent upon a knowledge of what the speaker is (nonconventionally) implicating and therefore must be part of pragmatics. We have already seen that a sentence such as There are three bulls in that field may be used to convey either a warning, a boast or a mere statement of fact (cf.ch.4 p.95). For 
a further example, consider I've got a headache. This sentence can be used at least as a warning, a request (for advice or sympathy) or an apology. In order for an utterance of this sentence to constitute a warning for example, the speaker must reason that the hearer will work out the relevance of the utterance on the basis that both speaker and hearer know, say, that when the speaker has a headache, he is normally very disagreeable and on the basis of this common assumption, the hearer will work out that the speaker is implicating that his company may be unpleasant and is thus giving the hearer prior warning. While this analysis is informal, it demonstrates nonetheless that the calculation of whether the statement is a warning is dependent on the implicatures of the utterance. This must be so since the illocutionary force relates directly not to the semantic content of the sentence used, but to the content of the message which the speaker is seeking to convey. At the rery least then, it seems certain that the prediction of illocutionary force for any utterance can only be part of a pragmatic theory.

There is however a stronger claim possible which naturally accounts for the dependence of illocutionary force on the Co-operative Principle, as we shall see immediately. Both Cohen (1969) and Searle (1968) have pointed out that all possible illocutionary forces can always be made explicit with the appropxiate use of a performative verb. Thus 'I've got a headache' construed as a warning corresponds to the explicit performative statement 'I warn you that I've got a headache'. On the basis of this, both argue that the distinction between illocutionary 
force and meaning is not well-founded and should be given up. 34

In the light of the deduction of warning that I gave on an utterance of I've got a headache, we can see why this distinction is so tenuous. Compare the first formulation with the following. S reasons in uttering 'I've got a headache' that since both he and $H$ know that when he has a headache he is very disagreeable, $H$ will deduce that $S$ is wishing to convey to $\mathrm{H}$ that his company is likely to be unpleasant and he is therefore implicating the statement 'I warn you that I am likely to be unpleasant'. The only difference between the two formulations: is that in the first, the warning is not itself said to be an implicature, whereas in the latter the speaker is said to be implicating the performative statement 'I warn you that....'. Is the difference between the two substantive? I think not, for reasons which are stated in detail by Cohen and Searle. Briefly, there is little justification for claiming that I warn you that I've got a headache is a specification of the illocutionary force of the utterance 'I've got a headache' rather than a specification of its (pragmatic) meaning, particularly since in the full performative, the specification given is unquestionably part of its meaning. If this is so, and the intended deduction of illocutionary force of the speaker's utterance is merely one type of implicature, 35 then it follows automatically

34. The solutions they offer are not however compatible.

35. An argument against this conclusion is given by Schiffer (1972 p.89) who claims that in order to know the illocutionary force of an utterance it is not enough to know what was meant by the sentence uttered, one must also know what i,s was meant as. If however I am right in saying that for every case where an utterance is construed 'as a warning' there is an equivalent analysis in which a performative statement (of warning) is construed as part of what is meant, then Schiffer's distinction falls to the ground. 
that an account of the illocutionary force of utterances is part and parcel of an account of the pragmatic properties of a language.

This is not to suggest that the concept of illocutionary force is necessarily redundant, and few would be foolish enough to suggest that re-analysing illocutionary force in terms of implicature did more than re-label the problem. In any case such an account raises extra problems for the Gricean framework. It is not obvious that the implication of warning (or request, apology etc) is dependent on the Co-operative Principle in the sense that its deduction depends on an apparent violation of the maxims. 36 However it seems reasonably clear that implicatures in general. arise even when maxims are not violated. There seems no reason to doubt for example that the implicature of the speaker's likely unpleasantness in the utterance of I've got a headaclie is just as plausible in answer to the question 'How are you?' (when it would certainly be relevant and there need be little reason to suppose it untrue) as if it were uttered with flagrant disregard for relevance (for example in response to the greeting 'Hello'). Thus the relation between the concept of implicature and the conversational maxims is not a problem specific to the incorporation of illocutionary force as one type of implicature but applies to the entire model. Whatever problems this re-analysis of illocutionary force gives to the general concept of the Co-operative Principle, the general tenor of the argument remains unaltered. Both the arguments given by Searle and Cohen and the close affinity between the deduction of illocutionary force and the deduction of implicatures suggest that illocutionary force on utterances is but one of the aspects of implicated meaning of utterances and is not different from it in kind. 36. Cf. ch.7 p.204 for Grice's own characterisation of implicature. 
8.10 Summary

In the course of chapters 7 and 8 , I have concentrated on two main problems: (a) whether Grice's Co-operative Principle can be given sufficient constraints to constitute a non-vacuous theory of communication; (b) whether the framework so specified can account for the wide range of phenomena which have been given by various people at various times the label of presupposition.

What I hope that chapter 8 has unequivocally shown is that the phenomena often incorporated into semantics under an umbrella label of presupposition can naturally be explained within a framework which depends on a logically prior system of linguistic conventions and that these phenomena are thus not themselves part of the semantics of that system. The more tentative part of these chapters concerns the constraints on that pragmatic framework. It seems clear that there must be such constraints and what I have put forward can be seen as a first attempt to provide them.

There are in any case serious problems for a Gricean theory of pragmatics, even in its most general form. One of these I have touched on: can the concept of implicature be defined as an assumption necessary to preserve the assumption of compliance with the pragmatic maxims? If the examples I considered in the preceding section ( $p_{0}$ 289) are correct, then it seems that implicatures need not be restricted to apparent violations of the maxims. There is also the problem of how the subject of any conversation can legitimately be changed. If a Gricean theory is to be accepted as the only serious contender for a pragmatic theory, then problems such as these will have to be solved. I have not gone into them here simply because there have been more immediate and pressing problems.

More important perhaps than all these points of detail is the question of what status a pragmatic theory has within an over-all. theory of language. It this question that I shall take up in the final chapter. 
CHAPTER 9 Pragmatics and The Competence-Performance Distinction

The main tasks of this thesis are now all complete. These were to set out as a preliminary a linguistic framework to provide a perspective within which all consequent arguments would be considered, and then to argue: (i) that semantics of natural language involves a statement of the conditions for the truth of all the sentences of that language (by a recursive finite procedure) ( $i i)$ that concepts pertaining to speakers' beliefs in uttering sentences are correctly excluded from that semantics by virtue of very general requirements on semantic theory (iii) that the logic required within such a truth-conditional semantics is two-valued (containing the values true and false) and is not a presuppositional three-valued logic (iv) that apparent counterexamples to these three hypotheses are naturally explained at a separate theoretical level, that of pragmatics, and thus do not in fact constitute counter-examples.

There would however be no justification whatever for assuming that there are now few remaining problems, even if my arguments are correct. Many, quite fundamental. problems remain at every stage. Within the semantic framework for example, it is not obvious that in formulating semantic interpretations along the lines of Bierwisch as I have done, one is doing anything more than translating into yet another syntax which demands an interpretation in its turn. Thus the argument raised by Lewis (1972) against Katz that his formalism merely constitutes an 
ad-hoc language, "Markerese", 1 could perhaps also be raised against the formalism adopted in this thesis. And within the pragmatic framework outlined by Grice, " we have already seen that large problems remain. In any case, not all the data hewe been taken into account $=$ I have not given a pragmatic explanation for some of the examples raised by Keenan. Since I could not pretend to solve all these problems within the bounds of a single thesis, I have concentrated my attention on those which seemed of primary importance. The others remain in need of a solution.

There is however one further problem which must be taken up. Though I have considered in some detail the nature of a theory of pragmatics, I have not yet broached the question of what status such a theory should have within an over-all linguistic theory. In order now to be able to discuss this, let us first recapitulate the whole range of phenomena for which an explanation is demanded. First there is the central ('referential' or 'cognitive') meaning of sentences and words, which can, I have argued, be stated w with very few exceptions - in terms of truth conditions on sentences (or in the case of words, the contribution they make to such sets of truth conditions). The fow exceptions are words like but, even, and possibly therefore (but cf. p. $302 \mathrm{ff}$ ), whose contribution to sentence-meaning does not appear to affect the truth conditions of sentences. Then there are the very general implications on sentences which I have argued cannot be seen as an inherent or necessary part of sentence-meaning in the same way as truth-conditional properties, since these implications

1. Cf. Lewis 1971 p.169f. 
can be cancelled out without resulting in a contradiction. Finally there are the occasion-specific implications which depend on assumptions shared by particular speakers and hearers, and which may run counter to the standard message conveyed by utterances of that same sentence.

It seems to me that this range of data could be incorporated into a formal linguistic modej in one of six possible ways. I (equivalent to the Lakoff' position) The distinction between semantics and pragmatics could be disputed and the entire theory of sentence interpretation based on a number of different procedures within the semantic component of the competence model. Implicit in this formulation would be the claim that the disparity of the evidence just listed should be reflected directly in a non-homogeneous account of natural language semantics. II (equivalent to the Kiparskys' and Fillmore's positions) Occasion specific implicatures would be explained as performance phenomena; but all general implicatures, whether contradictable or not, would be predicted within the semantic component. This could be done in two ways: (a) by recognising the non-homogeneity of semantics (similar to the view I above), and predicting strict entailments and general implications by two separate procedures ( $c f$. the Kiparskys' distinction between assertion and presupposition, 1970); (b) by generalising the concept of implication so that it apply regardless of whether the implication is cancellable or not (cf. Fillmore's use of presupposition, 1971). The distinction between semantics and pragmatics as I have drawn it is still disputed on both these positions: under position (b) semantic relations, though defined univocally, are not defined in terms of truth 
dependencies, and under position (a) the concept of natural language meaning is not defined univocally. As a consequence, in both cases, many implications which I have explained pragmatically fall under the domain of semantics.

III (equivalent to Katz' 1972 position - cf. p.420ff) The distinction between semantics and pragmatics is maintained as I have defined it and a pragmatic component (in the form of a model of Grice's theory) is incorporated into the competence model (with inputs from all three components, syntactic, semantic, and phonological). IV Semantics and pragmatics, as I have defined them, are formulated respectively within a competence and within a performance model but with one important exception. Conventional implicatures, such as on but and even, which are nonmcontradictable though not truthconditional, are listed in the lexicon (which otherwise specifies truth conditions for lexical items) with an ad-hoc device indicating that they are not themselves truth-conditional. V Pragmatics, along Gricean lines, is altogether formalised as a subpart of a theory of performance and the sole function of the semantic component of the competence moded is to predict truth conditions on sentences and consequent entailments between sentences.

Now it must be evident from the tenor of my arguments in all preceding chapters that I am tempted, if not committed, to embrace the strongest possibility, alternative V. Before considering the rashness of this move, let me take up each of the preceding alternatives. Since I discussed the consequences of adopting alternative $I$ in some detail in chapter 4, I shall not consider this position further other than to reiterate what I said there that since such a theory has no predictive power, it cannot provide an acceptable solution. 
What of the two alternatives listed under IIs Alternative II(a) is similar to alternative I in so far as the non-homogeneity of the data is reflected in the semantic statement. Rather than disagree with this argument directly, let us consider how such non-homogeneity could be written into the theory. The performance model would presumably incorporate the Gricean maxims to explain occasion-specific implicatures, and these would therefore play no part in the competence model. The problem would thus concern phenomena such as the interpretation of but, even, the (as distinct from the indefinite article), factive verbs (in positive and negative environments) and stress assignment. In a Gricean framework, the first two of these have conventional (non-contradictable implicatures) ${ }^{2}$ the last three general but contradictable implicatures. One possibility is to specify such implications as part of the lexical entry. Thus but might have an entry indicating that it always conveys some form of contrast between the two elements it conjoins. However there has to be some explicit indication that entries such as this are different in lind from other semantic components since setting up this form of semantic component must not make any predictions about the bohaviour of the item in question. Thus for example (as was pointed out in ch.4 p.117r), no contradiction arises if but conjoins two sentences which are entirely non-contrastive (a combination which would be contradictory if the component in question were truth-conditiona1). Furthermore in the case of the or the factive verbs involving implications which are cancellable, there will have to be some ad-hoc statement that these implications are normal but not necessary Implications.

2. Though cf. p.284f and the additional problems connected with even. 
One way (and arguably the only plausible way) round these problems is to postulate a distinction for cases such as these between their meaning and conditions for their use. Thus but could have two subsections to the semantic specification of its lexical entry: a statement of its meaning and a statement for conditions on its use - viz. that the speaker imply that there be some form of contrast between the two conjuncts. But this formulation not only meets exactly the same difficulties that face a separate theory of pragmatics, but appears to be no more than a terminological variant of it. Notice that within this partially truth-conditional framework, even has no meaning, just as in the exclusively truth-conditional framework; it merely has conditions for its use. Both formulations therefore predict that John was there and Even John was there do not differ in meaning. It thus seems that none of the problems for pragmatics are avoided. In any case, to give an ad-hoc label to certain components - say, "non-truth-conditional" or "a condition of use" ${ }^{3}-$ is surely equivalent to saying that this aspect of these words is of a quite different status from the central core notion of meaning - in other words that these particular aspects of words (or sentences) have to be described at a different level. But this is exactly what setting up a theory of pragmatics aims to capture. Moreover, there is no explanation whatever within this putative partially truth-conditional semantics for the fact that some of these non-truth-conditional properties (such as those on the) are cancellable while others are not. And it is not obvious how

3. In the case of general implicatures, the label preferred by Kartunnen (1971b) and Geiss and Zwicky (1971) is "invited inference". But this label merely describes the phenomena. It does not provide an explanation of them. 
this could be captured. It therefore seems reasonable to conclude that the non-homogeneity of sentence interpretations is captured by setting up the distinction between semantics and pragmatics and it is therefore redundant to introduce such non-homogeneity into the semantic formalisation itself.

Alternative II(b) constitutes a more radical criticism of the views I have put forward. On this view, the centraI importance of entailment is doubted and a weaker relation (to cover entailments and sentence-pairs such as I didn't regret going I went, Even John hit Mary Other people hit Mary, etc) is defined in its place. A supporter of this view might argue that in certain crucial cases $I$ have distorted the evidence so that the issue appears more clear-cut than it in fact is. For example, in chapter 4 I pointed out that sentences containing pretend such as John pretended that he was sick did not entail John was not sick despite a very general implication that this was so. Since the argument in chapters 4 and 5 did not depend on the nature of this implication, I did not pursue the matter further there. But it might be argued that this is one of many implications which linguistic semantics should wish to predict and if this relation is not reducible to a truth dependence, so much the worse for truthm dependent semantics. Verbs such as criticise and accuse provide further examples, and it no coincidence that Filimore chose this group of examples in seeking to attack a componential approach to semantics. I argued in chapter 4(p.99f) for example that John criticised Mary for taking his books did not presuppose that she took them, but rather entailed the weaker statement John was assuming that 
Mary took his books, whether or not she in fact did, and whether he believed it or not (cf. egs (18) and (21)). Now such a claim might be countered by the criticism that the inclusion of assumptions (as a primitive?) in the formal statement of criticise is merely an ad-hoc device to avoid recognising the need for a weaker implication between sentence pairs such as John criticised Mary for taking his books and Mary took his books. On this view, to formalise this relation as an entailment between John criticised Mary for taking his books and John was assuming that Mary took his books is a confusion of a metalinguistic statement and a statement of the object language. Confirmation of this general view might be sought by pointing out that even provides no anomaly in a system based on a weak (undefined?) form of implication. Even only provides a problem if entailments are to be predicted, since it is preciesly the set of entailments of a sentence to which it is attached that even appears not to affect.

This form of criticism is not however I think justified. Notice that by seeking to confirm or refute hypotheses of meaning by the evidence of contradictions, we successively refine our analyses of meaning so that they make exactly the predictions required. So for example the observation that John pretended that Mary was sick does not entail that Mary was sick merely indicates that the analysis of pretend is moxe complicated than the initial hypothesis suggested. A similar procedure applied in the case of criticise and accuse (cf. ch.4 p.98ff). In contrast to this, a theory of meaning based on some loosely defined umbrella term of implication would either not be able to make predictions of any sort since it would not distinguish between necessary and possible implications, or it would be of such general application (cf. the various uses of the term presupposition in ch.4 p.92) that its explanatory power would be nil. Firthermore, and more 
seriously, to base analyses on general implications rather than on necessary implications leads inevitably to shoddy results since as in the case of accuse, and criticise (and indeed pretend), general implications lead to approximate and untestable analyses (verifiable only by speakers' hazy intuitions as to what constitutes part of a sentence's meaning) rather than exact and testable ones. Thus the existence of implications on utterances which do not extend to all uses of that sentence does not seem to me to provide any evidence for the need to incorporate some looser form of implication into semantics, either in the form of alternative II(a) or the stronger alternative II(b) particularly since, as we have already seen, the general implications on negative factive sentences, on definite noun phrases, etc, can be given an explanation by reference to pragmatic constructs such as the Co-operative Principle and its maxims which are, by definition, logically posterior to a linguistic system.

There remain alternatives III, IV and $V$, each preserving much more closely the dichotomy that I have assumed in previous chapters of this thesis. Alternative III must, I think, be dismissed for the following reason. If a competence model was envisaged as containing a pragmatic component (dependent on information from the other three components of the grammar) then it would automatically become a matter of one linguistic knowledge that people generally speak the truth and stick to the point. In other words, 'Do not say what you believe to be false' and 'Be relevant' would become rules of one's competence. But the content of these rules and the way in which they apply are quite unlike any rules of either the syntactic, semantic or phonological component. In the first place, they can be broken. Not speaking the 
truth for example does not lead one to utter an ungrammatical sentence, though breaking a syntactic, semantic, or phonological rule does. In addition, the interpretations the maxims provide may have an indeterminacy which is quite unlike the outputs of the three existing components of the model. On the contraxy, the model is committed to providing a fully determinate syntactic, semantic, and phonological specification to the sentences it generates. In fact, all the problems which necessitated the delimitation of semantics to exclude speaker-belief constructs - the most important being the loss of predictive power immediately return if pragmatics is incorporated into the model of competence. These reasons suggest that the pragmatic maxims are not part of the central competence model but must rather be part of a theory of performance.

One rejoinder might be made to this conclusion. In chapter $7-8$ I went to considerable lengths to constrain the notions of informativeness and relevance so that the Gricean maxims might acquire at least some predictive power. It might however be argued that in doing so I have committed myself to incorporating some Gricean concept of pragmatics into a linguistic competence model, since the revised maxims make reference largely to the specific semantic and pragmatic content of messages and not to more general concepts (cf. in particular the postulation of a second maxim of Relation on $p_{.278}$ to account for stress phenomena and the interpretation of the maxim of Manner in connection with and on p.281f). Thus the maxims only apply to Iinguistic behaviour and no. longer constitute conventions on social behaviour in general as 
Grice appears to have intended them to. This rejoinder is not I think valid. Remember - the point of the increased specificity of the maxims was to increage their content so that they became less vacuous. If the rejoinder sugfested here were correct, it would seem that a necessary condition on performance theories is that they be so general as to guarantee vacuity. In any case there is no a priori reason why performance constructs should not refer to linguistic constructs. On the contrary, there is evidence that they must. If as Bever suggests (Bever 1970) there are perceptual strategies associated with the understanding of constructions, and if his formulation of such strategies is even partially correct, then it seems certain that whatever form an over-all theory of performance might take, it must make reference to specific linguistic constructs. The assumption behind such a criticism of the revised maxims thus seems to be false.

In suggesting that the maxims must be part of a theory of performance rather than the exclusively linguistic model, I have still not closed the door on alternative IV, though it may seem so at first glance. What is at issue here is not the general but contradictable implications on definite noun phrases or factives discussed in chapter 8. Both alternatives IV and $V$ are agreed that anything which can be explained by virtue of the maxims must be part of the domain of performance, since the maxims do not constitute Iinguistic rules. What is at issue are those implications which are apparently inherent properties of the word in question but which are not truth-conditional. We have already seen (ch.? p. 207) that not only are these counterexamples to a truth-conditional semantics but they are also, in effect, 
counter-examples to a Gricean pragmatics since they neither fall within the domain of his meaning ${ }_{n n}$ nor are they explicable by reference to the maxims of the Co-operative Principle. These then are the examples which do not fit satisfactorily into the semanticspragmatics dichotomy and which in addition cause pragmatics (if they be part of pragmatics) to apply across the competence-performance distinction.

In assessing these examples, perhaps the first questions to ask are 'How big is the list?' and 'How important are the items it contains?' Of the problems which have arisen in this thesis, just three appear to constitute conventional implicatures - the implications of but, even, and therefore. The last, therefore, was used by Grice as a standard example of this form of implication and $I$ bowed to this judgment in using it in chapter 7 (p.207), However the validity of this analysis is questionable. Consider what a statement of the meaning of therefore would have to indicate. To give the meaning of P and therefore $Q$ one would have to give the set of conditions guaranteeing the truth of $\underline{P \text { and } Q}$ together with a condition specifying, thoughly, that $Q$ follows from $\underline{P}$. If this last condition is not truth-conditional, it should not affect the truth value of two sentences it conjoins. But oonsider the following:

(1) If Bill hit Mary and therefore she was covered with bruises, she will have won her suit for damages.

Presumably we are agreed that this statement will be true if both antecedent and consequent have the same truth value, whether true or false, and false if the antecedent is true and the consequent false. 
Now suppose we envisage a situation such that (i) Bill did hit Mary, (ii) Mary was covered in brutses but none of them caused by his hitting her - she got them from falling off her bicycle in the rush hour, (iii) she did not win her suit for damages. That is to say, each of the separate claims made by the antecedent is true except for the condition expressed by means of therefore. Now if therefore does not contribute to the truth conditions of the sentences in which it occurs we would expect (1) to be false in the situation specified. But if on the contrary it does affect the truth-value assignment, then since the causal connection asserted is not fulfilled in the particular state of affairs, we would expect (1) to be true. And so, I think, it is. Consider also (2) (2) If it's not true that Bill hit Mary and therefore she's covered in bruises, then she will have given up her suit for damages

in conjunction with a situation in which (i) and (ii) hold as before Bill hit Mary but the bruises she has have nothing to do with his hitting her $=$ and this time, she sues him. That is, the claim made by the conjuncts in the antecedent are both true though they are not causaliy connected. Thus if therefore has contribution to make to a truth-conditional statement, the antecedent is false, since the conjunction is preceded by negation. If however therefore makes a contribution to the statement's set of truth conditions, then the conjunction of $\underline{\mathrm{P} \text { and therefore } Q}$ will in this case be false, and so the whole antecedent true. The consequent is false. If the implication 
on therefore is truth-conditional, we would predict that in this state of affairs, (2) will be false. If therefore only provides a conventional implicature on the other hand, we would predict that (2) will be true (both antecedent and consequent being false). Though one's intuitions have to work hard at this level of logical complexity, it seems certain that given the state of affairs outlined, (2) is false.

This example is interesting for a different reason. (2) provides an example in which the implication induced by therefore falls within the scope of negation. If this property is truth-conditional as statements (1) and (2) suggest, this is just as one would expect, since the rule interpreting negatives is a semantic rule. If however, the implication were pragmatic, then one might expect that such a property should not be subject to a semantic rule such as negation. Even and but are strikingly different from therefore in this respect. No statement of the form $=(P$ but $Q)$ can mean $P$ and $Q$, but there is no contrast between them". It is perhaps more unexpected that even behaves in a similar way. John didn't even whip Mary is not interpreted as "It is not the case that John even whipped Mary" but as "It is even the case that John did not whip Mary". That is to say, however the interpretation of even is formalised, the rule must operate on the output of the rule of negation. Moreover in cases parallel to examples (1) and (2) containing even we do not get changes in truth value, as we did with therefore. Consider (3)

(3) If John even hit Mary then Bill will have reported him to the police in conjunction with circumstances such that (a) John hit Mary, (b) John 
did nothing else at all (c) Bill did not report John. In this case (3) seems to me to be false, with the consequent false, even though the condition suggested by even that John did something else is not fulfilled. Similarly (4).

(4) If it's not the case that John even hit Mary, then Bill will have withdrawn his threat to report him to the police Here, imagine that as before John hit Mary, nothing else, and Bill does not withdraw his threat. Thus the constituent sentence inside the negation is true, except that John didn't do anything else, so the entire antecedent is false and with a false consequent this guarantees the truth of the claim. Thus even, as a pragmatic account would predict, seems to have no effect on the truth value of utterances. However therefore - on the evidence put forward hexe and contrary to my initial assumption - seems to be explicable straightforwardly in terms of truth conditions.

So our list of exceptions is reduced to two - even and but. Are these sufficient to constitute an issue? I think not. Notice that in both cases, their interpretation is extremely difficult to pin down, either semantically or pragmatically. In the case of even (cf. $\mathrm{ch} .8$ section 8.9), we saw that each of its implications was separately cancellable, though the basis for these cancellations did not appear to have any basis on the Co-operative Principle and its maxims. And in the case of but, not only does no contradiction arise if but, despite the requirement of contrast, occurs in an environment where there is no contrast between the sentences it conjoins, but unlike any other word it is impossible to challenge a person's use of the word but on the basis of its meaning. That is, if somebody says 
"John's sicls", you can challenge him by saying "Why do you say he's sick?" and he cannot reasonably reply "But I didn't imply that he was". By contrest, if somebody says "You may be sick, but so am I" and you challenge him (on the basis of some of Robin Lakoff's definitions of but - cf. R. Ialcoff 1971 section 3) saying "Why do you think there's anything unexpected about your being sick?" ox "Why do you think there"s anything odd about your being sick?" or "Why do you assume there's anything contrasting your being sick and mine?" he may well, and rea.sonebly, reply to all three questions "I didn't irmply there was".

So we have two possibilities to choose between. Hither we enter even and but as out-and-out exceptions to the generall format of the semantic component within the lexicon of that component, or we give them no interpretation in the semantic component other than, in the case of but, the truth table for and. It is not obvious that the two olternatives are in this form more than terminologically distinct. What evidence could lead to a choice between them? The formex conveys by ad-hoc listing that there are a few exceptions to a truth-conditional statement without any further explanation; the latter defines the exceptions within a theory of performance which automatically predicts that their interpretetion will be different in kind from words such as run and boy. Moreover if we are to give any substance to the statement that using but commits the spealrer to some form of contrast, we can go at least some way to specifying this contrast if - and only if - we indicate the way in which implicatures of contrast can be deduced by assumptions made by specific speakers on specific occasions (cf. R.Lakoff ibia pp.132ff). But to do so involves reference to the Co-operative Principle and its maxims and both alternatives IV and $V$ agxee, against altermative III, that the nature of the maxims is such as to exclude them from a competence model. It thus seems as though altemative $V$ provides the most explanatory solution.

It does however have one extremely counter-intuitive consequence. Performance conventions and constraints are in general not arbitrary in the way that linguistic conventions axe: it is not the case that in some societies people generally tell lies as a basis for communication, and it would indeed be suxprising to find a society which found centre-embedded. constructions easiex to understand the h co-oxdinated constructions. Yet clearly the conventions for the use of but and even ere axbitrary in just the same woy as any other linguistic sign: it is hardly a function either of the structure of the English brain or of our society that even and but 
have the interpretations they do. If then we are to include the interpretation of even and but within the unbrella of performance, it seems as though we shall have to distinguish this type of implication from all other performance conventions. We thus seem to have an impasse. On the one hand even and but disturb the univocality of semantics, and on the other hand they disturb the apparent univocality of performance. There is however one further piece of evidence - that of style. Stylistic differences between synonyms provide an anologous problem. They are normally excluded from semantics on the grounds that their difference is so much less important than their similarity. But if a stylistic account is excluded from competence on the basis that stylistic differences are merely a factor of use, then we seem to be invoking a concept of use extremely close to that characterised by the Co-operative Principle and its maxims. One might therefore expect such differences to be accounted for within a theory of performance. Yet some stylistio conventions are just as arbitrary as conventions for the use of even and but. We have here a very similar problem to that presented by but and even and their relation to pragmatics. Many stylistic conventions are nonarbitrary in the required sense. Complex noun phrases as subjects with simple predicates, such as the problem described above in which 'even' and Ibut' provide anomalies to eaoh logical possibility remains, may well be more unacceptable in conversation than in a written text by vixtue of more rigorous memory constraints in the former case. But conventions which mark fiddle as informal (in contrast to violin which is unmarked stylistically) are entixely arbitrary; and yet - along with all other stylistic problems such stylistic differences are not generally considered within a competence model. The explanation of their distribution therefore forms part of performance, despite the arbitrary nature of the convention in 
certain cases. But if an explanation of such stylistic distinctions falls within the domain of performance, non-arbitrariness cannot be a necessary condition of a performance factor. Since the univocality of the non-arbitrary nature of performance conventions seems in any case to be disturbed by the incorporation of stylistic conventions, I shall conclude that the interpretation of but and even forms paxt of a theory of use as a subpart of a theory of performance.

Thus somewhat hesitatingly, I wish to embrace alternative V: accordingly I suggest that Grice's explanation of communication, as extended and modified here, provides at least a first formulation of some data that a theory of performance will have to account for, and at most the first steps towards a theory of pragmatics as part of a theory of performance. (In any case, if the strongest position, stated as alternative $V$, has to be relinquished for alternative IV the essential parts of Grice's theory remain as part of a theoxy of performance, sinco as we have seen (p.301f), conventional implicatures such as carried by but and even are in effect exceptions to Grice's account as well.) It remains to be seen what formal representation can be provided to give serious content to the theory of pragmatics I have been pressing for here. In particular for example, I have said nothing about the intial translation from a truth-conditional semantic statement into a Gricean pragmatic statement (of meaning ${ }_{\mathrm{nn}}$ ) (cf. ch.7 pp.197ff). But problems such as this I must leave for another time. 
Alston, W.P. 1964: Philosophy of Language. Englewood Clifs, N.J. Anderson, S.R. 1972: 'How to get even' Ige 48 pp.893-906. Annear, S. 1965: 'English and Mandarin Chinese: Definite and Indefinite Determiners and Modifying Structures' Project on Iinguistic Analysis Papers. University of Ohio.

Apostel, L. 1971: 'Further Remariss on the Pragmatics of Natural Languages' in Bar-Hillel, ,. (ed.) Pragmatics of Natural Languages pp.1-34. Reidel, Holland. Austin, J.I. 1962: How To Do Things With Words. Clarendon Press, Oxford. Baker, A.J. 1956: 'Presupposition and Types of Clause' Mind 65 pp.368-78 Baker, C.L. 1966: 'Definiteness and Indefiniteness in English' MA Thesis, University of Illinois. Bar-Hillel, Y. 1954: 'Indexical Expressions' Mind 63 pp.359-79. Barrett, R.B. and Stenner, A.J. 1971: On the Myth of the Exclusive 'Or' Mind $79 \mathrm{pp} .116-21$.

Bendix, H.H. 1966: Componential Analysis of General Vocabulary, Bloomington, Indiana.

Bever, T.G. 1970: 'The Cognitive Base for Linguistic Structures' in Hayes,J.R. (ed.) Cognition and The Development of Language, pp.279-362. Wiley and Sons.

Bierwisch, M. 1969: 'On Certain Problems of Semantic Representation' FL 5 pp. $253-84$.

"1970: 'Semantics' in Lyons,..J. (ed.) New Horizons in Linguistics, pp.166-84. Penguin.

" 1971: 'On Classifying Semantic Features' in Steinberg, D.D. and Jakobovits, L.A. (eds.) Sernantics, pp.410-35. Cambridge.

BloomfieId, I. 1933: Language. Holt, Rinehart and Winston. Cassin, C.E. 1970a: 'Russell's Discussion of Meaning and Denotation: A Re-examination in Klemke, E.D. (ed.) Essays on Bertrand Russel1, pp. 256-72. University of Illinois Press. 
Cassin, C.E. 1970b: 'Russell's Distinction Between The Primary and Secondary Occurrence of Definite Descriptions' in Klemke,E.C.(ed.) Essays on Bertrand Russe17 pp.273 84.

Caton, C.E. 1959: 'Strawson on Referring' Mind 68 pp.539-44.

Chomsly, A.N. 1957: Syntactic Structures. Mouton.

"

11:

1965: Aspects of the Theory of Syntax. MTT.

11

"

1971: Deep Structure, Surface Structure and Semantic (eds.) Semantics, pp.183-216. Cambridge.

1969: 'Remarks on Nominalization' in Jacobs, R.A. and Rosenbaum P.S. (eds.) Readings in Plglish Pransformational Grarmax Interpretation' in Steinberg,D.D. and Jalkobovits, L.A.

1972: 'Some Empirical. Issues in The Theory of Transformational. Gremmar' in Peters,P.S. (od.) Goals of Linguistic Theory, pp.63-130. Prentice-Hall.

Clark, M. 1971: 'Ifs and Hooks' Analysis 32, pp.33-9.

Cohen, D. 1973: 'On The Mis-Representation of Presuppositions' Glossa 7 pp.21-38

Cohen, I.J. 1964: 'Do Illocutionary Forces Exist?' Philosophical Quarterly 14, pp.118-37.

"1971: 'Some Remaxks on Grice's Views About the Logical Particlea of Natural Language' in Bar-Hillel,Y. (ed.) Pragmatics of Natural Languages pp.60-8. Reidel.

Curry, H.B. 1953: 'Mathematics, Syntactics and Logic' Mind 62 pp.172-83. Davjdson, D. 1967: 'Truth and Meaning' Synthese XVII pp.304-23. Dretslke, F.I. 1970: 'Ipistemic Operators' The Joumal of Philosophy LXVII, pp.1007-23.

1972: 'Contrastive Statements' The Philosophical Review LXXXX, pp.411--37.

Dumnett, M. 1958/9: 'Truth' Proceedings of The Aristotelian Society 59, pp. 141-62.

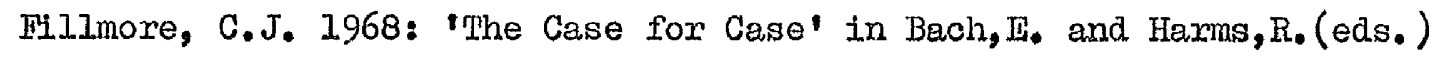
Universals in Linguistic Theory pp. 1 m88. Holt, Rinehart and Winston. 
Fillmore, C.J. 1969: 'Types of Lexical Information' in Kiefer,F.(ed.) Studies in Syntax and Semantics, pp.109-37. Dordrecht.

" 1971: 'Verbs of Judging: An Exercise in Semantic Description' in Fillmore,C.J. and Langendoen,D.T.(eds.) Studies in Iinguistic Semantics, pp.273-89. Holt, Rinehart, Winston.

Fodor, J. 1970: '3 Reasons for Not Deriving 'Kill' from 'Cause to Die' LI I. pp.429-37.

" and Garrett,M. 1966: 'Some Reflections on Competence and Performance' in Lyons, J. and Wales, R.J. (eds.) PsychoLinguistics Papers, pp.135-54. Edinburgh.

" and Katz,J.J. (eds.) The Structure of Language. Inglewood Cliffs, N.J.

Fraser, B. 1971: 'An Analysis of 'Even' in English' in Fillmore,C.J. and Langendoen,D.T.(eds.) Studies in Linguistic Semantics $\mathrm{pp} .151-78$.

Frege, G. 1892: 'ther Sinn und Bedeutung' transl. in Geach.P. and Black.M. Translations from The Philosophical Writings of Gottlob Frege pp.85-102. Blackwell, Oxford.

" 1918-19: 'The Thought: A Logical Inquiry' transl. by Quinton, A.M. and M. , 1956 Mind 65 pp.289-31I.

Gale, R.M. 1970: 'Negative Statements' in American Philosophical Quarterly 7.3 pp. 206-17.

Garner, R. 1971:' 'Presupposition' in Philosophy and Linguistics' in Fillmore, C.J. and Langendoen,D.T. Studies in Linguistic Semantics pp. $23-42$.

Geach, P.T. 1958-9: 'Russell on Meaning and Denoting' Analysis 19, pp.69-72. " 1965: 'Assertion' The Philosophical. Review LXXIV pp.449-65. Geiss, M.I. and Zwicky,A.M. I971: 'On Invited Inferences' LI II.4 pp.56I-6. Green, G. 1968: 'On too and either, and Not Just on too and either, either' in Darden, B.J. et al (eds.) Papers from the Fourth Regional Meeting of the Chicago Linguistic Society, pp.22-39.Chicago. Grice, H.P. 1957: 'Meaning' The Philosophical Review pp.377-88. 
Grice, H.P. 196I: 'The Causal Theory of Perception' in Proceedings of the Aristotelian Society Suppl.Vol. 35, pp.121-52.

11 1968:: 'Utterer's Meaning, Sentence-Meaning, and Word-Meaning' FI 4 pp. 225-42.

" 1968': 'Logic and Conversation'. mimeo.

" 1969: 'Utterer's Meaning and Intentions' Philosophical Review 78, pp.147-77.

Hall-Partee, B. 1970: 'Negation, Conjunction and Quantifiers: Syntax vs. Semantics' FL $6 \mathrm{pp} .153-65$.

"I 1971: 'On the Requirement that Transformations Preserve Meaning' in Fillmore,C.J. and Langendoen,D.T.(eds.) Studies in Linguistic Semantics pp.1-21

"1 1972: 'Opacity, Coreference and Pronouns' in Harman,G. and Davidson,D. (eds.) Semantics of Natural Language pp.415-4. . Reidel.

Hasegawa, K. 1972: 'Transformations and Semantic Interpretation' LI III pp. $141-59$.

Heidolph, K... 1970: 'Zur Bedeutung negativer Satze' in Bierwisch,M. and Heidolph,K.E. (ed.s.) Progress in Linguistics pp.86-1.01. Hintikka, J. 1962: Knowledge and Belief. Cornell University Press.

I"

"1

" 1968: 'Logic and Philosophy' in Klibansky, R. (ed.) Contemporary Philosophy Vol..I pp.3-30. T'lorence. 1969: Models for Modalities. Reidel. 1972: The Semantics of Modal Notions and The Indeterminacy of Ontology' in Harman,G. and Davidson,D. (eds.) Semantics of Natural Language, pp.398-414.

Hochberg, H. 1970: 'Strawson, Russell, and The King of France' in Klemke,E.D. (ed.) Essays on Bertrand Russe11, pp.309-37. Illinois. Horn, I. 1969: 'A Presuppositional Analysis of Only and Even' in Binnick R.I. et al (eds.) Papers from the Fifth Regional Meeting of The Chicago Linguistics Society, pp.98-107. Chicago.

Hudson, R.A. 1973: The Meaning of Questions'. mimeo. 
Jacobs, R.A. and Rosenbaum,P.S. 1968: English Transfoxmational. Grammar Ginn and Co.

Jacobson, A. 1970: 'Russell and Strawson on Referring' in Klemke E.D. (ed.) Essays on Bertrand Russe11, pp.285-308. IIIinois. Jackendoff, R. 1969: 'An Interpretive Theory of Negation' FL 5, pp.218-41.

" 1971: 'Modal Structure in Semantic Representation' LI II pp. $481-514$.

11972: Semantic Interpretation in a Generative Grammar. MTT. Jackson, I.A. 1971: 'A Transformational Theory of Context'. Unpublished Ph.D. London.

Kartunnen, L. 1971a: 'Definite Descriptions with Crossing Coreference' FL 7 pp. I57-82.

" 1971b: 'Counterfactual Conditionals' II II pp.566-9.

" 1973: 'Presuppositions of Compound Sentences' II IV pp.169-93.

Katz, J.J. 1964: 'Analyticity and Contradiction in Natural Language' in Fodor,J. and Katz,J.J. (eds.) The Structure of Language pp. 519-43.

" 1966a: The Philosophy of Language. Harper and Row.

" 1966b: 'Mr Pfeiffer on Questions of Reference' FL 2 pp.241-4.

" 1967: 'Recent Issues in Semantic Theory' IIL 3 pp.124-94.

" 1972: Semantic Theory. Harper and Row.

" and Fodor,J. 1963: 'The Structure of a Semantic Theory'

Lge $39 \mathrm{pp} .170-210$.

" and Postal,P.M. 1964: An Integrated Theory of Linguistic Descriptions. MIT.

Keenan, K.I. 1971: 'Two Kinds of Presupposition in Natural Language' in Fillmore,C.J. and Langendoen,D.T.(eds.) Studies in Linguistic Semantics pp.45-54.

" 1972: 'On Semantically Based Grammar' II III pp.413-61. 
Kiefer, $\mathrm{P}_{\text {. }}$ and Ruwet, N. (eds.) $\left.\right|_{:} ^{1972}$ Generative Grammax in Burope. Reidel.

Kiparsky, P. and Kiparsky, C. 1970: 'Fact' in Bierwisch, M. and Heidolph, K. (eds.) Progress in Iinguistics, pp.143-73. Mouton.

Klima, T.S. 1964: 'Negation j.n Inglish' in Fodor, J. and Katz, J. J. (ed.s) The Structure of Ianguage, pp. 246-323.

Kroch, A.S. 1973: 'Lexical and Inferred Meanings for Some Time Adverbs' Quartexly Progress Report no. 104 of the Research Laboratory of Electronics MTP, pp.260-7.

Kuroda, S-Y 1968: 'Mnglish Relativization and Certain Related Problems' Lige 44, pp. 244-66.

1969: "Remarks on Selectional Restrictions and Presuppositions" in Kiefer, F. (ed.) Studies in Syntax and Semantics, pp.138-67. Reidel.

Iakoff, G.N. 1968: 'Deep and Surface Grammax'. mimeo.

11

11

11

11

If.

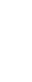

II

"

1970a: 'Repartee, or a Reply to Negation, Conjunction and Quantifiers' IL 6, pp.389-422.

1970b: Irregularity in Syntax. Holt, Rinehart, and Winston. 19700: 'A Note on Ambiguity and Vagueness' LI I pp.357-9. 1971a: 'On Generative Semontics' in Steinberg, D.D. and. Jakobovits, L.A. (ods.) Semantics, pp.232-96. Cambridge. 1971b: 'Presupposition and Relative Well-formedness' in Steinberg, D.D. and Jalsobovits, L.A. (eds.) Semantics, pp.329-40. 19710: 'The Role of Deduction in Grammar' in Tillmore, C.J. and Langendoen, D. T. Studies in Linguistic Semantics pp.63-72.

1972: 'Itngristics and Natural. Logic' in Harman, G. and Davidson, D. (eds.) Semantics of Natural Language, pp.545-665. Reidel.

Lakoff, R. 1969: 'A Syntectic Argument for Negative Transportation' in Binnick, R.I. et al (eds.) Papers from the Fifth Regional Meeting of the Chicago Linguistios Society pp.140-7. Chicago.

" 1971: 'If's, And's, and But's About Conjunction' in Fillmore, C.J. and Langendoen,D.T. (eds) Studies in Linguistic Semantics, pp.115-50. Holt, Rinehart and Winston. 
Landesman, C. 1972: Discourse and its Presuppositions. Yale University Press.

Lasnik, H.B. 1971: 'A General Constraint: Some Evidence From Negation' in Quarterly Progress Report no. 101 of the Research Laboratory of Electronics MIT, pp.215-7.

Leech, G.N. 1969: Towards a Semantic Description of English. Longman. Lees, R.B. 1960: The Grammar of English Nominalizations. Mouton. Lemmon, T.J. 1966: 'Sentences, Statements, and Propositions' in Williams,B. and Montefiore,A.(eds.) British Analytical Philosophy, pp.87-107. Routledge, and Kegan Paul.

Lewis, D.K. 1969: Convention: A Philosophical Study. Harvard University Press.

"1972: 'General Semantics' in Harman,G. and Davidson,D.(eds.) Semantics of Natural Language, pp.169-218. Reidel.

Linsky, I. 1967: Referring. New York.

Lyons, J. 1968: Introduction to Theoretical Linguistics. Cambridge. McCawley, J. 1968: 'The Role of Semantics in Grammar' in Bach, T. and Harms, R. (eds.) Universals in Lingui.stic Theory, pp.125-69. Holt, Rinehart and Winston.

11 1971: 'Where do Noun Phrases Come From?' in Steinberg,D.D. and Jakobovits,I.A. (eds.) Semanties, pp.217-31. Cambridge.

MacKay, A.F. 1972: 'On Mr. Grice's Theory of Meaning' Mind 80 pp.57-66. Martin, R.M. 1959: Toward a Systematic Pragmatics. North-Holland.

" 1971a: Logic, Language and Metaphysics. New York University Press,

" 1971b: 'Some Thoughts on The Formal Approach to The Philosophy of Language' in Bar-Hillel, Y. (ed.) Pragmatics of Natural Languages, pp.120-44. Reidel.

Montague, R. 1970: 'English as a Formal Language' in Linguaggi Nella Societa e Nella Tecnica, pp.189-223. Edizioni di Comunita, Milan. 
Montague, R. 1972: 'Pragmatics and Intensional Logic' in Harman,G. and Davidson,D. (eds.) Semantics of Natural Language, pp.142-68. Reidel.

Morgan, J. 1969: 'On the Treatment of Presuppositions in Transformational Grammax' in Binnick, R.I. et al (eds.) Papers from the Fifth Regional Meeting of the Chicago Linguistics Society, pp.169-77. Chicago.

Morris, C.W. 1938: Foundations of The Theory of Signs. Chicago. " 1946: Signs, Language and Behavior. New York.

Nerlich, G. 1965: 'Presupposition and Entailment' American Philosophical Quarterly 2, pp.33-42.

Odegard, D. 1963: 'Unique Reference and Entailment' Analysis 23. pp.73-9. Ogden, C.K. and Richards, I.A. 1923: The Meaning of Meaning. Routledge and Kegan Paul.

Perlmutter, D. 1970: 'On the Article in English' in Bierwisch,M. and Heidolph, K. E. (eds.) Progress in Linguistics pp.233-48. Mouton.

Postal, P. 1964: 'Underlying and Superficial Linguistic Structure Harvard Educational Review 34, pp.246-66.

" 1970: 'On the Surface Verb 'Remind" LI I, pp.37-120.

" 1971a: Cross-over Phenomena. Holt, Rinehart and Winston.

1 1971b: 'On Coreferential Complement subject Deletion' II II pp.439-500.

Prior, A.N. 1962: 'Possible Worlds' Philosophical Quarterly 12, pp.36-43. Quine, W.V. 1953: From a Logical Point of View. Harvard University Press. " 1966: Elementary Logic. 2nd edition. Harvard University Press. Quirk,R.,Greenbaum,S. ,Leech,G.N•,Svartvik,J. 1972: A Gremmar of Contemporaxy English. Longman. 
Reichenbach, H. 1947: Elements of Symbolic Logic. Dover.

Robbins, B. 1968: The Definite Article in English Transformations. Mouton. Roberts, G.W. 1969: 'A Problem about Presupposition' Mind 78, p.270f. Rosenbaum,P.S. 1967: The Grammar of English Predicate Complement Constructions. MIT.

Ross, J.R. 1967: 'Constraints on Variables in Syntax' Ph.D. MIT. Russell, B . 1905: 'On Denoting' Mind 14, pp.479-93. Schelling,T.C. 1960: The Strategy of Conflict. Harvard University Press. Schiffer, S.R. 1972: Meaning. Clarendon Press, Oxford.

Schnitzex, M. 1971: 'Presupposition, Entailment, and Russell's Theory of Descriptions' FI 7, pp. 297-9

Searle, J.R. 1968: 'Austin on Locutionary and Illocutionary Acts' Philosophical Review 77, pp.405-24.

"1969: Speech Acts: An Essay in The Philosophy of Language. Cambridge.

Sellars, W. 1954: 'Presupposing' Philosophical Review 63 pp.197-215. Smith, C. 1964: 'Determiners and Relative Clauses in a Generative Grammar of Inglish' Lge $40 \mathrm{pp} .37-52$.

Stalnaker, R.C. 1972: 'Pragmatics' in Harman,G. and Davidson,D. (ede) Semantios of Natural Language, pp.380-97, Reidel

Stenius, 『. 1967: 'Mood and Isanguage-Game ' Synthese 17 pp.254-74. Stockwell, R.P,Schachter,P., and Hall-Partee,B. 1973: The Major Syntactic Structures of English. Holt, Rinehart and Winston. Strawson, P. 1950: 'On Referring' Mind 59, pp.320-44.

"1952: Introduction to Logical Theory. Methuen.

"1954: 'A Reply to Mr Sellars' Philosophical Review 63,pp.216-31.

" 1964a: 'Identifying Reference and Truth Values' Theoria $\mathrm{xxx}, \mathrm{pp} .96-118$.

1 1964b: 'Intention and Convention in Speech Acts' Philosophical Review 73, pp. 439-60. 
Strawson, P. 1971a: Logico-Linguistic Papers. Methuen.

" 1971b: 'Meaning and Truth in Logico-Linguistic Papers, pp.170-89.

Thomason, R. 1973: 'Semantics, Pragmatics, Conversation, and Presupposition'. mimeo.

Vendler, Z. 1967a: Linguistics in Philosophy. Cornell University Pxess.

" 1967b: 'Causal Relations' Journal of Philosophy 64, pp.704-13.

Vermazen, B. 1966: Review of Katz, J. and Postal,P. An Integrated Theory of Linguistic Descriptions and Katz, J. The Philosophy of Language, Synthese $17 \mathrm{pp} .350-65$.

Weinreich, U. 1962: 'Lexicographic Definition in Descriptive Semantics' in Householder, Ir. and Saporta,S. (eds.) Problems in Lexicography, pp.25-43. Bloomington.

" 1966: 'Explorations in Semantic Theory' in Sebeok, T.A.(ed.) Current Trends in Linguistics III pp.395-477. Mouton.

Wiggins, D. 1971: 'On Sentence-sense, Word-sense and Difference of Wordsense. Towards a Philosophical Theory of Dictionaries' in Steinberg,D.D. and Jakobovits, I.A. (eds.) Semantics pp.14-34. Cambridge.

Wilson, D. 1972: 'Presuppositions on Factives' II III pp.405-1.10. Young, J.J. 1972: 'Ifs and Hooks: A Defence of The Orthodox View' Analysis 33, pp.56-63. 